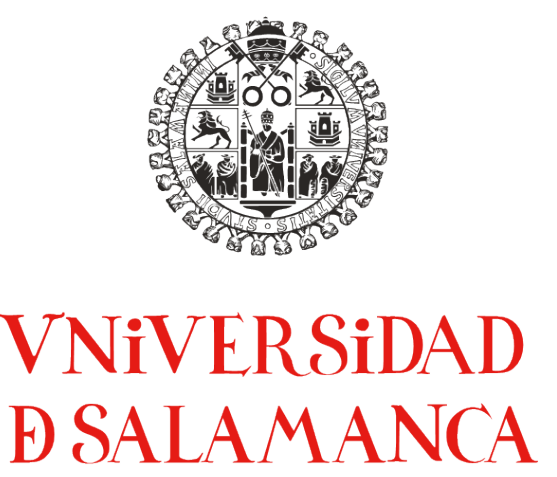

Facultad de Psicología

Departamento de Psicología Básica, Psicobiología y Metodología de las Ciencias del Comportamiento

\title{
GENERACIÓN VOLUMÉTRICA DE ESTRUCTURAS ENCEFÁLICAS IMPLICADAS EN TRASTORNOS NeUROPSICOLÓgICOS A PARTIR DE TÉCNICAS DE NeURoimAgen MULTiModales
}

\author{
Pablo Ruisoto Palomera \\ Tesis Doctoral dirigida por: \\ Dr. Juan Antonio Juanes Méndez \\ Dra. Paula Mayoral Babiano
}

Salamanca, 2011 



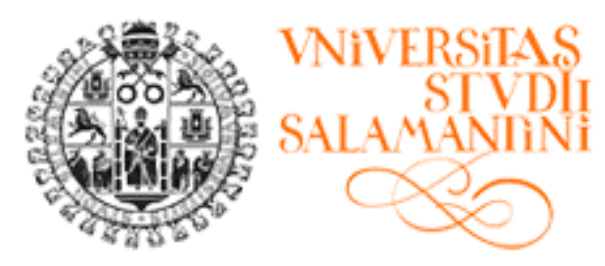

\section{Certificado}

D. JUAN ANTONIO JUANES MÉNDEZ Y D $\mathrm{D}^{\mathrm{a}}$. PAULA MAYORAL BABIANO, DOCTORES POR LA UNIVERSIDAD DE SALAMANCA, PERTENECIENTES A LOS DEPARTAMENTOS DE ANATOMÍA E HISTOLOGÍA HUMANAS, Y PSICOLOGÍA BÁSICA, PSICOBIOLOGÍA Y METODOLOGÍA DE LAS CIENCIAS DEL COMPORTAMIENTO DE LA UNIVERSIDAD DE SALAMANCA, RESPECTIVAMENTE,

\section{CERTIFICAMOS:}

Que el trabajo titulado “GENERACIÓN VOLUMÉTRICA DE ESTRUCTURAS ENCEFÁLICAS IMPLICADAS EN TRASTORNOS NEUROPSICOLÓGICOS A PARTIR DE TÉCNICAS DE NEUROIMAGEN MULTIMODALES“ ha sido realizado por D. PABLO RUISOTO PALOMERA bajo nuestra dirección; reuniendo, a nuestro juicio, los requisitos y méritos suficientes para que el autor pueda optar al Grado de Doctor por la Universidad de Salamanca.

Y para que así conste, firmamos el presente certificado en Salamanca a fecha, miércoles, 13 de julio de 2011. 
- 


\section{Resumen}

Uno de los objetivos de la investigación en neuroimagen es la creación de mapas morfológicos y funcionales del encéfalo en condiciones normales y patológicas. Los avances en las técnicas de diagnóstico por imagen han incrementado el número de estructuras que pueden ser valoradas y han permitido correlacionar alteraciones morfológicas y funcionales. Sin embargo, la integración de información de diferentes modalidades y la evaluación empírica de diferentes estrategias de visualización para la interpretación de neuroimágenes sigue siendo un desafío. Los objetivos de esta Tesis Doctoral fueron la generación volumétrica de estructuras encefálicas implicadas en enfermedades neurológicas y trastornos psiquiátricos, según la literatura, y el estudio empírico de la eficacia de la visualización volumétrica sobre el rendimiento en tareas de identificación y localización de dichas estructuras en la interpretación de neuroimágenes. Se realizó un estudio bibliométrico de las publicaciones en neuroimagen, neurociencia y conducta, y una revisión bibliográfica detallada de los trabajos publicados en la última década, sobre la base neuroanatómica macroscópica de los trastornos considerados a partir de técnicas de diagnóstico por imagen morfológicas y funcionales. Para la generación volumétrica se adquirieron imágenes anatómicas del VHP, radiológicas RM y funcionales con PET y SPECT en sujetos sin patología. La reconstrucción requirió segmentación manual de los ROIs y renderizado en malla mediante Amira®. Finalmente, se diseñó un cuasiexperimento intersujetos dirigido a evaluar la eficacia de la visualización volumétrica en la interpretación de neuroimágenes. Se generaron reconstrucciones volumétricas de estructuras encefálicas profundas: telencefálicas, diencefálicas, el sistema ventricular y sustancia blanca, embebidas en secciones morfológicas y funcionales. Se encontró evidencia a favor de la mayor efectividad de la visualización volumétrica frente a la visualización convencional 2D en tareas de identificación y localización de dichas estructuras. Se analizan la importancia y las aplicaciones de la generación y visualización volumétrica de estructuras encefálicas profundas en el ámbito formativo y el estado actual de conocimiento sobre la implicación de estructuras encefálicas profundas en los trastornos neuropsicológicos, destacando la inespecificidad e inconsistencia de los resultados obtenidos en la literatura revisada. Se concluye que la generación volumétrica de estructuras encéfalicas macroscópicas profundas, clínicamente relevantes, y su posterior visualización embebidas en secciones multimodales, mejora el rendimiento en la interpretación de neuroimágenes frente la visualización convencional 2D.

\section{Palabras clave}

Neuroimagen multimodal; visualización 3D; estructuras encefálicas profundas; trastornos neuropsicológicos; estudio empírico. 


\begin{abstract}
One of the objectives in neuroimaging investigation is the creation of morphological and functional brain maps in normal and pathological conditions. The progress in the diagnostic techniques per image has increased the number of structures that can be valued and correlate morphological and functional alterations. Nevertheless, the information integration of different modalities and the empirical evaluation of different visualization strategies continue to be a challenge. The objectives of this $\mathrm{PhD}$ Thesis were the volumetric generation of brain structures implicated in neurological diseases and psychiatric disorders, according to the literature, and the empirical study of the volumetric visualization efficacy over the performance in identification and localization tasks of such structures in the neuroimaging interpretation. A bibliometric study of neuroimaging, neuroscience and behavior publications was made, and a detailed literature review of published studies in the last decade on the neuroanatomical macroscopic basis of disorders, considered through different diagnostic morphological and functional imaging techniques. For the volumetric generation, anatomical VHP, radiological RM and functional PET and SPECT images were acquired in subjects without pathology. The reconstruction required manual segmentation of the ROIs and mesh rendering by means of Amira ${ }^{\circledR}$. Finally, an intersubject cuasiexperimental design was made to evaluate the efficacy of volumetric visualization in neuroimaging interpretation. Volumetric reconstructions of deep brain structures were generated: telencephalic, diencephalic, ventricular system and white matter, embedded in morphological and functional sections. Evidence was found favoring the greater effectiveness of volumetric visualization versus conventional $2 \mathrm{D}$ visualization in identification and localization tasks of such structures. The importance of applications in the generation and volumetric visualization of deep brain structures is discussed within the training environment, and the current state of knowledge on the implication of deep brain structures in neuropsychological disorders, highlighting the slight specificity and inconsistency of the results obtained in the reviewed literature. It is concluded that the volumetric generation of macroscopic deep brain structures, clinically relevant, and its posterior visualization embedded in multimodal sections, improve the performance in neuroimaging interpretation versus the conventional 2D visualization.
\end{abstract}

\title{
Key words
}

Multimodal neuroimaging; 3D visualization; deep brain structures; neuropsychological disorders; empirical study 


\section{Índice}

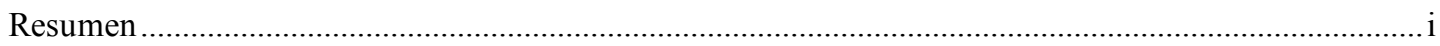

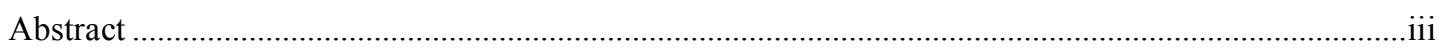

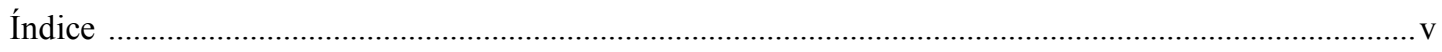

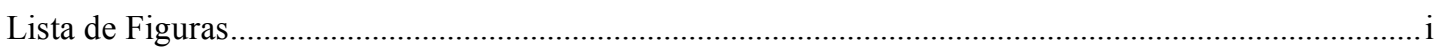

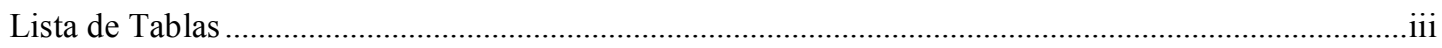

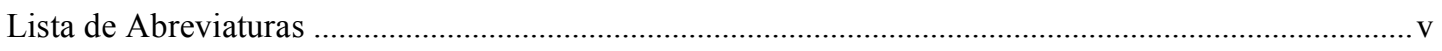

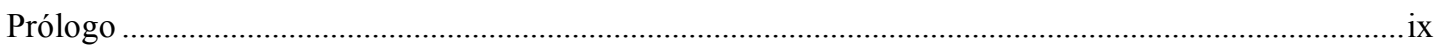

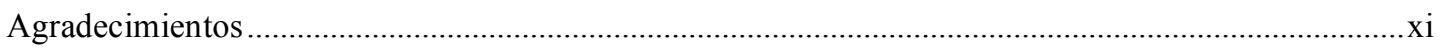

$\begin{array}{lr}\text { I. INTRODUCCIÓN } & 13\end{array}$

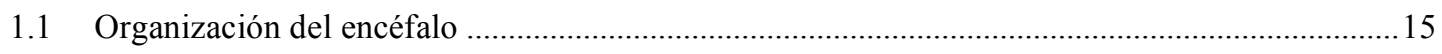

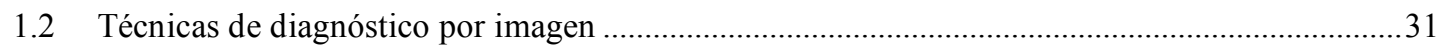

1.2.1 Técnicas de valoración morfológica ..............................................................................32

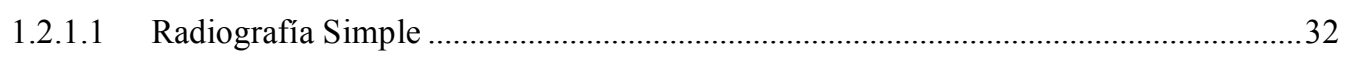

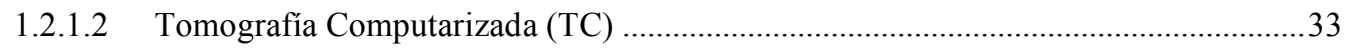

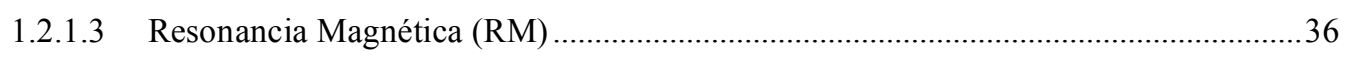

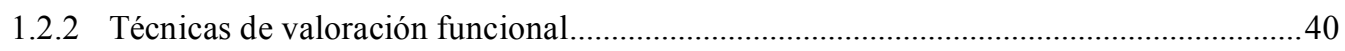

1.2.2.1 Tomografía Computarizada por Emisión de Fotón Único (SPECT) ...........................41

1.2.2.2 Tomografía por Emisión de Positrones (PET) .......................................................... 41

1.2.2.3 Resonancia Magnética Funcional (RMf) ...................................................................4 43

1.2.3 Integración de técnicas de neuroimagen............................................................... 45

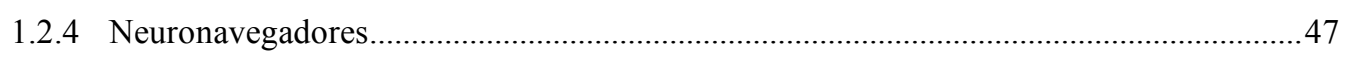

1.3 Visualización y reconstrucción de estructuras encefálicas .....................................................49

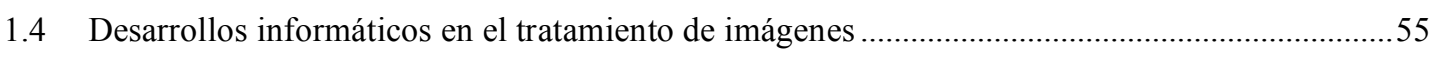

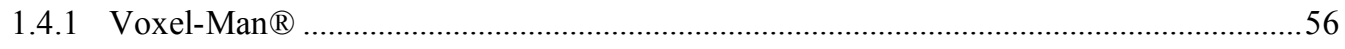

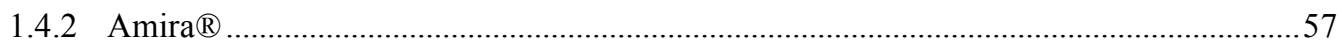

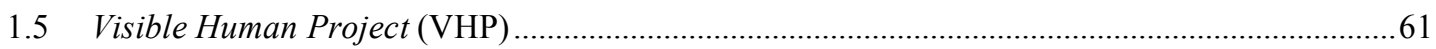

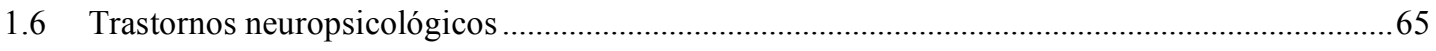

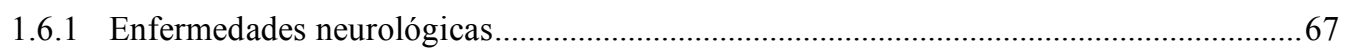

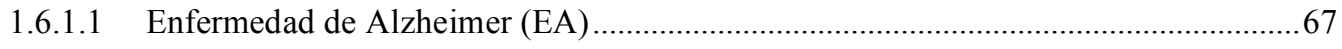

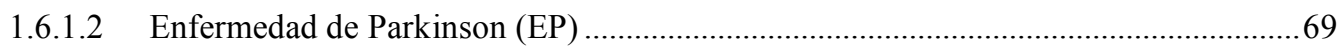

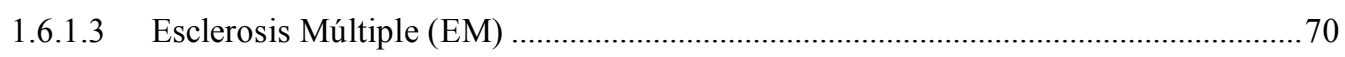

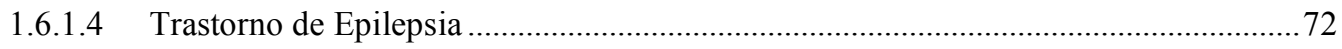




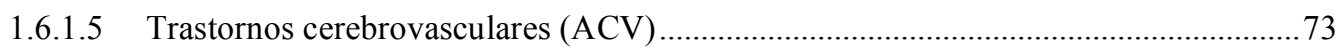

1.6.1.6 Traumatismos cráneo encefálicos (TCE) ........................................................................75

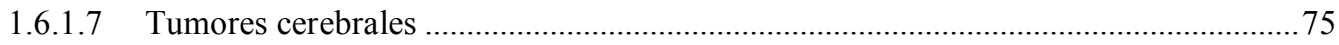

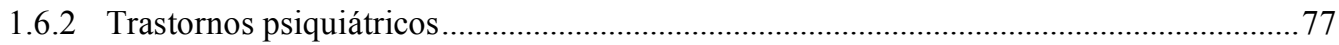

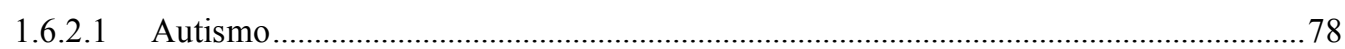

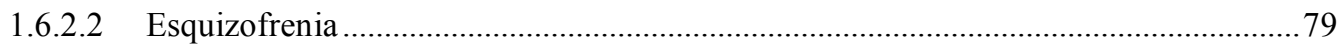

1.6.2.3 Trastorno de Estrés Postraumático (TEPT) ….................................................................. 81

1.6.2.4 Trastorno Obsesivo Compulsivo (TOC) …............................................................... 82

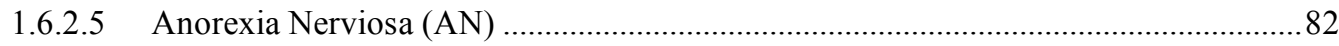

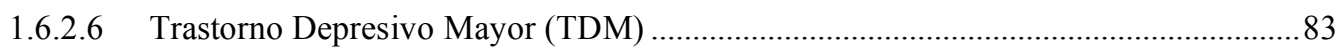

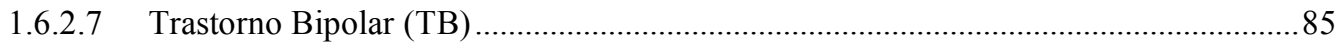

1.6.2.8 Trastorno por Déficit de Atención con Hiperactividad (TDAH) ................................86

II. PLANTEAMIENTO DEL PROBLEMA

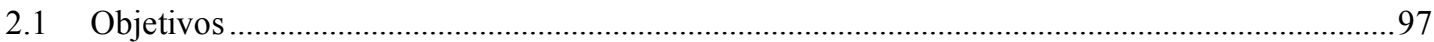

III. MATERIAL Y MÉTODOS 99

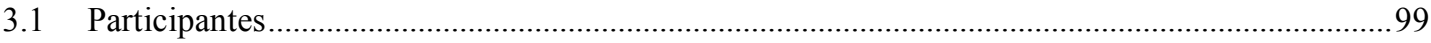

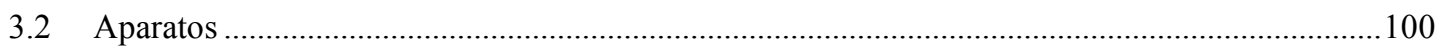

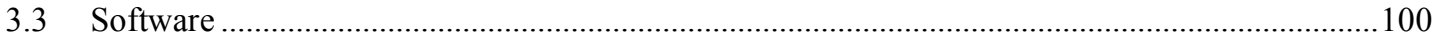

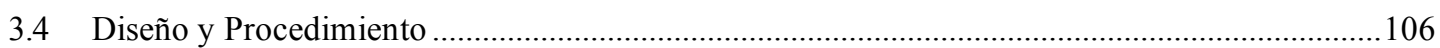

$\begin{array}{lr}\text { IV. RESULTADOS } & 123\end{array}$

4.1 Relevancia actual de la neuroimagen en neurociencia y conducta ......................................... 123

4.2 Estructuras encefálicas implicadas en trastornos neuropsicológicos .....................................127

4.3 Morfología de las estructuras encefálicas generadas volumétricamente ..................................133

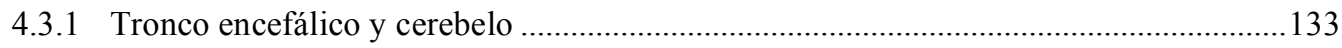

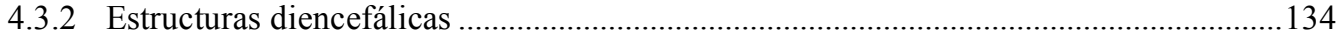

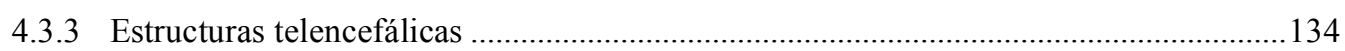

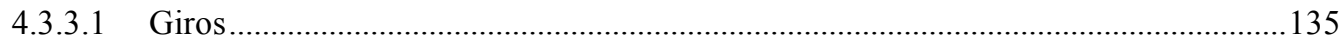

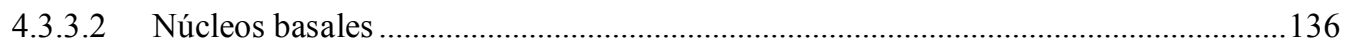

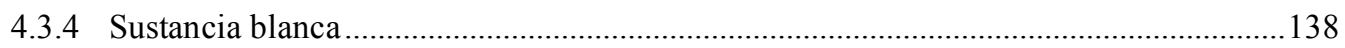

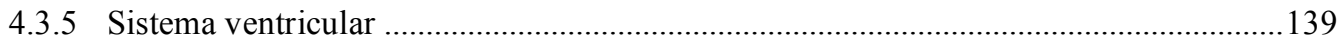

4.4 Eficacia de la visualización volumétrica 2D/3D en la interpretación de neuroimágenes...........163

$\begin{array}{lr}\text { V.DISCUSIÓN } & 167\end{array}$

$\begin{array}{ll}\text { VI. CONCLUSIONES } & 181\end{array}$

$\begin{array}{lr}\text { REFERENCIAS } & 183\end{array}$

ANEXO I. TEST DE DESARROLLO DE SUPERFICIES 229 


\section{Lista de Figuras}

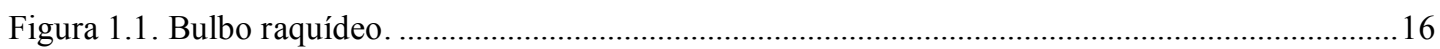

Figura 1.2. Protuberancia y vermis del cerebelo ................................................................................ 17

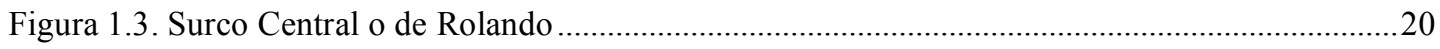

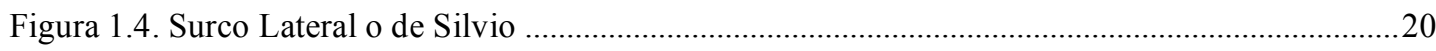

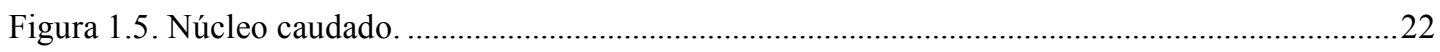

Figura 1.6. Núcleo putamen, globo pálido y tálamo …………………………………………………....22

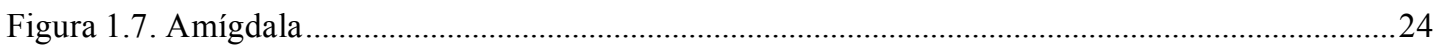

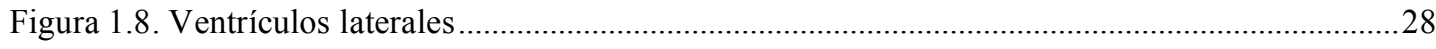

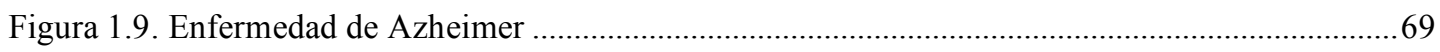

Figura 1.10. Esclerosis Múltiple (EM) …………………..........................................................

Figura 1.11. ACV isquémico agudo de la arteria cerebral media ...........................................................74

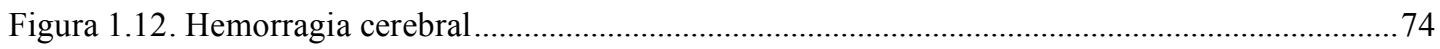

Figura 1.13 Astrocitoma en la región parieto-occipital ..........................................................................

Figura 2.1. Mapa conceptual de los elementos básicos del planteamiento del problema.......................96

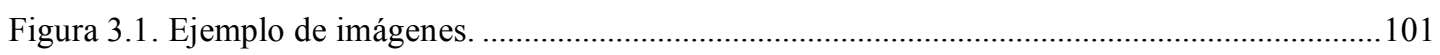

Figura 3.2. Código fuente en lenguaje HTML y PHP........................................................................102

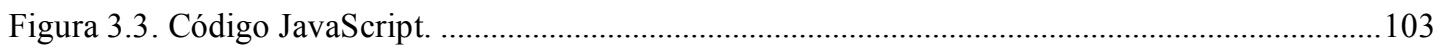

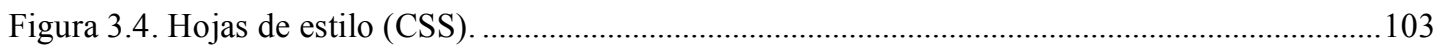

Figura 3.5. Ejemplo de desarrollo de superficies empleado en el test de aptitud visoespacial............105

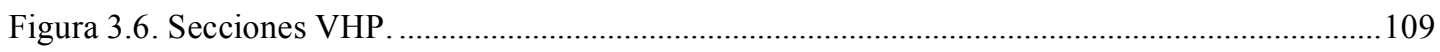

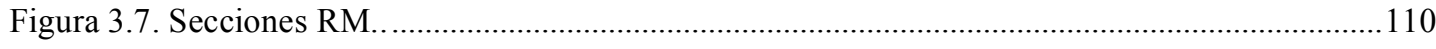

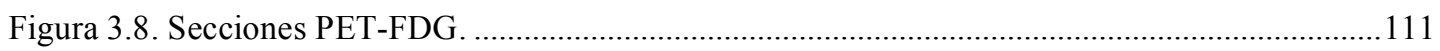

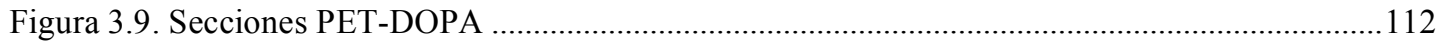

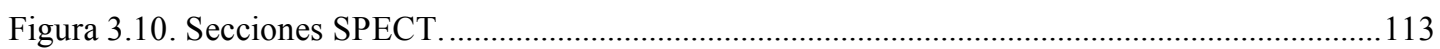

Figura 3.11. Estructura en malla triangular (o alambre) del cuerpo calloso, el fórnix, los VL y el

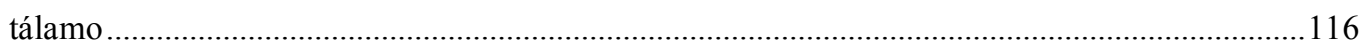

Figura 3.12. Estructura en malla triangular (o alambre) de los VL y tálamos. ……...............................119

Figura 3.13. Estructura en malla triangular (o alambre) del cuerpo neoestriado. ..................................119

Figura 4.1. Evolución del número de artículos de revisión en Brain Imaging......................................126 
Figura 4.2. Evolución del número de artículos en Brain Imaging.

Figura 4.3. Secciones ortogonales VHP y SPECT

Figura 4.4. Visualización volumétrica del tronco encefálico y cerebelo..

Figura 4.5. Generación volumétrica del tálamo.

Figura 4.6. Generación volumétrica del núcleo subtalámico.

Figura 4.7. Visualización volumétrica de giros cerebrales

Figura 4.8. Visualización volumétrica de giros cerebrales..

Figura 4.9. Visualización volumétrica de giros cerebrales..

Figura 4.10. Visualización volumétrica del núcleo caudado..

Figura 4.11. Visualización volumétrica del núcleo putamen.

Figura 4.12. Visualización volumétrica del núcleo globo pálido. .149

Figura 4.13. Visualización volumétrica del cuerpo neoestriado. 150

Figura 4.14. Visualización volumétrica del cuerpo estriado y hemisferio cerebral derecho. .151

Figura 4.15. Visualización volumétrica del núcleo lenticular 152

Figura 4.16. Visualización volumétrica del cuerpo estriado, tálamo y hemisferio. 153

Figura 4.17. Generación volumétrica del cuerpo estriado y tálamo. 154

Figura 4.18. Visualización volumétrica del cuerpo estriado y tálamo 155

Figura 4.19.Visualización volumétrica de la amígdala 156

Figura 4.20. Visualización volumétrica del hipocampo. 157

Figura 4.21. Visualización volumétrica de la amígdala, hipocampo y cuerpo estriado..... 158

Figura 4.22. Visualización volumétrica del cuerpo calloso.

Figura 4.23. Renderización del modelo 3D del fórnix. 160

Figura 4.24. Visualización volumétrica del fórnix 160

Figura 4.25. Renderización del modelo 3D del sistema ventricular .161

Figura 4.26. Visualización volumétrica del sistema ventricular. 162

Figura 4.27. Porcentaje de aciertos en las condiciones de visualización volumétrica 2D/3D y convencional

2D según nivel de formación. 165

Figura 4.28. Porcentajes de aciertos en las condiciones de visualización volumétrica 2D/3D y convencional

2D según la modalidad de las neuroimágenes. 165

Figura 4.29. Porcentajes de aciertos en las condiciones de visualización volumétrica 2D/3D y convencional 2D según la dificultad de las estructuras a identificar. 166 


\section{Lista de Tablas}

Tabla 1.1. Comportamiento de las distintas estructuras encefálicas en T1 y T2

Tabla 1.2. Comparación de modalidades de estudio funcional del encéfalo

Tabla 1.3. Clasificación de trastornos neurológicos y psiquiátricos con importantes efectos neuropsicológicos.

Tabla 3.1. Medias y desviaciones típicas en edad, aptitud visoespacial y años de experiencia según condición experimental.

Tabla 4.1. Instituciones más relevantes en Neurociencia y Conducta.

Tabla 4.2. Autores más relevantes en Neurociencia y Conducta. 124

Tabla 4.3. Revistas y número de publicaciones en Neuroimagen, Neurociencia y Conducta .125

Tabla 4.4. Número y porcentaje de revisiones en Brain Imaging según categoría. .127

Tabla 4.5. Estructuras encefálicas implicadas en trastornos neurológicos con importantes efectos neuropsicológicos

Tabla 4.6. Estructuras encefálicas implicadas en trastornos psiquiátricos y del desarrollo con importantes efectos neuropsicológicos.

Tabla 4.7. Medias y desviaciones típicas en aptitud visoespacial para los diferentes grupos. .163 


\section{Lista de Abreviaturas}

2D

Bidimensional

3D Tridimensional

5 HT Serotonina

a.c. antes de Cristo

ACA Arteria Cerebral Anterior

ACM Arteria Cerebral Media

ACP Arteria Cerebral Posterior

ACV Accidente Cerebro Vascular

ADNI Alzheimer's Diseae Neuroimaging Initiative

AN Anorexia Nerviosa

ANIMAL Automated Nonlinear Image Matching and Anatomical Labelling

ANOVA Analisys of Variance

APA American Psychiatric Association

ASN American Society of Neuroimaging

$\mathrm{Ba} \quad$ Bario

BIC McConnell Imaging Center

BN Bulimia Nerviosa

BOLD Blood Oxygen Level Dependent

C Carbono

$\mathrm{Ca} \quad$ Calcio

CBIC Caltech Brain Imaging Center

$\mathrm{CCNi} \quad$ Centre for Cognitive Neuroimaging

CD-ROM Compact Disc - Read Only Memory

CHS Center for Human Simulation

CIST Computer Assisted Surgery and Therapy

$\mathrm{cm} \quad$ Centímetro

CNI Center for Neurological Imaging (EEUU)

CNS Cognitive Neuroscience Society

$\mathrm{CO} \quad$ Monóxido de Carbono

CPF Córtex Prefrontal

CPF DL Córtex Prefrontal Dorsolateral

CRAI Centro de Recursos de Aprendizaje e Investigación

DICOM Digital Imaging and Communications in Medicine

DP Densidad Protónica 


\begin{tabular}{|c|c|}
\hline DSM & Diagnostic Statistical Manual \\
\hline DT o DTI & Resonancia Magnética por Tensor de Difusión \\
\hline DV & Demencia Vascular \\
\hline EA & Enfermedad de Alzheimer \\
\hline EEG & Electroencefalografía \\
\hline EET & Epilepsia Extratemporal \\
\hline EEUU & Estados Unidos \\
\hline ELT & Epilepsia del lóbulo temporal \\
\hline EM & Esclerosis Múltiple \\
\hline ENA & European Neuroscience Association \\
\hline EP & Enfermedad de Parkinson \\
\hline $\mathrm{EVH}$ & Explorable Virtual Human \\
\hline FDG & Fluorurodesoxiglucosa \\
\hline FECYT & Fundación Española de Ciencia y Tecnología \\
\hline FENS & Federation of European Neuroscience Societies \\
\hline $\mathrm{FSCr}$ & Flujo Sanguíneo Cerebral Regional \\
\hline FTP & File Transfer Protocol \\
\hline $\mathrm{Gb}$ & Gigabyte \\
\hline Gd & Gadolinio \\
\hline GBM & Gliobastoma Multiforme \\
\hline GCA & Giro Cingulado Anterior \\
\hline $\mathrm{H}$ & Hidrógeno \\
\hline HMPAO & hexametilpropilenaminooxima \\
\hline HTML & Hyper Text Markup Query Language \\
\hline PHP & Hypertext Preprocessor \\
\hline CSS & Cascading Style Sheets \\
\hline MySQL & Structured Query Language \\
\hline I & Iodo \\
\hline ICBM & International Consortium for Brain Mapping \\
\hline ILAE & International League Against Epilepsy \\
\hline INM & Institute of Neuroscience of Medicine \\
\hline ISI & Institute for Scientific Information \\
\hline $\mathrm{LCR}$ & Líquido Cefalorraquídeo \\
\hline LONI & Laboratory of Neuroimagen \\
\hline LPBA40 & LONI Probabilistic Brain Atlas \\
\hline $\mathrm{Mb}$ & Megabyte \\
\hline M-BIC & Maastricht Brain Imaging Center \\
\hline
\end{tabular}




\begin{tabular}{|c|c|}
\hline MCI & Mild Cognitive Impairment \\
\hline MedIC & Laboratory of Medical Image Computing \\
\hline MEG & Magnetoencefalografía \\
\hline $\mathrm{mg}$ & Miligramo \\
\hline MICINN & Ministerio de Cultura, Ciencia e Innovación \\
\hline $\mathrm{mm}$ & Milímetro \\
\hline Mp & Megapíxel \\
\hline $\mathrm{ms}$ & Milisegundo \\
\hline MTI & Imagen de Transferencia de Magnetización \\
\hline $\mathrm{mV}$ & Milivoltio \\
\hline $\mathrm{N}$ & Nitrógeno \\
\hline $\mathrm{Na}$ & Sodio \\
\hline NASA & National Aeronautics and Space Administration (EEUU) \\
\hline NCIGT & National Center for Image Guided Therapy (EEUU) \\
\hline NIH & National Institute of Health (EEUU) \\
\hline NIMH & National Institute of Mental Health (EEUU) \\
\hline NINDS & National Institute of Neurological Disorders and Stroke (EEUU) \\
\hline NIRS & Near-infrared spectroscopy \\
\hline \multicolumn{2}{|c|}{ NPAC/OLDA Visible Human Viewer } \\
\hline NITRC & Neuroimaging Informatics Tools and Resources Clearinghouse \\
\hline $\mathrm{O}$ & Oxígeno \\
\hline $\mathrm{P}$ & Fósforo \\
\hline PET & Positron Emission Tomography \\
\hline PET-DOPA & Tomografia por Emisión de Positrones-Dopamina \\
\hline PET-FDG & Tomografía por Emisión de Positrones-Fluorurodesoxiglucosa \\
\hline PET-PIB & Tomografía por Emisión de Positrones- Pittsburgh Compound-B \\
\hline PICS & Program for Imaging and Cognitive Sciences \\
\hline PNL & Psychiatry Neuroimaging Laboratory \\
\hline $\mathrm{px}$ & Picture element \\
\hline RF & Radiofrecuencia \\
\hline RII & Research Imaging Institute \\
\hline RM & Resonancia Magnética Estructural \\
\hline RMf & Resonancia Magnética Funcional \\
\hline ROI & Region of interest \\
\hline $\mathrm{Rx}$ & Rayos X \\
\hline s. & siglo \\
\hline $\mathrm{SfN}$ & Society for Neuroscience \\
\hline
\end{tabular}




$\begin{array}{ll}\text { SN } & \text { Sistema Nervioso } \\ \text { SNC } & \text { Sistema Nervioso Central } \\ \text { SPECT } & \text { Single Photon Emission Computed Tomography } \\ \text { SPL } & \text { Surgical Planning Laboratory } \\ \text { SPSS } & \text { Statistical Package for the Social Sciences } \\ \text { SUMMIT } & \text { Stanford University Medical Media and Information Technologies } \\ \text { T } & \text { Tesla } \\ \text { T1 } & \text { Tiempo de Relajación Longitudinal } \\ \text { T2 } & \text { Tiempo de Relajación Transversal } \\ \text { Tb } & \text { Terabyte } \\ \text { TB } & \text { Trastorno Bipolar } \\ \text { TC } & \text { Tomografia Computarizada } \\ \text { TCE } & \text { Traumatismo Craneoencefálico } \\ \text { TCP/IP } & \text { Transmisión Control Protocol/ Internet Protocol } \\ \text { TDAH } & \text { Trastorno de Déficit de Atención con Hiperactividad } \\ \text { TDM } & \text { Trastorno Depresivo Mayor } \\ \text { TE } & \text { Tiempo Eco } \\ \text { TEPT } & \text { Trastorno por Estrés Post-Traumático } \\ \text { TIA } & \text { Accidente Isquémico Transitorio } \\ \text { TMS } & \text { Estimulación Magnética Transcraneal } \\ \text { TOC } & \text { Trastorno Obsesivo Compulsivo } \\ \text { TR } & \text { Tiempo de Repetición } \\ \text { UCL } & \text { University College of London } \\ \text { UH } & \text { Unidades Hounsfield } \\ \text { VHP } & \text { Visible Human Project } \\ \text { VL } & \text { Ventrículos Laterales } \\ \text { WBIC } & \text { Wolfson Brain Imaging Centre } \\ \text { WHO } & \text { World Heath Organization } \\ \text { Xe } & \text { Extensible Markup Language } \\ & \end{array}$




\section{Prólogo}

- ¿Podrías decirme, por favor, qué camino debo seguir para salir de aquí?

- Depende en gran parte del sitio al que quieras llegar...

- No me importa mucho el sitio...

- Entonces tampoco importa mucho el camino que tomes...

- ... siempre que llegue a alguna parte....

- ¡Oh, siempre llegarás a alguna parte... si caminas lo suficiente!

Traducción a partir del original: Carroll, 1960, p. 64

Al finalizar mi licenciatura en Psicología y como resultado de mi interés por las neurociencias, comencé el Programa de doctorado en Neuropsicología Clínica en la Universidad de Salamanca. Mi estancia en la Universidad de Jyväskyla (Finlandia) acentuó mi interés, después de tener la oportunidad de estudiar con el Dr. Heikki Lyytien, especializado en el estudio neuropsicológico de trastornos del aprendizaje. Posteriormente, mi atención se centró en la neuroimagen, tras mi visita al Maastricht Brain Imaging Center (M-BIC) en los Países Bajos.

Mi segunda estancia en el extranjero, en este caso en Southeast Missouri State University en Missouri (EEUU) bajo la supervisión del Dr. Norman Kinney, me ofreció el marco perfecto para incorporar los conocimientos metodológicos y procedimentales necesarios para desarrollar una investigación del calibre que requiere una tesis doctoral.

Al regresar de Estados Unidos, me incorporé como profesor asociado al área de Psicobiología en la Facultad de Psicología de la Universidad de Salamanca, permitiéndome, en primer lugar, profundizar en el estudio morfológico y funcional del sistema nervioso, especialmente la vertiente clínica, por el carácter práctico de la docencia asignada y, en segundo lugar, evidenciar que el conocimiento cristalizado de una materia y su didáctica son competencias distintas. Mi experiencia como docente en Psicobiología me ha otorgado una visión más cercana y completa de las posibilidades e implicaciones de un estudio como el que se presenta, de cara a la mejora del proceso de enseñanza/ aprendizaje de la neuroanatomía.

Mi participación en la elaboración del Proyecto de Innovación Docente "Estudio Anatomo-Funcional del Sistema Nervioso Central" y reciente colaboración en la elaboración del libro de trabajo "Fundamentos Biológicos de la Conducta" para la asignatura homónima, ejemplifican el esfuerzo conjunto de los docentes del área de Psicobiología de esta Universidad, en la innovación y aplicación de nuevas tecnologías para la organización y presentación de conocimientos neuroanatómicos básicos en la formación de un psicólogo.

Esta afinidad por las nuevas tecnologías y sus aplicaciones ha sido una constante tanto en mi ámbito personal como profesional y, la asimilación y habituación de las nuevas aportaciones 
han supuesto un reto constante dado su ritmo acelerado de desarrollo. Mi interés en neuroimagen, junto con mi trayectoria académica y docente en neurociencias en general y, en neuroanatomía, en particular, han discurrido de forma paralela hasta la actualidad.

La posibilidad de realizar mi trabajo en el área de la neuroimagen ha sido una gran oportunidad que me ha permitido profundizar en un campo en creciente expansión y con múltiples aplicaciones en el ámbito formativo y clínico. Ha supuesto un desafío tanto por su novedad como por la cantidad de trabajo requerido pero, sin duda, gratificante. Considero especialmente interesante la disponibilidad de estudios y datos que vinculan los trastornos psiquiátricos con alteraciones neuroanatómicas, e hitos como el Visible Human Project, desarrollado a finales de los 80 por la Biblioteca Nacional de Medicina de Estados Unidos, que ha supuesto un punto de inflexión en neuroanatomía y multiplicado exponencialmente sus aplicaciones a distintos contextos.

La consecución del grado de Doctor, no sólo constituye el siguiente paso en el progreso de mi carrera profesional, sino un estímulo derivado del propósito de este trabajo: crear modelos 3D de estructuras encefálicas relevantes en la práctica clínica, su integración en imágenes morfológicas del VHP o RM, y funcionales PET y SPECT; y finalmente, la evaluación de efectividad en la interpretación de neuroimágenes. Todo ello, gracias al empleo de aplicaciones informáticas de vanguardia que permiten reproducir con precisión la anatomía real de estructuras encefálicas difícilmente accesibles de otra forma.

La generación volumétrica supone un paso más allá de la mera representación esquemática hipotética de dichas estructuras, de por sí una tarea compleja, tal y como expresa F.H. Netter, en la tercera edición de su Atlas de Anatomía Humana "la ilustración artística es una disciplina muy rigurosa. Cuando se escribe, es posible dar rodeos en torno a un tema si no se está seguro de los detalles pero, con el pincel en la mano, es necesario ser preciso y realista. El papel en blanco con que se enfrenta el dibujante es la verdad". Dichos modelos 3D ofrecen nuevos desafíos, pero también nuevas posibilidades para el estudio de las bases neuroanatómicas de trastornos neuropsicológicos y prácticas neuroquirúrgicas. 


\section{Agradecimientos}

Es un privilegio expresar mi más sincero agradecimiento a todas las personas y servicios que han colaborado en esta tesis en cualquier forma y grado y, mis disculpas a las personas que olvidé. La consecución de este trabajo no habría sido posible sin todos ellos.

Muy especialmente quiero agradecer a los directores, el Dr. Juan Antonio Juanes Méndez, Profesor del Departamento de Anatomía e Histología Humanas y la Dra. Paula Mayoral Babiano, Profesora de Psicología Básica, Psicobiología y Metodología de las Ciencias del Comportamiento, ambos de la Universidad de Salamanca, por brindarme la oportunidad de realizar esta tesis y por su orientación académica, entusiasmo y aliento permanentes, sin cuya contribución no hubiera llegado a término.

Mi agradecimiento al Departamento de Psicología Básica, Psicobiología y Metodología de las Ciencias del Comportamiento y a sus miembros, por una gestión ágil y eficaz del proyecto, al Departamento de Anatomía e Histología Humanas, por guiarme y facilitarme el acceso a los servicios de Radiodiagnóstico y Medicina Nuclear de los centros hospitalarios participantes.

También quisiera agradecer la inestimable colaboración de los servicios radiológicos y de Medicina Nuclear del Hospital Clínico Universitario de Salamanca, Hospital Universitario Río Hortega de Valladolid, Clínica Universitaria de Navarra, Hospital 12 de Octubre de Madrid y Hospital Clinic de Barcelona. Y al Profesor Alberto Prats Galino, Catedrático de Anatomía Humana de la Universidad de Barcelona, por su especial colaboración en la segmentación de estructuras anatómicas mediante Amira®.

Igualmente, quisiera agradecer a Desarrollos Informáticos Abadía (Madrid) su constante asesoramiento profesional y supervisión, a D. Jesús López como responsable del Centro de Recursos de Aprendizaje e Investigación (CRAI) de la Facultad de Psicología de la Universidad de Salamanca por su asesoramiento en el estudio bibliométrico y a D. Rubén Simón, Técnico de Laboratorio de la Facultad de Psicología por su disposición y atención. También a $\mathrm{D}^{\mathrm{a}}$. Anne Rita del Departamento de Psicología de Jyväskylä Yliopisto (Finlandia) y al profesor Dr. Richard A. Burns y profesor Dr. Norman E. Kinney del Departamento de Psicología de Southeast Missouri State University (Estados Unidos).

Finalmente, deseo agradecer a $\mathrm{D}^{\mathrm{a}}$. Verónica Mayado, Psicóloga Especialista en Psicología Clínica, por apostar por mí como psicólogo profesional, y ser un modelo de habilidades de afrontamiento ante dificultades de la vida. A Da. Marisa Vicente, Psicopedagoga, por su compromiso social y brillantes conversaciones de cafetería, al Dr. Luis Rodríguez, D. Juan Luis Cuesta y $\mathrm{D}^{\mathrm{a}}$ Judith Fernández por su humildad, calidez y calidad humana, al Dr. Raúl Cacho por su cercanía, al Dr. Israel Contador por su disponibilidad y valiosos consejos, y a todos los que alguna vez han estado ahí generosamente. 
Por último, deseo dar las gracias a Pedro Hernández y Jose Luis Garduño por su valiosa y sincera amistad año tras año, a mi familia por una vida de dedicación y entrega, y a Verónica Laso por su cariño, paciencia y entrega inagotables. 


\section{Introducción}

Este apartado ofrecerá aclaraciones terminológicas y un marco conceptual de los elementos que vertebran el presente trabajo. En apartados posteriores plantearemos el problema, describiremos la metodología seguida, presentaremos los resultados y discutiremos sus implicaciones.

En la primera parte de esta introducción se describen, primero, aspectos relativos a la organización general del sistema nervioso, prestando especial atención a las estructuras encefálicas profundas. A continuación, se presentan las técnicas de diagnóstico por imagen actuales, utilizadas en la adquisición de imágenes en este trabajo. Posteriormente, se describe una selección de enfermedades neurológicas y trastornos psiquiátricos, destacando las estructuras encefálicas implicadas como base neuroanatómica, según los resultados obtenidos por estudios de la literatura científica revisada, a partir de la aplicación de técnicas de neuroimagen morfológicas y funcionales. Posteriormente, se ofrece una visión general de los esfuerzos y logros actuales en la representación 3D de estructuras encefálicas, prestando especial atención a la aportación del VHP. Finalmente, se describen dos de los desarrollos informáticos que permiten el tratamiento de imágenes médicas para su posterior generación volumétrica.

El interés por estudiar la relación entre conducta y biología ha sido una constante desde el comienzo de la Psicología como disciplina. En concreto, el encéfalo humano ha sido y continúa siendo, uno de los temas centrales de investigación, no sólo en Psicología, sino en otras ciencias biomédicas. Sigmund Freud y Wilhelm Max Wund quisieron basar el estudio de esta disciplina en la comprensión de las bases biológicas de los sucesos mentales, si bien no contaron con las técnicas que permitieran el estudio en profundidad del encéfalo humano.

Actualmente, gran parte del conocimiento en neurociencias y de su acelerado ritmo de crecimiento, en relación con el conocimiento de la estructura y función del encéfalo, se debe a los avances en las técnicas de diagnóstico por imagen y a las aplicaciones informáticas que permiten el tratamiento de las neuroimágenes obtenidas.

El Congreso de los Estados Unidos de América denominó a la década de los 90 como la "Década del Encéfalo", en reconocimiento al progreso en este campo. Estos avances podrían resumirse en tres: el desarrollo de la neuroimagen funcional, que ha permitido localizar y registrar patrones específicos de actividad neuronal, asociados a un determinado proceso cognitivo en el encéfalo humano vivo y con la resolución temporal de la propia respuesta hemodinámica; el paso de imágenes analógicas a digitales, que ha permitido su tratamiento mediante desarrollos informáticos $\mathrm{y}$, finalmente, la generación de modelos 3D de estructuras anatómicas como avance más reciente. 
Los manuales tradicionales y atlas de referencia en neuroanatomía han coincidido en destacar la utilidad de la visualización 3D como estrategia para optimizar la comprensión morfofuncional del SN (Young, 2001; Kalat, 2003; Standring, 2005; Afifi \& Bergman, 2006; Haines, 2006; Puelles, 2008; Snell, 2008; Snell, 2009). Sin embargo, se han limitado a incluir colecciones de esquemas e imágenes 2D unimodales en papel o en formato digital (en soporte CD-ROM o mediante acceso online) insuficiente para mostrar las relaciones anatómicas y funcionales de las estructuras encefálicas (Scarabino, Salvolini, DiSalle, Duvernoy, \& Rabischong, 2006; Crossman \& Neary, 2007; Duane, 2008; Barr, 2009). A pesar de estas limitaciones, los atlas han sido una de las herramientas más difundidas en neuroanatomía en contextos formativos y clínicos para la planificación de intervenciones quirúrgicas (Scarabino et al., 2006; Crossman, \& Neary, 2007; Duane, 2008; Talos, Kikinis, \& Shenton, 2008).

Las generaciones volumétricas proporcionarán una visión más realista y completa de la complejidad morfológica y espacial de las estructuras encefálicas implicadas en trastornos neuropsicológicos. La principal aportación de la representación conjunta de modelos 3D e imágenes radiológicas morfológicas y de Medicina Nuclear funcional, como la que se presenta en este trabajo, consiste en optimizar la visualización detallada de aspectos morfológicos y funcionales que permitan identificar las áreas donde se produce la activación funcional, resolviendo las limitaciones asociadas al uso independiente de imágenes unimodales 2D. 


\subsection{ORGANIZACIÓN DEL ENCÉFALO}

El conocimiento de la organización morfo-funcional del SNC es una condición sine qua non en la valoración neuropsicológica, entendida como el análisis de la correlación entre las evidencias obtenidas a partir de técnicas de diagnóstico por imagen y las alteraciones neuropsicológicas encontradas. En este apartado, se describe la organización morfo-funcional del encéfalo a modo de recuerdo neuroanatómico y como presentación de las estructuras reconstruidas en este trabajo. Presentaremos tanto sus características morfológicas a nivel macroscópico, como su importancia clínica o funcional.

Una idea básica en relación a la arquitectura del encéfalo la constituyen los tres planos de referencia ortogonales: axial, coronal y sagital, y los ejes rostral-caudal y dorsal-ventral. En humanos, la parte anterior del encéfalo es rostral, la posición superior es dorsal y la base es ventral. Otros ejes perpendiculares son antero-posterior y superior-inferior. La línea media discurre por el centro del encéfalo, separando izquierda y derecha.

El tronco encefálico ocupa la fosa craneal posterior y conecta la médula espinal y el encéfalo anterior. Se divide en el bulbo raquídeo, la protuberancia y el mesencéfalo. En su cara externa es visible el origen aparente de todos los nervios craneales, excepto el olfatorio (I par craneal) y el óptico (II par craneal). Sirve de conducto para tractos ascendentes y descendentes que conectan la médula espinal con centros superiores del encéfalo anterior y desempeña un papel importante en el mantenimiento de la homeostasis. Controla funciones autonómicas como la respiración, la tasa cardíaca y la presión sanguínea, además de participar en la organización de movimientos reflejos y movimientos finos de las extremidades y de la cara (Kandel, Schwartz, \& Jessel, 2000; Standring, 2005; Duane, 2008; Woolsey, Hanaway, \& Gado, 2008; Haines, 2006; Snell, 2008; Barr, 2009; Snell, 2009).

Respecto a las funciones superiores, muy pocos trastornos cognitivos han sido asociados con el tronco encefálico. Lesiones en el tronco encefálico, especialmente a nivel de la protuberancia por ACV isquémico, se han asociado con presencia de bostezos patológicos (Cattaneo, Cucurachi, Chierici, \& Pavesi, 2006).

El bulbo raquídeo es una estructura de forma cónica que conecta la protuberancia con la médula espinal y contiene numerosos núcleos de pares craneales. En la cara ventral se observa la fisura mediana anterior que continúa en la médula espinal. A cada lado de ésta, aparece un engrosamiento denominado pirámide bulbar, formado por fibras corticoespinales que parten del giro precentral del córtex y que se cruzan formando la decusación de las pirámides a nivel inferior del bulbo raquídeo. Las olivas bulbares son elevaciones ovaladas producidas por el núcleo olivar inferior y se encuentran anterolaterales repecto a las pirámides. El origen aparente del nervio hipogloso (XII par craneal) se encuentra en el surco preolivar y las raíces de los nervios gloseofaríngeo (IX par craneal), vago (X par craneal) y nervio accesorio espinal (XI par 
craneal) en el surco retroolivar. En la mitad superior de la cara posterior del bulbo raquídeo, se encuentra el suelo del cuarto ventrículo y, en la parte inferior, la continuación en la médula espinal. El surco medio posterior separa el tubérculo grácil de cada lado (formado por el núcleo grácil) y un engrosamiento similar situado lateralmente, denominado el tubérculo cuneado (formado por el núcleo cuneado).

La importancia clínica del bulbo raquídeo radica en que sus pares craneales participan en la regulación de funciones autónomas y sirve como conducto para tractos descendentes y ascendentes que conectan la médula espinal con centros superiores del SN (Kandel et al., 2000; Standring, 2005; Duane, 2008; Woolsey et al., 2008; Haines, 2006; Snell, 2008; Barr, 2009; Snell, 2009).

En la Figura 1.1 se observa la localización del bulbo raquídeo y IV ventrículo en secciones axiales obtenidas a partir de PET y SPECT.

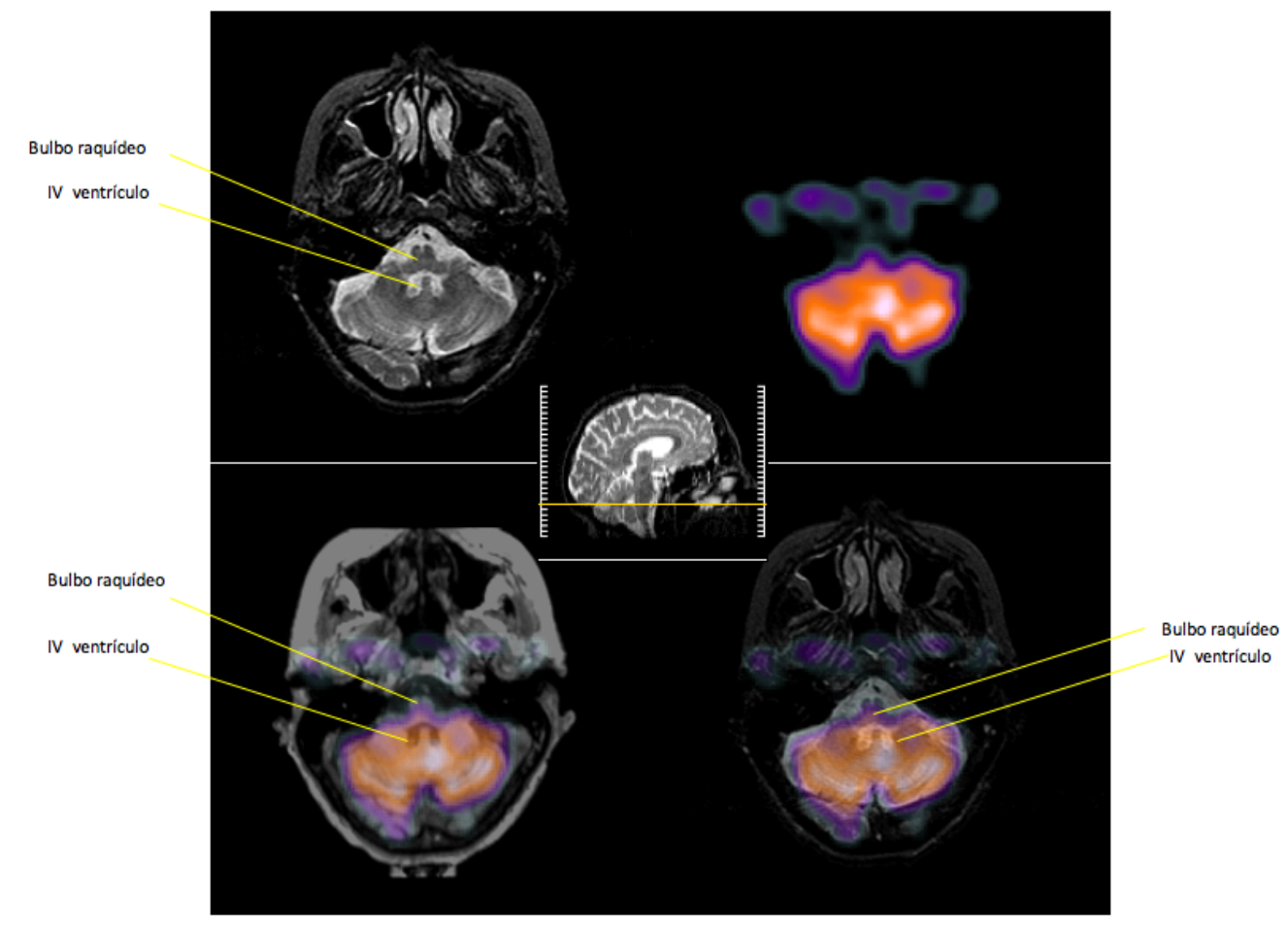

Figura 1.1. Bulbo raquídeo: RM T2 (imagen superior izquierda), SPECT (imagen superior derecha), SPECT registrada con RM T1 (imagen inferior izquierda) y SPECT registrada con RM T2 (imagen inferior derecha). Fuente: Johnson \& Becker, 2010.

La protuberancia anular o puente de Varolio se sitúa en la cara anterior del cerebelo, inferior al mesencéfalo y superior al bulbo raquídeo. Recibe su nombre por su aspecto desde la vista ventral, similar a un puente conectando los dos hemisferios cerebelosos. En la región intermedia de la cara anterior se encuentra el origen aparente de nervio trigémino (V par craneal). Los del nervio abducens (VI par craneal), el nervio facial (VII par craneal) y el nervio vestibulococlear (VIII par craneal) surgen por el surco bulboprotuberancial o protuberancial 
inferior y la arteria basilar discurre por la línea media de la cara anterior de la protuberancia (Kandel et al., 2000; Haines, 2006; Duane, 2008; Barr, 2009).

La cara posterior de la protuberancia está oculta a la vista por el cerebelo y forma la mitad superior del suelo del cuarto ventrículo. En la línea media se encuentra el surco mediano y lateralmente los pedúnculos cerebelosos superiores.

Desde el punto de vista funcional, la protuberancia está relacionada con la circulación anterior a través de la arteria basilar y con el sistema ventricular a través del cuarto ventrículo. Contiene el origen aparente de varios núcleos de pares craneales, sirve como conducto para importantes tractos ascendentes y es la región del encéfalo más asociada con la respiración (Alheid, Milsom, \& McCrimmon, 2004; Cattaneo et al., 2006). También está implicada en el control muscular, postura, equilibrio, procesamiento de información sensorial gustativa y acústica (siendo el lugar por el que la información sensorial auditiva entra en el encéfalo) y el sueño (Xi \& Luning, 2009).

En un estudio de caso con lesión en la protuberancia, se registraron sueños vívidos y violentos que incluyeron gritos, movimientos de los brazos, puñetazos y patadas (tratadas con éxito mediante fármacos anticonvulsivos). Sin embargo, muy pocas alteraciones cognitivas se han asociado con la protuberancia.

En la Figura 1.2 se identifican la protuberancia y el vermis del cerebelo en secciones axiales de RM y SPECT.

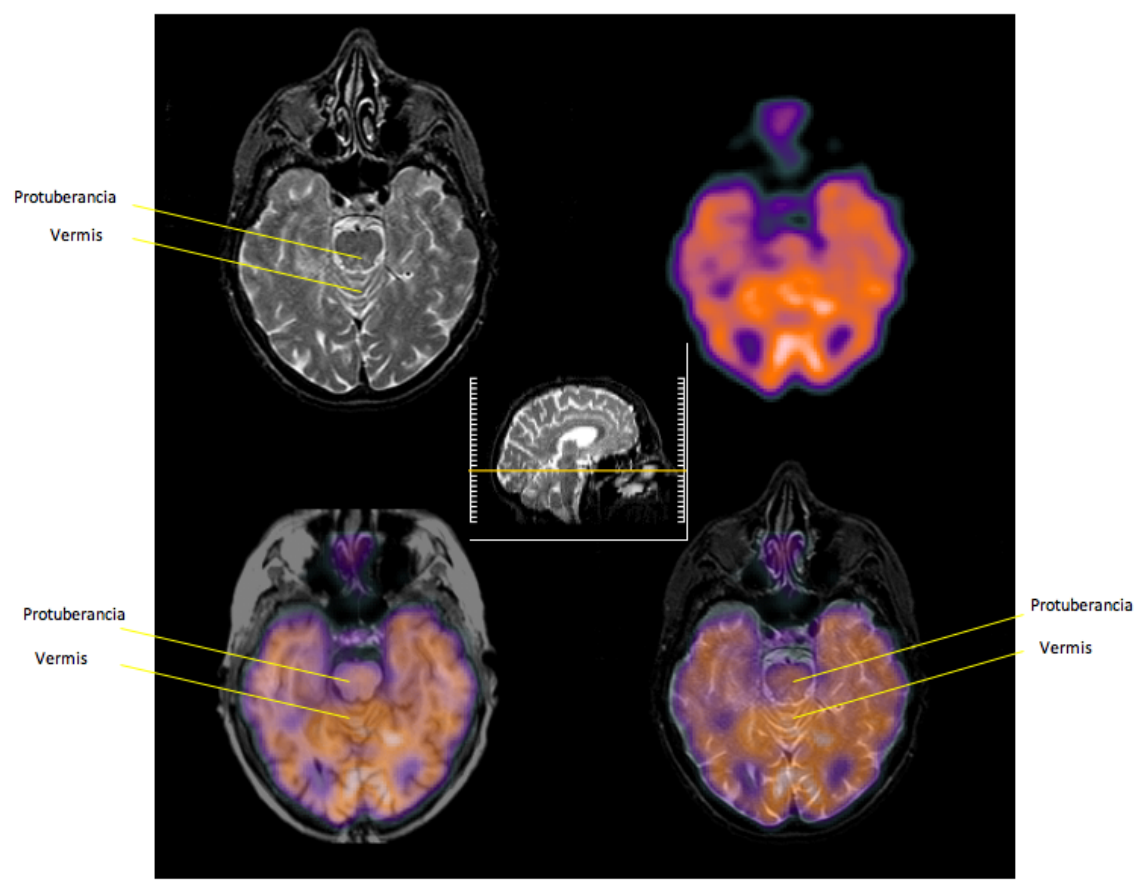

Figura 1.2. Protuberancia y vermis del cerebelo: RM T2 (imagen superior izquierda), SPECT (imagen superior derecha), SPECT registrada con RM T1 (imagen inferior izquierda) y SPECT registrada con RM T2 (imagen inferior derecha). Fuente: Johnson \& Becker, 2010. 
El mesencéfalo es una estructura de unos dos centímetros de longitud aproximadamente localizado entre el diencéfalo y la protuberancia.

En la línea media de la cara anterior del mesencéfalo, se encuentra la fosa interpeduncular y el origen aparente del nervio oculomotor (III par craneal). En el interior se localiza el acueducto de Silvio que conecta los ventrículos III y IV.

En la cara posterior, se encuentran los tubérculos o colículos cuadrigéminos, cuatro eminencias redondeadas divididas en superiores, asociadas con reflejos visuales, e inferiores con centros auditivos. Debajo de los colículos inferiores y, desde una posición medial, surge el origen aparente del par craneal troclear (IV).

Desde el punto de vista clínico, el mesencéfalo contiene dos núcleos de pares craneales, centros visuales y auditivos, el núcleo rojo y la sustancia negra que participa en la función motórica. También funciona como conducto para numerosos tractos ascendentes y descendentes (Kandel et al., 2000; Kalat, 2003; Standring, 2005; Haines, 2006; Duane, 2008; Barr, 2009).

El cerebelo se aloja en la fosa craneal posterior del cráneo, dorsal respecto a la protuberancia y la médula oblongada. Consiste en dos hemisferios laterales conectados por una porción media, el vermis (Figura 1.2). El cerebelo se divide en tres lóbulos principales: el lóbulo anterior, el lóbulo medio y el lóbulo flóculonodular. Está conectado con el mesencéfalo a través de los pedúnculos cerebelosos superiores, con la protuberancia, a través de los pedúnculos cerebelosos medios y con la médula espinal a través de los pedúnculos cerebelosos inferiores. El córtex de la superficie externa de cada hemisferio cerebeloso forma pliegues separados por fisuras transversales. El interior contiene masas de sustancia gris incrustadas en la sustancia blanca, siendo el núcleo dentado el de mayor tamaño.

La importancia clínica del cerebelo está íntimamente relacionada con su función principal: la regulación de movimientos que permiten su ejecución suave y precisa, y el aprendizaje motor como caminar o bailar (Brown, Martínez, \& Parsons, 2006). El cerebelo no es capaz de iniciar movimientos musculares porque no está directamente conectado con las neuronas motoras inferiores, pero sí ejercer control a través del córtex cerebral y tronco encefálico. Como resultado, lesiones en el cerebelo pueden afectar a la habilidad para corregir movimientos (Kandel et al., 2000; Kalat, 2003; Standring, 2005; Haines, 2006; Duane, 2008; Barr, 2009; Snell, 2009).

Recientemente, el cerebelo se ha asociado a funciones cognitivas superiores como el aprendizaje y la atención (Glickstein, 2007). Sin embargo, los resultados no son consistentes. Se han encontrado casos de lesiones cerebelosas sin alteraciones cognitivas (Richter et al., 2007).

El cerebro es la parte más grande del encéfalo y se subdivide en dos partes: telencéfalo y diencéfalo.

El telencéfalo agrupa los dos hemisferios cerebrales, conectados entre sí por masas de fibras blancas comisurales, como el cuerpo calloso, descrito en páginas siguientes. Cada 
hemisferio está compuesto por una superficie exterior o córtex, los núcleos basales y un ventrículo lateral. La fisura longitudinal separa ambos hemisferios en la parte superior, extendiéndose desde los huesos craneales frontales hasta los occipitales por encima de la fosa craneal anterior y media hasta el tentorium cerebelli (Kandel et al., 2000; Kalat, 2003; Standring, 2005; Haines, 2006; Puelles, 2008; Duane, 2008; Barr, 2009; Snell, 2009).

El lóbulo frontal es la región del encéfalo más sobresaliente en cuanto a tamaño y localización de funciones cognitivas superiores. Contiene importantes subestructuras como el córtex prefrontal (CPF), el córtex motor y premotor, el giro frontal medio e inferior y el área de Broca. Desde el punto de vista funcional, estas estructuras, y especialmente el CPF, están implicadas en procesos ejecutivos como la toma de decisiones, planificación, resolución de problemas, pensamiento, atención, lenguaje y juicio moral (Jurado \& Rosselli, 2007; Wilson, Gaffan, Browning, \& Baxter, 2010).

Lesiones en el CPF y sus subestructuras, córtex orbitofrontal y CPF-DL y prefrontal ventral se han asociado, principalmente, a una afectación en el sistema ejecutivo, como la capacidad de planificación, resolución de problemas, atención selectiva, toma de decisiones y regulación del comportamiento social (Jansma, Ramsey, Slagter, \& Khan, 2001; Tanji, Shima, \& Mushiake, 2007; Shaw, 2007; Forbes \& Grafman, 2010). El lóbulo frontal también se ha asociado con la personalidad y emociones, participando en la valoración y control del comportamiento social apropiado (Siever, 2008; Méndez, 2009). El famoso caso de Phineas Gage ilustra esta relación entre lesiones en el CPF, afectación del comportamiento social y de la personalidad (Ratiu, Talos, Haker, Lieberman, \& Everett, 2004).

La lobectomía del lóbulo frontal en el tratamiento de diferentes trastornos de personalidad, y consecuente afectación del córtex motor y premotor, también suele afectar a los movimientos voluntarios.

El córtex es la capa más externa de cada hemisferio, de grosor variable y dispuesta formando pliegues o giros separados por fisuras o surcos, que incrementa significativamente su superficie. Por convención, la superficie de cada hemisferio se subdivide en lóbulos siguiendo las divisiones marcadas por determinados surcos y fisuras.

Los surcos de Rolando (Figura 1.3), parietoccipital y de Silvio (Figura 1.4) en la superficie externa y el surco parietoccipital externo e interno, en la cara interna, son los límites empleados para la división de los lóbulos frontal, parietal, temporal y occipital, que reciben su nombre de los huesos del cráneo en los que se alojan. Sin embargo, hay diferencias individuales en la claridad con que éstos quedan delimitados, variando ligeramente de un individuo a otro. Al igual que sucede con la densidad, tamaño y forma de las neuronas de las diferentes áreas (Kandel et al., 2000; Kalat, 2003; Standring, 2005; Duane, 2008; Puelles, 2008; Barr, 2009). 


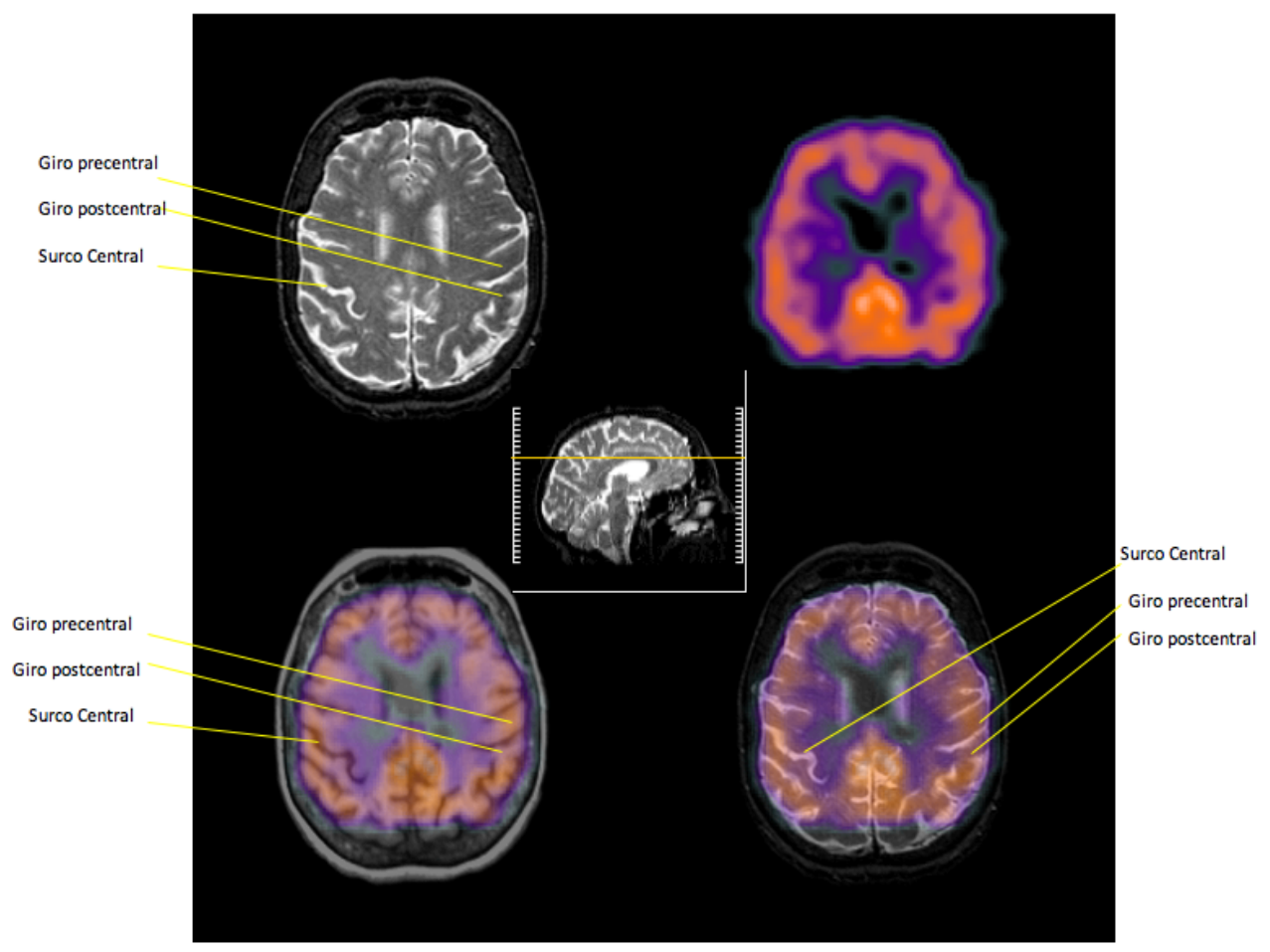

Figura 1.3. Surco Central o de Rolando: RM T2 (imagen superior izquierda), SPECT (imagen superior derecha), SPECT registrada con RM T1 (imagen inferior izquierda) y SPECT registrada con RM T2 (imagen inferior derecha). Fuente: Johnson \& Becker, 2010.

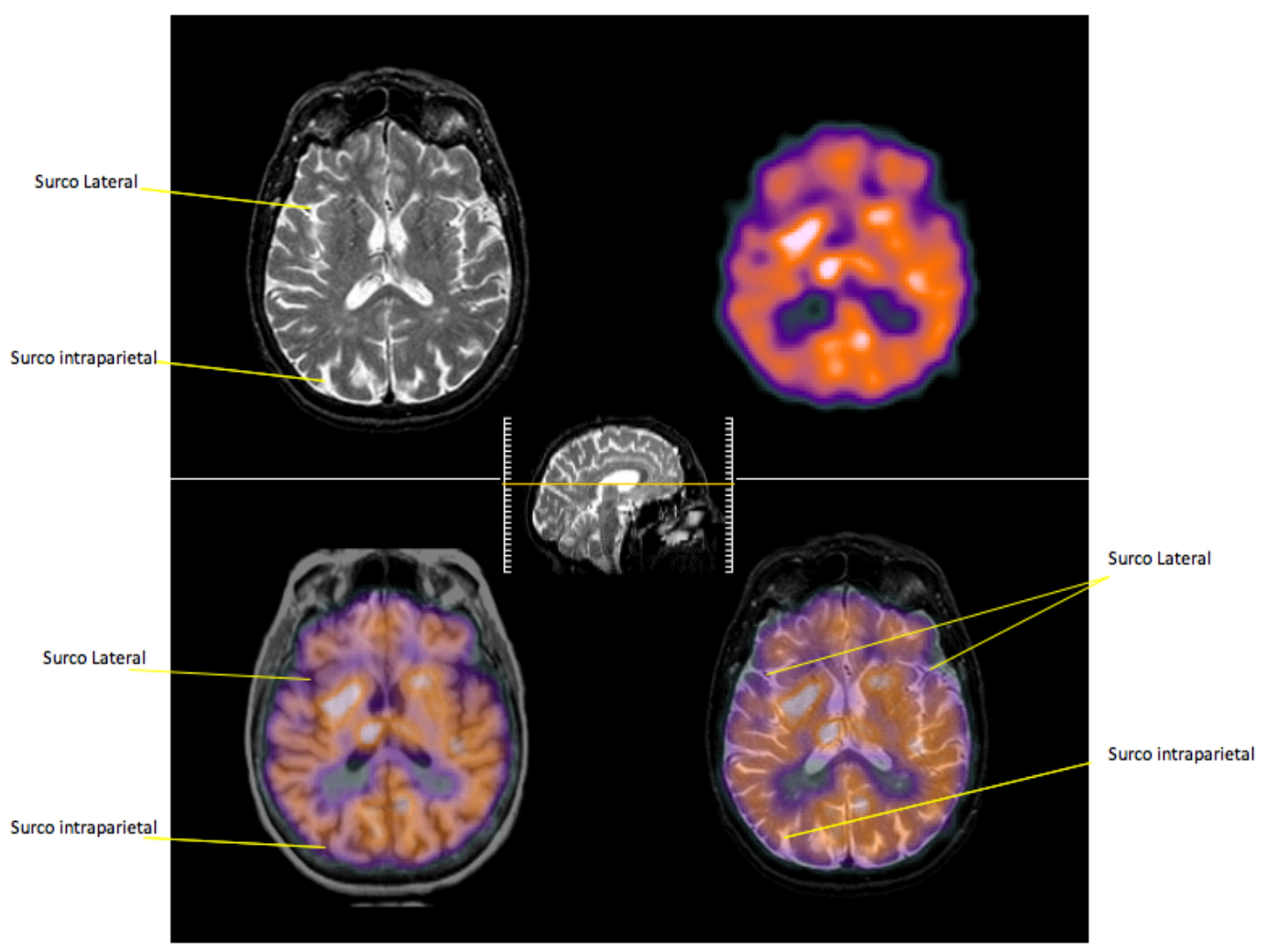

Figura 1.4. Surco Lateral o de Silvio: RM T2 (imagen superior izquierda), SPECT (imagen superior derecha), SPECT registrada con RM T1 (imagen inferior izquierda) y SPECT registrada con RM T2 (imagen inferior derecha). Fuente: Johnson \& Becker, 2010. 
Desde el punto de vista clínico, diferentes áreas del encéfalo están asociadas a el procesamiento de distintos tipos de información y el desarrollo de diferentes funciones. Por ejemplo, el área de Broca, implicada en la producción del lenguaje, está localizada en la parte inferior del lóbulo frontal y el área de Wernicke, responsable de la comprensión del lenguaje, se localiza en el lóbulo temporal (Arnott, Binns, Grady, \& Alain, 2004).

La localización de las áreas responsables del procesamiento primario son las que se conocen con mayor precisión. Las áreas complementarias, normalmente, desempeñan funciones más complejas en base al procesamiento realizado en las áreas primarias. En general, los dos hemisferios cerebrales son simétricos, aunque existen dominancias según la tarea y su organización funcional, puede modificarse como resultado de la recuperación, parcial o total, después de lesiones cerebrales (Duane, 2008; Barr, 2009; Snell, 2009).

La representación gráfica de la organización del córtex somatosensorial en el giro postcentral o del córtex motor en el giro precentral, se conoce como homúnculo sensorial y motor. Estas áreas están delimitadas por el surco precentral, el surco de Rolando y el surco postcentral, cuya localización aparece indicada en las secciones axiales RM y SPECT de la Figura 1.3.

La importancia clínica del córtex radica en que permite discriminar y asociar la información procedente de experiencias sensoriales y provocar respuestas motoras asociadas. Generalmente, estas funciones del córtex se han estudiado a través de los efectos de su lesión por cirugía, TCE, o por el registro de la actividad eléctrica de distintas áreas del córtex durante la estimulación en un paciente consciente (Kandel et al., 2000; Young, 2001; Standring, 2005; Afifi \& Bergman, 2006; Haines, 2006; Snell, 2009).

Los núcleos basales son masas de sustancia gris localizadas en el interior de los hemisferios cerebrales. Incluyen el cuerpo estriado, compuesto por el núcleo caudado, situado en el lado medial de la cápsula interna de cada hemisferio (Figura 1.5) y el núcleo lenticular, situado lateral respecto a la cápsula interna, formado por el globo pálido y el núcleo putamen (Figura 1.6). La amígdala y el claustro también se consideran núcleos basales. Las fibras en forma de abanico que comunican el córtex con el tronco encefálico se denominan corona radiada y convergen a nivel de los núcleos basales discurriendo entre ellos, formando la cápsula interna (Kandel et al., 2000; Kalat, 2003; Standring, 2005; Duane, 2008; Puelles, 2008; Barr, 2009). 


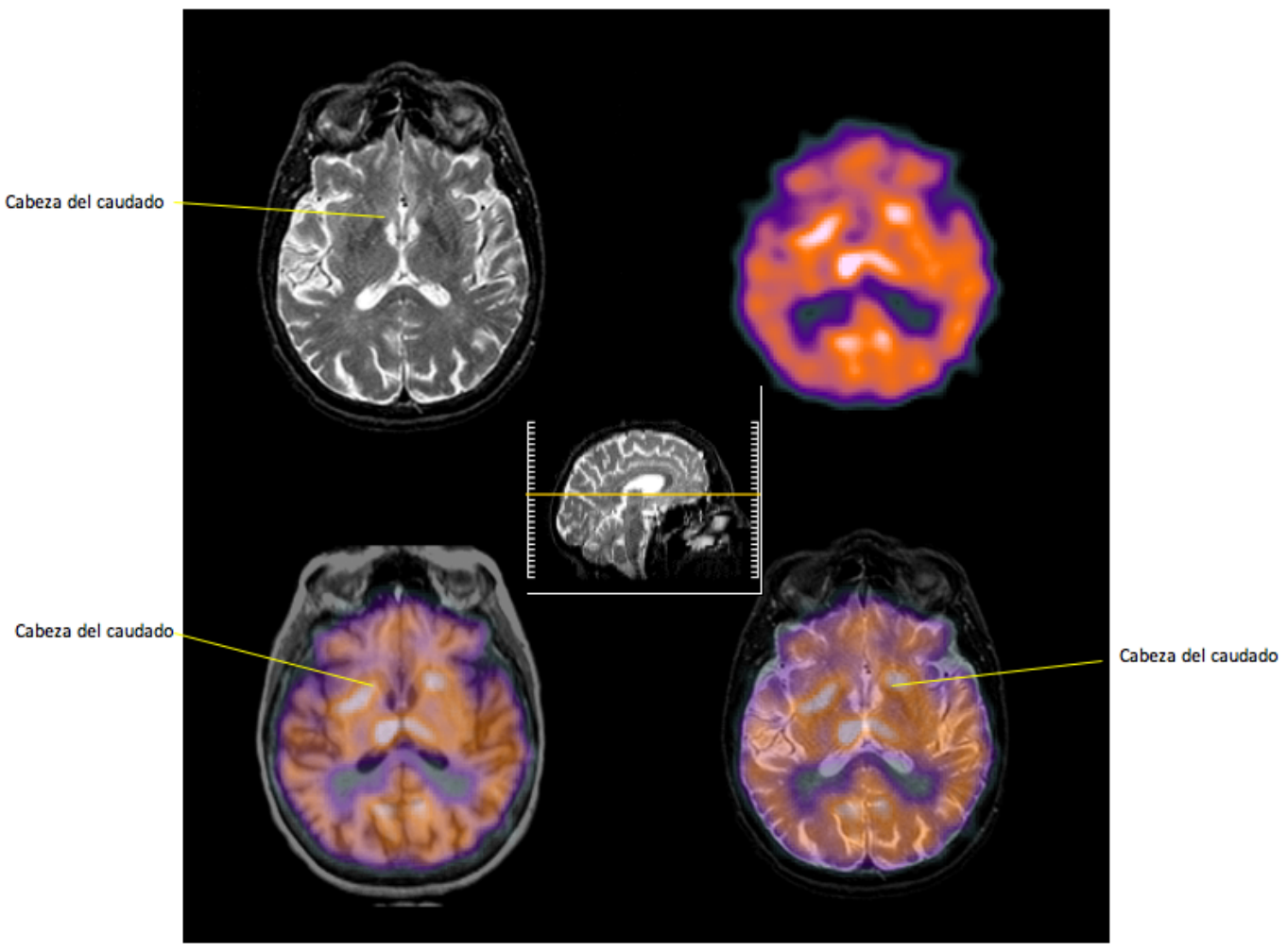

Figura 1.5. Núcleo caudado: RM T2 (imagen superior izquierda), SPECT (imagen superior derecha), SPECT registrada con RM T1 (imagen inferior izquierda) y SPECT registrada con RM T2 (imagen inferior derecha). Fuente: Johnson \& Becker, 2010.

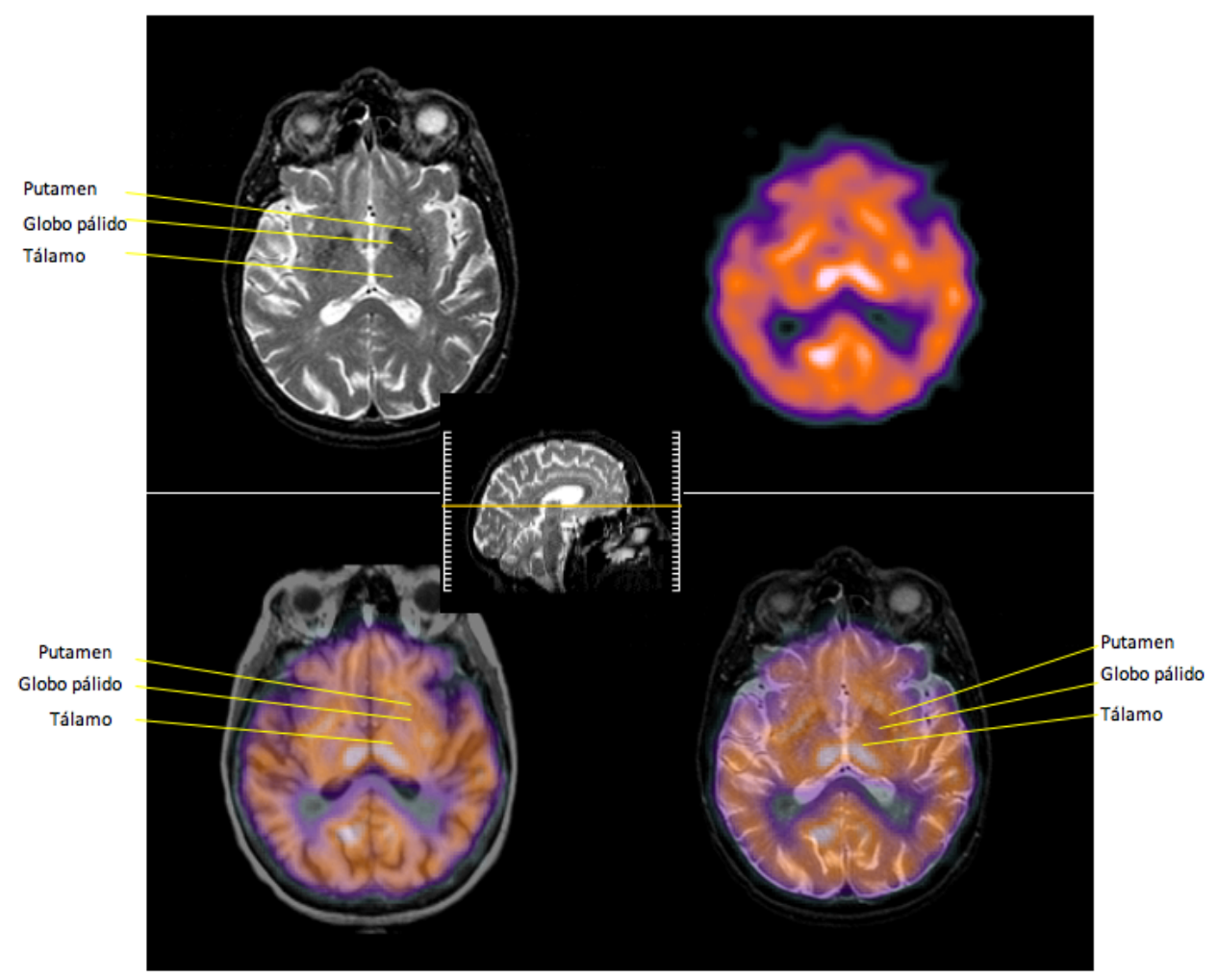

Figura 1.6. Núcleo putamen, globo pálido y tálamo: RM T2 (imagen superior izquierda), SPECT (imagen superior derecha), SPECT registrada con RM T1 (imagen inferior izquierda) y SPECT registrada con RM T2 (imagen inferior derecha). Fuente: Johnson \& Becker, 2010. 
Tradicionalmente, el cuerpo (neo)estriado (caudado y putamen), se ha asociado con funciones motoras, de forma que lesiones en estos núcleos están relacionadas con trastornos hipercinéticos, caracterizados por la presencia de movimientos excesivos y anormales. Sin embargo, cada vez hay más evidencia de su participación en funciones cognitivas jugando un papel central en la memoria de trabajo (Lewis, Dove, Robbins, Barker, \& Owen, 2004) y el aprendizaje o formación de hábitos y sistema de recompensa. E núcleo caudado, que participa en el aprendizaje de conductas dirigidas a la consecución de objetivos y percepción del feedback e incentivo contingentes (Grahn, Parkinson, \& Owen, 2008).

Especial atención merece la amígdala (Brabec, Rulseh, Hoyt, Vizek, Horinek, Hort, \& Petrovicky, 2010), implicada en la respuesta emocional a señales sociales, como la percepción del estado emocional de los demás, saliencia de estímulos visuales y respuesta apropiada en situaciones sociales, por lo que algunos autores se han referido a esta estructura como un verdadero "cerebro social" (Adolphs, 2001; Amaral, Bauman, Capitanio, Lavenex, Mason, Mauldin-Jourdain, \& Mendoza, 2003; Schultz, 2005; Skuse, 2006). La amígdala también juega un papel central en el procesamiento selectivo de estímulos amenazantes, tales como expresiones faciales de miedo y odio y las respuestas de ansiedad y consecuente dificultad para mantener un comportamiento social apropiado (Whalen, Shin, McInerney, Fischer, Wright, \& Rauch, 2001; Phan, Wager, Taylor, \& Liberzon, 2002; Anderson, Christoff, Panitz, DeRosa, Gabrieli, 2003; Kim, Somerville, Johnstone, Alexander, \& Whalen, 2003; Somerville, Kim, Johnstone, Alexander, \& Whalen, 2004; Schumann \& Amaral, 2006). Varios autores han encontrado que las amígdalas derecha e izquierda desempeñan funciones distintas aunque complementarias en dichas respuetas. La amígdala derecha facilitaría el reconocimiento de emociones negativas por la amígdala izquierda a través del procesamiento cognitivo. La izquierda estaría asociada a la percepción o interpretación de amenazas percibidas a través de expresiones faciales de miedo, un tipo de procesamiento cognitivo selectivo (Sah et al., 2003; Singer, Kiebel, Winston, Dolan, \& Frith, 2004; Somerville, Kim, Johnstone, Alexander, \& Whalen, 2004; Das et al., 2005). La amígdala derecha estaría asociada con la intensidad de la respuesta afectiva, medida a partir del grado de arousal autónomo (con una modesta influencia en el reconocimiento cognitivo) (Anderson \& Sobel, 2003; Sah, Faber, López, \& Power, 2003). Lesiones en la amígdala izquierda no afectan a la respuesta autónoma de ansiedad, pero sí al reconocimiento de emociones negativas, y lesiones en la amígdala derecha provocan, principalmente, una afectación en la respuesta autónoma (Glascher \& Adolphs, 2003; Hariri, Mattay Tessitore, Fera, \& Weinberger, 2003; Williams, Morris, McGlone, Abbott, \& Mattingley, 2004; Williams, McGlone, Abbott, \& Mattingley, 2005). Lesiones bilaterales, en ausencia de otros déficits, se han asociado con la incapacidad para reconocer o dibujar caras de miedo (Murray, 2007). 
En la Figura 1.7 se identifica la amígdala en secciones axiales obtenidas a partir de RM y SPECT. Se observa la dificultad de localización de estructuras de estas caractarísticas en imágenes $2 \mathrm{D}$.

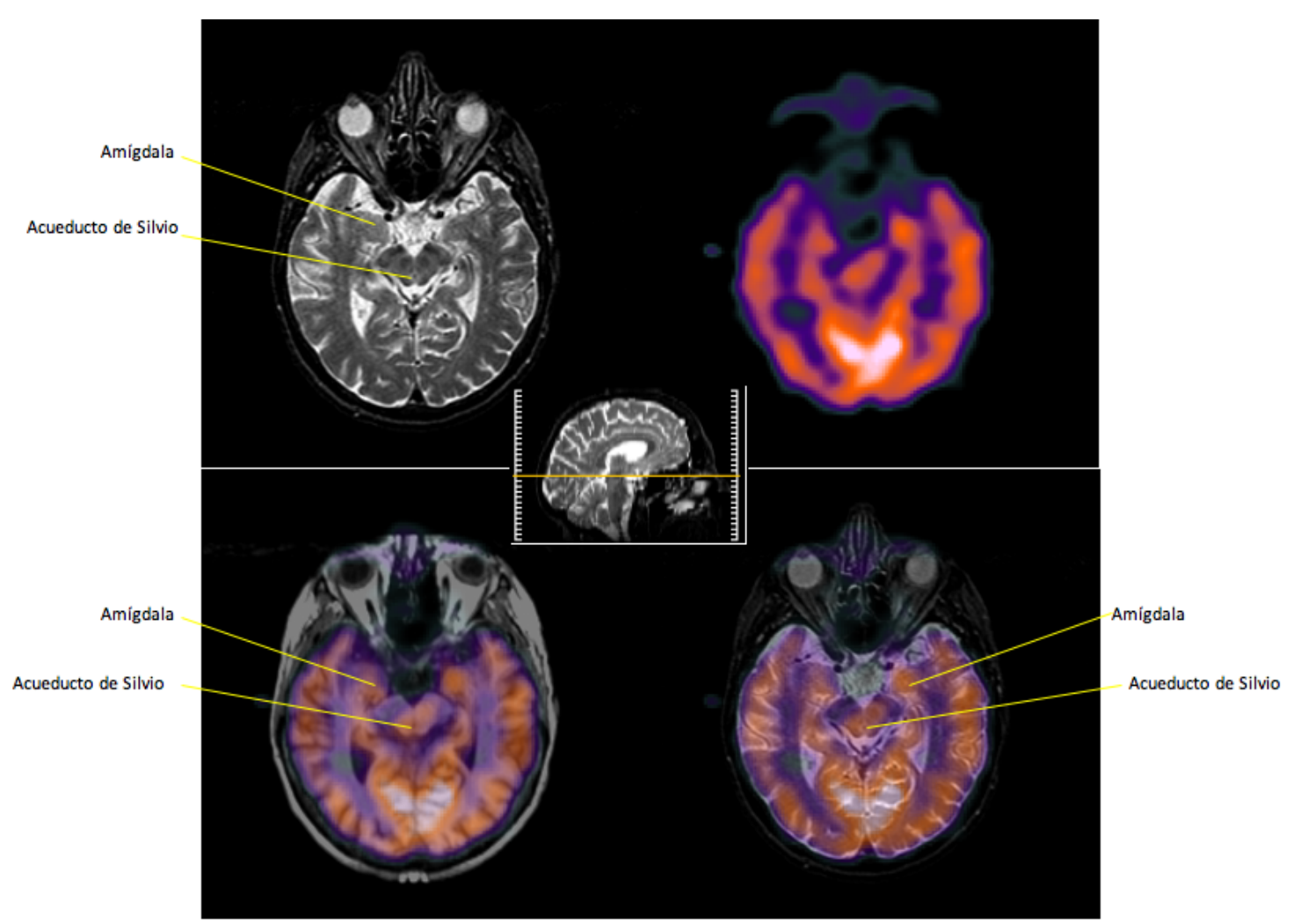

Figura 1.7. Amígdala: RM T2 (imagen superior izquierda), SPECT (imagen superior derecha), SPECT registrada con RM T1 (imagen inferior izquierda) y SPECT registrada con RM T2 (imagen inferior derecha). Fuente: Johnson \& Becker, 2010.

Dentro de la sustancia blanca, el cuerpo calloso está constituido por fibras comisurales que permiten la transferencia de información entre ambos hemisferios cerebrales y cuya sección ha permitido estudiar éstos de forma independiente. Los primeros trabajos sobre "cerebros divididos" se remontan a los años 60 con Michael Gazzaniga y Roger Wolcott Sperry, cuyos estudios han contribuido a la consideración de la especialización linguística, el reconocimiento facial y monitorización atencional al hemisferio izquierdo (Gazzaniga, 2005; Glickstein, \& Berlucchi, 2008), junto con el reconocimiento de uno mismo asociado al hemisferio izquierdo y el reconocimiento de los demás al derecho (Turk, Heatherton, Kelly, Funell, Gazzaniga, \& Macrae, 2002).

El diencéfalo es un conjunto de estructuras mediales con dos mitades simétricas: derecha e izquierda, que se extiende desde el orificio intraventricular hasta el punto en el que el ventrículo III se convierte en el acueducto de Silvio, de forma que el ventrículo III formaría el verdadero techo del diencéfalo. 
La parte superior del diencéfalo está definida por el fórnix o trígono, un conjunto de fibras que parten del hipocampo en el lóbulo temporal y discurren, en forma de arco, hacia la parte posterior y sobre el tálamo para unirse a los cuerpos mamilares. Sin embargo, el verdadero techo del diencéfalo está formado por la pared superior del tercer ventrículo. La parte inferior o suelo del diencéfalo está formado por el hipotálamo, el quiasma óptico, el infundíbulo con el tuber cinereum y los cuerpos mamilares.

Las cuatro estructuras principales que componen el diencéfalo son: el tálamo, subtálamo, epitálamo e hipotálamo.

El tálamo es una gran masa ovoide de sustancia gris que forma la mayor parte del diencéfalo (Figura 1.6). La parte medial del tálamo delimita la parte superior de la pared lateral del ventrículo III y ambos tálamos están conectados por una banda de sustancia gris denominada conexión intertalámica. La parte anterior del tálamo, estrecha y redondeada, forma el límite posterior del orificio interventricular. La parte posterior del tálamo se expande para formar el pulvinar. El cuerpo geniculado lateral forma una pequeña elevación en la porción lateral del pulvinar mientras que el cuerpo geniculado medial se encuentra a ambos lados de la línea media. Los núcleos geniculados forman la estructura denominada metatálamo (Kandel et al., 2000; Kalat, 2003; Standring, 2005; Duane, 2008; Puelles, 2008; Barr, 2009).

Desde el punto de vista funcional, el tálamo comunica diferentes áreas del córtex y cerebelo, participando en numerosas funciones como percepción, atención y movimiento, además de jugar un papel central en el nivel de alerta y consciencia (Cano, Bezdudnaya, Swadlow, \& Alonso, 2006; Sherman, 2007). En un estudio de caso con lesión talámica se encontró sinestesia táctil y auditiva (Ro et al., 2007).

El subtálamo es una zona de transición de la parte anterior del diencéfalo que se localiza entre el tálamo, el hipotálamo y el tegmento del mesencéfalo. Entre sus componentes destaca el núcleo subtálamico que mantiene conexiones con el cuerpo estriado, participando en el control de la actividad muscular.

El epitálamo comprende la glándula pineal o epífisis, los núcleos habenulares y sus conexiones. La epífisis consiste en una pequeña glándula endocrina con estructura cónica, responsable de la secreción de melatonina según la cantidad de luz solar existente.

El hipotálamo constituye un conjunto de núcleos que se extienden desde el quiasma óptico hasta la parte caudal de los cuerpos mamilares. Es una estructura anatómicamente pequeña pero situada estratégicamente cerca del sistema límbico, los tractos ascendentes y descendentes y la hipófisis. Lesiones en el hipotálamo como resultado de algunos tumores, por ejemplo, el adenoma pituitario, afectarán a su funcionalidad, relacionada directa o indirectamente, con la mayoría de las funciones vitales, incluyendo la regulación de la temperatura corporal, funciones genitales, sueño, ingesta alimentaria... 
El sistema límbico ha sido un término empleado para describir la parte del encéfalo localizada entre el córtex cerebral y el hipotálamo. Entre las estructuras que lo componen, la mayoría de los autores incluyen la amígdala, el hipocampo, el septum, los cuerpos mamilares, el hipotálamo, epitálamo, el giro cingulado, giro dentado, córtex enthorhinal y el fórnix, aunque no hay consenso respecto a cada una de las estructuras que lo componen (Kandel et al., 2000; Young, 2001; Afifi \& Bergman, 2006; Haines, 2006; Snell, 2009). Las conexiones entre estas estructuras son extremadamente complejas y aún no se comprenden plenamente, aunque sí parecen jugar un papel importante en el procesamiento y regulación de emociones, las respuestas viscerales que les acompañan, la activación sexual, la memoria, ritmos y en la respuesta del cuerpo al estrés, al estar intensamente conectado con el sistema endocrino y vegetativo (Sapolsky, 2003; Herman, Ostrander, Mueller, \& Figueiredo, 2005). Alteraciones en estructuras del sistema límbico se han asociado con trastornos psiquiátricos como la esquizofrenia, el trastorno bipolar (TB) y el trastorno depresivo mayor (TDM), como veremos con más detalle en el apartado 1.6.

Además de la amígdala, que participa en el procesamiento de emociones, el hipocampo es otra de las estructuras más características del sistema límbico y de gran importancia clínica (Hui, Cavazos, \& Tien, 1997; Hayman, Fuller, Cavazos, Pfleger, Meyers, \& Jackson, 1998). Desde el punto de vista funcional, participa en el aprendizaje de respuestas de miedo, a través de la formación de recuerdos y contextualización de las amenazas detectadas en la amígdala, e incluso en la propia respuesta a emociones faciales negativas junto a esta (Surguladze, Brammer, Young, Andrew, Travis, Williams, \& Phillips, 2003; Skuse, 2006). El hipocampo y la amígdala permiten diferenciar un procesamiento declarativo, centrado en hechos de estímulos amenazantes, de respuestas basadas en experiencias viscerales, participando conjuntamente en la respuesta de lucha y huída (Williams et al., 2001; Sandi \& Pinelo-Nava, 2007; Pessoa, 2008).

El giro cingulado es otra región del sistema límbico con importantes funciones neuropsicológicas como la regulación de emociones desagradables y experiencias dolorosas. La región anterior está implicada en el procesamiento emocional de la respuesta de miedo, especialmente, en la predicción y recuerdo de consecuencias negativas, que contribuye a la evitación de estímulos aversivos (Vogt, 2005; Nente, Carrillo-Mezo, Mendez, \& RamirezBermudez, 2007; Posner, Rothbart, Sheese, \& Tang, 2007).

El córtex del lóbulo occipital constituye la principal área visual del encéfalo. Recibe proyecciones desde la retina vía tálamo y participa en el procesamiento del color, orientación y movimiento, reconocimiento de objetos y su localización. En casos de sinestesia se han encontrado activación en áreas del córtex occipital cuando los sujetos ven letras o números (Hubbard \& Ramachandran, 2005; Sperlling, Prvulovic, Linden, Singer, \& Stirn, 2006).

El córtex del lóbulo parietal participa en la integración de información proveniente de diferentes sentidos como la relativa a vías visuales ventrales, asociadas con el reconocimiento de 
objetos, y vías visuales dorsales, relacionadas con la localización y coordinación de la manipulación de objetos (Hubbard, 2007). También, participa en el procesamiento atencional y representación de números. Lesiones en la región posterior de éste provocan negligencia hemiespacial o incapacidad para atender al lado contralateral a la lesión (normalmente, el hemisferio derecho) incluso en imaginación (Bisiach \& Luzzatti, 1978) y alteraciones en la imagen corporal.

El lóbulo temporal contiene numerosas subestructuras, tales como la amígdala, el córtex primario auditivo, los giros temporales superior, medio e inferior, el giro fusiforme, y el área de Wernicke, el hipocampo y el giro cingulado (DeFelipe, Fernández-Gil, Kastanauskaite, Bote, Presmanes, \& Ruiz, 2007). Funcionalmente, estas estructuras participan en funciones cognitivas como percepción, reconocimiento facial, memoria, comprensión del lenguaje y reacciones emocionales (Eichenbaum, Yonelinas, \& Ranganath, 2007). La estimulación profunda del lóbulo temporal se ha asociado con experiencias religiosas y extracorpóreas (Previc, 2006) y lesiones en este área pueden provocar agnosias o incapacidad para reconocer categorías específicas (partes del cuerpo, colores, caras, música, olores...).

Omitiremos la presentación de la formación reticular, al tratarse de una red difusa de núcleos, no identificable a nivel macroscópico. Finalmente, se excluye la descripción de los nervios periféricos craneales y espinales, y meninges, que no serán objeto de reconstrucción en este trabajo.

El sistema ventricular recibe su nombre de los ventrículos o cavidades encefálicas que lo conforman. Se trata de espacios que son extensiones de la médula espinal y contienen LCR. Protegen el encéfalo y sirven como estructuras de referencia útiles o landmarks para localizar distintas estructuras encefálicas.

En la Figura 1.8 se observan los VL, que se comunican con el ventrículo III a través del agujero de Monro u orificio interventricular. El ventrículo III está conectado con el cuarto a través del acueducto cerebral o de Silvio. Y el ventrículo IV está comunicado con el canal central de la médula espinal y con su techo a través de los forámenes de Luschka y Magendie. El canal central de la médula también presenta una pequeña dilatación en su parte final que se denomina ventrículo terminal (Kandel et al., 2000; Kalat, 2003; Standring, 2005; Haines, 2006; Duane, 2008; Puelles, 2008; Woolsey et al., 2008; Barr, 2009; Snell, 2009).

Existen diferentes patologías encefálicas: tumorales, inflamatorias o malformaciones congénitas del desarrollo, que pueden interferir la circulación del LCR en el sistema ventricular, cuyo bloqueo producirá un acúmulo excesivo de LCR que conducirá a hidrocefalia o aumento anormal de su volumen.

El LCR circulante en las cavidades ventriculares y espacio subaracnoideo facilita el aislamiento del sistema nervioso de la sangre y asegura, junto con la barrera hematoencefálica, un ambiente estable, necesario para el funcionamiento correcto del SNC. 


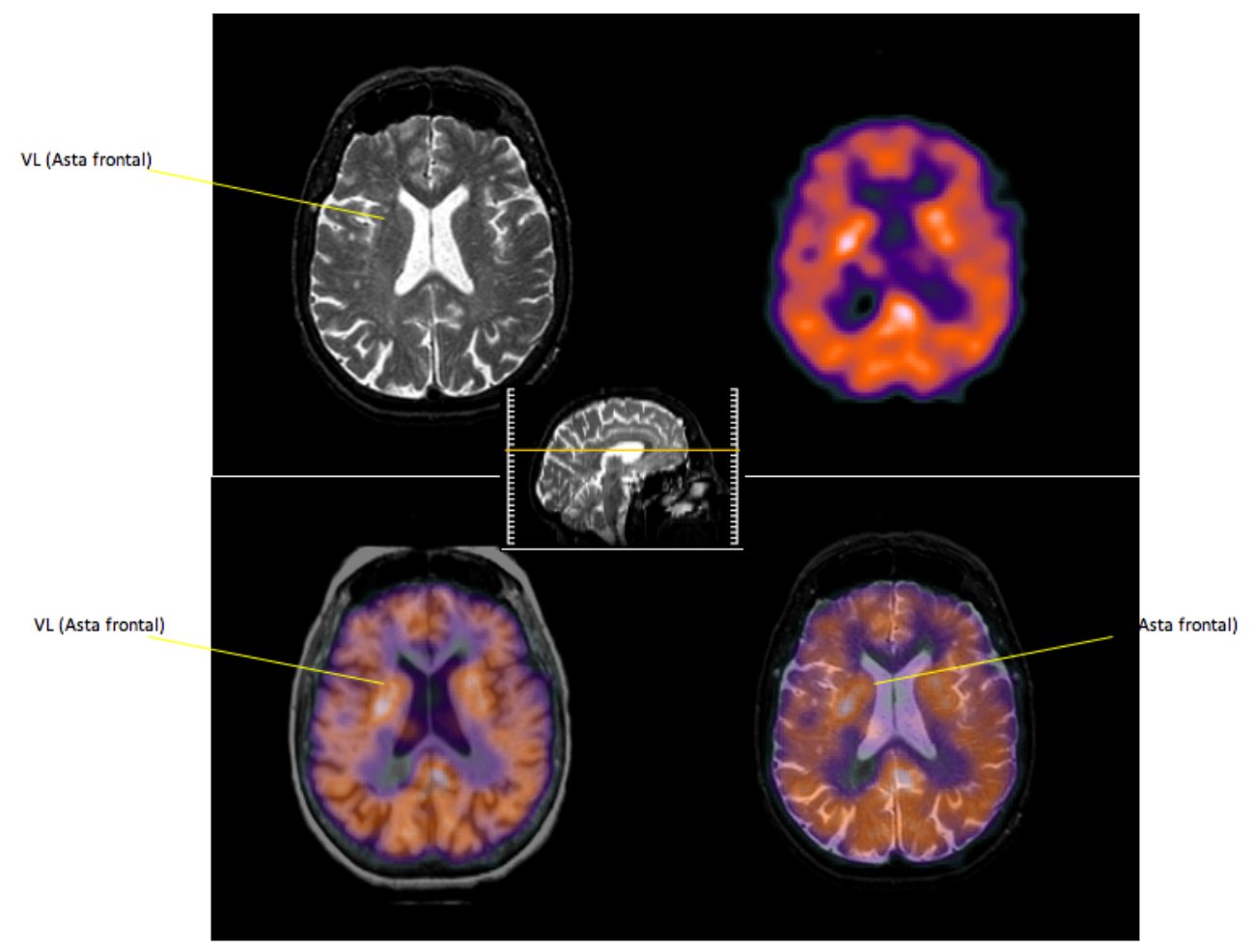

Figura 1.8. Ventrículos laterales: RM T2 (imagen superior izquierda), SPECT (imagen superior derecha), SPECT registrada con RM T1 (imagen inferior izquierda) y SPECT registrada con RM T2 (imagen inferior derecha). Fuente: Johnson \& Becker, 2010.

En relación con los territorios cerebrales de vascularización del encéfalo, cada hemisferio cerebral recibe su aporte sanguíneo de una arteria carótida interna, con origen en la carótida común, situada por debajo de la mandíbula. La arteria carótida interna se introduce en el cráneo a través del conducto carotídeo, cruza el seno cavernoso donde surge la arteria oftálmica y penetra en la duramadre para dividirse en ACA y ACM.

Las principales ramas superficiales de la $\mathrm{ACM}$ ofrecen aporte sanguíneo a la corteza cerebral, la sustancia blanca de la cara inferior del lóbulo frontal, a la superficie medial de los lóbulos frontal y parietal y a la parte anterior del cuerpo calloso. Las ramas penetrantes de menor tamaño aportan riego sanguíneo a las áreas más profundas de los hemisferios cerebrales y del diencéfalo, incluyendo estructuras límbicas, la cabeza del caudado y el brazo anterior de la cápsula interna.

Las principales ramas superficiales de la ACM irrigan la mayor parte de la corteza y la sustancia blanca de la convexidad del hemisferio, como los lóbulos frontal, parietal, temporal y occipital y la ínsula. Las ramas penetrantes de menor tamaño irrigan la sustancia blanca y las estructuras diencefálicas profundas, como el brazo posterior de la cápsula interna, el putamen, el globo pálido lateral y el cuerpo del núcleo caudado. Por su parte, la carótida interna da origen a la carótida anterior, que vasculariza la parte anterior del hipocampo y a un nivel inferior, el brazo posterior de la cápsula interna. 
Las arterias vertebrales izquierda y derecha penetran en el cráneo a través del agujero magno. Cada una de ellas da lugar a una arteria espinal anterior y a una arteria cerebelosa inferoposterior. Las arterias vertebrales se unen a nivel de la protuberancia y el bulbo raquídeo para formar la arteria basilar, que a nivel de la protuberancia origina la arteria cerebelosa inferoanterior y la arteria laberíntica. Y en el mesencéfalo, la arteria cerebelosa superior. A continuación, la arteria basilar se divide en las dos ACP que irrigan la zona inferior de los lóbulos temporales, la zona medial de los lóbulos occipitales y el sector posterior del cuerpo calloso. Las ramas penetrantes de menor tamaño de estos vasos aportan riego sanguíneo a estructuras diencefálicas, como el tálamo y los núcleos subtalámicos, además de algunas áreas del mesencéfalo (Kandel et al., 2000; Kalat, 2003; Standring, 2005; Haines, 2006; Duane, 2008; Puelles, 2008; Snell, 2008; Barr, 2009; Snell, 2009). 



\subsection{TÉCNICAS DE DIAGNÓSTICO POR IMAGEN}

Tradicionalmente, el conocimiento morfofuncional del SNC del encéfalo se había basado en estudios histológicos de casos clínicos y otros métodos invasivos. Sin embargo, las técnicas de diagnóstico por imagen generan imágenes morfológicas y funcionales que han permitido visualizar estructuras encefálicas in vivo, aunque con diferencias en cuanto a resolución espacial y temporal, que dificultan el proceso de valoración clínica.

Gracias a los avances en neurociencias, actualmente, se acepta que la conducta y los procesos cognitivos superiores normales y patológicos están mediados por la función neuronal y que las técnicas de diagnóstico por imagen constituyen herramientas útiles en el estudio de las bases biológicas de trastornos neurológicos y psiquiátricos con importantes efectos neuropsicológicos. Por este motivo, neurólogos, neuropsicólogos, psiquiatras y psicólogos clínicos necesitan familiarizarse con las diferentes técnicas y los principios en que se basan.

Una de las aportaciones más importantes de estas técnicas y que ha contribuido a su rápido desarrollo, es su capacidad para discriminar entre estructura del encéfalo y su función. Como afirmó el neurólogo británico John Hughlings Jackson en los años 80 del siglo XIX, la estructura del encéfalo no es igual a la función y viceversa. Lesiones en la estructura encefálica, como un tumor, pueden producir la pérdida o aumento de la función normalmente asociada a dicha región. Incluso, es posible tener una estructura normal del encéfalo (al menos dentro de los límites que permite medir la tecnología actual) y mostrar una función marcadamente afectada.

Otra de las razones que han contribuido al rápido desarrollo de estas técnicas, ha sido su utilidad, al facilitar la correcta identificación de diferentes trastornos neuropsicológicos y la monitorización de su evolución durante el proceso de recuperación, después de una lesión adquirida o de una intervención quirúrgica, farmacológica, o psicoterapéutica, incluyendo recientemente, el estudio de trastornos psiquiátricos (Abou-Saleh, 2006; Irani, Platek, Bunce, Ruocco, \& Chute, 2007; Pearlson \& Calhoun, 2007; Zipursky, Meyer, \& Verhoeff, 2007; Frodl et al., 2008; Malhi \& Lagopoulos, 2008; Hendler, Bleich-Cohen, \& Sharon, 2009; Glenda \& MacQueen, 2010).

La rápida evolución de las técnicas de diagnóstico por imagen ha supuesto avances en los métodos de adquisición de imágenes, en sus métodos de análisis y en sus aplicaciones clínicas (Monchi, Benali, Doyon, \& Strafellas, 2008). La integración o fusión de imágenes morfológicas y funcionales supondría un paso más en esta dirección.

En este apartado se ofrece una visión general de las principales técnicas de neuroimagen morfológicas: radiografía simple, TC y RM y funcionales: PET y SPECT, que se han empleado en este trabajo y que suponen herramientas básicas en la valoración clínica de trastornos neuropsicológicos. Posteriormente, describiremos en qué consiste la integración o fusión de diferentes modalidades o técnicas multimodales, como estrategia dirigida a preservar las ventajas 
y superar las limitaciones de cada modalidad individual. Finalmente, ofreceremos una visión general del concepto de neuronavegador.

No se incluirán descripciones de ultrasonografías basadas en el empleo de ondas mecánicas de ultrasonido, porque están más indicadas para el estudio de estructuras relativamente superficiales como las abdominales o torácicas que no están protegidas por estructuras óseas como el cráneo.

\subsubsection{Técnicas de valoración morfológica}

En la descripción de cada una de las siguientes técnicas de Radiodiagnóstico se hace referencia a su origen, los principios físicos en que se basan, sus indicaciones y las limitaciones asociadas a cada una. En primer lugar, describiremos la radiografía simple como punto de partida para comprender las características de la TC, que se presenta a continuación.

\subsubsection{Radiografía Simple}

El descubrimiento de los Rayos X (Rx) por Wilhelm Conrad Roentgen en 1895 puede considerarse el nacimiento de la radiología y, probablemente, el descubrimiento físico más importante en el campo de la Medicina.

La propiedad fundamental de los Rx, que justifica su uso en el diagnóstico por imagen, es su capacidad de penetrar en los diferentes tejidos de las estructuras encefálicas, absorbiéndose de forma selectiva (atenuación) y producir luz (luminiscencia), permitiendo su impresión sobre una película radiográfica o placa. Actualmente, la tendencia al formato digital es evidente, y la radiografía simple en formato analógico (placa) está dejando lugar a las radiografías digitales, aunque el fundamento físico sigue siendo el mismo.

$\mathrm{La}$ atenuación del haz de $\mathrm{Rx}$ dependerá, principalmente, del número atómico del elemento que compone la materia o tejido de las estructuras encefálicas con las que interacciona (a mayor número atómico, mayor absorción), de la densidad del medio (a mayor densidad, más absorción) y de la longitud de onda de la radiación (a mayor longitud de onda o radiación blanda, mayor absorción) (Novelline, 2000; Bushberg, Seibert, Leidholdt, \& Boone, 2002; Cabrero, 2002; Delgado, Martínez-Morillo, \& Otón, 2002; Alcaráz, 2003; Turner, \& Jones, 2003; Cabrero, 2004).

Una de las limitaciones de la Radiografía Simple es que sólo permite diferenciar 5 densidades radiológicas básicas: densidad aire, compuesta por elementos de número atómico bajo ${ }^{1} \mathrm{H},{ }^{6} \mathrm{C},{ }^{7} \mathrm{~N} \mathrm{y}{ }^{8} \mathrm{O}$, que se visualizan en tonos negros (radioluminiscente o radiotransparente); densidad grasa, que se visualiza en tonos grises; densidad agua de los tejidos blandos que aparece en color gris claro casi blanco; densidad hueso, como el cráneo, con número atómico relativamente alto ${ }^{15} \mathrm{P},{ }^{20} \mathrm{Ca}$, que se visualizan en tonos blancos (radioopacos) y densidad metal, como los contrastes como el bario $\left({ }^{56} \mathrm{Ba}\right)$ y aquéllos que contienen yodo $\left({ }^{53} \mathrm{I}\right)$ que se visualizan 
muy blancos (Bushberg et al., 2002; Cabrero, 2002; Delgado et al., 2002; Alcaráz, 2003; Turner \& Jones, 2003).

Otra limitación de la Radiografía Simple es el carácter 2D de la imagen, que implica una pérdida de información respecto al 3D de las estructuras encefálicas originales. Una estructura de menor densidad, pero de mayores dimensiones, podría verse igual que otra de mayor densidad pero menores dimensiones, o dos estructuras superpuestas, se superpondrían en la radiografía. Para obtener una imagen igual a la estructura encefálica explorada, el foco de Rx debería estar situado a una distancia infinita, si bien, en la práctica, se asume que el tamaño es el mismo con distancias superiores a $150 \mathrm{~cm}$ (telerradiografías) (Delgado, Martínez-Morillo, \& Otón, 2002; Alcaráz, 2003; Cabrero, 2004).

La TC permite solucionar estos problemas, al menos parcialmente, utilizando secciones o cortes de las estructuras encefálicas internas.

\subsubsection{Tomografía Computarizada (TC)}

Después del descubrimiento de los Rx, la mayor contribución al diagnóstico por imagen, desde el punto de vista histórico, fue el desarrollo de la TC por Godfrey M. Hounsfield, quien elaboró una técnica de reconstrucción algebraica para componer las imágenes detectadas por sensores de Rx. Tal fue su repercusión que fue galardonado, junto a Allan M. Cormack, con el Premio Nobel de Medicina en 1979.

El término tomografia significa imagen de un corte o sección, de forma que la TC es una técnica basada en la visualización de estructuras encefálicas a partir de múltiples cortes axiales, para obtener reconstrucciones en cualquier plano.

El agente físico de la TC sigue siendo Rx, al igual que en la Radiografía Simple, pero con una capacidad de discriminación muy superior.

Los componentes de los tomógrafos están contenidos en una caja de material rígido denominado gantry y son los siguientes: el tubo emisor de Rx, el colimador y los detectores.

El tubo de Rx y el sistema de detectores posicionados alrededor de la circunferencia del escáner, forman un conjunto que se mueve simultáneamente para obtener proyecciones desde diferentes ángulos. Posteriormente, y previa conversión analógico-digital, la reconstrucción de las imágenes digitales en los tres planos se realiza a partir de una serie de algoritmos matemáticos (Bushberg et al., 2002; Delgado et al., 2002; Rowlands, 2002; Alcaráz, 2003). Supone procesar más de 1000 proyecciones en 360 grados, cada una conteniendo datos de miles de detectores, lo que implica que deben de resolverse cientos de miles de ecuaciones de atenuación simultáneamente, por lo tanto, esta tarea no ha sido posible hasta el desarrollo de potentes computadores, lo que dio lugar al apelativo de tomografia "computarizada".

Cada una de estas ecuaciones de atenuación está definida por los siguientes factores: $\mathrm{I}_{\mathrm{x}}=$ $\mathrm{I}_{0} \cdot e^{-\mu \mathrm{x}}$. Es decir, la intensidad de la radiación X, después de atravesar el espesor de una 
determinada estructura $\left(\mathrm{I}_{\mathrm{x}}\right)$, depende de la intensidad de la radiación que incide sobre su superficie $\left(\mathrm{I}_{0}\right)$ y el coeficiente lineal de atenuación para un determinado vóxel $(\mu \mathrm{x})$.

A diferencia de la radiografía simple que ofrece un valor medio al atravesar diferentes estructuras encefálicas, la TC permite obtener el perfil de atenuación en cada uno de los vóxeles, gracias a que los haces inciden en cada vóxel desde distintos ángulos o proyecciones (Cabrero, 2002; Delgado et al., 2002; Rowlands, 2002; Alcaráz, 2003; Cabrero, 2004).

El valor de atenuación de Rx en un determinado píxel medido en UH es una unidad relativa al coeficiente de atenuación del agua $(0 \mathrm{UH})$, que es similar en la mayoría de los tejidos. Los valores $\mathrm{UH}$ vienen determinados por la fórmula $\mathrm{UH}=\left(\mu_{\text {tejido }}-\mu_{\text {agual }} / \mu_{\text {agua }}\right) \cdot 1000$ (siendo $\mu$ el valor de los diferentes coeficientes de atenuación) y se visualizan según una escala de grises denominada Escala de Hounsfield donde el blanco corresponde al valor de máxima intensidad de absorción, como el hueso compacto (1.000 UH) y el negro al valor de mínima intensidad (-1.000 UH) (Bushberg et al., 2002; Cabrero, 2002; Delgado et al., 2002; Rowlands, 2002; Alcaráz, 2003; Turner \& Jones, 2003; Cabrero, 2004).

La gama de colores completa de esta escala comprende 2.000 tonalidades de grises, muy superior al número que puede discriminar el ojo humano. Por este motivo, se utiliza el concepto de selección de ventana y nivel de ventana, que consiste en la representación de un sector parcial de los valores TC que nos interesan (selección de ventana). Podemos destacar tanto partes blandas del encéfalo (ventana de partes blandas) como el cráneo (ventana ósea). Paralelamente, desplazando el centro de la ventana podemos maximizar las posibilidades de discriminación entre las estructuras que nos interesan, de forma que cuanto más estrecha sea la ventana, mayor será el contraste.

En la evolución de los tomógrafos desde principios de los años 70, podemos distinguir hasta cuatro "generaciones" de los equipos que han aumentado el número de detectores disminuyendo progresivamente el tiempo de exploración.

Los tomógrafos de primera generación consistían en la obtención de secciones mediante un tubo emisor de Rx muy colimado que se desplazaba junto al detector (sólo uno o dos en este caso), en un movimiento mecánico de traslación y rotación de 180 grados del tubo y detector/es. El tiempo de exploración era de aproximadamente 4 minutos.

En los tomógrafos de segunda generación, los Rx se emitían en forma de abanico, de aproximadamente 5 grados y se empleaban entre 10 y 30 detectores. Aunque el ángulo de giro seguía siendo de 180 grados, al aumentar el número de detectores se reducía el número de movimientos de traslación y rotación, y como consecuencia, el tiempo de exploración hasta los 15 segundos por corte o 10 minutos en la exploración completa.

Los tomógrafos de tercera generación emplean un abanico de $\mathrm{Rx}$ de entre 25 a 30 grados. El gantry rota de forma contínua alrededor del paciente reduciendo, significativamente, el 
tiempo de exploración. Se utiliza un conjunto de detectores que varía entre 300 y 50 en 360 grados, que también rotan alrededor del paciente.

En los tomógrafos de cuarta generación, como los usados en este trabajo, sólo gira el tubo emisor de Rx alrededor del encéfalo y se emplean entre 1.200 y 4.800 detectores, en un anillo fijo (360 grados) que rodean totalmente el círculo del gantry, reduciendo al mínimo el tiempo de exploración.

A finales del siglo XX aparecen los escáneres multicorte, hasta 8 veces más rápidos que los de 1 corte y con un grosor de 2 a $3 \mathrm{~mm}$.

Una de las principales ventajas de la TC es su gran disponibilidad, bajo coste y calidad superior de visualización de elementos como el hueso respecto a la Radiografía Simple, siendo la modalidad de elección para estudiar lesiones cerebrales con calcificaciones intracraneales, detección rápida y simple de hemorragias o infartos y fracturas del cráneo en pacientes con traumatismos en la cabeza, malformaciones del cráneo y alargamiento de los ventrículos (Cabrero, 2004). Mientras que la Radiografía Simple puede mostrar diferencias del 10\% en la intensidad de los tejidos, la TC puede detectar diferencias de tan sólo un 1\% o menos, empleando ajustes de la escala de grises "ventana".

La exploración TC es equivalente a una gran cantidad de Radiografías Simples, por lo tanto comparte limitaciones inherentes al empleo de radiaciones $\mathrm{X}$, como el número total de exploraciones que pueden realizarse en un sujeto con cierto margen de seguridad. Otra desventaja es la ingente cantidad de datos generados y que requieren ser almacenados y procesados.

\section{TC helicoidal}

Los primeros estudios por TC Helicoidal o Espiral se realizaron en 1989 y constituye uno de los avances tecnológicos más recientes en el campo de la TC. Los elementos fundamentales del tomógrafo integrados en el gantry siguen siendo los mismos: el tubo generador de $\mathrm{Rx}$, los detectores para la medición de $\mathrm{Rx}$ atenuados y un sistema de adquisición de datos para la medición y digitalización de la señal proveniente de los detectores.

A continuación, describiremos brevemente la TC Helicoidal, una técnica donde la exploración se realiza en espiral, durante el movimiento continuo de la mesa con el paciente mientras se hace girar el gantry.

En la exploración TC convencional se obtenían imágenes a partir de secciones axiales individuales y movimiento del conjunto tubo-detectores alrededor del paciente. Esta exploración requería varios cortes sucesivos con una breve pausa después de cada uno, para que la mesa de exploración avanzara hasta la siguiente posición. Con la incorporación de la TC helicoidal o espiral, la adquisición de datos se realiza sin interrupción por la rotación continua del tubo de $\mathrm{Rx}$ y del sistema de detección, mientras la mesa del paciente avanza a una velocidad constante a través del gantry, reduciendo, significativamente, el tiempo de exploración. La combinación de la 
rotación contínua del tubo emisor y detector de Rx describiendo un movimiento en espiral en torno al paciente, mientras es trasladado sin interrupción a lo largo del gantry, permite explorar grandes volúmenes en una sola inspiración mantenida del paciente. Es decir, posibilita la obtención de todas las secciones simultáneamente.

En los nueos equipos TC multicorte, la resolución espacial es casi isotrópica, lo que significa que se consigue un registro perfecto. El primer escáner de dos cortes, apareció en 1991 y se basó en el uso de dos filas paralelas de detectores que permitían obtener dos cortes en cada rotación del gantry. En 1998 aparecieron los escáneres de cuatro cortes, significativamente más rápidos, y en 2002, sistemas de 6, 8, 10 y 16 cortes. Actualmente, se dispone de equipos con 64 cortes o superiores.

\subsubsection{Resonancia Magnética (RM)}

La denominación actual de RM sustituye a la denominación anterior de Resonancia Magnética Nuclear, por referencia al papel que desempeñan algunos núcleos con propiedades radioactivas, a diferencia de la Radiografía Simple o TC que emplean radiación ionizante para la obtención de imágenes. Su historia se remonta a 1946 cuando Bloch y Purcel demostraron que ciertos núcleos atómicos sometidos a un campo magnético intenso, son capaces de absorber energía y generar una señal de RF capaz de ser captada por una antena receptora. La aplicación de la RM al estudio del encéfalo humano vivo data de los años 70 con los trabajos de Damadian y Lauterbur.

La RM se basa en la interacción de campos magnéticos y ondas de RF con los tejidos de las estructuras encefálicas. Primero se coloca al sujeto bajo un potente campo magnético que provoca la alineación paralela de los protones de las moléculas de agua del cuerpo respecto al campo magnético. Después, se introduce un pulso de RF que provoca un cambio en la alineación de aquéllos. Posteriormente, se interrumpe el pulso, los protones se realinean liberando energía de RF. Finalmente, la señal es detectada y localizada por una antena de radio localizada en el interior del escáner y a partir de la cual se reconstruye la imagen final (Bushberg et al., 2002; Cabrero, 2004).

A continuación, explicaremos con mayor nivel de detalle estos principios:

El primer principio tiene que ver con el concepto de campo magnético al que se expone al sujeto. El momento magnético de los núcleos de hidrógeno $(\mathrm{H})$ del organismo se orienta en la dirección de un campo magnético constante, homogéneo y de gran intensidad (de 0,5 a 7T). El elemento base es $\mathrm{H}$ porque es el más abundante en el organismo y técnicamente, más fácil de tratar con campos magnéticos, pero se podría aplicar a cualquier núcleo sin un momento magnético nulo, es decir, cuyo número atómico sea impar. Antes de aplicar el campo magnético, los momentos magnéticos individuales de los protones de $\mathrm{H}$ de un vóxel se orientan de manera aleatoria y giran al azar de forma que sus momentos se neutralizan. Cuando el sujeto es colocado 
en la RM, los momentos magnéticos se orientan en la dirección y sentido de este campo magnético externo (magnetización longitudinal) (Bushberg et al., 2002; Brown \& Semelka, 2003; Cabrero, 2004).

El segundo principio se refiere al concepto de resonancia. Al aplicar un segundo campo magnético formado por breves pulsos de RF en una segunda dirección y con una frecuencia precisa, igual a la frecuencia de resonancia de los núcleos de ${ }^{1} \mathrm{H}$, hace que el momento magnético de los átomos de ${ }^{1} \mathrm{H}$ cambie (inclinándose en torno a su eje vertical, de forma muy parecida a como sucede cuando en una peonza la fuerza de gravedad compite con la fuerza de rotación), absorban energía de RF y giren acompasados. Se dice entonces que esos átomos están en resonancia. El movimiento de precesión crea un campo magnético (con un componente vertical y un componente horizontal) que varía en el tiempo y que genera una corriente eléctrica, que en realidad, es lo que se mide en la RM. La tasa o frecuencia de precesión es específica para los átomos de ${ }^{1} \mathrm{H}$ (en comparación con otros átomos), pero también depende de la fuerza del campo magnético aplicado, que variará dependiendo de la posición particular del átomo de ${ }^{1} \mathrm{H}$ en una molécula. Es decir, ${ }^{1} \mathrm{H}$ tendrá una frecuencia de precesión diferente en el agua, en comparación con ese mismo ${ }^{1} \mathrm{H}$ en lípidos (Bushberg et al., 2002; Brown \& Semelka, 2003; Cabrero, 2004).

El tercer principio es el concepto de relajación. Cuando cesa el pulso de RF se produce una liberación de energía, también en forma de onda de RF, como resultado de la vuelta del momento magnético de los núcleos a su orientación inicial (relajación). El pulso de RF (o excitación) provoca la disminución de la magnetización longitudinal (hasta el punto de que puede desaparecer) y hace que aparezca una nueva magnetización transversal. Una vez desconectado el pulso de RF, disminuirá rápidamente la magnetización transversal (relajación transversal) y se recuperará progresivamente la magnetización longitudinal (relajación longitudinal). La representación gráfica de las magnetizaciones en función del tiempo, después de interrumpir el pulso de RF, define la curva T1 (tiempo de relajación longitudinal) y la curva T2 (tiempo de relajación transversal). T1 (tiempo que tarda la magnetización longitudinal en recuperar el 63\% de su estado de equilibrio) y T2 (tiempo que tarda la magnetización transversal adquirida en descender en un $63 \%$ de su fuerza máxima) varían según los distintos tejidos que componen las estructuras encefálicas. T1 es más largo en líquidos que en sólidos y T2 es siempre más breve que T1 (Bushberg, et al., 2002; Turner \& Jones, 2003; Cabrero, 2004).

Finalmente, la energía liberada o señal de relajación es detectada con una antena y analizada de forma que las señales ofrecen una imagen de dicha zona. El problema es que la señal de RF emitida en el proceso de relajación por los protones de cada vóxel de tejido es muy débil. Para intensificarla, se emplean secuencias de pulsos de RF, separados por pausas, que se repiten varias veces. El tiempo que pasa desde que se envía el pulso hasta que se recibe la señal se denomina tiempo eco o TE y el intervalo entre pulsos sucesivos se denomina tiempo de repetición o TR. Dependiendo de sus valores, podemos distinguir varias secuencias. La secuencia 
spin-eco es la más empleada y consiste en un pulso de 90 grados y otro de 180 grados que se repite hasta conseguir la información de la imagen.

Modificando los valores TE y TR se influye en la señal resultante de los distintos tejidos $\mathrm{y}$, por lo tanto, se puede mejorar la visualización de la morfología de distintas estructuras encefálicas. Si aumentamos el TR después de un primer pulso de 90 grados, los tejidos habrán recuperado la magnetización longitudinal casi por completo. Por lo tanto, cuanto más corto sea el TE, más fuerte será la señal de un tejido. En general, las imágenes potenciadas en T1 emplean TR y TE cortos ( $<30 \mathrm{~ms})$ y el LCR aparece negro, la sustancia gris más oscura que la sustancia blanca y permiten un mejor contraste entre tejidos. El resultado son imágenes muy anatómicas, con una buena resolución, indicadas para el estudio morfológico de las estructuras encefálicas. En el caso de las imágenes potenciadas en T2, los tejidos son más fáciles de distinguir cuando se emplean TE y TR largos (que no producirían diferencias significativas en T1). Las imágenes potenciadas en T2 son menos anatómicas, pero son más útiles para estudiar procesos patológicos como el ictus cerebral, y donde el LCR aparece en blanco. Finalmente, en el caso de la RM potenciada en densidad protónica, se emplea un TR largo y un TE corto, de forma que la imagen está influida por la diferencia en la DP de los tejidos, por lo que a más protones, la señal será más potente. En general, cuando el LCR se ve más oscuro (hipodensidad) que los sólidos, la imagen está potenciada en densidad protónica o T1 y cuando el LCR aparece en tonos blancos (hiperdensidad), lo está en T2. Es decir, la intensidad de la señal de las imágenes RM puede ser alta o baja (claro u oscuro) según la secuencia de pulso utilizada y el tipo de tejido (Bushberg et al., 2002; Brown \& Semelka, 2003; Turner \& Jones, 2003; Cabrero, 2004).

En la Tabla 1.1 se incluye un resumen del comportamiento de las distintas estructuras encefálicas en imágenes potenciadas en RM T1 y RM T2. En las imágenes obtenidas a partir de secuencias T1, aparecerán en oscuro los siguientes tejidos: calcificación, tumor, infarto, inflamación, infección, hemorragia, etc. y en claro o brillante: grasa, flujo lento de sangre, necrosis resultado de infarto cerebral, etc. La presencia de ${ }^{64} \mathrm{Gd}$, una sustancia química no radiactiva que actúa como contraste y se elimina rápidamente por la orina, a diferencia de los medios de contraste empleados con $\mathrm{Rx}$, no contiene I, por lo tanto, rara vez produce reacciones alérgicas u otro tipo de problemas. En las imágenes obtenidas a partir de secuencias T2, aparecerán en tonos claros o brillantes: tumor, infarto, inflamación, infección, etc. y en tonos oscuros: calcificación, tejido fibroso, desoxyhemoglobina... 
Tabla 1.1. Comportamiento de las distintas estructuras encefálicas en T1 y T2. Fuente: Cabrero, 2004.

\begin{tabular}{|c|c|c|}
\hline Estructuras encefálicas & $\mathrm{T} 1$ & $\mathrm{~T} 2$ \\
\hline Sustancia blanca & Blanco & Gris oscuro \\
\hline Sustanca gris & Gris & Gris claro \\
\hline LCR & Negro & Blanco \\
\hline Lesión cerebral & Hiposeñal & Hiperseñal \\
\hline
\end{tabular}

La reconstrucción de la imagen se realiza según un proceso matemático denominado Transformada de Fourier, donde se asigna un valor numérico a las intensidades de las señales de cada píxel y después se trasladan a formato visual en escala de grises dentro de una matriz. Cada punto de la imagen de RM corresponde a la señal que se obtiene del comportamiento de estos protones. Por ejemplo, los protones de $\mathrm{H}$ de la grasa tardan más tiempo en "relajarse" que en otros tejidos.

La resolución espacial de la RM depende, fundamentalmente, de la potencia del campo magnético y de la técnica de pulso empleada. En la actualidad, se están empleando potencias de hasta 4T, obteniendo imágenes con una resolución inferior a $1 \mathrm{~mm}$. Los de alto poder son capaces de producir campos magnéticos de más de $1 \mathrm{~T}$, los sistemas de mediano poder producen entre 0.35 y $0.5 \mathrm{~T}$ y los de bajo poder producen un campo magnético de menos de $0.2 \mathrm{~T}$ (Brown \& Semelka, 2003).

Una de las ventajas de la RM es que no emplea radiación, sino campos magnéticos donde no se han encontrado alteraciones biológicas perjudiciales y permite obtener imágenes en cualquiera de los planos ortogonales. Es la técnica morfológica de preferencia para el estudio de tejidos blandos del encéfalo como la hipófisis (Servera, Quaranta, Markarian, \& Nagel, 2005) y patologías infecciosas como en la EM (Sharma \& Aggarwarl, 2010), el estudio de la circulación del LCR (Brown \& Semelka, 2003; Bargall, 2004), el estudio integral de tumores, (Letteboer, Olsen, Dam, Willems, Viergever, \& Niessen, 2004; Clatz, Sermesant, Bondiau, Delingette, Warfield, Malandain, \& Ayache, 2005; Dou, Ruan, Chen, Bloyet, \& Constans, 2007), y ACVs, especialmente en la detección de infartos en fases iniciales, aunque la visualización de pequeños vasos puede requerir el empleo de un medio de contraste, generalmente ${ }^{64} \mathrm{Gd}$ (Brown \& Semelka, 2003; Sharma \& Aggarwarl, 2010).

Una de las limitaciones es la incompatibilidad de RM en pacientes portadores de marcapasos cardíacos, personas con implantes metálicos o pacientes con claustrofobia, aunque en este último caso, es posible proceder a una sedación intensa o utilizar una unidad de RM de campo abierto. 


\subsubsection{Técnicas de valoración funcional}

El comienzo de la Medicina Nuclear podría situarse en 1934 cuando Frederick Folliot e Irene Curie aislaron el isótopo del fósforo $\left({ }^{30} \mathrm{P}\right)$. En 1943, Von Hevesy recibió el premio Nobel de Química por sus estudios con radiotrazadores en animales y en 1962, la informática quedó incorporada a las técnicas de Medicina Nuclear. Los primeros experimentos para medir el FSCr emplearon óxido nitroso, midiendo las diferencias entre el imput arterial y el flujo de salida venoso de cuya diferencia se calculaba el gasto celular.

Las tres técnicas de Medicina Nuclear diagnóstica más empleadas, que permiten estudiar aspectos funcionales de las distintas estructuras encefálicas in vivo, tanto en sujetos sanos como con patologías, son: SPECT, PET y RMf. La actividad neuronal puede ser definida en términos hemodinámicos basados en el cambio del flujo sanguíneo o metabolismo. Los primeros emplean radionúclidos o isótopos radioactivos artificiales, inhalados o inyectados, de forma independiente o unidos a una molécula específica (radiofármaco). Actualmente, los radioisótopos más empleados en Medicina Nuclear son cinco: ${ }^{133} \mathrm{Xe},{ }^{127} \mathrm{Xe},{ }^{99 \mathrm{~m}} \mathrm{Tc},{ }^{123} \mathrm{I} \mathrm{y}{ }^{201} \mathrm{Tl}$, especialmente el ${ }^{99 \mathrm{~m}} \mathrm{Tc}$ radiofármaco, ${ }^{99 \mathrm{~m}} \mathrm{Tc}$-pertecnetato, un emisor de rayos gamma puro con una energía de $140 \mathrm{KeV}$, un período de semidesintegración de 6 horas y que se incorpora fácilmente a un gran número de moléculas. Estos radionúclidos son absorbidos de forma selectiva en diferentes regiones del encéfalo y emiten radiaciones gamma que son registradas. Su localización es un indicador de la tasa de actividad neuronal (Cabeza \& Kingstone, 2001; Bushberg et al., 2002; Frackowiak, 2003).

Las áreas de mayor intensidad o zonas calientes indican las zonas de acumulación de grandes cantidades o con altos niveles de actividad metabólica. Las áreas con menor intensidad o zonas frías indicarían una menor concentración de isótopos radioactivos y, por tanto, menor actividad (Cabeza \& Kingstone, 2001; Frackowiak, 2003).

Uno de los problemas es averiguar la relación exacta entre el incremento en la actividad metabólica o el FSCr y la función a estudiar. El área con un aumento en su actividad puede provocar el trastorno o comportamiento estudiado, o puede ser resultado del intento del encéfalo de regular dicho trastorno o conducta, o el estudio puede haber sido mal diseñado y el área en cuestión haberse activado accidentalmente. Se asume que las estructuras del encéfalo que están más activas consumen más glucosa y oxígeno, por lo tanto, reciben un mayor aporte sanguíneo. En estudios PET, las áreas más activas proporcionarán una mayor señal de los marcadores como

${ }^{15} \mathrm{O}$, dependiente del cambio en el flujo sanguíneo, o glucosa $\left({ }^{18} \mathrm{FDG}\right)$, dependiente del nivel de metabolismo. La comparación del nivel de activación de determinadas áreas encefálicas al realizar tareas cognitivas y emocionales, en comparación con el nivel de activación basal, permite determinar qué estructuras están implicadas en qué procesos. 


\subsubsection{Tomografía Computarizada por Emisión de Fotón Único (SPECT)}

El SPECT surge como resultado del desarrollo de los métodos de adquisición de datos desde diferentes ángulos y de la aplicación de métodos computarizados para la construcción tomográfica de la TC.

El principal objetivo de SPECT consiste en medir el FSCr a través del mapeo o representación de la acumulación y distribución en el encéfalo de un radionúclido emisor de fotón gamma, previamente administrado por secciones (Bushberg et al. 2002). Permite detectar estructuras encefálicas con una respuesta vasodilatadora asociada a una demanda mayor de circulación cerebral durante la realización de una tarea.

Las unidades SPECT de los servicios de Medicina Nuclear disponen de gammacámaras rotatorias de uno, dos o más cabezales que reducen el tiempo de exploración. Estos cabezales rotan en torno al paciente y detectan la emisión del radionúclido administrado en cada posición. La técnica SPECT permite la reconstrucción y visualización de imágenes coronales, sagitales, axiales y oblicuas de cualquier parte del encéfalo.

El SPECT puede conceptualizarse como un método de TC que emplea radionucleótidos capaces de emitir un fotón único de determinada energía, pero a diferencia de la PET, donde la aniquilación positrón-electrón provoca la emisión de dos fotones a 180 grados, la SPECT requiere alinear los fotones, que implica la pérdida de muchos fotones disponibles y, como resultado, la degradación de la imagen. Los radioisótopos más empleados en SPECT son el ${ }^{133} \mathrm{Xe}$ y el ${ }^{99 m}$ Tc-HMPAO, como trazador más empleado (Carrió, González, Estorch, Canessa, Mitjavila, \& Massardo, 2003).

Estos marcadores se deterioran más lentamente que muchos de los marcadores PET, lo que significa que los estudios SPECT permiten periodos test-retest más largos que los PET. Están más limitados en cuanto al tipo de actividad encefálica que pueden monitorizar y la resolución o nivel de detalle, especialmente, para estructuras profundas del encéfalo, que es menor que con PET (Carrió et al., 2003).

Entre las indicaciones más frecuentes del SPECT, al igual que el PET, destaca el diagnóstico de enfermedades neurológicas como EA y trastornos psiquiátricos con importantes efectos neuropsicológicos como Autismo, Esquizofrenia, problemas de ansiedad y del estado de ánimo.

\subsubsection{Tomografía por Emisión de Positrones (PET)}

La exploración PET surge a finales de los años 70 como una técnica de diagnóstico por imagen en Medicina Nuclear, que proporciona imágenes funcionales del metabolismo celular, a partir de la detección de los fotones emitidos por radionúclidos emisores de positrones, que dan lugar a su nombre. 
El principio básico de esta técnica es que la actividad neuronal está acompañada de un aumento en el metabolismo neuronal y éste, a su vez, de un incremento del FSC para aportar el oxígeno y glucosa necesarios, que pueden ser marcados con isótopos radioactivos, previamente administrados. Como sucedía con el SPECT, el PET registra la acumulación de dicho marcador en las diferentes estructuras del encéfalo.

Un positrón es la antipartícula del electrón, con la misma masa, pero carga eléctrica positiva. Un positrón no permanece en la materia en estado libre, sino que interacciona con un electrón provocando la aniquilación de ambas partículas y la emisión de dos fotones gamma de 0,511 MeV cada uno, que se propagan en la misma dirección pero en sentidos contrarios (fenómeno de aniquilación) (Bushberg et al. 2002; Carrió et al., 2003; Cabrero, 2004).

El proceso de reconstrucción de la imagen PET, requiere la detección de la radiación gamma emitida y la dirección de propagación de la radiación emitida como resultado de la destrucción de dos masas electrónicas (electrón-positrón). Esta detección se logra gracias a un conjunto de anillos en el gantry compuestos por cientos de detectores emparejados, separados entre sí 180 grados, situados alrededor del encéfalo del sujeto objeto de exploración. Estos detectores captan los dos fotones gamma emitidos simultáneamente, registrando una señal al recibir la radiación al mismo tiempo (con una diferencia aceptable de $12 \mathrm{~ns}$ ), lo que indica que la aniquilación ha ocurrido en algún punto de la línea definida por ambos (detección en coincidencia). Los distintos procesos de aniquilación proporcionan información desde diferentes ángulos al ordenador que, permiten reconstruir la imagen.

Los radionúclidos utilizados en la PET son de vida muy corta, sin tiempo para su traslado, de modo que se producen en un ciclotrón in situ. Su función es producir positrones cargados positivamente a partir de la aceleración de partículas a gran velocidad, que se emplearán para bombardear el elemento elegido y formar distintos isótopos radioactivos. Por ejemplo, ${ }^{15} \mathrm{O}$, cuyo periodo de desintegración es de 2,07 minutos, $y{ }^{18} \mathrm{~F}$, con un período de desintegración de 109,8 minutos (Bushberg et al., 2002; Carrió et al., 2003).

Los radiofármacos se sintetizan y se marcan gracias a los radionúclidos obtenidos en el ciclotrón, creando isótopos emisores de positrones, en el laboratorio radioquímico. El marcador más utilizado para el estudio del metabolismo cerebral a través de la tasa de consumo de glucosa cerebral regional es ${ }^{18} \mathrm{~F}-\mathrm{FDG}$, pero también puede utizarse el ${ }^{15} \mathrm{O}$. La adquisición de neuroimágenes con ${ }^{15} \mathrm{O}$ lleva, aproximadamente, de 1 a 5 minutos y con ${ }^{18} \mathrm{~F}$ FDG unos 20-30 minutos. Actualmente, también es posible marcar neurotransmisores como la ${ }^{18} \mathrm{~F}$ DOPAMINA.

La ventaja de emplear nucleótidos PET de vida corta es la disminución de la dosis de radiación a la que se somete al sujeto respecto a otras técnicas radiológicas. El empleo de dosis ínfimas reduce al máximo el peligro de reacciones adversas. El punto fuerte de la PET, en comparación con otros métodos menos invasivos y accesibles como la RMf, es su habilidad para mapear neurotransmisores emisores de positrones tales como ${ }^{18} \mathrm{~F}$ DOPA, que permite el 
seguimiento de este neurotransmisor en pacientes con EP y estudios análogos sobre farmacodinámica y farmacocinética de otras drogas y neurotransmisores, incluyendo la velocidad con la que actúan en el receptor neuronal, el tiempo de ocupación de dichos receptores, efectos de tratamientos conductuales y/o farmacológicos, por mencionar algunos (Carrió, González, Estorch, Canessa, Mitjavila, \& Massardo, 2003).

Esta técnica se ha empleado en el estudio de diferentes trastornos neurológicos como tumores cerebrales, principal campo de aplicación, demencias, ACV (Maldonado, Trampal, \& Ortega, 1998) y recientemente, en el estudio de trastornos psiquiátricos.

La mayor captación de radiofármacos suele presentarse en la sustancia gris y los núcleos basales, la sustancia blanca presenta menor actividad al estar menos vascularizada y los VL no muestran actividad. Las disminuciones en el FSC y metabolismo cerebral se presentan como hipoactivas, mientras que los incrementos, como en el caso de tumores, producen áreas hiperactivas.

Finalmente, los aparatos PET/TC combinan un tomógrafo computarizado helicoidal y uno de emisión de positrones dentro del mismo gantry, donde se llevan a cabo, secuencialmente, dos exploraciones sin mover al paciente y con una diferencia de tiempo mínima entre las imágenes que van a ser fusionadas, solucionando los problemas que conlleva el estudio a través de diferentes equipos (Carrió et al., 2004)

\subsubsection{Resonancia Magnética Funcional (RMf)}

La RMf consiste en el registro de una secuencia de imágenes en diferentes momentos temporales que permite localizar la actividad encefálica en función de la medida de pequeñas diferencias en las propiedades magnéticas de la hemoglobina oxigenada y desoxigenada. Una disminución de la concentración de hemoglobina provocaría un aumento de la señal dependiente del nivel de oxigenación sanguínea, denominada BOLD (Jezzard, Matthews, \& Smith, 2001; Huettel, Song, \& McCarthy, 2004; Buxton, 2009). Por lo tanto, se deben comparar imágenes entre dos exploraciones para ofrecer un cuadro con sentido.

La RMf no requiere inyección de isótopos radioactivos en el torrente sanguíneo a modo de contraste, porque la propia hemoglobina funciona como marcador. Como consecuencia, una persona puede ser explorada en repetidas ocasiones, incluso durante la misma sesión.

La resolución espacial de esta técnica es muy alta. Actualmente, se dispone de equipos 7 $\mathrm{T}$ que permiten mapear la actividad neuronal por debajo de $1 \mathrm{~mm}$ (superior a los $4 \mathrm{~mm}$ de resolución espacial PET). Sin embargo, la RMf no puede registrar la actividad neuronal por debajo del ms en la que operan las neuronas y la respuesta hemodinámica (Jezzard et al., 2002; Huettel et al., 2004; Buxton, 2009).

Sin embargo, durante la RMf el sujeto explorado debe permanecer completamente inmóvil, sin ansiedad, confusión o dolor, porque podrían contaminar los resultados. 
Por ese motivo se emplean estímulos control, patrones visuales o sonidos simples audibles, que se repiten varias veces con periodos de descanso intermedios, de forma que pueden observarse las áreas del cerebro activas durante la estimulación e inactivas durante el periodo de descanso.

Dos de las técnicas de RMf más relevantes son las siguientes:

\section{$R M f B O L D$}

Actualmente, es la técnica más utilizada y mide las diferencias regionales en sangre oxigenada, asumiendo que cuando una región del encéfalo está activada, la sangre arterial oxigenada será redistribuida y aumentará en dicha área.

Las imágenes se obtienen en T2 a partir de las propiedades magnéticas de las moléculas de hemoglobina. En un área con más sangre oxigenada, la oxihemoglobina (paramagnética) se mostrará más intensa en imágenes T2, al retenerse más tiempo, en comparación con áreas donde hay menos sangre oxigenada alrededor, desoxihemoglobina (dimagnética).

El principal problema es que los cambios locales en el nivel de oxigenación revelan áreas neuronales activas, pero con cierto retraso. Este lapso de tiempo oscila entre 3 y 6 segundos y ocurre desde el momento en que una región es activada y se registra del aumento en el flujo sanguíneo (Jezzard et al., 2001; Huettel et al., 2004; Buxton, 2009). Durante este periodo, las áreas activadas experimentan una relativa disminución de la sangre oxigenada, como resultado de la extracción de oxígeno por las neuronas activas del área. Después, la cantidad de sangre que alcanza el área sobrepasa la cantidad de oxígeno extraída, por lo que la sangre oxigenada es mayor. A continuación sigue un periodo donde el flujo sanguíneo aumenta, no sólo hasta un nivel donde se da respuesta a la demanda de oxígeno, sino incluso superándolo. El pico máximo de flujo sanguíneo se alcanza transcurridos unos 6 segundos para después volver a la línea base (Jezzard et al., 2001; Heutel, Song, \& McCarthy, 2004; Buxton, 2009).

En el futuro, se podría mejorar la resolución temporal de la RMf midiendo la disminución inicial de sangre oxigenada contingente al inicio de la activación.

En los paradigmas RMf BOLD se comparan imágenes relativas a varios periodos de descanso alternados con varios periodos de activación. Las imágenes obtenidas en los primeros 3-6 segundos de cada periodo son descartadas debido al retraso en la respuesta hemodinámica. Por este motivo, el estudio de las emociones es más difícil dado la lentitud y variabilidad de su aparición y su inhabilidad para desaparecer rápidamente.

Esta técnica se ha empleado en el mapeo de áreas vitales (lenguaje, función motora, memoria...) antes de realizar abordajes quirúrgicos, y recientemente, en el estudio de trastornos psiquiátricos como $\mathrm{TB}$, trsatorno depresivo mayor, e investigaciones con niños, entre otras aplicaciones, si bien aún no hay indicaciones en Psiquiatría o Psicología Clínica (Carrió et al. 2003; Heutel et al., 2004; Buxton, 2009). 


\section{Tractografia, RM DT ó Imagen por tensor difusión, DTI}

La RM estructural es insensible a la dirección de las fibras y como resultado, la sustancia blanca aparece homogénea. Sin embargo, el desarrollo de RM DT permite superar este problema, permitiendo la reconstrucción de fibras y valoración de su integridad a partir de la difusión del agua del tejido cerebral.

Esta técnica permite visualizar la localización, orientación y anisotropía o cambios según la dirección de los tractos de sustancia blanca del encéfalo que son examinados. La formación de conjuntos de fibras en paralelo y sus vainas de mielina facilitan la difusión de las moléculas de agua en la misma dirección.

La señal de RM es sensible a los movimientos de los átomos de $\mathrm{H}$ en las moléculas de agua en el encéfalo y este movimiento es mayor en los axones. La DTI permite visualizar in vivo las fibras que tienen la misma orientación en el encéfalo, informando sobre su integridad y orientación. Las membranas de los axones y vainas de mielina suponen un obstáculo al movimiento de las moléculas de agua en direcciones distintas a su propia orientación, por lo tanto, la dirección de máxima difusividad coincide con la orientación del haz de fibras de sustancia blanca (Tuch, Reese, Wiegell, \& Wedeen, 2003; Assaf \& Pasternak, 2008).

La dirección de la fibra aparece indicada por el color del principal vector, que puede codificarse en rojo, para la dirección izquierda-derecha, azul, para la dirección superior-inferior y verde para la dirección anterior-posterior. Como resultado, se genera una representación de las posiciones y direcciones de los tractos, donde el brillo representa la anisotropía de los tractos (Mori \& Van Zijl, 2002; Catani, 2006).

Actualmente, se está empleando en el estudio de trastornos neurológicos como la EM, discriminación entre antiguas y nuevas isquemias, y distintos trastornos psiquiátricos, entre otras aplicaciones (Rosenbloom, Sullivan, \& Pfefferbaum, 2003; Cascio, Gerig, \& Piven, 2007; Jiang, Liu, Shi, Shu, Liu, Jiang, \& Zhou, 2008; Reich, Zackowski, Gordon-Lipkin, Smith, Chodkowski, Assaf, \& Pasternak, 2008)

\subsubsection{Integración de técnicas de neuroimagen}

Hasta ahora hemos presentado las características de las distintas técnicas de valoración morfológica y funcional de forma independiente, las cuales varían a lo largo de un amplio rango de resoluciones espacio-temporales y mecanismos biofísicos. Las técnicas de Medicina Nuclear ,como PET y SPECT, proporcionan una resolución espacial a nivel de centímetros y temporal ,que oscila de varios minutos a un minuto. La RMf proporciona una resolución espacial por debajo del milímetro, pero su resolución temporal es del orden de segundos al estar limitada por la dinámica de la respuesta vascular asociada a cambios en la actividad neuronal (Buxton, 2009). En la Tabla 1.2 se comparan las principales técnicas funcionales. 
Tabla 1.2. Modalidades de estudio funcional del encéfalo. Adaptado de Commowick, 2007.

\begin{tabular}{|c|c|c|c|}
\hline Técnica & Resolución & Ventajas & Desventajas \\
\hline \multirow{2}{*}{ SPECT } & \multirow{2}{*}{$10 \mathrm{~mm}$} & Bajo coste & Invasivo \\
\hline & & Disponible & Resolución limitada \\
\hline PET & $5 \mathrm{~mm}$ & $\begin{array}{l}\text { Sensibilidad temporal } \\
\text { Buena resolución } \\
\text { Estudios metabólicos y mapeo de receptores }\end{array}$ & $\begin{array}{l}\text { Invasiva } \\
\text { Muy cara }\end{array}$ \\
\hline RMf & $3 \mathrm{~mm}$ & $\begin{array}{l}\text { Excelente resolución } \\
\text { No invasivo }\end{array}$ & $\begin{array}{l}\text { Caro } \\
\text { Limitado a estudios de } \\
\text { activación }\end{array}$ \\
\hline \multirow{2}{*}{ RM } & \multirow{2}{*}{ Bajo } & No invasivo & Caro \\
\hline & & Estudios metabólicos & Baja resolución \\
\hline
\end{tabular}

La integración multimodal permite superar las desventajas y mantener las ventajas asociadas al uso independiente de cada una de estas técnicas de indudable valor diagnóstico y clínico.

El objetivo de cualquier enfoque de neuroimagen multimodal es proporcionar la localización exacta, extensión, actividad metabólica y relación espacial de distintas estructuras encefálicas, asumiendo que las alteraciones en estos parámetros estarán asociadas a patologías.

La integración multimodal es uno de los focos de atención y tendencia actual en muchos centros de neuroimagen de todo el mundo, junto a la exploración de pacientes con un espectro más amplio de trastornos clínicos, especialmente, los trastornos psiquiátricos y el empleo de muestras de mayor tamaño (Mosely \& Donnan, 2004; Pearlson \& Calhoun, 2007).

El corregistro de imágenes representa la forma más básica de integración multimodal y consiste en la superposición de imágenes de Medicina Nuclear con TC o RM, tal y como hemos visto en las imágenes correspondientes a las figuras empleadas en el apartado relativo a la descripción de la organización del encéfalo y que permite la localización precisa de la actividad funcional en regiones encefálicas específicas, por ejemplo, con imágenes de baja resolución PET con RM de mayor resolución o el corregistro con un encéfalo estándar de referencia como el Atlas de Talairach (Talairach \& Toruneau,1988).

La integración de PET y RM se ha empleado en Oncología (Schirner, Menrad, Stephens, Frenzel, Hauff, \& Licha, 2004; Scheidhauer, Walter, \& Seemann, 2004). También se ha logrado la integración de EEG/MEG y RMf gracias a que ambas señales están, directamente emparejadas ,con la actividad eléctrica neuronal: EEG y MEG reflejan el potencial eléctrico y el campo magnético resultante de los potenciales de acción (Dale \& Halgren, 2001; Czisch, Wehrle, Kaufmann, Wetter, Holsboer, Pollmacher, \& Auer, 2004; Martínez-Montes, Valdes-Sosa, 
Miwakeichi, Goldman, \& Cohen, 2004), pero no serán consideradas en este trabajo, ya que el EEG no constituye una técnica de neuroimagen.

Para desarrollar métodos de fusión automatizados, se requiere el desarrollo de aplicaciones informáticas potentes y estándares de compatibilidad de imagen entre los distintos fabricantes como DICOM.

Los híbridos, por ejemplo PET/SPECT y PET/TC constituyen el último logro en relación a la fusión o integración multimodalidad, permitiendo la integración multimodal en una sola exploración.

\subsubsection{Neuronavegadores}

Tradicionalmente, el propósito de los atlas estereotáxicos era crear un sistema de coordenadas que permitiera describir con precisión la posición de determinadas estructuras encefálicas dentro del cráneo, empleando puntos de referencia fijos, con el objetivo de guiar los instrumentos del cirujano hacia una estructura diana concreta.

Actualmente, el término neuronavegación es un neologismo utilizado para referirse al hardware y tecnologías asistidas por ordenador, empleadas por neurocirujanos para guiarse dentro del cráneo durante las intervenciones quirúrgicas, y que constituye un paso más allá de la tradicional cirugía estereotáxica, que ha venido empleándose, desde principios de siglo, en el tratamiento de trastornos del movimiento como la EP.

Esta tecnología ofrece al cirujano información útil para la planificación de abordajes quirúrgicos precisos en la lesión diana, incluso definiendo las estructuras neurovasculares que las rodean. La incorporación de datos funcionales a estas tecnologías, como los obtenidos a partir de RMf, ayudan a reducir el riesgo de afectar estructuras relevantes durante cirugías, tales como biopsias, drenajes ventriculares, localización de un tumor, valoración de estructuras neurovasculares adyacentes a tumores, etc.

Las versiones más modernas de neuronavegadores ofrecen verdaderos sistemas de navegación para la realización de abordajes quirúrgicos, como O-arm®. Permiten visualizar la posición de un instrumento quirúrgico real en las manos del cirujano respecto a las estructuras encefálicas diana en la sala de operaciones en tiempo real, denominándose: virtualización quirúrgica, donde el neurocirujano es capaz de visualizar, a través de modelos 3D manipulables, el escenario de cirugía, permitiendo la práctica y revisión de diferentes abordajes quirúrgicos, alternativas, e incluso valorar posibles dificultades que pudieran surgir durante la cirugía real (Sutherland, Newhook, Feil, Fielding, Greer, \& Latour, 2008; Choi, \& Sutherland, 2009; Levy, Cox, Hader, Myles, Sutherland, \& Hamilton, 2009; Pandya, Motkoski, Serrano-Almeida, Greer, Latour, \& Sutherland, 2009; Lang \& Sutherland, 2010; Sutherland, Kelly, Morrish, \& Sutherland, 2010; Lang, Greer, \& Sutherland, 2011; Lang, Kelly, \& Sutherland, 2011). Otro 
ejemplo de sistemas de navegación para la realización de abordajes quirúrgicos precisos es el $O$ arm ${ }^{\circledR}$ Surgical Imaging System de Medtronic Stealth Station. 


\subsection{VISUALIZACIÓN Y RECONSTRUCCIÓN DE ESTRUCTURAS ENCEFÁLICAS}

La capacidad de comprensión de estructuras encefálicas está íntimamente relacionada con la habilidad para visualizarlas. Personas con diferente grado de conocimientos neuroanatómicos literalmente "ven" dichas estructuras de forma relativamente distinta. Tradicionalmente, las distintas modalidades de neuroimagen han compartido una limitación común, la bidimensionalidad de las representaciones, en contraposición con la tridimensionalidad de las estructuras a representar.

La visualización e interpretación de imágenes de regiones encefálicas internas, obtenidas a partir de técnicas de diagnóstico por imagen, supone una dificultad añadida debido a su complejidad, dificultad de acceso, diferencias individuales en su morfología (variabilidad biológica) y susceptibilidad al cambio en el tiempo.

El aprendizaje de la neuroanatomía requiere la comprensión de las características anatómicas y relaciones espaciales de vecindad entre dichas estructuras encefálicas 3D. La visualización volumétrica optimiza la presentación de la compleja información contenida en las neuroimágenes morfológicas y/o funcionales tradicionales. No sólo se mejora la capacidad sintética de visualización, sino también el grado de interactividad y realismo, superando las restricciones inherentes a las representaciones 2D tradicionales (Talairach \& Tournoux, 1988; Juanes, Prats, Riesco, Blanco, Velasco, Cabrero, \& Vázquez, 2001; Juanes, Cabrero, Riesco, Blanco, Velasco, Vázquez, \& Prats, 2001; Temkin, Acosta, Hatfield, Onal, \& Tong, 2002; Temkin, Acosta, Malvankar, \& Vaidyanath, 2006).

El proceso de reconstrucción 3D o generación volumétrica consiste en la adquisición de una o más series de imágenes tomográficas, la posterior segmentación o identificación y etiquetado de las estructuras encefálicas a reconstruir, la extracción de contornos/superficies en secciones transversales adyacentes, y el renderizado del modelo 3D (Pommert, Tiede, \& Höhne, 2002). Sin embargo, actualmente, existen métodos para la Visualización Directa de Volúmenes (Direct Volume Visualization) que ofrecen vistas 3D a partir de los datos originales y que puede incluir o no un paso previo explícito de segmentación.

Las primeras imágenes 3D del encéfalo humano completo aparecieron a finales de los años 80, a partir de imágenes RM, y a principios de los años 90 surgieron las primeras aplicaciones clínicas, en el contexto de la cirugía craneofacial, a partir de imágenes óseas TC (Altobelli, Kikinis, Mulliken, Cline, Lorensen, \& Jolezz, 1993). Actualmente, numerosos centros y laboratorios europeos y estadounidenses están trabajando en iniciativas dirigidas a la visualización y reconstrucción de estructuras encefálicas como las que nos ocupan en este trabajo. 
En EEUU, la Biblioteca del Congreso y el NIMH denominaron "Década del Encéfalo" al periodo comprendido entre 1990 y 1999 como estrategia para la promoción y difusión de investigaciones sobre el encéfalo. Incluso la NASA realizó aportaciones como Neurolab, dirigido a potenciar la comprensión del encéfalo desarrollando investigaciones sobre EA y Epilepsia.

Uno de los proyectos de mayor transcendencia dentro de la Década del Encéfalo ha sido el Proyecto del Encéfalo Humano, desarrollado por el Caltech Brain Imaging Center (CBIC), un intento de integrar neurociencia e informática consistente en la elaboración de un atlas del desarrollo del encéfalo vivo, a partir de imágenes RM (Proyecto Atlas) y algoritmos para su análisis y visualización 3D (Proyecto Algoritmos) (Caltech, 2009).

El proyecto Whole Brain Atlas desarrollado por la Facultad de Medicina de la Universidad de Harvard nació con el objetivo de desarrollar un atlas del encéfalo completo de un sujeto con trastornos neurológicos como ACV, tumores, EA y EM, entre otros. Hasta el momento, han identificado hasta 106 estructuras encefálicas a través de secciones obtenidas por TC, RM, SPECT y que hemos empleado para ilustrar el apartado y describir la organización del encéfalo (Summers, 2003; Johnson \& Becker, 2010). Sin embargo, no incluyen aún, reconstrucciones $3 \mathrm{D}$, las secciones se limitan a secciones axiales, no coronales ni sagitales, los cortes de interés se tienen que seleccionar haciendo click en el nivel apropiado de la vista sagital y no permite combinar vistas y técnicas de adquisición de las imágenes.

La organización BrainMaps ha conseguido desarrollar el atlas del encéfalo de mayor resolución elaborado hasta la fecha, con más de 20 millones de Mp y una resolución por debajo de la micra, elaborado a partir de imágenes escaneadas de secciones de encéfalos humanos, otros primates y especies no primates. Los más de $60 \mathrm{~Tb}$ de datos sobre imágenes del encéfalo están accesibles online y permiten la exploración de secciones del encéfalo a nivel histológico. Esta organización también ofrece aplicaciones para el análisis de imágenes como Brain Maps Analize y un visor para la navegación a través de las diferentes secciones neuroanatómicas en $2 \mathrm{D}$ y $3 \mathrm{D}$, denominado Brain Maps Stack Vis (Trotts, Mikula, \& Jones, 2007; Mikula, Stone, \& Jones, 2008). Si consideramos BrainMaps.org como un equivalente a Google Maps específico del encéfalo, Stack Vis sería similar a Google Earth o el reciente Google Body Browser de Google que optimiza el uso de gráficos $3 \mathrm{D}$ en la visualización y experiencia web gracias a la implementación de WebGL en Chrome (Google, 2011).

Cuatro de los centros e instituciones de investigación en neuroimagen más importantes a nivel internacional se agruparon en 1993 para formar el International Consortium for Brain Mapping (ICBM), esponsorizados por el NIMH de Estados Unidos en el marco de la Década del Encéfalo. El objetivo del proyecto fue el desarrollo de un atlas de referencia del encéfalo humano para la anatomía estructural y funcional a nivel macroscópico y microscópico. Un atlas probabilístico que pudiera proporcionar un marco común para el intercambio de datos entre la ingente cantidad disponible en neurociencias. 
A continuación presentamos las principales contribuciones de estos cuatro centros:

El Laboratory of Neuroimaging (LONI) de la Universidad de California (EEUU) ha desarrollado un atlas probabilístico denominado LPBA40, consistente en un conjunto de mapas de 56 estructuras encefálicas a partir de los datos RM de 40 sujetos voluntarios (Shattuck et al., 2008). Sus dos líneas de investigación más importantes son el proyecto denominado Mouse Atlas Project 2.0, que consiste en la elaboración de un atlas detallado del encéfalo de un ratón adulto y de un ratón en desarrollo. Y el proyecto Alzheimer's Disease Neuroimaging Initiative (ADNI), dirigido al desarrollo de nuevos tratamientos y monitorización de su efectividad a través de técnicas de neuroimagen.

El segundo es el McConnell Brain Imaging Center (BIC) del Instituto Neurológico de Montreal, en la Universidad norteamericana de McGill, que lleva realizando investigaciones sobre el encéfalo humano a partir de técnicas de neuroimagen desde 1994, convirtiéndose en uno de los centros de investigación en neuroimagen más importantes del mundo, no sólo como socios fundadores del International Consortium for Brain Mapping, sino como la institución líder de un proyecto para la elaboración del atlas del desarrollo del encéfalo infantil normal, junto al NIH a través de RM denominado MRI Study of Normal Brain Development o Pediatric MRI Study. Su objetivo es mejorar la comprensión del proceso de maduración normal del encéfalo y del desarrollo anormal asociado a diferentes trastornos y enfermedades. Este centro también ha desarrollado un programa propio para el análisis y segmentación de imágenes del encéfalo denominado ANIMAL y una base de datos 3D de estructuras encefálicas completas obtenidas a partir de RM para dos modelos anatómicos: uno normal y otro de EM, denominada Simulated Brain Database.

El tercer centro es Research Imaging Institute (RII) del Centro de Ciencias de Salud de la Universidad de Texas (EEUU) que también se ha centrado en la investigación básica y clínica a partir de RM y PET.

Finalmente, el $\mathrm{CuO}$ Vogt Institute of Brain Research y el Institute of Neuroscience and Medicine (INM) de la Universidad Heninrich Heine, en Alemania, han trabajado en el desarrollo de un nuevo modelo 3D del encéfalo pero utilizando datos moleculares y relativos a su citoarquitectura.

Además del ICBM, otros centros y laboratorios han trabajado con la finalidad de mejorar la visualización y reconstrucción 3D de estructuras encefálicas, congruentes con los objetivos planteados en la década del encéfalo.

El National Institute of Neurological Disorders and Stroke (NINDS) den EEUU, constituye el organismo líder en investigación del encéfalo, participando activamente en la investigación de más de 600 trastornos neurológicos.

El Surgical Planning Laboratory (SPL), fundado en 1990 y asociado a la Facultad de Medicina de Harvard ha desarrollado métodos de tratamiento de imágenes digitales médicas en 
contextos clínicos y la evaluación pre y postoperatoria en casos de tumores y evaluación de alteraciones morfométricas asociadas con distintos trastornos como la Esquizofrenia, la EM y el envejecimiento normal o patológico. Uno de los logros más destacados del SPL y el laboratorio de neurociencias de Harvard, actualmente denominado Laboratorio de Neuroimagen en Psiquiatría, ha sido la elaboración del SPL-PNL Brain Atlas (Talos et al., 2008), a partir de la exploración RM de un sujeto sano, que consiste en más de 160 modelos 3D de las estructuras anatómicas etiquetadas, del sistema motor, sistema visual y sistema límbico, diencéfalo, tronco encefálico y hemisferio cerebral izquierdo. Otro centro asociado al SPL es el National Center for Image Guided Therapy (NCIGT) que trabaja, fundamentalmente, en intervenciones médicas mejoradas por neuroimagen.

El Laboratory of Medical Image Computing (MedIC) de la Universidad Johns Hopkins ha trabajado en el desarrollo de una aplicación informática para la reconstrucción de la superficie cortical denominada CRUISE Control.

En la Universidad de Columbia el laboratorio de RMf cuenta con varios proyectos como el Program for Imaging and Cognitive Sciences (PICS), dirigido al descubrimiento de las áreas del encéfalo implicadas en las ilusiones visuales y percepción de profundidad; el estudio de áreas específicas del lenguaje como segundo idioma (en un área adyacente pero separado del área de Broca de la lengua materna si el segundo idioma se adquiere en la adultez, pero solapado con dicho área cuando se adquiere durante la infancia) y la aplicación en la planificación de abordajes neuroquirúrgicos comparando los resultados pre y post quirúrgicos con la predicción basada en el mapa obtenido a través de RMf.

El Digital Anatomist Project es un proyecto de la Universidad de Washington (en Seatle) que pretende representar gráficamente la anatomía humana de una forma comprehensiva. Junto con otros trabajos en la misma dirección, contribuyó al desarrollo del Visible Human Proyect de la Bibliteca Nacional de Medicina de EEUU que desarrollaremos con más detalle más adelante. Esta Universidad también ha desarrollado MindSeer, un visor 3D del encéfalo en Java, siendo Brain Visualizer su web-based interface. Se basa en un client-side applet configurado para conectar al servidor y permitir al usuario elegir un paciente que el servidor carga en base a las imágenes obtenidas por RM, generando modelos 3D o volúmenes anatómicos.

El desarrollo del Virtual Anatomy Lab de la Universidad de Indiana, también emplea modelos 3D generados por ordenador para facilitar el aprendizaje de la localización y posición relativa de estructuras neuroanatómicas y se ha utilizado en la coordinación de sesiones de aprendizaje sobre anatomía a través de internet (Campbell, Rosse, \& Brinkely, 2001).

La primera organización internacional dedicada a la investigación en neuroimagen surgió en 1995, como resultado de los avances del momento en este campo y se denominó Organization for Human Brain Mapping, que celebra anualmente la International Conference on Functional Mapping of the Human Brain con el propósito de promover la elaboración de un 
mapa, no sólo de la estructura, sino también de la función del encéfalo, especialmente a partir del empleo de técnicas no invasivas.

Uno de los problemas de la reconstrucción y visualización 3D de estructuras encefálicas en los diferentes atlas mencionados, es que cada uno emplea diferentes escalas, resoluciones espaciales, métodos de organización e interacción con la información (Toga, 2005). Una de las propuestas de solución sería crear una base de datos universal coordinada empleando tecnología wiki (Nielsen, 2009).

En Europa, contamos con el Maastricht Brain Imaging Centre (M-BIC), centro de investigación fundado por la Facultad de Psicología y Neurociencias de la Universidad de Maastricht que cuenta con un grupo de trabajo puntero en neurociencia cognitiva, especialmente en relación a los correlatos neurales de la visión, audición, lenguaje, atención e imaginación. También ha desarrollado nuevos métodos de análisis para datos de RM y EEG como el denominado BrainVoyager que se está empleando en más de 300 investigaciones, actualmente. Por otro lado destaca el Centro PET de Turku en Finlandia, como parte del Instituto de Investigación Nacional Finés para el uso de PET en investigación médica. También se ha dedicado al estudio funcional del encéfalo desde 1996.

Sin embargo, es Reino Unido el país con mayor número de centros y laboratorios líderes en este área. El Centre for Cognitive Neuroimaging (CCNi) de la Universidad de Glasgow, creado en noviembre del 2008, en su facultad de Psicología recibió, en su primer año, un total de 8,2 millones de euros para desarrollar programas dirigidos a mejorar la comprensión del funcionamiento del encéfalo, a través de medidas de neuroimagen en RMf, MEG y EEG. El Aberdeen Biomedical Imaging Centre, del Instituto de Ciencias Médicas de la Universidad de Aberdeen, se ha dedicado al estudio de los correlatos estructurales y funcionales del desarrollo normal y anormal del encéfalo, además de la mejora del diagnóstico y comprensión de la respuesta terapéutica de los tumores al tratamiento, utilizando RM y PET. El Wolfson Brain Imaging Centre (WBIC) de la Universidad de Cambridge, se ha centrado en el estudio de lesiones en el encéfalo humano a través de neuroimagen PET y RM. El Wellcome Trust Centre for Neuroimaging de la University College de London, es otro centro británico dedicado al estudio de funciones cognitivas superiores junto con la afectación de estos procesos en trastornos neurológicos y psiquiátricos.

Además de los centros y laboratorios reseñados anteriormente, tanto en EEUU como en Europa, las siguientes organizaciones también han jugado un papel determinante en el desarrollo de la neuroimagen y sus aplicaciones, dentro de las cuales destaca la reconstrucción y visualización 3D de estructuras encefálicas:

La Society for Neuroscience ( $S f N$ ) es una organización sin ánimo de lucro, con sede en Washington, que con más de 38.000 miembros en 2009, constituye la organización de científicos y profesionales más grande del mundo dedicada al avance del estudio del encéfalo. 
La Federation of European Neuroscience Societies (FENS) fundada en 1998, sucesora de la European Neuroscience Association (ENA) y equivalente europeo de la American Society for Neuroscience, representa la mayoría de sociedades nacionales a nivel europeo para la investigación y educación en neurociencia.

La Cognitive Neuroscience Society (CNS), desde su fundación en 1994, se ha dedicado a la divulgación y promoción de investigaciones dirigidas al estudio de las bases biológicas de los procesos psicológicos, presentando sus resultados anualmente en una conferencia internacional.

La International Society of Neuroimaging in Psychiatry es una organización sin ánimo de lucro de carácter científico dedicada a la difusión de los últimos avances en el campo de la neuroimagen en Psiquiatría y mejora de las intervenciones en trastornos neuropsicológicos.

La American Society of Neuroimaging (ASN) es una organización internacional fundada en 1999 por neurólogos, neurocirujanos, neuroradiólogos y neurocientíficos para la promoción de las técnicas de neuroimagen. 


\subsection{DESARROLLOS INFORMÁTICOS EN EL TRATAMIENTO DE IMÁGENES}

El desarrollo de las técnicas de diagnóstico por imagen y la sustitución de las imágenes analógicas tradicionales por digitales no habrían sido posible sin el desarrollo paralelo de la informática, que ha permitido disponer de ordenadores de alto rendimiento, sistemas de almacenamiento masivo adecuados para el gran volumen de información generado, monitores de alta resolución para la visualización de dichas imágenes y redes de alta velocidad para su transmisión.

Convertir imágenes analógicas en digitales requiere descomponer la imagen original en una matriz de px (contracción y plural de la expresión picture element) a los que se les asignan valores numéricos que corresponden a diferentes tonos de grises, codificados según el sistema binario. El número de píxeles que representa la imagen, definiría la resolución espacial de ésta. Las matrices más empleadas tienen un tamaño de 512x512 px, pero pueden alcanzar los 4096 x 4096 px. Los niveles de grises asignados a cada píxel determinarán los detalles que se pueden apreciar en la imagen digital. En 1 bits o dígito binario de información (binary digit) se pueden almacenar dos niveles de información, blanco y negro, y en 12 bits serían $2^{12}$ niveles de grises, es decir, 4.096 tonalidades. Esta cantidad de información no es discriminable por el ojo humano, pero sí puede almacenarse y manipularse por ordenador según nuestras preferencias.

Entre las ventajas de las imágenes digitales frente a las analógicas destacan la mejor resolución, manipulación y almacenamiento en bases de datos que facilitan su acceso inmediato.

Actualmente, las exploraciones TC y RM realizadas en los distintos centros hospitalarios producen cientos de $\mathrm{Mb}$ de datos cada día, cuya información generalmente se analiza de forma visual a partir de secciones transversales. Sin embargo, es difícil valorar cambios sutiles en el volumen o forma de una estructura 3D como un tumor cerebral, simplemente, a partir de este tipo de información. Gracias a la generación de volúmenes o reconstrucción 3D de estructuras encefálicas, podemos acceder a información más completa, incluso ampliando la de la visión humana.

Para una revisión detallada de los desarrollos informáticos empleados, actualmente, en el análisis y tratamiento de imágenes médicas, el Neuroimaging Informatics Tools and Resources Clearinghouse (NITRC) ha elaborado un análisis comparativo de más de un centenar de desarrollos informáticos para estos fines, algunos de los cuales hemos descrito previamente en base a su especial relevancia.

El software empleado en la generación volumétrica de estructuras encefálicas que nos ocupa en este trabajo ha sido Amira ${ }^{\circledR}$, sin embargo, antes de proceder a su descripción, presentaremos otro desarrollo informático comercial paralelo denominado Voxel-Man ${ }^{\circledR}$, en 
reconocimiento a la cantidad de investigaciones asociadas, y que tampoco aparece incluido en la revisión de NITRC.

\subsubsection{Voxel-Man ${ }^{\circledR}$}

Se trata de un conjunto de aplicaciones informáticas para la creación y visualización de modelos digitales 3D, desarrollado por el Instituto de Matemáticas y Ciencia Computacional en Medicina del Hospital Universitario de la Universidad de Hamburg-Eppendorf en Alemania. Recibe su nombre del término vóxel, que proviene de la contracción de los términos en inglés volumetric pixel y que representa la unidad cúbica mínima procesable de una matriz 3D, a partir de la cual se compone un objeto 3D, equivalente a un píxel 3D. Voxel-Man ${ }^{\circledR}$ también se ha empleado como término genérico para hacer referencia a una representación digital del cuerpo humano en el estudio de la anatomía humana (Schiemann, Tiede, \& Höhne, 1996; Lowndes, Morris, \& Schubert, 1997). Las aplicaciones más actuales incluyen la elaboración del atlas del cráneo y encéfalo (Voxel-Man-3D-Navigator: Brain and Skull) (Maki \& Griffiths, 1996), de los órganos internos (Voxel-Man-3D-Navigator: Inner organs) (Höhne et al., 2003) y de los miembros superiores (Voxel-Man-3D-Naigator: Upper Limb), además de simulaciones quirúrgicas (Voxel-Man-TempoSurg simulator) (Ajioka, 1995; Pommert et al., 2001).

La versión " $d$ " incorpora imágenes de la base de datos del VHP y tiene como finalidad servir como un atlas neuroanatómico multimedia, incluyendo etiquetado y descripción de más de 250 estructuras anatómicas, cuya exploración interactiva se realiza a través de reconstrucciones 3D e imágenes radiológicas del VHP (Ajioka, 1995; Schiemann et al., 1996).

El simulador Voxel-Man TempoSurg es una herramienta basada en modelos 3D virtuales de la base del cráneo obtenidos a partir de TC, y que sirven para el entrenamiento y planificación de abordajes quirúrgicos en el oído medio. Este entorno virtual quirúrgico estereoscópico incluye controles que reciben feedback en relación a la fuerza y resistencia ejercidas. La simulación del procedimiento es prácticamente idéntica a la situación real en relación a la orientación del paciente, la dirección de la vista del cirujano, la orientación de la mano y la sensación háptica. El cirujano puede elegir el ángulo de visión e incluso su magnificación, tipo y tamaño del puntero, y la velocidad de su rotación (Ajioka, 1995; Lowndes et al., 1997).

En las fases iniciales de entrenamiento se pueden mostrar los órganos en riesgo en colores predefinidos, tanto en el entorno quirúrgico 3D, como en las vistas de secciones transversales, de forma que se active una alarma cuando se dañen dichos órganos. Además, es posible grabar la intervención para su evaluación y corrección, reduciendo, significativamente, la inversión asociada a un laboratorio quirúrgico tradicional (Rizzolo et al., 2006; Rizzolo \& Stewart, 2006). 


\subsubsection{Amira ${ }^{\circledR}$}

Es el desarrollo informático profesional de referencia en este trabajo y permite múltiples funcionalidades como el análisis de datos de imágenes, reconstrucción volumétrica o modelado 3D y visualización avanzada. Los componentes básicos de Amira ${ }^{\circledR}$ son los módulos y los datos relativos a los objetos, en este caso, las distintas estructuras encefálicas. Los módulos se utilizan para la visualización de datos de las estructuras encefálicas y realización de operaciones como la creación de modelos poligonales a partir de imágenes 3D, que pueden combinarse para producir una sola escena, mostrando múltiples conjuntos de datos simultáneamente. Los datos de objetos se crean, automáticamente, a partir de los datos del archivo de entrada que se estén leyendo, o como salida de las operaciones de los módulos.

En Amira ${ }^{\circledR}$, reconstrucción significa que los objetos 3D, estructuras encefálicas en nuestro caso, se pueden representar como una malla volumétrica de superficie triangular o tetrahedral a partir de los datos que representan el volumen de una imagen (vóxeles). Visualización significa que es posible mostrar conjuntos de datos de imágenes a través de un visor 3D interactivo que permite observar el modelo desde diferentes posiciones, rotar el objeto en el espacio moviendo el cursor del ratón dentro de la ventana del visor e incluso aplicar zoom.

Amira ${ }^{\circledR}$ permite cargar cualquier conjunto de datos de imagen médica incluyendo RM, TC, PET y SPECT y soporta distintos formatos de imagen digital, añadiendo el formato estándar para imágenes radiológicas DICOM y es empleado en el manejo, almacenamiento y transmisión de imágenes médicas en redes (TCP/IP), impresoras y discos (formato de fichero).

Los distintos módulos permiten, en primer lugar, la exploración rápida, comparación y medición de los volúmenes obtenidos a partir de distintas modalidades de neuroimagen y en segundo lugar, la segmentación de las estructuras encefálicas objeto de estudio y posterior creación de modelos poligonales y verdaderas mallas volumétricas, que simulan los distintos volúmenes.

El conjunto de herramientas de Amira ${ }^{\circledR}$ es accesible a partir de una interface visual de programación, que permite aplicar tareas de los distintos módulos, mediante selección y arrastre o a través de barras de herramientas que pueden personalizarse con las acciones más comunes y sin necesidad de conocimientos profundos de programación. Los componentes de los módulos están representados por pequeños iconos colocados en la parte superior derecha, conectados por líneas para indicar las dependencias entre componentes, es decir, qué módulos pueden aplicarse a qué tipo de datos. También incluye vistas en miniatura de las imágenes cargadas. Lo más difícil es acostumbrarse a utilizar todos los módulos que se incluyen debido a que cada uno tiene distintas restricciones respecto al tipo de datos a utilizar y es necesario familiarizarse con sus propios parámetros.

Entre las tareas y herramientas más útiles que incluye Amira ${ }^{\circledR}$ de cara a la reconstrucción de modelos 3D de estructuras encefálicas destacan las siguientes: 


\section{Segmentación de imágenes}

Consiste en separar estructuras dentro de un volumen, asignando a cada píxel de la neuroimagen una etiqueta referente a qué región pertenece el píxel, por ejemplo, tálamo o VL. La segmentación se almacena por separado en el apartado de datos de objetos denominado LabelField y sirve como prerrequisito para poder medir con precisión el volumen y generar la superficie del modelo. Los LabelField se pueden visualizar y modificar utilizando el editor de segmentación de imagen, de forma que se pueden suavizar los datos y conseguir una superficie más limpia y agradable del objeto. Este editor contiene múltiples herramientas que van desde las puramente manuales a las completamente automáticas: pincel (pintar), lazo (contorno), varita mágica, tijeras inteligentes, interpolación y extrapolación del contorno, varios filtros como el de suavizado, limpieza... y pueden aplicarse tanto en 2D como en 3D. El editor no almacena las regiones que rodean a los contornos, sino las etiquetas de la región, por lo tanto, se garantiza una clasificación única y bien definida.

\section{Reconstrucción de la superficie}

Se trata de la construcción o generación de una superficie o modelo de superficie en malla triangular de la estructura encefálica, que aparece insertada en el conjunto de datos. El modelo de superficie poligonal, se puede crear una vez que las características referentes al volumen de la imagen 3D han sido segmentadas, garantizando una superficie poligonal topológicamente correcta, sin autointersecciones. Durante la segmentación, el sistema produce límites suaves entre las caras que forman parte del modelo, consiguiendo modelos realistas de alta calidad, incluso si los datos de la imagen inicial contienen ruido.

\section{Simplificación de la superficie}

Es la reducción del número de triángulos en un modelo de superficie, debido a que el número inicial generado por el módulo SurfaceGen es demasiado grande para que los modelos de malla generados puedan ser procesados por ordenadores estándar. La clase de datos que representa las superficies triangulares en Amira ${ }^{\circledR}$ se denomina HxSurface. La generación de la malla tetrahedral requiere pasar satisfactoriamente el test de orientación e intersección. Después de la simplificación de la superficie, puede aparecer alguna incorrección de orientación, es decir, un pequeño número de triángulos pueden solaparse parcialmente. Estas incorrecciones se reparan de forma automática y si falla la reparación, se señalan cuáles son los triángulos afectados, de forma que puedan corregirse manualmente.

\section{Registro}

Se refiere a la integración de los volúmenes obtenidos con las diferentes modalidades (por ejemplo, PET y RM) en un mismo sujeto. Este módulo puede fusionar datos morfológicos con datos funcionales y datos de 2D y $3 \mathrm{D}$. Normalmente, se toma una de las bases de datos como referencia y las demás se transforman hasta que coincidan empleando landmarks. El módulo para 
el registro en Amira ${ }^{\circledR}$ permite, por ejemplo, determinar la transformación óptima respecto a la traslación, rotación, escalamiento...

\section{Generación de una Malla Tetraédrica}

Consiste en el relleno del volumen definido por la superficie con tetraedros, a modo de pirámides triangulares, generando una verdadera malla volumétrica tetraédrica a partir de la superficie triangular creada previamente, ahora sí, adecuada para simulaciones en 3D. En entornos gráficos, esta malla volumétrica tetraédrica determina el número de caras y, por lo tanto, la velocidad de renderización asociada.

Amira ${ }^{\circledR}$ soporta mallas con estructura hexaédrica, compuesta por muchos tetraedros, definida por una cadena de nodos, donde cada nodo es colocado por coordenadas 3D (i,j,k). Este tipo de malla se puede usar para realizar simulaciones y mantiene una considerable cantidad de información. Para cada tetraedro, las coordenadas de sus cuatro vértices se almacenan, al igual que el número que indica el segmento al que pertenece, tal y como se obtuvo en el procedimiento de segmentación. Cuando se selecciona una malla, se muestra información sobre el número de sus vértices, aristas, caras y tetrahedros.

Otro método de reconstrucción de modelos de superficie poligonales es a través de isosuperficies, generando menos triángulos, de forma que grandes conjuntos de datos $3 \mathrm{D}$ se pueden visualizar consumiendo menos recursos. En este caso, al igual que otros modelos poligonales, las isosuperficies pueden colorearse y se les pueden aplicar transparencias, facilitando la comprensión de estructuras espaciales complejas.

\section{Renderización Volumétrica}

Es una de las técnicas más potentes para la visualización de datos de imágenes en 3D. Consiste en asignar a cada punto del volumen, parámetros de emisión y absorción de luz. La simulación de la transmisión de luz a través del volumen hace posible mostrar los datos desde cualquier dirección sin necesidad de construir modelos poligonales intermedios. Amira® puede aplicar esta técnica de renderización prácticamente en tiempo real incluso con datos originales de más de $40 \mathrm{Mb}$. Hasta el momento, es el único desarrollo informático que permite renderizar múltiples conjuntos de datos al mismo tiempo. 



\subsection{VISIBLE HUMAN PROJECT (VHP)}

El VHP es la primera base de datos que contiene imágenes de secciones anatómicas de la anatomía masculina y femenina completas con un nivel de precisión por debajo del mm, que constituyen los conjuntos de datos multimodales más completos, hasta la fecha, en anatomía humana.

Este repositorio de datos de dominio público ha significado uno de los avances más importantes en el estudio anatómico del encéfalo humano. Se considera el mejor punto de referencia digital para el estudio de neuroanatomía y es el más difundido, con más de 2.500 licencias en más de 42 países y 921 publicaciones a fecha de abril de 2007 (Burke \& Patrias, 2007).

El proyecto comenzó poco antes de 1990, cuando la Biblioteca Nacional de Medicina de EEUU decidió financiar su creación y desarrollo asignado en 1991 a la Universidad de Colorado en EEUU, bajo la dirección de. Dr. Michael J. Ackerman, Dr. Victor M. Spitzer y Dr. David G. Whitlock, como investigadores principales (Anderson \& Cook, 2006; Seifert \& Carmichael, 2006).

La primera fase del proyecto consistió en la recogida de datos para la construcción de una biblioteca de imágenes digitales de datos volumétricos completos de un varón y una mujer considerados sanos. Se utilizaron imágenes digitalizadas de tres modalidades: fotografías de criosecciones de los cadáveres de ambos, TC y RM.

En noviembre de 1994, la Biblioteca Nacional de Medicina de EEUU hizo público el Visible Human Masculino (Visible Human Male), después de más de 2 años buscando un cadáver apropiado que, finalmente, correspondió al de Joseph Paul Jernigan, un hombre de 39 años condenado a muerte por asesinato en Texas en 1993, quien había donado su cuerpo a la investigación científica, aunque desconocía la existencia del proyecto VHP (Kiernan, 1994; Ackerman, Spitzer, Scherzinger, \& Whitlock, 1995; Sechrest, 1995; Toh, Ackerman, \& Main, 1995; Toh, Ackerman, \& Main, 1995; Toh, Flak, Horowitz, \& Main, 1995; Pallen, 1996; Spitzer, Ackerman, Scherzinger, \& Whitlock, 1996; Toh, Banvard, Ackerman, Rodgers, \& Main, 1996; Toh, Flak, Horowitz, \& Main, 1995; Slavin, 1997; Spitzer, 1997; Ackerman, 1998; Spitzer \& Whitlock, 1998; Rath, 1999; Ackerman, 2000; Spitzer \& Scherzinger, 2000; Ackerman, 2002).

El conjunto de datos del VHP masculino completo original pesó, aproximadamente, 15Gb. Las imágenes de RM axiales de la cabeza y cuello y las secciones longitudinales del resto del cuerpo se obtuvieron a intervalos de $4 \mathrm{~mm}$, potenciadas en T1, T2 y densidad protónica, con una resolución de 256 x 256 px y 12 bites de información (colores). Los datos de TC consistieron en secciones axiales del cuerpo completo tomadas a intervalos de $1 \mathrm{~mm}$, con una resolución de 512 x 512 px y 12 bites de tonalidades de gris cada uno. Las imágenes anatómicas axiales pesaron, aproximadamente, 7,5 Mb cada uno, con una resolución de $2.048 \times 1.216 \mathrm{px}$, donde 
cada píxel midió unos $0,33 \mathrm{~mm}$ de longitud y 24 bites. Estas secciones anatómicas se realizaron a intervalos de $1 \mathrm{~mm}$ para coincidir con las imágenes obtenidas por TC, contabilizándose hasta 1.871 secciones (Ackerman, 1998; Pallen, 1996; Spitzer et al., 1996; Toh et al., 1996; Slavin, 1997; Spitzer, 1997; Rath, 1999).

En el año 2000 se digitalizaron las fotografías de criosecciones para el conjunto de datos masculinos de $1 \mathrm{~mm}$, mejorando la resolución a 4096 x 2700 px. Cada una de estas imágenes tiene un tamaño de $32 \mathrm{Mb}$, aproximadamente, disponibles a color para las 1.871 crio-secciones. El peso total del nuevo conjunto de datos masculinos es de más de 65 Gb (Ackerman, 1998; Ackerman, 2000; Ackerman, 2002; Ratiu, Hillen, Glaser, \& Jenkins, 2003; Seifert \& Carmichael, 2006; Vaidyanath \& Temkin, 2006; Ackerman \& Yoo, 2007).

El conjunto de datos del VHP Femenino se hizo público en 1995 por la Biblioteca Nacional de Medicina de EEUU, un año después del Visible Human Male, también para libre acceso vía FTP bajo licencia sin coste. Se utilizó el cuerpo de una mujer de 59 años de Maryland (EEUU), fallecida por paro cardíaco, que había solicitado, explícitamente, participar en el proyecto VHP. Los datos del conjunto femenino poseen las mismas características que los del conjunto masculino, con la diferencia de que las imágenes anatómicas axiales se obtuvieron a intervalos de 0,3 $\mathrm{mm}$ para encajar con el tamaño de $0,33 \mathrm{~mm}$ de cada píxel en el plano xy y facilitar la reconstrucción 3D, al trabajar con vóxeles cúbicos. El espacio en el plano z se redujo a 0,3 mm. En total, el conjunto de datos del Visible Human Female consistió en 5.189 imágenes anatómicas axiales con un peso de $40 \mathrm{~Gb}$, aproximadamente, disponibles para acceso público (Spitzer, 1997; Spitzer \& Whilock, 1998; Treichler, Cartwright, \& Penley, 1998).

Aunque el conjunto de datos de las imágenes masculinas pesó $15 \mathrm{~Gb}$ y el conjunto relativo a la base de datos femenina $40 \mathrm{~Gb}$, cada imagen de TC, RM y de criosección se almacenó en un archivo independiente, de forma que puede descargarse, aislada o conjuntamente, con otras, incluyendo el conjunto total de los datos. Actualmente, se dispone de varios sitios espejo con los conjuntos de datos completos, con la finalidad de facilitar su descarga (Ratiu et al., 2003; Seifert \& Carmichael, 2006; Ackerman \& Yoo, 2007; Burke \& Patrias, 2007).

La segunda fase del Proyecto consistió en el desarrollo de herramientas para el registro y segmentación de las imágenes de las bases de datos, en base a seis contratos, concedidos por la Biblioteca Nacional de Medicina de Estados Unidos en 1999. El resultado concluyó a finales del2002 y se denominó Insight Segmentation and Registration Toolkit, que permitió el análisis, segmentación, clasificación y registro deformable de las imágenes. Sin embargo, no se incluyó una interface gráfica de usuario que permitiera su navegación (Ackerman \& Yoo, 2003; Yoo \& Metaxas, 2005) ni siquiera en la versión 3.14 de septiembre de 2009.

Actualmente, el VHP se considera un estándar de referencia en anatomía en general, y en neuroanatomía en particular. Ha permitido establecer un sistema de coordenadas anatómicas universales susceptibles de aplicación, tanto en investigación básica como clínica, de forma que 
los datos del VHP podrían funcionar como un mapa de carreteras en la navegación a través de éstos. Sin embargo, uno de los problemas más importantes sigue siendo la dificultad de navegación con una cantidad de datos tan grande.

Además, los datos y reconstrucciones 3D asociadas al VHP parten de un solo individuo en un momento determinado del ciclo vital, por lo tanto, no permiten considerar la variabilidad interindividual de la morfología de las estructuras encefálicas o su evolución a lo largo el tiempo (Pommert et al., 2001).

Hasta la fecha, se han obtenido conjuntos de datos del VHP para muestras procedentes de China (Yuan et al., 2003; Zhang, Heng, \& Liu. 2006; Bao, Sun, Tian, \& Tang, 2007; Chen, Zhang, Heng, \& Deshen, 2008; Heng, Zhang, Xie, Wong, Chui, \& Cheng, 2006) y de Corea (Chung, Kim, Hwang, \& Park, 2002; Park, Chung, Hwang, Lee, Har, \& Park, 2005; Park, Chung, Hwang, Shin, \& Park, 2006; Choi et al., 2007).

Las numerosas aplicaciones del VHP se pueden clasificar en formativas y clínicas (Juanes, Prats, Lagándara, \& Riesco, 2003; Dev \& Senger, 2005; Robb \& Hanson, 2006). Respecto a la primera categoría, la aplicación más común ha sido la creación de atlas y reconstrucciones 3D a partir de las secciones seriadas del proyecto, sistemas de manipulación y navegación de datos a través de la obtención de cortes sagitales y coronales, partiendo de cortes axiales mediante re-slicing (Toh et al., 1995; Ross, 1996; Senger, 1996; Toh et al., 1996; Zhou, Henderson, \& Seamans, 1998; Stephens, Temkin, Krummel, \& Heinrichs, 2000; Duan, Tan, Jia, \& Lu, 2001; Temkin et al., 2002; Juanes, Prats, Lagándara, \& Riesco, 2003; Shelton, Stetten, Aylward, Ibanez, Cois, \& Stewart, 2005; Rizzolo et al., 2006; Rizzolo \& Stewart, 2006; Temkin et al., 2006; Prats \& Juanes 2007), y otras aplicaciones desarrolladas por la Biblioteca Nacional de Medicina de EEUU o bajo su financiación, para la mejora del estudio anatómico del encéfalo a partir del VHP. Reseñamos, a continuación, algunas de las más representativas:

Visible Human Viewer NPAC/OLDA es un interface gráfico interactivo de código abierto desarrollado por la Universidad de Syracuse (EEUU), que consiste en un conjunto de applets de java que permite la visión de los datos originales del VHP en secciones axiales, sagitales y coronales, aunque restringiendo la exploración a secciones 2D.

El Visible Human Server (VHS), desarrollado por la Escuela Politécnica Federal de Lausanne en Suiza, también consiste en applets java que permiten la visualización, extracción de características 3D y animación de secciones originales del VHP.

Anatquest es un visor de imágenes que permite la visualización y navegación a través de imágenes renderizadas 3D de objetos anatómicos, creados desde criosecciones del VHP y asociadas con su terminología anatómica correspondiente.

El propio Center for Human Simulation (CHS) de la Universidad de Colorado ha trabajado en el desarrollo del Explorable Virtual Human (EVH), un sistema que ofrece entornos anatómicos 3D interactivos con alto grado de realismo a partir de los datos del VHP. Uno de los 
logros en este sentido ha sido la elaboración del atlas Visible Human Proyect Atlas of Functional Human Anatomy, versión 1.0 Head and Neck.

Desde la Universidad de Michigan y con el Dr. Brian Athey como investigador principal, se está trabajando en el proyecto Next Generation Internet Implementation to Serve Visible Human Datasets, que permitirá desarrollar nuevas aplicaciones de los datos del VHP con fines educativos a través de Internet. Pretente implementar un sistema de navegación web para la creación y visualización de estructuras anatómicas bajo el control manual del usuario, habilitar etiquetas anatómicas que mejoren dichas visualizaciones e incluir enlaces a recursos web apropiados empleando xml, además de incluir acceso a varios recursos multimedia de alta calidad.

El proyecto Remote, Real-time Simulation for Teaching Human Anatomy, cuyo principal investigador es el Dr. Parvati Dev de la Universidad de Standford (Stanford University Medical Media and Information Technologies (SUMMIT), se ha centrado en la mejora del aprendizaje visoespacial, de forma que los estudiantes puedan apreciar la proximidad y los rasgos de estructuras adyacentes.

Finalmente, en cuanto a las aplicaciones clínicas del VHP, se ha empleado en el entrenamiento virtual de cirujanos en el contexto de la planificación y evaluación de abordajes quirúrgicos (Baerson, 1991; Kerr, Ratiu, \& Sellberg, 1996; Nieder \& Nagy, 1996; Robb, 1998; Spitzer \& Whitlock, 1998; Lange, Indelicato, \& Rosen, 2000; Juanes et al., 2003; Valentini, Dinapoli, Nori, Mattiucci, Mantello, Marucci, Rosetto, \& Cellini, 2004; Shelton et al., 2005; Spitzer \& Scherzinger, 2006; Heng, 2007; Kim, Choi, \& De Srinivasan, 2007). 


\subsection{TRASTORNOS NEUROPSICOLÓGICOS}

Tradicionalmente, Neurología y Psicología Clínica/Psiquiatría se han desarrollado de forma independiente. Sin embargo, el desarrollo de la Neuropsicología y, en concreto, la Neuropsiquiatría, en las dos últimas décadas, se ha convertido en una subdisciplina de unión entre ambas. Se basa en la aplicación de los principios de la neurociencia al estudio y manejo de trastornos de conducta, también llamados psicopatológicos, psiquiátricos o mentales, asumiendo la implicación de alteraciones en el encéfalo. Por lo tanto, requiere habilidades y conocimientos tanto de Psiquiatría/Psicología Clínica como de Neurología.

Dentro de los trastornos neuropsicológicos a los que hace referencia el enunciado, consideraremos trastornos neurológicos y psiquiátricos, si bien subrayaremos una característica común: ambos suponen la afectación de la relación entre aspectos morfofuncionales del encéfalo y procesos de razonamiento-resolución de problemas, aprendizaje-recuerdo, atención selectivasostenida, sensación-percepción, lenguaje, control de movimientos, etc. En concreto, nos centraremos en las estructuras encefálicas implicadas a cada uno, según los resultados expuestos por los trabajos revisados.

En primer lugar, nos vamos a centrar en una selección de trastornos neurológicos y, posteriormente, en una selección de trastornos psiquiátricos y del desarrollo. No se pretende realizar una descripción exhaustiva de todos los trastornos, ni de todas las estructuras propuestas por la literatura, que sobrepasaría los objetivos de este trabajo, sino una selección de aquellas en las que existe mayor producción científica (Ver Tabla 1.3).

Tabla 1.3. Clasificación de enfermedades neurológicas y trastornos psiquiátricos.

Trastornos neurológicos Trastornos psiquiátricos Trastornos del desarrollo

\begin{tabular}{l}
\hline Alzheimer (EA) \\
Parkinson (EP) \\
Esclerosis Múltiple (EM) \\
Epilepsia \\
Accidentes CerebroVas \\
(ACV) \\
Traumatismos Craneo \\
Encefálicos (TCE) \\
Neoplasias
\end{tabular}
Trastorno de Esquizofrenia Trastorno Autista Trastornos de Estrés Trastorno por Déficit de Postraumático (TEPT) Atención con Hiperactvidad Anorexia Nerviosa (AN) (TDA-H)

Trastorno Depresión Mayor

(TDM)

Trastorno Bipolar (TB)

Trastorno Obsesivo

Compulsivo (TOC)

Según la Organización Mundial de la Salud, actualmente, las enfermedades neurológicas constituyen un serio problema para en la salud pública a nivel mundial. La EA y otras demencias, 
la EP, la EM y los ACV constituyen más del $6 \%$ del total del espectro de enfermedades y son la causa mayor de pérdida de años de vida saludables y mortalidad, y más del 10\% del número de muertes totales en 2005. Sólo los ACVs han sido responsables del 85\% de las muertes atribuidas a trastornos neurológicos y se estima que estas cifras sigan aumentando, de acuerdo con las estadísticas realizadas para los años 2015 y 2030 (World Health Organization [WHO], 2006).

Según el NINDS de Estados Unidos, existen 451 trastornos neurológicos (National Institute of Neurological Disorders and Stroke [NINDS], 2009) susceptibles de clasificarse atendiendo a diferentes criterios. En nuestro trabajo revisaremos las estructuras encefálicas asociadas a trastornos neurológicos degenerativos como la EA, la EP y la EM. También describiremos brevemente la Epilepsia, ACVs, TCE y Neoplasias, aunque en estos casos, la variabilidad en la afectación de las funciones cognitivas superiores será aún mayor según la localización y extensión de la lesión, siendo difícil establecer una base neuroanatómica común.

Respecto a los trastornos psicopatológicos, psiquiátricos o mentales, tradicionalmente, su diagnóstico se ha basado en la historia clínica y en el examen psicopatológico. Sin embargo, actualmente, se están empleando técnicas de neuroimagen, útiles para el estudio de alteraciones morfológicas y funcionales del encéfalo, con la intención de objetivar el diagnóstico clínico y mejorar la comprensión de su sustrato biológico, lo que podría permitir discriminar entre población clínica, subclínica y sujetos sanos (Holler, Kronbichler, Zeller, Klein, Hinterhuber, Golaszewski, \& Ladurner, 2009).

La American Psyquiatric Assosiation (APA) en el DSM-IV-TR (American Psychiatric Association [DSM-IV-TR], 2000), manual de referencia en Psicología Clínica y Psiquiatría para el diagnóstico de los trastornos psiquiátricos o mentales, definen a éstos como una condición asociada a cambios en el comportamiento, especialmente, de funcionamiento cognitivo, que provocan malestar y dificultad de funcionamiento en la persona que lo padece y que, independientemente de su causa original, debe considerarse una manifestación de una alteración biológica en el individuo. No se trata de una definición suficientemente específica, ni están claros sus límites, pero sí merece especial atención el énfasis en el sustrato biológico de éstos.

En este trabajo incluiremos trastornos psiquiátricos o mentales, según en el DSM-IV-TR y enfermedades neurológicas según el NINDS. Sin embargo, las líneas entre enfermedades neurológicas y trastornos mentales se está difuminando progresivamente al aumentar la evidencia en favor de diferencias en la morfología y funcionamiento de diferentes estructuras encefálicas.

El propio uso del término "trastorno mental" se ha criticado dado que "mental" implica una visión cartesiana del problema "cuerpo-mente" según el cual, se asume que el encéfalo y la mente son dos realidades separables y distintas. Una idea que no es consistente con el estudio científico del comportamiento y que omite la base física. Como resultado, se ha propuesto el término "trastorno psiquiátrico" que subraya la idea de que estas condiciones, al igual que las enfermedades neurológicas, implican un sustrato biológico. Sin embargo, este término induce a 
pensar, incorrectamente, que sólo los psiquiatras están entrenados para el diagnóstico y manejo de estas condiciones, surgiendo el "trastorno psicopatológico" como alternativa.

Emplear el término trastorno mental/psiquiátrico/psicopatológico constantemente resultaría farragoso, así que podrán usarse indistintamente a lo largo del presente trabajo.

En relación con la base biológica de estos trastornos, actualmente, seguimos sin contar con biomarcadores específicos que los definan, por ese motivo, el criterio de malestar clínicamente significativo sigue empleándose para diferenciar un trastorno de la normalidad. Según la revisión de la definición de trastorno mental de cara a la elaboración del DSM V desde el grupo de trabajo Anxiety, Obsessive-Compulsive, Posttraumatic, and Dissociative Disorders Work Group, se enfatiza aún más la conceptualización del trastorno mental como reflejo de una alteración biológica (Stein, Phillips, Bolton, Fulford, Sadler, \& Kendler, 2010).

Los resultados de la aplicación de técnicas de diagnóstico por neuroimagen en el estudio de trastornos psiquiátricos han sugerido múltiples cambios en estructuras corticales y subcorticales. Sin embargo, era necesario hacer una breve revisión de los últimos descubrimientos en esta área (Mateus, Silva, Nogueiro, \& Redondo, 2009) y que se responderá, al menos parcialmente, en el apartado correspondiente a trastornos psiquiátricos con importantes efectos neuropsicológicos.

\subsubsection{Enfermedades neurológicas}

Se describen las estructuras encefálicas macroscópicas asociadas a los distintos procesos patológicos en base a los estudios revisados, especialmente, desde estudios basados en técnicas de diagnóstico por imagen morfológicas y funcionales.

Se incluye una selección de trastornos degenerativos que suponen el deterioro anormal de parte de los componentes del encéfalo (por lo tanto, no incluiremos el envejecimiento), independientemente de su etiología, como sucede en el caso de la EA, EP y EM. Posteriormente, describeremos brevemente la epilepsia, ACV, TCE y Neoplasias como frecuentes causas de lesión en estructuras encefálicas con importantes efectos neuropsicológicos.

\subsubsection{Enfermedad de Alzheimer (EA)}

La EA es un trastorno neurodegenerativo que supone la pérdida progresiva e irreversible de funciones cognitivas superiores, incluyendo memoria, habilidades linguísticas, percepción del tiempo y habilidades de autocuidado. La muerte neuronal es secundaria a la formación de placas por depósitos de beta amiloide. Sólo el 2\% de los casos comienza antes de los 53 años, pero a partir de esta edad, la prevalencia se dobla cada 5 años, afectando a un total de 24 millones de personas en todo el mundo (World Health Organization [WHO], 2006).

La aplicación de RM ha servido para estudiar el grado y localización de la atrofia cortical en demencias, contribuyendo a la discriminación entre EA y demencia frontotemporal (Mungas 
et al., 2002; Kawas, 2003; Ramani, Jensen, \& Helpern, 2006; Henry-Feugeas, 2007; Rabinoviciet al., 2008; Fennema-Notestine, Hagler, McEvoy, Fleisher, Wu, Karow, \& Dale, 2009). Las técnicas de neuroimagen funcionales también han contribuido al diagnóstico diferencial entre diferentes tipos de demencia y/o el envejecimiento normal, incluyendo estudios SPECT (Dougall, Bruggink, \& Ebmeier, 2004) y estudios de metabolismo cerebral PET- ${ }^{18}$ F-FDG y RMf (Buckner, Snyder, Sanders, Raichle, \& Morris, 2000; Kogure, Matsuda, Ohnishi, Asada, Uno, Kunihiro, Nakano, \& Takasaki, 2000; Ebmeier, Donahey, \& Dougall, 2005; Matsuda, 2007; Rabinovici et al., 2007; Chua, Wen, Slavin, \& Sachdev, 2008; Eldaief \& Dougherty, 2008; Zhou, et al. 2010). Sin embargo, se considera que la integración de diferentes modalidades mejora la precisión de las predicciones sobre la evolución de la EA (Chen, Reiman, Alexander, Bandy, Renaut, Crum, Fox, \& Rossor, 2004; Ramani et al., 2006).

Recientemente, se ha desarrollado una nueva técnica denominada PET PiB capaz de identificar con precisión los depósitos beta-amiloide responsables de pérdida neuronal, empleando un trazador que se une selectivamente a las placas amiloides (Jack et al., 2008; Konomovic et al., 2008; Rostomian, Madison, Rabinovici, \& Jagust, 2011). Esta técnica emplea como componente ${ }^{11} \mathrm{C}-\mathrm{PiB}$ y se considera que podría discriminar con un $86 \%$ de seguridad, qué personas con MCI desarrollarán EA en dos años, y con un 92\% de seguridad quienes (Abella, 2009).

Dos estructuras encefálicas macroscópicas parecen estar especialmente implicadas en EA: el hipocampo y la amígdala (Buckner et al., 2000; Jack et al., 2000; Mungas et al., 2002; Becker, Davis, Hayashi, Meltzer, Toga, López, \& Thompson, 2006; Ebmerirer et al., 2005; Morra et al., 2009; Schroeter, Stein, Maslowski, \& Neumann, 2009; Apostolova et al., 2010; Guo et al., 2010). El hipocampo parece ser una de las estructuras especialmente afectadas en fases iniciales, siendo coherente con con la participación del hipocampo en la formación de recuerdos y los frecuentes síntomas de afectación de la memoria y desorientación asociados a fases iniciales de esta enfermedad (Lowndes \& Savage, 2007; Persson et al., 2008). Posteriormente, la EA progresaría a otras áreas de asociación del córtex (Matsuda, 2007).

Otros autores han encontrado un alargamiento de los VL que acompaña a la progresión de este tipo de demencia (Carmichael et al., 2007; Wang, Ekin, \& de Haan, 2008), alteraciones de la sustancia blanca, en concreto, en estructuras posteriores como el cuerpo calloso, especialmente el esplenio (Tomimoto et al, 2004; Ramani et al., 2006; Chua et al., 2008; Pitel, Chanraud, Sullivan, \& Pfefferbaum, 2010; Seoung, Kim, Cho, Hong, Woo, \& Choe, 2010; Serra, et al., 2010; Di Paola et al., 2010; Guo et al., 2010) y el fórnix, que correlaciona con las alteraciones en el hipocampo (Copenhaver et al., 2006; Kantarci et al., 2010; Pievani, Agosta, Pagani, Canu, Sala, Absinta, \& Fillippi, 2010) y diferencias en el giro cingulado posterior (Henry-Feugeas, 2007). Los cambios asociados al envejecimiento normal se localizarían en 
posiciones más anteriores como el giro cingulado anterior (GCA) y el genu del cuerpo calloso (Ramani et al., 2006).

En la Figura 1.9 se observa hipometabolismo en el lóbulo temporal consistente con la afectación del hipocampo y amígdala identificados por la literatura, y un ensanchamiento de los surcos hemisféricos en un caso de EA correspondiente a un sujeto de 70 años, con una historia de 9 meses de problemas de memoria y desorientación.

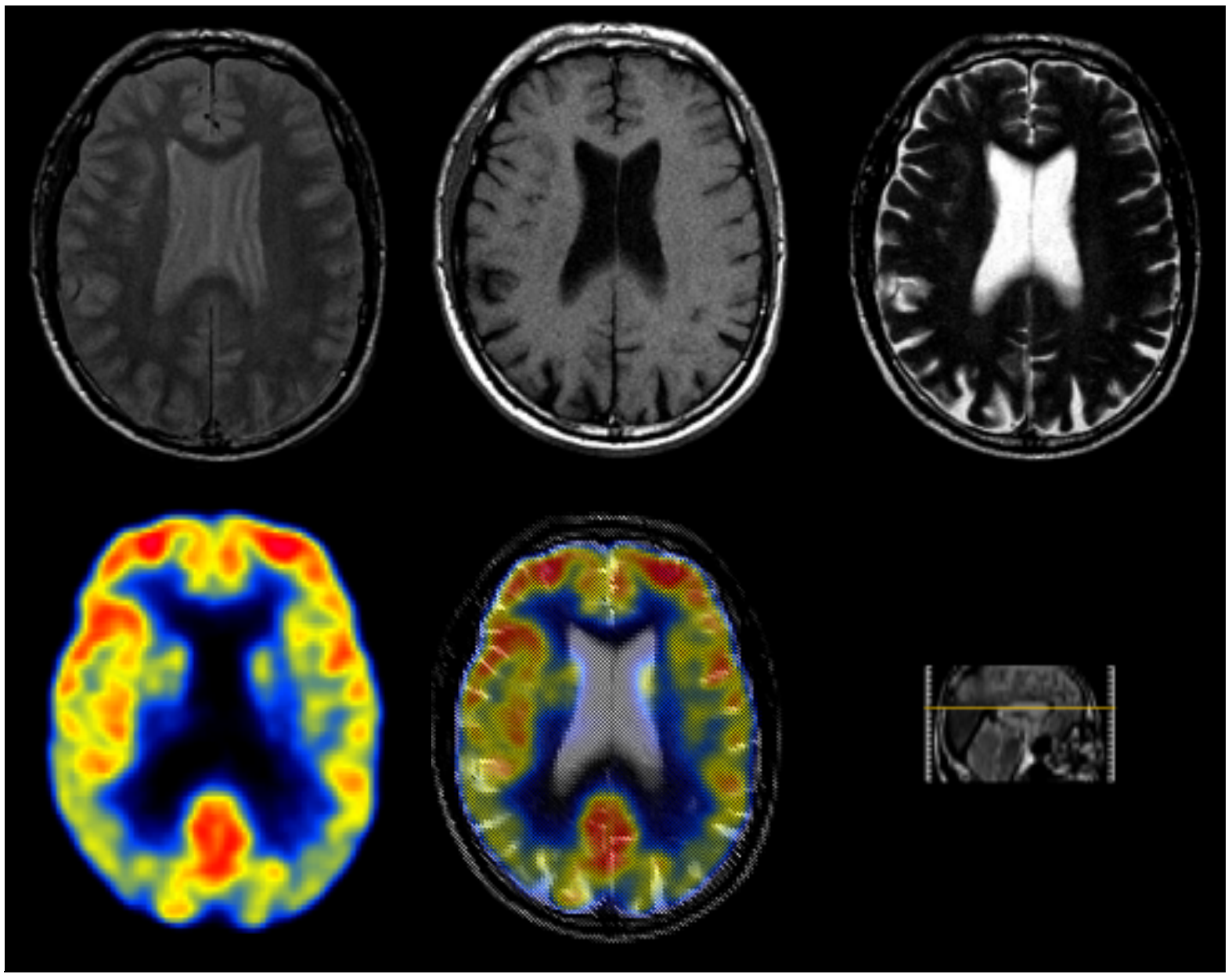

Figura 1.9. Enfermedad de Azheimer (leve): RM DP (imagen arriba a la izquirda), RM T1 (imagen arriba a la derecha), MR T2 (imagen del medio a la izquierda), PET ${ }^{18} \mathrm{~F}-\mathrm{FDG}$ (imagen del medio a la derecha) y PET ${ }^{18} \mathrm{~F}-$ FDG con RM T2 (imagen abajo). Nótese la dificultad de identificación y localización del hipocampo y amígdala como estructuras implicadas. Fuente: Johnson \& Becker, 2010.

\subsubsection{Enfermedad de Parkinson (EP)}

Es una enfermedad neurodegenerativa caracterizada por tremor, resultado de la contracción alternativa de agonistas y antagonistas, que resulta más visible cuando los miembros están en reposo; resistencia a movimientos pasivos y movimientos bruscos denominados rueda dentada, bradiquinesia o dificultad para iniciar movimientos y enlentecimiento (falta de contoneo en los brazos al caminar); alteraciones posturales como posición encorvada, brazos flexionados y 
pérdida de expresividad en la cara. Además del Parkinson primario, el más frecuente en la práctica clínica, existen otros que reciben su nombre según la etiología asociada. Por ejemplo, el Parkinson postencefálico se originó con la aparición del virus encefalitis a principios del siglo $\mathrm{XX}$, que afectó a los núcleos basales. El denominado Parkinson iatrogénico sería un efecto secundario de fármacos antipsicóticos que bloquean los receptores dopaminérgicos estriados denominados D2.

El Parkinson primario representa el $85 \%$ de los casos de Parkinson, aproximadamente, y se asocia con la afectación de los núcleos basales, en concreto, los síntomas más característicos son resultado de la disminución de la actividad de las neuronas dopaminérgicas por muerte neuronal en la sustancia negra y cuerpo estriado, según los resultados de estudios PET estriado (Eidelberg \& Edwards, 2000; Obeso, Rodríguez-Oroz, Marín, Alonso, Zamarbide, Lanciego, \& Rodríguez Díaz, 2004; Berg, Merz, Reiners, Naumann, \& Becker, 2005; Piccini \& Brooks, 2006; Obeso, Rodríguez-Oroz, Benitez-Temino, Belsa, Guridi, Marin, \& Rodríguez, 2008; Sharma \& Ebadi, 2008; Janke, 2009; Jubault, Brambati, Degroot, Kullmann, \& Strafella, 2009; Pavase \& Brooks, 2009; Bronstein et al., 2010). Otros datos que avalan la implicación de estas estructuras son la mejora en el funcionamiento motor en pacientes con EP después del transplante de neuronas dopaminérgicas en el núcleo caudado y núcleo putamen (Olanow, 2004), junto a la reducción de signos parkinsonianos después de una palidotomía (Yu \& Neimat, 2008).

Finalmente, estudios recientes apoyan la implicación del núcleo subtalámico directa o indirectamente (Visser-Vandewalle, van der Linden, Temel, Celik, Ackermans, Spincemaille, \& Caemaert, 2005; Anatonelli, Ray, \& Strafella, 2010; Chereau, De Chazeron, Rieu, Derost, Lemaire, \& Durif, 2010; Feher et al., 2010; Wylie et al., 2010; Boon, Dandachi-FitzGerald, Dutis, Temel, Visser-Vandewalle, \& van den Hout, 2011; Rodríguez-Oroz et al., 2011).

\subsubsection{Esclerosis Múltiple (EM)}

La EM se ha convertido en una de las enfermedades del SNC con mayor incidencia y causa de discapacidad en adultos jóvenes, especialmente, en Europa y Norte América (Warren \& Warren, 2001).

Esta enfermedad cursa con la progresiva desmielinización de la sustancia blanca del SNC, por lo que se considera una enfermedad degenerativa. Desde el punto de vista etiológico, es una enfermedad infeccioso-inflamatoria, al surgir como resultado de la interacción entre una infección vírica y la respuesta autoinmune del individuo. La inflamación y desmielinización consecuente a la infección, provocarían la reducción de la velocidad del potencial de acción y, finalmente, su bloqueo (Frohman, Racke, \& Raine, 2006; Charil \& Filippi, 2007; Lassmann, Bruck, \& Lucchinetti, 2007; Lisak, 2007).

Dentro de las manifestaciones clínicas, destacan la aparición de pérdida visual, trastornos de los movimientos oculares, parestesias, pérdida de sensibilidad, debilidad, disartria, 
espasticidad, ataxia... El patrón más frecuente consiste en la presencia de ataques recurrentes seguidos por un periodo de recuperación parcial (EM, recaída-remisión), pero también puede presentarse de forma aguda y crónica progresiva (EM progresiva).

Las técnicas de diagnóstico por imagen morfológicas han jugado un papel clave a la hora de conocer la distribución topográfica de las lesiones o regiones inflamadas, donde se forman las placas escleróticas. En concreto, la RM DTI podría considerarse la técnica de referencia para el diagnóstico (Polman, Wolinsky, \& Reingold, 2005) y el estudio de su evolución temporal y espacial en EM (Bakshi, 2005; Besada, Funes, Sinay, \& Santa Cruz, 2005; Zivadinov \& Cox, 2007; Rashid \& Miller, 2008). Según los resultados del estudio desarrollado por el Center for Neurological Imaging $(C N I)$ de Harvard en 50 pacientes con EM, cuya evolución se monitorizó durante años, las lesiones aparecen como luminiscentes en RM (Meier \& Guttmann, 2006).

Sin embargo, no sólo se han encontrado placas en la sustancia blanca, sino también en la sustancia gris, aumentando la diversidad de las presentaciones clínicas y el deterioro cognitivo asociado (Besada et al., 2005; Ghaffar, \& Feinstein, 2007; Rashid, \& Miller, 2008). Entre las estructuras frecuentemente implicadas a la EM, según la literatura revisada, destacan el tálamo (Ghaffar \& Feinstein, 2007; Rashid \& Miller, 2008; Trovar-Moll et al., 2009; Rocca, Mesaros, Pagani, Sormani, Comi, \& Fillippi, 2010; Yokoyama, Hasegawa, \& Yagishita, 2010; Zhou, Zee, Gong, Shiroishi, \& Li, 2010), cuya estimulación disminuye el tremor (Schulder, Sernas, \& Karimi, 2003; Rashid \& Miller, 2008; Moore, Vitali, Leung, Laule, Kozlowski, MacKay, \& Honey, 2009) y el cuerpo estriado (Calabrese et al. 2010; Paseve, Metta, Bose, Chaudhuri, \& Brooks, 2010; Yokoyama et al.2010).

En la Figura 1.10 se incluyen imágenes RM correspondientes a la evolución de un caso de EM progresiva, donde resulta difícil identificar las estructuras concretas afectadas.

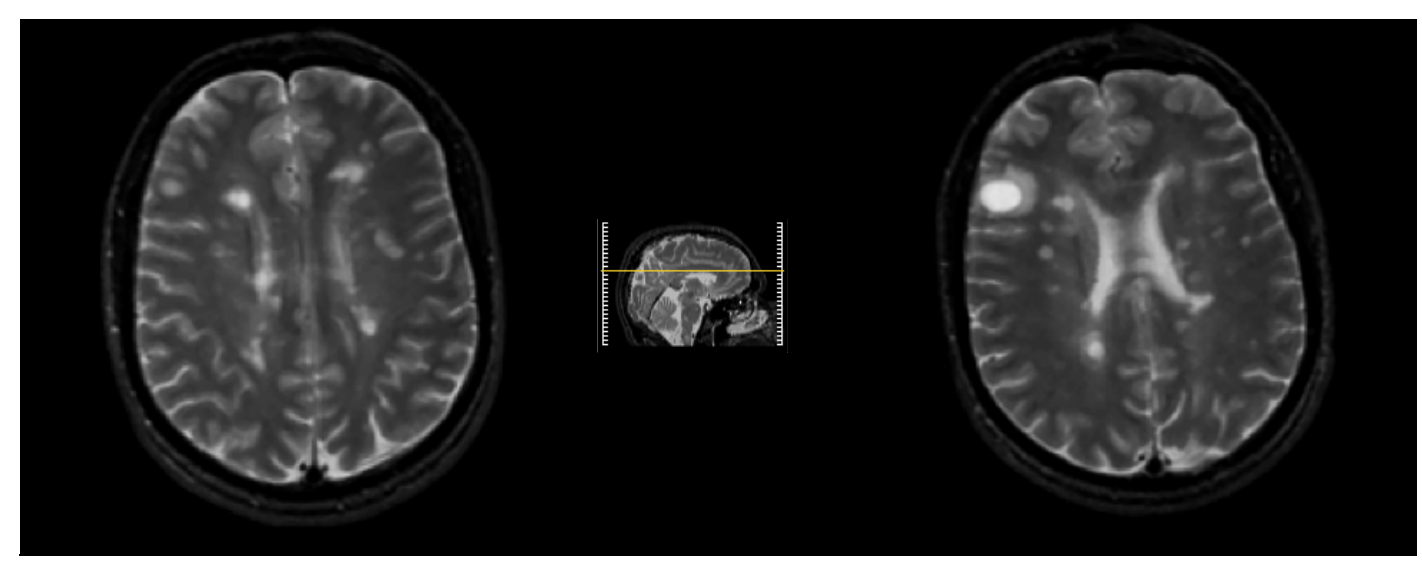

Figura 1.10. Esclerosis Múltiple (EM): RM T2. Se observan lesiones de diferente tamaño en el lóbulo frontal derecho (imagen izquierda) y la evolución tres semanas después (imagen derecha) donde se observa una señal de alta intensidad (blanco) alrededor de la lesión. Fuente: Johson y Becker, 2010. 


\subsubsection{Trastorno de Epilepsia}

La epilepsia afecta a 50 millones de personas en todo el mundo, tanto hombres como mujeres de todas la edades, y se considera una de las enfermedades neurológicas más frecuentes (Kotsopoulos, van Merode, Kessels, de Kron, \& Knottnerus, 2002; Forsgren, Beghi, Oun, \& Sillanpää, 2005).

Las crisis epilépticas y, por extensión, los trastornos por epilepsia, suponen la alteración espontánea y transitoria del gradiente eléctrico del encéfalo, definido por una alta concentración de $\mathrm{K}+$ intracelular y $\mathrm{Na}+$ extracelular, con un potencial de memoria de descanso del orden de -60 $\mathrm{mV}$, y un potencial de acción de forma natural si el diferencial se despolariza y alcanza -50 ó -40 $\mathrm{mV}$. Las crisis se caracterizan por una hiperexcitabilidad sincrónica de la actividad eléctrica de un grupo de neuronas, cuya etiología, prácticamente, se desconoce en la mitad de los casos.

Según la International League Against Epilepsy (ILAE), las crisis epilépticas pueden clasificarse según área afectada por la alteración eléctrica en: crisis focales o parciales, ausencias o petit mal y crisis generalizadas tónico-clónicas o grand mal (Fisher, Van Emde Boas, Blume, Elger, Genton, Lee, y Engel, 2005; Engel, 2006) y que suelen estar precedidas por lesiones en estructuras encefálicas, infecciones o enfermedades degenerativas.

$\mathrm{Si}$ asumimos que las crisis epilépticas son un síntoma de un trastorno subyacente en determinadas estructuras encefálicas, la localización precisa del foco epileptógeno facilitará su tratamiento y ayudará a prevenir mayores lesiones en las estructuras afectadas. Especialmente, en el caso de pacientes que no responden a la medicación, donde la cirugía puede ser la única solución, extirpando la parte del encéfalo responsable de las crisis epilépticas (Wetjen, CohenGadol, Maher, Marsh, Meyer, \& Cascino, 2002; Kellinghaus, \& Luders, 2004).

La técnica de preferencia, hasta la fecha, ha sido el análisis de los registros EEG asociados con presencia de crisis. La ventaja de esta técnica, junto con el MEG, frente a las técnicas de neuroimagen, es su resolución temporal por debajo de $1 \mathrm{~ms}$. El EEG tiene la ventaja de ofrecer registros de video EEG a largo plazo, incluyendo todos los periodos de ciclos de vigilia y sueño. Tanto las localizaciones mostradas por el EEG como por el MEG, muestran un alto grado de concordancia con registros eléctricos invasivos, lo que clarifica la relación espacial entre la zona irritativa y las lesiones estructurales (Barkley \& Baumgartner, 2003). Sin embargo, se requieren técnicas de neuroimagen como RM para visualizar las estructuras encefálicas afectadas (Bonilha, Montenegro, Cendes, \& Li, 2004).

Las técnicas funcionales PET y SPECT han permitido estudiar uno de los rasgos característicos del trastorno de epilepsia, el cambio en el metabolismo de glucosa en una determinada área durante el periodo ictal e interictal. Tanto PET como SPECT, pueden emplearse para estudiar anormalidades interictales, aunque la SPECT es más fácil de administrar durante crisis epilépticas, preparando el radiomarcador mientras el sujeto está siendo monitorizado e inyectarlo tan pronto como el ataque comience. 
Los estudios PET han mostrado mayor sensibilidad para el diagnóstico de la Epilepsia del Lóbulo Termporal (ELT), por lesión del hipocampo, y los SPECT para Epilepsia Extratemporal (EET) (Lado, Laureta, \& Moshe, 2002; Bonilha et al., 2004; Powell, Koepp, Richardson, Symms, Thompson, \& Duncan, 2004).

\subsubsection{Trastornos cerebrovasculares (ACV)}

El correcto funcionamiento de las estructuras encefálicas, y por extensión, de las funciones cognitivas en que participan, es extremadamente vulnerable a las alteraciones del riego sanguíneo. Por lo tanto, la importancia clínica de la vascularización cerebral se hace evidente.

Los trastornos vasculares comprenden lesiones del SNC provocadas por isquemias, generalmente, o por hemorragias. Las funciones cognitivas afectadas dependerán del tamaño de la arteria ocluida, el estado de anastomosis colateral y las estructuras encefálicas afectadas (Del Zoppo, 2006; Valencia-Calderón, Calderón-Valdiviezo, Muntané-Sánchez, Bechich, OliveróRigau, \& Segura-Cros, 2009).

Las lesiones vasculares podrían acelerar el comienzo de síntomas clínicamente significativos en personas con EA, lo que difumina la distinción tradicional entre EA y DV y concuerda con la alta prevalencia de patologías mixtas (World Health Organization [WHO], 2006).

Los ACVs pueden deberse a enfermedades que provocan alteraciones en la presión sanguínea como hipertensión, enfermedades de las paredes de las arterias o enfermedades que provocan la obstrucción de la luz arterial, como la formación de placas ateroescleróticas. Un angiograma permitiría el estudio de las arterias y un venograma el de las venas.

La patología isquémica más frecuente es por oclusión de la ACM, cuyas ramas penetrantes irrigan el tálamo, una de las estructuras con mayor variedad de efectos cognitivos y conductuales (Carrera \& Bogousslavsky, 2006). También son frecuentes las microlesiones en los núcleos basales por infartos cerebrales (denominados silenciosos), que afectan a entre un 5\% y $10 \%$ de los adultos aparentemente sanos (Das et al., 2008).

En la Figura 1.11 se ilustra un ejemplo de ACV isquémico que afecta a la ACM derecha. Corresponde a una mujer de 45 años que experimentó debilidad en el lado derecho del cuerpo y problemas para el habla de forma repentina. Como en casos anteriores, resulta difícil apreciar las estructuras encefálicas afectadas a partir de la interpretación de neuroimágenes convencionales 2D. 


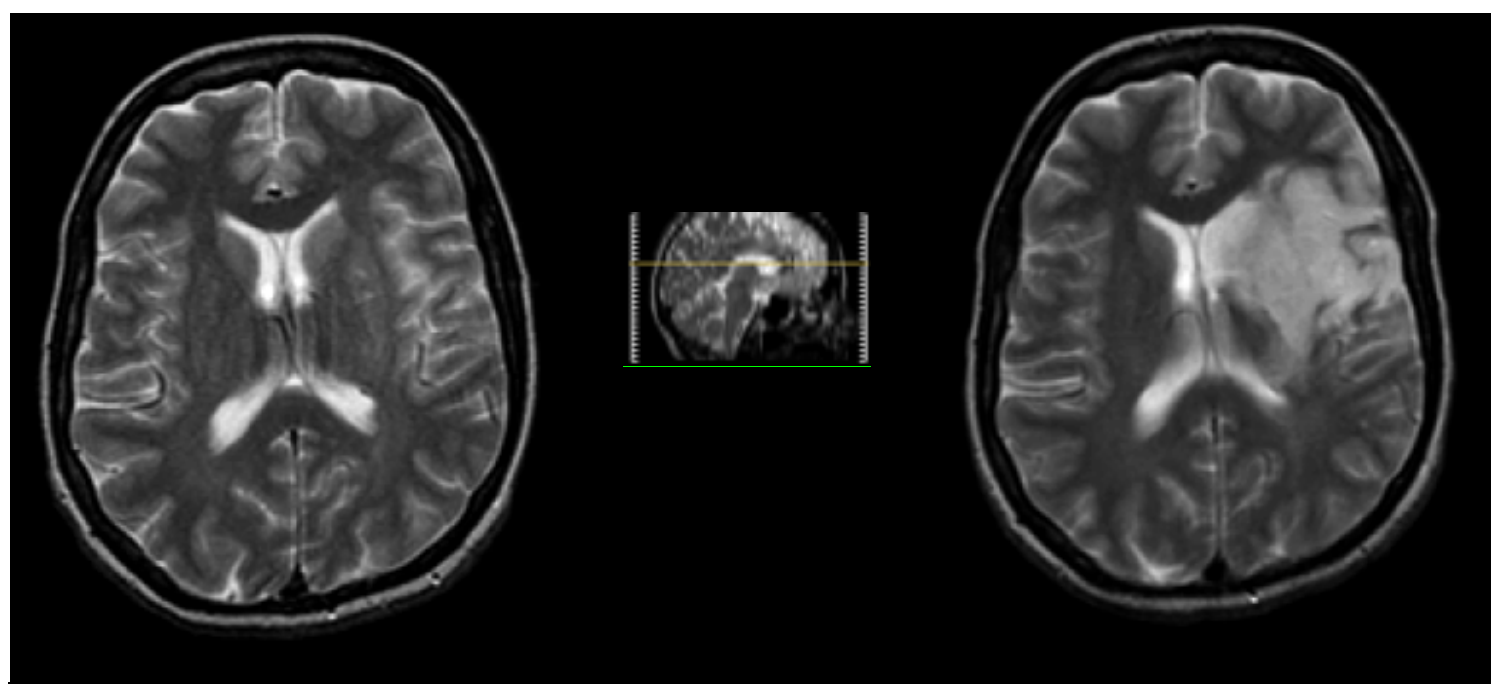

Figura 1.11. ACV isquémico agudo de la arteria cerebral media: RM T2 obtenida 8 horas (imagen izquierda) y 4 semanas después del comienzo de los síntomas (imagen derecha). Fuente Johnson y Becker, 2010.

Los ACV de tipo hemorrágico pueden originarse, no sólo como resultado de lesiones vasculares, frecuentemente asociadas a casos de hipertensión o aneurismas, sino también como resultado de TCE. Las técnicas de diagnóstico por imagen permiten la correcta identificación de la hemorragia (epidural, subdural o subaracnoidea), vasos afectados, generalmente la ACM, y patología subyacente (aneurisma, neoplasia, infarto...) como paso previo al tratamiento (Snell, 2009). En las dos últimas décadas, la RM y la PET se han convertido en herramientas indispensables en el diagnóstico de ACVs y están sustituyendo a la angiografía cerebral al permitir realizar el diagnóstico de forma más rápida, precisa y segura (Mungas et al., 2002).

La Figura 1.12 ilustra un caso de ACV hemorrágico correspondiente a una mujer de 49 años con historia de hipertensión $(240 / 130 \mathrm{mmHg})$ y diabetes mellitus que experimentó entumecimiento y hormigueo repentinos en la pierna izquierda.

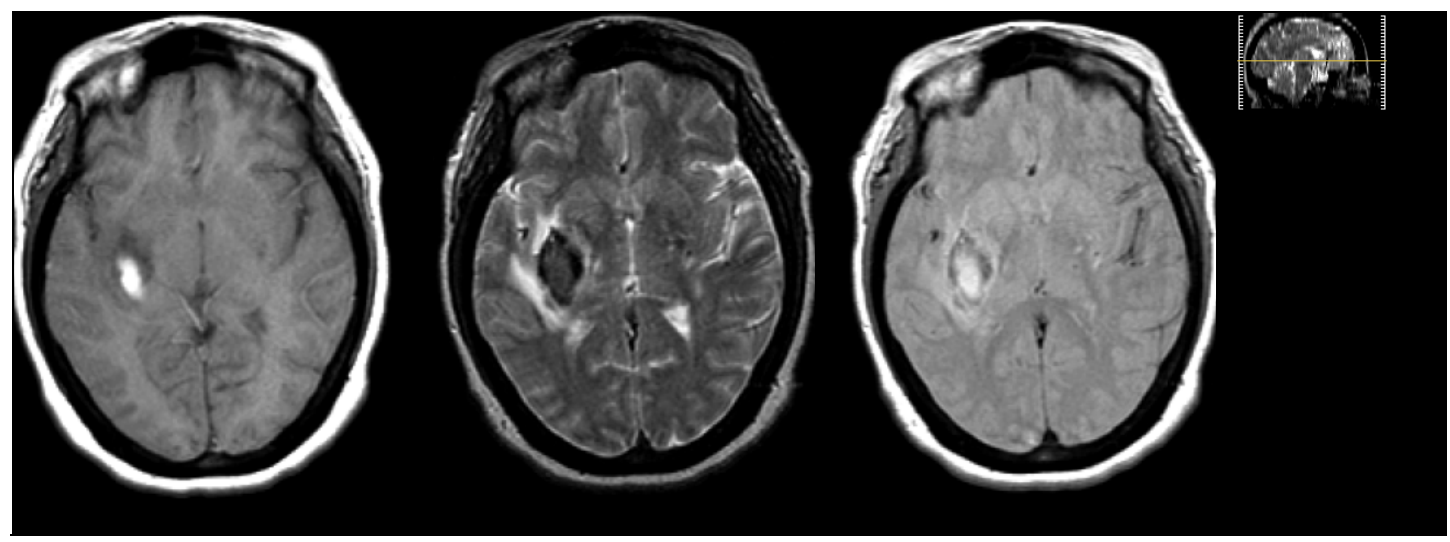

Figura 1.12. Hemorragia cerebral: RM T1 (imagen izquierda), RM T2 (imagen media) y RM DP (imagen inferior). Se aprecia la dificultad inherente a la localización de las estructuras encefálicas afectadas. Fuente: Johnson \& Becker, 2010. 


\subsubsection{Traumatismos cráneo encefálicos (TCE)}

Los TCE comprenden lesiones provocadas por acción mecánica externa sobre el cráneo, siendo las causas más frecuentes: accidentes de tráfico, deportivos, asaltos, etc. Las lesiones afectan a estructuras internas del encéfalo, pares craneales, meninges... y pueden clasificarse, principalmente, en penetrantes, o no y si existe una hemorragia asociada, o no.

Como ocurría en el caso de los trastornos vasculares, las manifestaciones clínicas dependerán de las características de la lesión. Lesiones difusas suelen estar asociadas con coma, mientras que lesiones más localizadas pueden estar asociadas con alteraciones neuropsicológicas, incluyendo déficits neurológicos focales y alteraciones psiquiátricas. Una de las manifestaciones más frecuentes es la aparición prematura de enfermedades neurológicas como EA y EP (Kiral \& Kiraly, 2007) y trastornos psiquiátricos, especialmente, el TDM (Koponer et al., 2002; Sudarsanan, Chaudhary, Pawar, \& Srivastava, 2007).

En un estudio con 120 pacientes adultos con TCE, el 21,7\% sufrieron un trastorno psiquiátrico (frente al $16.4 \%$ de la población general), siendo el Trastorno Depresivo Mayor el más prevalente con un 13,9\% (en comparación con el 0,8\% de la población) (Deb, Lyons, Koutzoukis, Ali, \& McCarthy, 1999). Consistentemente, otro estudio con pacientes de similares características encontró que el TDM también fue el más frecuente (26,7\% de los pacientes) (Koponer et al., 2002).

En estudios más recientes, se han documentado casos de pseudopsicopatía, en forma de desinhibición, conducta antisocial e impulsividad, y pseudodepresión con lesiones prefrontales; agresividad y sexualidad alterada, con lesiones de la amígdala; y trastornos del estado de ánimo asociados a lesiones en estructuras fronto-temporales (Sudarsanan et al., 2007).

\subsubsection{Tumores cerebrales}

Los tumores cerebrales son neoplasias que afectan a algún componente intracraneal del encéfalo, incluyendo los hemisferios cerebrales, núcleos basales, hipotálamo, tálamo, tronco encefálico y cerebelo. Estas masas se pueden clasificar en primarias, originadas a partir del crecimiento incontrolado de un órgano o tejido encefálico como el tejido linfático, células gliales, vasos sanguíneos, glándula pituitaria, glándula pineal y cráneo; o secundarias, por metástasis.

Se trata de una de las alteraciones más frecuentes que afectan a la morfología y funcionalidad de las estructuras encefálicas, por lo que su diagnóstico y tratamiento son de vital importancia. De nuevo, los efectos neuropsicológicos dependerán de la localización y grado de afectación neuronal por el blastoma (Doolittle, 2004). Una de las dificultades asociadas a la identificación de estructuras encefálicas afectadas por los tumores se debe, generalmente, a que 
cada tumor primario, además de la porción sólida del tumor, viene acompañado del edema o aumento en el volumen del encéfalo, además de la necrosis en el interior del tumor.

Los tumores cerebrales se puede clasificar, principalmente, según el tejido implicado, el lugar del tumor y su grado de malignidad. Sin embargo, se ha desarrollado una nueva clasificación, en base a la apariencia de estos tumores en RM T1, considerándolo el principal parámetro para establecer la malignidad de un tumor primario si no consideramos aspectos histológicos (Khotanlou, 2008). Las cuatro categorías de esta clasificación son: no potenciados por contraste (aparecen hipodensos en RM T1), completamente potenciados con contraste sin edema (aparecen hipodensos en RM T1 e hiperdensos en RM T2), completamente potenciados con contraste con edema y la parte sólida hiperdensa en RM T1 (las dos partes hiperdensas en RM T2) y tumores potenciados con contraste en anillo (la necrosis central aparece hipodensa en T1 y la parte sólida que lo rodea aparece hiperdensa en T1, en RM T2 ambas aparecen hipodensas) (Khotanlou, 2008).

La RM es el método de diagnóstico por imagen de preferencia en neurooncología para la evaluación y seguimiento de pacientes con tumores cerebrales, porque no emplea radiación ionizante y, como hemos visto, ofrece una mejor resolución de contraste para la detección de pequeñas masas. El principal problema es la falta de especificidad de zonas hipodensas en RM T1 e hiperdensas en RM T2. Por ejemplo, los daños por radiación, incluyendo necrosis, son indiferenciables de la reaparición de un tumor. Así que, no se puede emplear sólo RM para comprobar si el tumor está reapariciendo o no, después de radioterapia. Además, las imágenes RM por sí solas, tampoco permiten distinguir la extensión exacta de un tumor como hemos señalado anteriormente.

Las técnicas funcionales permiten visualizar la fijación de determinados fármacos marcados con isótopos radioactivos a estructuras encefálicas afectadas, localizando con precisión áreas diana sobre las que dirigir dosis altas de radiación de forma selectiva en radioterapia.

En la Figura 1.13 se ilustra un caso de astrocitoma de grado IV detectado tras una biopsia posterior a una crisis epiléptica tónico-clónica en un sujeto de 53 años. Las secciones RM y PET, incluso en registro, resultan insuficientes para identificar con precisión las estructuras afectadas en este caso. 


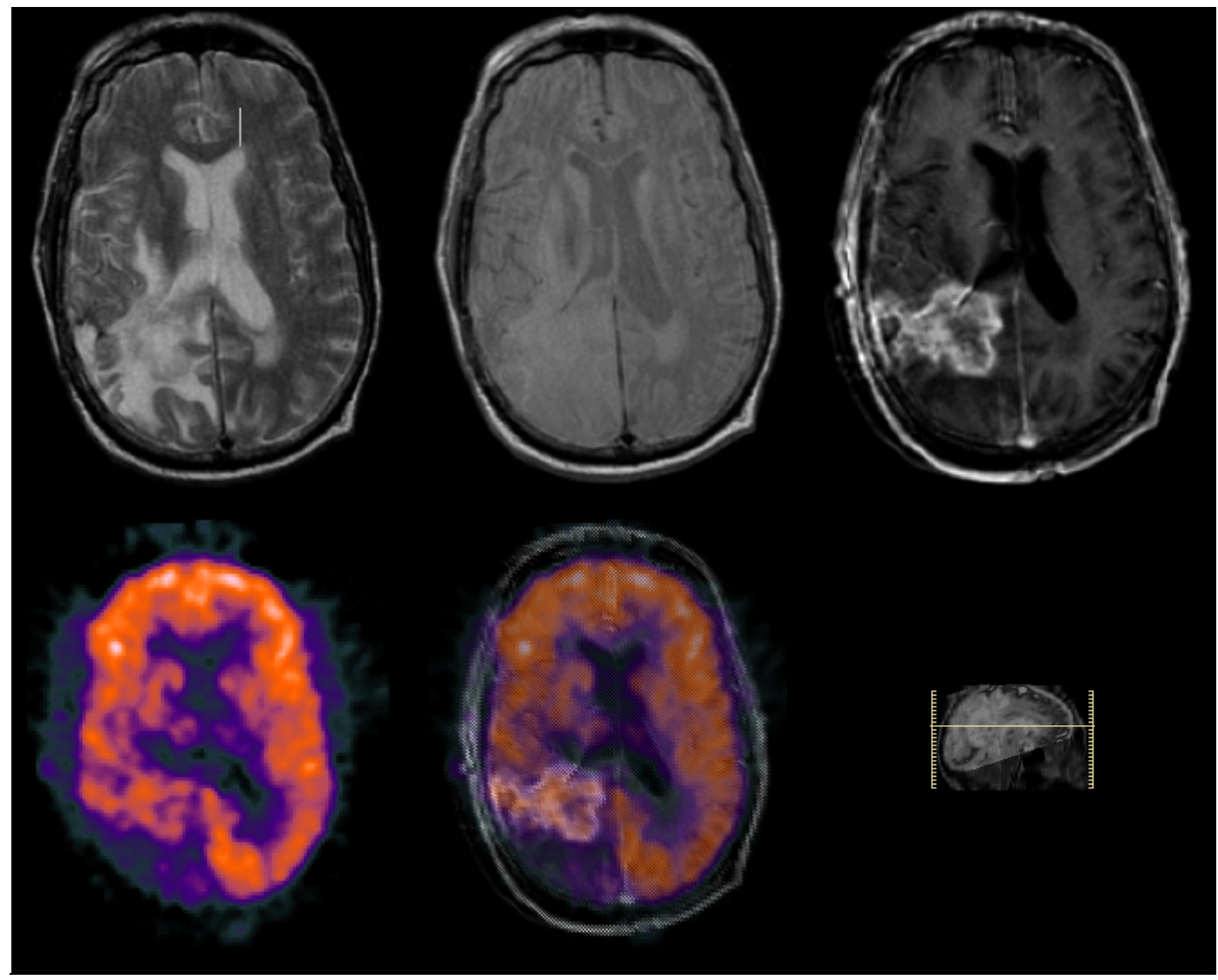

Figura 1.13 Astrocitoma en la región parieto-occipital: RM T2 (imagen superior iquierda), RM DP (imagen superior media), RM Gd. (imagen superior derecha), PET ${ }^{18} \mathrm{~F}-\mathrm{FDG}$ (imagen inferior izquierda) y RM Gad superpuesta con PET ${ }^{18}$ F-FDG (imagen inferior media). Fuente: Johnson \& Becker, 2010.

\subsubsection{Trastornos psiquiátricos}

Según expresó Philip Campbell, editor de la revista Nature, en la primera publicación de 2010, el periodo comprendido entre 2010 y 2019 será la "década de los trastornos psiquiátricos". Los motivos que justificaron su predicción no han tenido que ver con el aumento en su prevalencia, significativamente alta actualmente, ni por la aparición de nuevos trastornos, que seguirá aumentando si consideramos la trayectoria del DSM; sino por la importancia de las aportaciones derivadas de las neurociencias, especialmente desde la neuroimagen, que transformarán nuestra comprensión de estos trastornos $\mathrm{y}$, por extensión, la práctica de la Psiquiatría y Psicología Clínica (Campbell, 2010; Insel \& Wang, 2010).

Consistentemente, en mayo de 2010, la revista Journal of the American Medical Association dedicó un número al tema de salud mental y trastornos mentales (Glass, 2010) y en noviembre de 2010, la revista Nature se dedicó a la Esquizofrenia, el trastorno psiquiátrico por excelencia (Editorial, 2010).

Otros trastornos psiquiátricos como los relacionados con problemas de ansiedad y del estado de ánimo son igualmente importantes. Actualmente, se considera que éstas son las 
condiciones psiquiátricas que provocan un mayor grado de aflicción o "miseria" en la vida del paciente, superando incluso a los casos de Esquizofrenia (Arehart-Treichel, 2011).

A continuación, se presenta, de forma sintética, una descripción de las estructuras encefálicas implicadas en éstos y otros trastornos psiquiátricos incluidos en el DSM IV-TR, en base a los resultados de la literatura revisada, y donde los estudios de diagnóstico por imagen han sido una herramienta fundamental: Autismo, Esquizofrenia, TEPT, AN, TDM, TB, TOC y TDAH.

\subsubsection{Autismo}

Los tres síntomas característicos del Autismo son: las dificultades en la interacciones sociales, las dificultades de comunicación verbal y no verbal y los comportamientos repetitivos y estereotipados (American Psychiatric Association, 2000). Estos síntomas se han asociado con alteraciones en las siguientes estructuras encefálicas:

El CPF, en concreto, el GCA juega un papel importante en la regulación emocional (empatía), como la percepción/expresión de emociones, necesarias para el adecuado funcionamiento en contextos sociales. Consistentemente, se ha encontrado hipoactivación de esta estructura en sujetos autistas en comparación con controles (Dapretto, Davies, Pfeifer, Scott, Sigman, Bookheimer, \& Iacoboni, 2006; Thakkar, Polli, Joseph, Tuch, Hadjikhani, Barton, \& Manoach, 2008; Di Martino, Ross, Uddin, Sklar, Castellanos, \& Milham, 2009; Agam, Joseph, Barton, \& Manoach, 2010; Chan, Han, Leung, Leung, Wong, \& Cheung, 2011).

Otra estructura especialmente relevante en contextos sociales es la amígdala, también denominada "cerebro social" (Adolphs, 2001; Amaral, Capitanio, Jourdain, Mason, Mendoza, \& Prather, 2003; Schumann et al., 2004; Schultz, 2005; Schumann, \& Amaral, 2006; Skuse, 2006; Ulay \& Ertugrul, 2009; Dziobek, Bahnemann, Convit, \& Heekeren, 2010; Green, \& Ben-Sasson, 2010; Neuhaus, Beauchaine, \& Bernier, 2010; Kim, Lyoo, Estes, \& Renshaw, 2010; Kleinhans, Richards, Weaver, Johnson, Greenson, Dawson, \& Aylward, 2010; Monk et al., 2010), cuyas alteraciones contribuyen a la predicción de la gravedad y evolución de este trastorno (Amaral, 2002; Schultz, 2005; Munson et al., 2006; Skuse, 2006; Arehart-Treichel, 2007; Amaral \& Corbett, 2008; Blair, 2008; Brun et al., 2009; Mosconi, Cody-Hazlett, Poe, Gerig, Gimpel-Smith, \& Piven, 2009; Verhoeven, De Cock, Lagae, \& Sunaert, 2010). En concreto, estudios volumétricos han encontrado que un alargamiento bilateral de la amígdala durante la infancia, especialmente derecha, correlaciona con la severidad de los síntomas (Sparks et al. 2002; Schumann et al., 2004; Munson et al., 2006).

Paralelamente, se han encontrado alteraciones en el cuerpo estriado, especialmente, el núcleo caudado (Stanfield, McIntosh, Spencer, Philip, Gaur, \& Lawrie, 2008; Brun et al., 2009; Langen, Schnack, Nederveen, Bos, de Jonge, van Engeland, \& Durston, 2009; Qiu, Adler, 
Crocetti, Miller, \& Mostofsky, 2010; Verhoeven et al., 2010) y el tálamo (Brun et al., 2009; Tamura, Kitamura, Hasegawa, \& Someya, 2010; Verhoeven et al., 2010)

En cuanto a las alteraciones que afectan a la sustancia blanca, varios estudios han hallado una significativa reducción del volumen del cuerpo calloso (Kilian et al., 2008; Stanfield, McIntosh, Spencer, Philip, Gaur, \& Lawrie, 2008; Casanova et al., 2009; Brun et al., 2010; Noriuchi, et al., 2010; Verhoeven et al., 2010).

Finalmente, otros estudios han propuesto diferencias que afectan al cerebelo (Petropoulos, Friedman, Shaw, Artru, Dawson, \& Dager, 2006), un alargamiento general del encéfalo (Redcay \& Courchesne, 2005; Stanfield et al., 2008), aumento del grosor del córtex (Hardan, Muddasani, Vemulapalli, Keshavan, \& Minshew, 2006), la ínsula (Uddin \& Menon, 2009) y alteraciones en el tronco encefálico (Rodier, 2002).

\subsubsection{Esquizofrenia}

La Esquizofrenia es un trastorno caracterizado por la presencia de síntomas clasificados en positivos y negativos. Los primeros se refieren a la presencia exagerada de procesos cognitivos, incluyendo pensamientos distorsionados, alucinaciones e ideas paranoides. Los segundos, a la ausencia de emociones o emocionalidad plana (American Psychiatric Association, 2000).

Es la condición psiquiátrica que ha recibido mayor número de investigaciones dirigidas al estudio de su base neuroanatómica, y actualmente, se considera una alteración bien establecida, al igual que la implicación de alteraciones volumétricas y/o funcionales de diferentes estructuras encefálicas (Wright, Rabe-Hesketh, Woodruff, David, Murray, \& Bullmore, 2000; Antonova, Sharma, Morris, \& Kumari, 2004; Lawrie, McIntosh, Hall, Owens, \& Johnstone, 2008).

El descubrimiento del alargamiento de los VL en pacientes esquizofrénicos hace más de 30 años (Johnstone, Crow, Frith, Husband, \& Kreel, 1976) sirvió para ilustrar, por primera vez, la base física de un trastorno mental, consitituyendo un punto de inflexión en neurociencias. En los últimos años numerosos estudios han encontrado alteraciones volumétricas en los VL (Antonova, Sharma, Morris, \& Kumari, 2004; DeLisi, Sakuma, Maurizio, Reija, \& Hoff, 2004; Strasser et al., 2005; McDonald et al., 2006; Lawrie, McIntosh, Hall, Owens, \& Johnstone, 2008; Pol et al., 2008; Czechowska et al. 2009; Wexler et al., 2009; Rosa et al., 2010; Kempton, Stahl, Williams, $\&$ De Lisi, 2010; Puri 2010; Tanskanen et al., 2010).

Sin embargo, actualmente se considera que el CPF es el área afectada de forma más consistente, según los resultados obtenidos a partir de estudios PET que han encontrado una disminución de la activación de dicha región, en comparación con sujetos control. En concreto, la esquizofrenia se ha asociado con una reducción en el FSCr en tareas como la Tarea de Clasificación de Tarjetas de Wisconsin, con un fuerte componente atencional, coherente con un 
patrón de hipoprefrontalidad localizado en esta región del CPF-DL (activada en sujetos sanos para realizar esta tarea) y coherente con la participación de esta área en procesos ejecutivos, memoria de trabajo y planificación del comportamiento futuro (Callicott, Bertolino, Mattay, Langheim, Duynl, Coppola, \& Goldberg, 2000; Riehemann, Volz, Stutzer, Smesny, Gaser, \& Sauer, 2001; Bunney, Bunney, Stein, \& Potkin, 2003; Heinz, Braus, Romero, Gallinat, Puls, Juckel, \& Weinberg, 2004; Hill, Mann, Laws, Stephenson, Nimmo-Smith, \& McKenna, 2004; Hulshoff Pol et al., 2004; Hulshoff Pol et al., 2006; Iritani, 2007; McDonald, Thermenos, Barch, \& Seidman, 2009; Kalus, Falkai, \& Heinz, 2008; Kéri, 2008; Lawrie et al., 2008; Venkatasubramanian, Jayakumar, Gangadhar, \& Keshava, 2008; Fornito, Yücel, \& Pantelis, 2009; Kawada et al., 2009; Ragland, Laird, Ranganath, Blumenfeld, Gonzales, \& Glahn, 2009; Farzan, Barr, Levinson, Chen, Wong, Fitzgerald, \& Daskalakis, 2010; Patel, Vyas, Puri, Nijran, \& Al-Nahhas, 2010; Rosso et al., 2010; Zavitsanou \& Dalton, 2010; Heinz, Braus, Romero, Gallinat, Puls, Lesh, Niendam, Minzenberg, \& Carter, 2011; Lesh, Niendam, Minzenberg, \& Carter, 2011). Este hallazgo es coherente con la reducción del volumen del CPF-DL encontrado por estudios volumétricos (Niznikiewicz, Kubicki, \& Shenton, 2003; Antonova et al., 2004; Pearlson, \& Calhoun, 2007; Fung, Sivagnanasndaram, \& Weickert, 2010; Sismanlar, Anik, Coskun, Agaoglu, Karakaya, \& Yavuz, 2010).

Paralelamente, se han encontrado alteraciones, principalmente, en dos áreas límbicas: la región anterior del giro cingulado (Yücel et al., 2003; Haznedar, Buchsbaum, Hazletta, Shihabuddina, Newa, \& Sievera, 2004; Fujiwara, Hirao, Namiki, Yamada, Shimizu, Fukuyama, Hayashi, \& Murai, 2007; Fornito, Yücel, Dean, Wood, \& Pantelis, 2009; Costain, Crawley, Mikulis, Brzustowicz, Chow, \& Bassett, 2010; Ellison-Wright, \& Bullmore, 2010; Jung, Jang, Byun, An, \& Kwon, 2010; Smieskova et al., 2010; White, Joseph, Francis, \& Liddle, 2010) y el hipocampo, relacionado con el procesamiento de características contextuales de los estímulos o eventos emocionalmente importantes (Williams, Das et al., 2004) y, por extensión, en la percepción de amenazas o peligros potenciales en lugares o contextos inapropiados (Seidman et al., 2003; Niznikiewicz et al., 2003; Antonova et al., 2004; Achim \& Lepage, 2005; Honea, Crow, Passingham, \& Mackay, 2005; Strasser et al., 2005; Iritani, 2007; Kalus et al., 2008; McDonald et al., 2009; Hall et al., 2010; Javadapour, Malhi, Ivanovski, Chen, Wen, \& Sachdev, 2010; Mamah, Wang, Csernansky, Rice, Smith, \& Barch, 2010; Rimol et al., 2010; Sismanlar et al., 2010; Koolschijn et al., 2010; Witthaus et al., 2010).

Los recientes estudios de RM DTI han sugerido la afectación de la conexión entre éstas estructuras temporales, como el hipocampo, y prefrontales, como el CPF-DL (Niznikiewicz et al., 2003; Buchsbaum et al., 2006; Meyer-Lindenberg, Olsen, Kohn, Brown, Egan, Weinberger, \& Berman, 2005). En concreto, se ha encontrado una reducción del volumen en la parte anterior del cuerpo calloso (Burns, Job, Bastin, Whalley, Macgillivray, Johnstone, \& Lawrie, 2003; Niznikiewicz et al., 2003; Buchsbaum et al., 2005; Kubicki, Westin, McCarley, \& 
Shenton, 2005; Meyer-Lindenberg et al., 2005; Stephan, Baldeweg, \& Friston, 2006; Uchino, Takase, Nomiyama, Egashira, \& Kudo, 2006; Kubicki et al., 2007; Szeszko et al., 2008; Walterfang et al., 2008; Puri, 2010).

En cuanto a la implicación de los núcleos basales, se han descubierto alteraciones especialmente en el núcleo putamen (Mitelman, Canfield, Chu, Brickman, Shihabuddin, Hazlett, \& Buchsbaum, 2009) y el núcleo caudado. Personas diagnosticadas de trastorno de personalidad esquizotípica han mostrado alteraciones en el volumen y forma global de este núcleo (Levitt et al., 2009). Varios estudios PET también han encontrado un aumento de la densidad de receptores dopaminérgicos $\mathrm{D}_{2}$ estriados y disminución de la densidad de receptores $\mathrm{D}_{1}$ corticales y de la transmisión glutamatérgica (Frankle \& Laruelle, 2002; Abi-Dargham \& Laruelle, 2005; Frankle, 2007).

También se ha hallado una significativa reducción del volumen del tálamo que correlaciona con las habilidades lingüisticas y ejecutivas (Clinton \& Meador-Woodruff, 2004; Coscia et al., 2009; Qui, Zhong, Graham, Chia, \& Sim, 2009; Ellison-Wright \& Bullmore, 2010; Moghaddam, 2010) y apoya la concepción de la Esquizofrenia o su sintomatología como "dismetría cognitiva", caracterizada por alteraciones en la coordinación de la percepción, codificación, recuerdo y priorización de la experiencia e información (Clinton \& MeadorWoodruff, 2004; Qui et al., 2009).

\subsubsection{Trastorno de Estrés Postraumático (TEPT)}

Varios estudios de neuroimagen dirigidos a encontrar las bases neuroanatómicas de la experiencia de ansiedad y sus trastornos, tales como el TEPT, han propuesto la amígdala como la estructura encefálica más relevante (Amaral, 2002; Das et al. 2005; Deckersbach, Dougherty, \& Rauch, 2006; Crespo-Facorro et al., 2007; Brewin, 2008; Byne, Hazlett, Buchsbaum, \& Kemether, 2009; Shin \& Liberzon, 2010). Este dato es coherente con la importancia de la amígdala como elemento esencial del sistema de detección de amenazas (saliencia), participando en la regulación de la respuesta emocional a señales sociales, especialmente, en la percepción de estímulos amenazantes y respuesta fisiológica de ansiedad consecuente (Amaral, 2002; Critchley, Mathias, \& Dolan, 2002; Phan et al., 2002; Anderson \& Sobel, 2003; Kim, Somerville, Johnstone, Polis, Alexander, Shin, \& Whalen, 2004; Whalen et al., 2004; Adolphs, Gosselin, Buchanan, Tranel, Schyns, \& Damasio, 2005).

Paralelamente, estudios morfológicos han encontrado una reducción del volumen del hipocampo en víctimas de abusos sexuales en la infancia o en ex-combatientes, coherente con la participación de esta estructura en el procesamiento de señales contextuales y extinción del miedo condicionado; y la presencia de flashbacks, déficits en memoria explícita y recuerdos fragmentados de los eventos traumáticos característicos del TEPT (Bremner et al., 1995; Van der Kolk, 1997; Tupler \& De Bellis, 2006; Brewin, 2008). 
Por su parte, los estudios funcionales han encontrado una significativa hiperactivación en el hipocampo (Sapolsky, 2003; Deckersbach, Dougherty, \& Rauch, 2006; Gilbertson et al., 2007 que han considerado de utilidad diagnóstica (Newport \& Nemeroff, 2000; Ruiz, 2004; Tupler \& De Bellis, 2006).

La amígdala podría estar implicada en las experiencias viscerales de ansiedad, mientras que el hipocampo participaría en el procesamiento declarativo de los hechos o estímulos amenazantes (Williams, 2001).

Otros estudios PET han mostrado hipoactivación del CPF, especialmente el GCA (Frank, Bailer, Henry, Wagner, \& Kaye, 2004; Etkin, Egner, Peraza, Kandel, \& Hirsch, 2006; Shin \& Liberzon, 2010; Van Tol et al., 2010), que modularía la actividad de la amígdala (Newport \& Nemeroff, 2000; Das et al. 2005; Etkin, Egner, Peraza, Kanderl \& Hirsch, 2006; Shin \& Liberzon, 2010).

\subsubsection{Trastorno Obsesivo Compulsivo (TOC)}

El TOC se considera un trastorno de ansiedad caracterizado por la presencia recurrente y persistente de obsesiones, definidas como ideas, pensamientos o imágenes intrusivas que son vividas como significativamente molestas o sin sentido; o compulsiones, entendidas como comportamientos repetitivos que el sujeto reconoce como absurdos y que no suponen ningún placer, excepto reducir tensión (American Psychiatric Association, 2000).

En general, existe acuerdo en señalar alteraciones en el el CPF y volumen del cuerpo estriado, especialmente el núcleo caudado, como la base neuroanatómica de este trastorno. En concreto se ha propuesto una disminución del volumen de la región anterior del giro cingulado y un aumento del volumen del cuerpo estriado (López-Ibor Alcocer, Ortiz Alonso, Encinas Mejías, Fernández, Maestúvy, López-Ibor, \& Aliño, 2000; Van den Heuvel et al., 2005; Lipsman, Neimat, \& Lozano, 2007; Menzies et al., 2007; Christian et al., 2008; Menzies, Chamberlain, Laird, Thelen, Sahakian, \& Bullmore, 2008; Radua \& Mataix-Cols, 2009; Bear, Fitzgerald, Rosenfeld, \& Bittar, 2010; Radua, van den Heuvel, Surguladze, \& Mataix-Cols, 2010; Rotge et al., 2010; Van den Heuvel et al., 2010).

Un estudio PET ha encontrado hiperactividad dopaminérgica del CPF e hipoactivación serotoninérgica en el cuerpo estriado, que podrían estar asociados, por un lado, a un aumento de la distractibilidad ante estímulos irrelevantes, tendencia a la abstracción extrema, sobreintelectualización, preocupación por el futuro y planificación excesiva, y por otro, a la planificación e incio de acciones apropiadas (Abramowitz, Tylor, \& McKay, 2009).

\subsubsection{Anorexia Nerviosa (AN)}

Numerosos estudios PET y SPECT han mostrado, repetidamente, alteraciones en áreas prefrontales relacionadas con la toma de decisiones y, especialmente, agravado por estados de 
malnutrición (McCormick, Keel, Brumm, Bowers, Swayze, Andersen, \& Andreasen, 2008), la región del CPF-DL y el giro cingulado (Frank, Bailer, Henry, Wagner, \& Kaye, 2004; Cavedini, Zorzi, Bassi, Gorini, Baraldi, Ubbiali, \& Bellodi, 2006; Pieters, de Bruijin, Maas, Hulstijin, Vandereycken, Peuskens, \& Sabbe, 2007; Kaye, 2008; Redgrave et al., 2008; Kaye, Fudge \& Paulus, 2009; Van Den Eynde \& Treasure, 2009; Van Kuyck, Gerard, Van Laere, Casteels, Pieters, Gabriels, \& Nuttin, 2009; Zastrow et al., 2009; Castro-Fornieles, García, Lázaro, AndrésPerpina, Falcon, Plana, \& Bargallo, 2010; Joos et al., 2010; Miyake, Okamoto, Onoda, Kurosaki, Shirao, Okamoto, \& Yamawaki, 2010). Sin embargo, un estudio reciente ha cuestionado la existencia de estas alteraciones (Guillaume, Sang, Jaussent, Raingeard, Bringer, Joliant, \& Courtet, 2010).

La insatisfacción corporal es una de las variables determinantes en la génesis de AN más importantes. En un reciente estudio funcional, se operativizó como grado de ansiedad inducida por la exposición y autocomparación a imágenes delgadas, encontrando diferencias en el grado de activación de la amígdala, además de las relativas al CPF mencionadas anteriormente (Friederich et al., 2007).

Finalmente, y en relación con los resultados del primer estudio volumétrico sobre BN, no se encontraron alteraciones en ninguna estructura encefálica, a diferencia de la AN (Joos et al. 2010).

\subsubsection{Trastorno Depresivo Mayor (TDM)}

El TDM supone la presencia de, al menos, un episodio depresivo mayor, caracterizado por la presencia de un bajo estado de ánimo, o bien, una pérdida de interés/placer, que puede estar acompañada de síntomas tales como pérdida de peso, fatiga, alteraciones del sueño e ideación suicida durante un periodo superior a dos semanas (American Psychiatric Association, 2000).

Las técnicas más empleadas en el estudio de la base neuroanatómica han sido RM y PET, y las alteraciones más frecuentes se han referido al CPF (Deckersbach et al., 2006; Maletic, Robinson, Oakes, Iyengar, Ball, \& Russell, 2007; Serene, Ashtari, Szeszko, \& Kumra, 2007; Clark, Chamberlain, \& Sahakian, 2009; Cook, Hunter, Abrams, Siegman, \& Leuchter, 2009; Takahashi et al., 2009; Portella, Morgan-Ferrando, \& Gómez-Anson, 2009; Cooney, Joormann, Eugene, Dennis, \& Gotlib, 2010; Northoff, 2010; Vedeniapin, Cheng, \& George, 2010), especialmente el área del CPF-DL (Xia, Yang, Lei, \& Zhou, 2010) y GCA, donde sistemáticamente, se ha encontrado una reducción de su tamaño, análogo al encontrado en el TEPT, independientemente de la severidad del TDM, la medicación empleada y sexo del paciente (Yücel et al., 2003; Vogt, 2005; Deckersbach et al., 2006; Cook et al., 2009; Lorenzetti, Allen, Fornito, \& Yücel, 2009; Savitz \& Dreets, 2009; Koolschijn, Van Haren, LensveltMulders, Hulshoff Pol, \& Kahn, 2009; Takahashi et al., 2009; Van Tol et al., 2010). 
También se han encontrado alteraciones en estructuras límbicas que participan en la evaluación del valor emocional de los estímulos. En concreto, alteraciones en el volumen y nivel de activación de la amígdala, mostrando hiperactivación ante la exposición a estímulos negativos como caras tristes, e hipoactivación ante estímulos agradables (caras felices) (Rosso, Cintron, Steingard, Renshaw, Young, \& Yurgelun-Todd, 2005; Deckersbach et al., 2006; Weniger, Lange, \& Irle, 2006; Northoff, 2007; Clark et al., 2009; Savitz \& Drevets, 2009; Lorenzetti et al., 2010), y alteraciones en el hipocampo (Hsieh, McQuoid, Levy, Payne, MacFall, \& Steffens, 2002; Sheline, Mittler, \& Mintun, 2002; Campbell \& MacQueen, 2004; Rosso et al., 2005; Deckersbach et al., 2006; Milne, MacQueen, Yücel, Soreni, \& Hall, 2009; Clark et al., 2009; Cook et al., 2009; Koolschijn et al., 2009; Kronmüller et al., 2008; Kronmüller et al., 2009; Lorenzetti, Allen, Fornito, \& Yücel, 2009; McKinnon, Yücel, Nazarov, \& MacQueen, 2009; Savitz \& Dreets, 2009; Takahashi et al., 2009; Xia et al., 2010). Tanto las alteraciones encontradas en la amígdala, como en el hipocampo, son mayores en los casos más severos o formas del trastorno más persistentes (Deckersbach et al., 2006; Koolschijn et al., 2009; Lorenzetti et al., 2009; Savitz \& Dreets, 2009).

Otros estudios recientes han encontrado alteraciones en el cuerpo estriado, especialmente, el núcleo caudado (Gabbay, Hess, Liu, Babb, Klein, \& Gonen, 2007; Stathis, Panourias, Themistocleous, \& Sakas, 2007; Kim, Hamilton, \& Gotlib, 2008; Bluhm et al., 2009; Butters et al., 2009; Clark et al., 2009; Koolschijn et al., 2009; Naismith, Lagopoulos, Ward, Davey, Little, \& Hickie, 2010; Vang, Ryding, Traskman-Bendz, van Westen, \& Lindstrom, 2010).

Las alteraciones cognitivas encontradas en el TDM son compatibles con un patrón de hipometabolismo e hipoperfusión de estructuras dorsales, como el CPF-DL, y los síntomas vegetativos y emocionales, con un patrón de hiperactivación en áreas ventrales como el GCA, el hipocampo y la amígdala. De forma que la recuperación del grado de activación normal correlacionaría con la mejora sintomática (Deckersbach et al., 2006).

En el primer metaanálisis, realizado hasta la fecha, sobre estudios RM en casos de TDM, y que constituye el artículo más citado en el campo de la neuroimagen en Psiquiatría en los últimos años, se encontraron reducciones significativas del volumen del CPF-DL, GCA, reducciones moderadas del hipocampo y también en el cuerpo estriado (Koolschijn et al., 2009). Sin embargo, conviene destacar que, tanto las alteraciones prefrontales como las relativas a las estructuras límbicas señaladas, no fueron suficientemente sensibles como para justificar su uso en contextos clínicos (Koolschijn et al., 2009). Los autores destacaron la dificultad de comparar resultados de distintos estudios debido a la heterogeneidad del diagnóstico de depresión en cuanto a severidad, medicación, historia de trastornos mentales y otras variables. 


\subsubsection{Trastorno Bipolar (TB)}

El TB es un trastorno del estado de ánimo caracterizado por severos cambios de humor (episodios maníacos o de depresión mayor) y una tendencia a la remisión y recurrencia (American Psychiatric Association, 2000).

Desde el punto de vista puramente morfológico, la mayoría de los estudios revisados señalan una disminución del volumen del área CPF-DL y GCA como las alteraciones más sobresalientes (Blumberg et al., 2000; Rajkowska, Halaris, \& Selemon, 2000; Stoll, Renshaw, Yurgelun-Todd, \& Cohen, 2000; Dixon, Morris, Bullmore, Brammer, Williams, Sharma, Murray, \& McGuire, 2001; Rubinsztein et al., 2001; López-Larson, DelBello, Zimmerman, Schwiers, \& Strakowski, 2002; Yücel et al., 2003; Strakowski, DelBello, \& Adler, 2005; Todtenkopf, Vincent, \& Benes, 2005; Bearden et al., 2007; Serene et al., 2007; Kempton, Geddes, Ettinger, Williams, \& Grasby, 2008; Bora, Vahip, \& Akdeniz, 2008; Beyer, Kuchibhatla, Payne, Macfall, Cassidy, \& Krishnan, 2009; Emsell \& McDonald, 2009; Womer, Kalmar, Wang, \& Blumberg, 2009; Pavuluri, Passarotti, Harrai, \& Sweeney, 2010).

Desde el punto de vista funcional, la inestabilidad afectiva e impulsividad han sugerido una pérdida del control prefrontal caracterizado por una hipoactivación del CPF-DL, implicado en funciones más racionales, e hiperactivación del CPF ventral, más implicado en aspectos emocionales por sus conexiones con la amígdala (Carlson, Singh, Zarate, Drevets, \& Manji, 2006; Womer et al., 2009). Por lo tanto, se trata de un patrón similar al encontrado en el caso de esquizofrenia, y más alejado del descrito para el TDM (Stoll et al., 2000; Strakowski, Delbello, \& Adler, 2005; Beyer et al., 2009).

Sin embargo, un reciente metaanálisis de 98 artículos publicados entre 1980 y 2007 donde se había empleado RM y TC para el estudio del TB, concluyó que el alargamiento de los VL fue una de las alteraciones más sobresalientes, como sucedía en la esquizofrenia (Kempton et al., 2008). Este resultado también sería coherente con la similitud sintomática encontrada en ambas condiciones psiquiátricas (Stoll et al., 2000; Silverstone, McGrath, \& Kim, 2005; Strakowski et al., 2005; Strasser et al., 2005). Sin embargo, no todos los estudios revisados han identificado diferencias en los VL (Kempton et al., 2008; Rosa et al., 2010).

Otros estudios han indicado alteraciones en las siguientes estructuras límbicas:

En primer lugar, la amígdala, donde se han hallado alteraciones tanto volumétricas como funcionales (Altshuler et al., 2000; DelBello, Zimmerman, Mills, Getz, \& Strakowski, 2004; Scherk, Reith, \& Falkai, 2004; Strakowski, Delbello, \& Adler, 2005; DelBello, Adler, \& Strakowski, 2006; Weniger et al., 2006; Phillips \& Vieta, 2007; Scherk, 2007; Serene et al., 2007; Doty, Payne, Steffens, Beyer, Krishnan, \& Labar, 2008; Foland et al., 2008; Emsell \& McDonald, 2009; Womer et al., 2009; Gruber et al., 2010; Mamah et al., 2010; Usher et al., 2010). Sin embargo, otros estudios no han encontrado diferencias en esta estructura respecto a sujetos control (Brambilla et al., 2003), o en comparación con parientes de los pacientes (Hajek, 
Gunde, Slaney, Propper, MacQeen, Duffy, \& Alda, 2009). En segundo lugar, algunos estudios han señalado alteraciones en el hipocampo (Colla, M., Schubert, Heidenreich, Seifert, Bubner, Bajbouj, \& Heuser, 2005; Frazier et al., 2005; DelBello, Adler, \& Strakowski, 2006; McDonald et al., 2006; Tordesillas-Gutierrez, Glahn, Franklin, Barret, Caetano, Soares, \& Fox, 2006; Scherk, 2007; Bearden et al., 2008; Foland et al., 2008; Kempton et al., 2008; Hall et al., 2010; Javadapour et al., 2010; Mamah et al., 2010; Rimol et al., 2010). Sin embargo, los resultados tampoco han sido consistentes respecto a esta estructura, siendo varios los estudios que no han encontrado diferencias en el volumen del hipocampo respecto al grupo control, a diferencia del aumento del volumen del hipocampo hallado en pacientes con esquizofrenia (Altshuler et al., 2000; Strasser et al., 2005), o respecto a sus parientes (Hajek et al., 2009).

Otra de las estructuras encefálicas donde se han encontrado alteraciones en el grado de activación ha sido el cuerpo estriado, especialmente, el núcleo caudado (Blumberg et al., 2000; Strakowski et al., 2002; Strakowski et al., 2005; Strakowski, Delbello, \& Adler, 2005; DelBello et al., 2006; Serene et al., 2007; Kempton et al., 2008).

En general, las estructuras encefálicas implicadas en el TB están menos definidas que en el trastorno por depresión mayor, presentado anteriormente. Sin embargo, los resultados encontrados apoyan la hipótesis de una afectación de la modulación prefrontal de estructuras límbicas (anteriores) como la amígdala, el hipocampo y el cuerpo estriado asociadas con alteraciones del estado de ánimo.

\subsubsection{Trastorno por Déficit de Atención con Hiperactividad (TDAH)}

El TDAH comienza en la infancia con la aparición de signos que muestran un desarrollo inapropiado de la atención, impulsividad e hiperactividad. Sin embargo, a pesar de que la mayoría de los casos cursa con falta de atención e impulsividad-hiperactividad, uno de los dos patrones suele destacar sobre el otro (American Psychiatric Association, 2000). Los síntomas suelen atenuarse durante la adolescencia, aunque una minoría experimenta síntomas en la primera fase de la etapa adulta. En la revisión del estudio de las bases neuroanatómicas de este trastorno, a partir de técnicas de neuroimagen, no hemos encontrado suficiente información relativa a esta condición en adultos para incluirla en este trabajo.

Las alteraciones encontradas, tanto volumétricas como funcionales, sugieren la afectación de áreas del CPF, tanto CPR-DL como relativas al GCA, y el cuerpo estriado, especialmente el núcleo putamen y núcleo caudado (Kim, Lee, Shin, Cho, \& Lee, 2002; Raz, 2004; Bush, Valera, \& Seidman, 2005; Carrasco, López, \& Aboitiz, 2005; Schulz, Tang, Fan, Marks, Cheung, Newcorn, Halperin, 2005; Arnsten, 2006; Halperin \& Schulz, 2006; Schneider, Retz, Coogan, Thome, \& Rösler, 2006; Aron, Durston, Eagle, Logan, Stinear, \& Stuphorn, 2007; Berger, Kofman, Livneh, \& Henik, 2007; Serene et al., 2007; Sheridan et al., 2007; Chamberlain et al., 2008; Kieling, Goncalves, Tannock, \& Castellanos, 2008; Arnsten, 2009; Cherkasova \& 
Hechtman, 2009; Curatolo, Paloscia, D’Agati, Moavero, \& Pasini, 2009; Emond, Joyal, \& Poissant, 2009; Hechtman, 2009; Quintero, Navas, Fernández, \& Ortiz, 2009; Tripp \& Wickens, 2009; Negoro, Lida, Ota, Tanaka, \& Kishimoto, 2010). Las alteraciones en estas estructuras serían congruentes con la paticipación, especialmente del CPF, en funciones ejecutivas y atencionales, incluyendo la toma de decisiones e inhibición comportamental (Arnsten, 2009). Sin embargo, algunos autores no han encontrado alteraciones en la actividad del CPF (Halperin \& Schulz, 2006).

Otros autores han propuesto, aunque con menor apoyo, alteraciones tales como la reducción global del volumen del encéfalo (Chamberlain, Robbins, \& Sahakian, 2007; Curatolo et al., 2009), la amígdala, el tálamo (Perlov et al., 2009), el cerebelo (Krain \& Castellanos, 2006), o alteraciones en el esplenio del cuerpo calloso (Hutchinson, Mathias, \& Banich, 2008; Cao et al., 2010; D'Agati, Casarelli, Pitzianti, \& Pasni, 2010). Sin embargo en un reciente estudio, no se encontraron diferencias en el cuerpo calloso (McNally, Crocetti, Mahone, Denckla, Suskauer, \& Mostofsky, 2010). 



\section{Planteamiento del Problema}

En el primer apartado de este trabajo hemos expuesto, brevemente, aspectos morfológicos y funcionales de estructuras encefálicas vinculadas a enfermedades neurológicas, y trastornos psiquiátricos, de las técnicas de diagnóstico por imagen empleadas en su estudio según la literatura revisada. Hemos destacado la relevancia actual de la visualización $3 \mathrm{D}$, reseñando las contribuciones más sobresalientes de distintos centros, laboratorios e instituciones internacionales, y descrito Amira ${ }^{\circledR}$ y Voxel-Man ${ }^{\circledR}$ como herramientas para la reconstrucción 3D a partir de neuroimágenes. Finalmente, hemos prestado especial atención al Visible Human Project (VHP), que consideramos uno de los avances más relevantes en el campo de la neuroimagen en base al volumen de investigaciones y aplicaciones prácticas que se han derivado de él.

A continuación, describiremos la evolución y relevancia de la imagen clínica diagnóstica en el estudio del encéfalo y trastornos asociados, hasta llegar a la visualización 3D. Este apartado finaliza con la exposición de los objetivos de nuestro estudio.

Según Luria, el estudio de esta relación de estructuras encefálicas y comportamiento, referido como formas complejas de actividad mental, sería el objetivo único y específico en Neuropsicología (Luria, 1973). Esta misma idea apareció reflejada años después en la famosa “astonishing hypothesis" del Premio Nobel Francis Crick (Crick, 1994), "[...] Usted, sus alegrías y sus penas, sus recuerdos y sus ambiciones, su propio sentido de la identidad personal y su libre voluntad, no son más que el comportamiento de un vasto conjunto de células nerviosas y de moléculas asociadas".

Varias disciplinas comparten el estudio por dicha relación, diluyendo o cuestionando los límites entre ellas. La Neurología, tradicionalmente, se ha centrado en alteraciones estructurales como EP y EM, mientras que la Psiquiatría o Psicología Clínica se han centrado en lo funcional o no orgánico. Sin embargo, la Neurología ha aumentado su interés por el estudio de funciones cognitivas y síntomas psiquiátricos en enfermedades neurológicas y se han aplicado metodologías neurológicas al estudio de trastornos psiquiátricos, mejorando el conocimiento de sus bases biológicas. Como resultado, ha surgido la Neuropsiquiatría, integrando a ambas. La Neuropsicología y la Neurología Conductual, surgida del interés de la Neurología por los comportamientos complejos y sus alteraciones, también comparten el interés por el estudio de la relación entre la conducta y su relación con las estructuras encefálicas. El neurólogo conductual priorizaría el estudio de la estructura del encéfalo sobre las funciones cognitivas superiores, principalmente, afasia y amnesia, mientras que el neuropsicólogo enfatizaría los procesos psicológicos y sus métodos de evaluación, respecto a las estructuras encefálicas. 
Paralelamente, la Psiquiatría Biológica también se ha interesado por el efecto de los psicofármacos en la conducta y funciones cognitivas, centrándose en el estudio de neurotransmisores y sus mecanismos de acción.

Desde el punto de vista histórico, el punto de partida en la comprensión de esta relación entre encéfalo y conducta, entendida como el intento de localizar las funciones cognitivas y sus alteraciones, se remonta al siglo V a.c. cuando Hipócrates refirió el encéfalo como el órgano de la inteligencia y el corazón como el órgano de los sentidos. Posteriormente, Galeno dio un paso más proponiendo la localización de las funciones cerebrales en los VL.

En 1848, John Harlow destacó la importancia del CPF del lóbulo frontal en la personalidad y conducta moral, en base a las observaciones realizadas en el caso Phineas Gage, (Harlow, 1848; Harlow, 1869) y que, actualmente, constituye uno de los casos médicos clave en lesiones encefálicas dentro del campo de la Neurología.

Uno de los primeros intentos sistemáticos de relacionar estructura y función en el encéfalo se denominó frenología (Gall \& Spurzheim, 1810), según la cual, funciones cognitivas superiores como rasgos intelectuales, morales y de personalidad se localizaban en 27 irregularidades de la superficie externa del cráneo.

Las inconsistencias e imprecisiones de la frenología dejaron paso al enfoque localizacionista de Pierre Paul Broca. En 1861, Broca observó que muchos de sus pacientes con incapacidad para la expresión verbal, compartían lesiones en el giro frontal inferior del hemisferio izquierdo (Broca, 1861). En 1874, Carl Wernicke hizo una observación similar a la de Paul Broca. En este caso, pacientes con lesiones en el giro temporal superior izquierdo eran capaces de producir lenguaje, pero sin ningún sentido (Wernicke, 1874).

En 1870, dos científicos alemanes, Gustav Fritsch y Eduard Hitzig, empezaron a localizar funciones a través de la estimulación de distintas zonas de la corteza motora primaria en la superficie del encéfalo de un perro, deduciendo la localización frontal de áreas motoras y posterior de áreas no motoras (Fritsch \& Hitzig, 1870), técnica posteriormente desarrollada por el fisiólogo Walter Rudolf Hess, obteniendo el premio Nobel de Medicina y Fisiología junto con Egas Moniz en 1949.

En 1932 Charles S. Sherrington, también fue galardonado con el premio Nobel de Medicina por sus trabajos en el campo de la neurofisiología, sobre localización de las funciones del córtex cerebral, tales como reflejos. En una de sus obras más relevantes titulada "The Integrative Action of the Nervous System" (Sherrington, 1906), recopilación de diez clases impartidas en la Universidad de Yale, abordó el debate "Reticular Theory versus Neuron Doctrine" en relación a la naturaleza del SN, defendiendo la segunda, e influyendo en la forma en la que las siguientes generaciones entendieron la organización del SNC (Burke, 2007).

Paralelamente, el trabajo del anatomista Korbinian Brodmann de 1909, sobre las conocidas áreas que llevan su mismo nombre, continuó con la idea de funcionalidad específica, 
mostrando que la citoarquitectura del encéfalo difería sustancialmente de unas regiones a otras y distinguiendo varias funciones (Brodmann, 1909).

A comienzos de los años 50 ya existía un extenso conocimiento sobre la especificidad funcional y organización de las neuronas, a partir de los experimentos del neurocirujano Wilde Penfield sobre estimulación cortical directa en áreas específicas del encéfalo como el giro precentral y postcentral (Penfield \& Rasmussen, 1952).

Sin embargo, funciones complejas como la resolución de problemas, desafían los esfuerzos dirigidos a su localización. Hasta la introducción de las técnicas de neuroimagen, los estudios funcionales eran virtualmente imposibles, y la mayor parte de la información disponible sobre el encéfalo humano y la relación entre su actividad y las funciones cognitivas se limitaba a inferencias hechas a partir de observaciones de pacientes con lesiones cerebrales como las señaladas o pacientes con trastornos neurológicos como epilepsia severa, cuyos tratamientos consistían, con relativa frecuencia, en la extirpación de regiones del encéfalo, o la sección del cuerpo calloso (Sperry, 1968).

La aparición y desarrollo de las técnicas de neuroimagen morfológicas y funcionales en las últimas décadas ha supuesto un punto de inflexión en el estudio de la relación entre estructuras anatómicas y funciones cognitivas, al permitir su visualización in vivo y de forma no invasiva (Bankman, 2000). La neuroimagen morfológica comenzó con el empleo de Rx y, posteriormente, marcadores radioactivos inyectados o inhalados, que mejoraron el contraste de la neuroimagen.

La primera representación de neuroimagen funcional se remonta a 1984, valorando el FSC a través de una exploración PET utilizando ${ }^{15} \mathrm{O}$ durante una tarea de lenguaje, donde se observó un aumento de la activación en el giro temporal superior (área de Wernicke) y giro frontal inferior (área de Broca).

Los estudios tradicionales de neuroanatomía a partir de técnicas de diagnóstico por imagen, tanto morfológicos como funcionales, se han caracterizado por el uso de imágenes que suponen una visión 2D de las estructuras encefálicas. Sin embargo, los continuos avances de estas técnicas han mejorado su resolución espacial y la evolución de los desarrollos informáticos ha permitido una reducción espectacular del tiempo requerido para el procesamiento $\mathrm{y}$ un aumento de las herramientas de tratamiento de imágenes.

Paralelamente, las técnicas de diagnóstico por imagen se están dirigiendo, cada vez más, no sólo al estudio de enfermedades neurológicas, sino también al de trastornos psiquiátricos, de forma que las diferencias entre unas $\mathrm{y}$ otras se refieren al grado de evidencia sobre manifestaciones clínicas y sustrato neuroanatómico patológico. La Neurología trataría con enfermedades estructurales del encéfalo y la Psiquiatría/ Psicología Clínica con trastornos funcionales de la mente. Sin embargo, Kraepelin y Maudsely consideraron los trastornos psiquiátricos como enfermedades del encéfalo, a pesar de que las correlaciones entre las 
manifestaciones clínicas y el sustrato neuroanatómico siguen siendo un desafío, facilitando la asociación de los trastornos psicológicos o funcionales con alteraciones no localizadas y los trastornos orgánicos con alteraciones localizadas.

Otros autores han mapeado funciones cognitivas como la respuesta de ansiedad, asociada a la amígdala (Elkin et al., 2006) y la mentira, entendida como juicio moral complejo, que requiere una toma de decisiones, localizado en el CPR DL (giro frontal superior y medio), exactamente el lugar donde John Harlow localizó la lesión de Phineas Gage, según estudios recientes de la universidad de Harvard y Princeton (Greene et al., 2001).

En conjunto, podemos decir que el tradicional método médico de correlaciones clínicopatológicas, referido anteriormente, se está aplicando a un nuevo campo de interés, los comportamientos complejos y procesos cognitivos superiores, incluyendo aquéllos definitorios de los trastornos psiquiátricos.

El problema con las neuroimágenes $2 \mathrm{D}$, morfológicas o funcionales, es que no aportan una visualización precisa de los datos originales, dado que las estructuras encefálicas son volúmenes, y esta inherente pérdida de información podría influir en la interpretación de neuroimágenes para la localización del daño en pacientes con lesiones, la planificación de neurocirugías y el entrenamiento de procedimientos quirúrgicos.

En arquitectura, la representación 2D tradicional de la planta, perfil y alzado para la representación de volúmenes geométricos ha evolucionado hacia la generación de

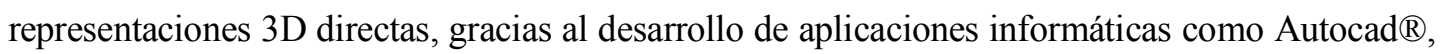
mejorando el grado de realismo obtenido en la visualización de imágenes, además del grado de interactividad por parte del usuario.

Recientemente, el Servicio de Radiología del Hospital General de Massachusetts de la Universidad de Harvard y el Instituto de Investigaciones Biomédicas de Barcelona, revisaron la aportación de las representaciones 3D, a partir de la ecografía, en el conocimiento de la anatomía funcional de la válvula mitral del corazón y sus aplicaciones clínicas. Concluyeron que las reconstrucciones 3D aportaron conocimientos únicos, tanto anatómicos como funcionales, para mejorar la comprensión y tratamiento de distintas patologías asociadas (Solis, Sitges, Levine, \& Hung, 2009).

Las innumerables investigaciones derivadas del VHP, muchas de ellas dirigidas a la elaboración de atlas, destacan el potencial de la visualización 3D de estructuras anatómicas humanas tanto con fines formativos, como de cara a la planificación o simulación quirúrgica (Juanes et al., 2001; Juanes, Riesco, Blanco, Velasco, Vázquez, \& Prats, 2002).

Este trabajo continúa en esta línea, pero considerando las estructuras encefálicas implicadas, según la literatura, en una selección de trastornos con importantes efectos neuropsicológicos y analizando, de forma empírica, la eficacia de la visualización volumétrica respecto a la visualización convencional 2D. 
La mejora de la compresión neuroanatómica a partir de la visualización volumétrica o combinada 2D/3D, se basaría en la concepción de la interpretación volumétrica como una habilidad fenotípica, característica de los seres humanos, resultado de nuestra interacción diaria con estructuras $3 \mathrm{D}$, y que supone una diferencia respecto al análisis de radiografias y otras imágenes 2D obtenidas a partir de técnicas de diagnóstico por imagen, que requieren un entrenamiento específico complementario intenso.

La generación y visualización de modelos 3D podría facilitar la localización de estructuras encefálicas profundas difícilmente accesibles, pero a la vez clínicamente relvantes en neuropsicología en particular y neurociencias en general, según hemos reseñado en el apartado 1.6. La visualización de generaciones volumétricas embebidas en neuroimágenes sería especialmente relevante para mejorar la pobre resolución espacial asociada a las imágenes funcionales.

Por lo tanto, este trabajo pretende obtener generaciones volumétricas a partir de imágenes morfológicas como RM o VHP que serán fusionadas con dichas secciones o con imágenes funcionales de PET y SPECT, facilitando la visualización morfológica y funcional de dichas estructuras encefálicas.

Nuestro estudio integra una variedad de técnicas morfológicas y funcionales que no hemos encontrado en los trabajos revisados. Y supone un esfuerzo multidisciplinar, al requerir conocimientos propios de Neuroanatomía, Radiología e Informática.

Dos premisas básicas para este trabajo son, por un lado, la consideración de la neuroanatomía como un aspecto clave en la formación de un neuropsicólogo y otros profesionales clínicos, y por otro, la necesidad de disponer de contenidos eficaces que faciliten una adecuada formación en este área y una óptima atención sanitaria.

La enseñanza de la neuroanatomía humana es extremadamente compleja y no es de extrañar que los estudiantes de neurociencias presenten dificultades en la identificación y localización de estructuras neuroanatómicas, especialmente, profundas como los núcleos basales y el sistema límbico.

La pérdida del carácter tridimensional (3D) de las representaciones convencionales 2D, morfológicas y funcionales, dificulta su interpretación. Por un lado, las estructuras aparecen con diferente apariencia según el nivel de la sección, debido a la morfología irregular, y por otro, la alta densidad de estructuras encefálicas profundas y su reducido tamaño, interfieren con su localización o identificación. La interpretación de las secciones funcionales resulta especialmente problemática debido a su baja resolución espacial, uno de los factores de calidad de la imagen, significativamente inferior en comparación con las morfológicas.

A pesar de estas dificultades, garantizar un nivel de competencia en la interpretación de neuroimágenes es un objetivo en la enseñanza de la neuroanatomía en neurociencias. La imagen clínica médica está evolucionando desde simples proyecciones 2D en tres vistas estándar (sagital, 
coronal y axial) a visualizaciones 3D que proporcionan información sobre la estructura espacial 3D.

Las principales estrategias de visualización de datos volumétricos en 3D son el método de renderizado directo del volumen y el método de extracción de isosuperficies. El primero emplea algoritmos capaces de renderizar, de forma automática, estructuras cuya composición es suficientemente heterogénea como tejido óseo, muscular y vascular, pero resulta insuficiente para generar volúmenes de estructuras encefálicas profundas de composición homogénea.

La visualización volumétrica o combinada 2D/3D supone registrar mentalmente ambas vistas. Dependiendo del método empleado para su visualización, pueden implicar distintas transformaciones mentales tales como rotación mental, escalamiento y traslado. En la técnica denominada "exo vis" la interpretación de la imagen requiere traslado y escalado del modelo, pero no su rotación; en la técnica "orientation Icons" la vista 2D y 3D aparecen separadas en diferentes áreas de la pantalla, como resultado el registro requiere el traslado, escalado y rotación mental. Finalmente, la técnica "in-place" no requiere transformaciones mentales para combinar 2D y 3D (Tory, Moller, Atkins \& Kirkpatric, 2004).

La incorporación de visualizaciones 3D ofrece una oportunidad para el diseño de escenarios o contextos formativos de mayor validez externa para el entrenamiento de los estudiantes y permite mayor autonomía en el aprendizaje por parte del alumno, uno de los objetivos del EEES (Espacio Europeo de Educación Superior), promoviendo el paso de un aprendizaje centrado en el profesor a un aprendizaje centrado en el alumno.

Numerosos estudios apoyan la preferencia de los estudiantes por sistemas de visualización 3D y volumétrica 2D/3D, implementados en aplicaciones computarizadas, frente a secciones convencionales 2D y en el contexto de la enseñanza de la neuroanatomía (Novak, 2003; McLachlan, Bligh, Bradley, \& Searle, 2004; Silén, Wirell, Kvist, Nylander, \& Smedby, 2008), en el estudio anatómico de estructuras óseas, vasculares y musculares (Perandini, Faccioli, Zaccarella, Re, \& Mucellir, 2010) el hígado (Crossingham, Jenkinson, Woolridge, Gallinger, Tait, \& Multon, 2009), la mano y la muñeca (Grauke, \& Richardson, 2010), el pie y el tobillo (Goodman, Richardson, Bush, Mulcahy, \& Chew, 2009) y la pelvis (Proscia, Jaffe, Neville, Wang, Dale, \& Merkle, 2010).

Sin embargo, todos estos estudios se basan en el estudio anatómico de estructuras heterogéneas desde el punto de vista de su composición y, por lo tanto, fácilmente segmentables. Estructuras profundas, como el cuerpo estriado, el hipocampo, la amígdala, el tálamo y el núcleo subtalámico, no pueden ser segmentadas y renderizadas de forma automática, a pesar de su relevancia desde el punto de vista clínico. Como consecuencia, el estudio anatómico de estas estructuras se ha limitado a maquetas o esquemas 2D.

En base a los estudios mencionados que muestran la preferencia y utilidad práctica de las generaciones volumétricas según los datos aportados por escalas de satisfacción (Silén at al., 
2004), sería conveniente analizar experimentalmente la eficacia de estos recursos docentes en el campo de la neuroanatomía. Estudios sistemáticos similares se han realizado en otros campos y el apoyo empírico de la visualización 3D frente a la 2D ha resultado contradictorio. La visualización $2 \mathrm{D}$ podría facilitar una búsqueda visual más rápida y mediciones precisas entre objetos representados y la visualización 3D la comprensión a nivel de morfología y relaciones espaciales (Estévez, Lindgren, \& Bergethon, 2010). La visualización 2D (sección o vista ortográfica) y $3 \mathrm{D}$ podrían considerarse estrategias útiles por diferentes motivos, sugiriendo que la combinación o fusión de ambas en una misma presentación visual podría ser la estrategia más eficaz. Varios autores han encontrado evidencias a favor de esta hipótesis en el contexto del reconocimiento de caras (Husken, Brauckmann, Gehlen, \& Von der Malsburg, 2005; Abate, Nappi, Riccio, \& Sabatino, 2007), y cuando se han comparado las distintas estrategias de visualización de forma independiente (Tory et al., 2004).

Sin embargo, no hemos encontrado estudios que evalúen empírica y sistemáticamente la eficacia de este sistema de visualización en el contexto de la formación en neuroanatomía.

Variables como la aptitud visoespacial, pueden jugar un papel importante en el registro de vistas 2D y 3D, y por tanto, ser relevante a la hora de explicar el rendimiento diferencial de los participantes. Las limitaciones asociadas a la mera inspección visual de neuroimágenes convencionales 2D sólo pueden ser compensadas por la reconstrucción mental de la estructura diana. Un proceso vinculado a transformaciones como la rotación mental cognitivamente exigente, (Pillay, 1994), subjetivo y dependiente de características como la formación y experiencia previa del sujeto.

En este estudio analizamos de forma empírica y sistemática, la eficacia de la modalidad de visualización combinada 2D/3D frente a la visualización convencional $2 \mathrm{D}$ en tareas de identificación/localización de estructuras encefálicas internas clínicamente relevantes.

Se trata del primer estudio de esta índole en este campo de conocimiento desde la perspectiva docente. Controla la aptitud visoespacial, definida como la habilidad para ejercer control sobre una representación mental de una estructura. Diferencias en esta aptitud podrían influir en la interpretación de neuroimágenes, entendida como el rendimiento en una tarea de desarrollo de superficies, donde se requiere asociar visualizaciones $2 \mathrm{D}$ y $3 \mathrm{D}$ de una misma estructura a partir del plegamiento del desarrollo de ésta. 
En la Figura 2.1 se presentan los elementos básicos que vertebran el planteamiento del problema de este trabajo.

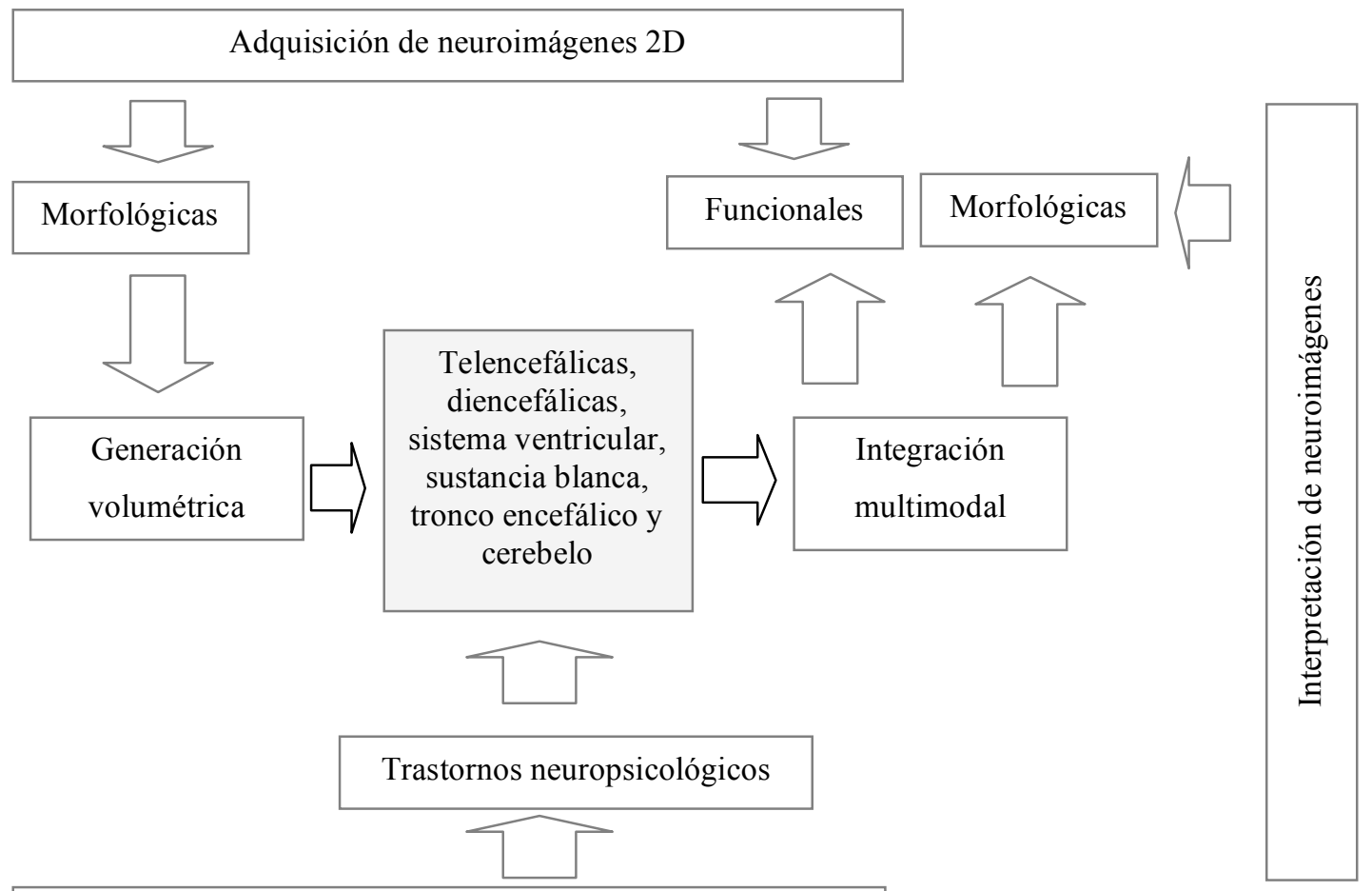

Selección estructuras encefálicas

Figura 2.1. Mapa conceptual de los elementos básicos del planteamiento del problema. 


\subsection{OBJETIVOS}

El objetivo general de este trabajo de Tesis es la generación volumétrica de estructuras telencefálicas, diencefálicas, el sistema ventricular y sustancia blanca a partir de imágenes VHP y RM, y posterior superposición en secciones del VHP, RM, PET y SPECT. Se incluyen reconstrucciones óseas del cráneo, pertenecientes a secciones TC Voxel-Man ${ }^{\circledR}$ y reconstrucción del tronco encefálico y cerebelo.

Los objetivos específicos que nos hemos planteado, por orden de importancia, son los siguientes:

1. Desarrollar generaciones volumétricas de dichas estructuras encefálicas e ilustrar, iconográficamente, su morfología $3 \mathrm{D}$ en diferentes posiciones espaciales y embebidas en secciones anatómicas, radiológicas y funcionales, que sirvan de apoyo en procesos formativos y clínicos.

2. Analizar, empíricamente, la eficacia de la visualización volumétrica $3 \mathrm{D}$ frente a la visualización convencional $2 \mathrm{D}$ en la interpretación de neuroimágenes para la identificación y localización de estructuras encefálicas profundas, clínicamente relevantes.

3. Realizar una revisión bibliográfica sobre la implicación de estructuras encefálicas en trastornos neuropsicológicos, en base a la aplicación de técnicas de diagnóstico por imagen en la última década.

4. Realizar un estudio bibliométrico que ofrezca indicadores objetivos y tangibles sobre la cantidad y calidad de la producción científica en neuroimagen en la última década.

Para la consecución de los objetivos propuestos, los pasos seguidos han sido los siguientes:

En primer lugar, se realizó un estudio bibliométrico y revisión bibliográfica exhaustiva, en las principales bases de datos, sobre la aplicación de técnicas de diagnóstico por imagen morfológicas y funcionales en el estudio de los trastornos neuropsicológicos.

En segundo lugar, se llevó a cabo una descripción y clasificación de los principales trastornos neuropsicológicos y estructuras encefálicas implicadas en cada uno, en base a la información revisada.

En tercer lugar, se procedió a la adquisición de imágenes seriadas, a partir de secciones anatómicas de cadáver del VHP, radiológicas a través de RM y funcionales SPECT y PET, procedentes de sujetos explorados en distintos centros hospitalarios nacionales. 
En cuarto lugar, se identificaron y segmentaron cada una de las estructuras encefálicas seleccionadas para su reconstrucción 3D, a partir de las imágenes morfológicas originales adquiridas de los procedimientos diagnósticos señalados.

En quinto lugar, se llevó a cabo la generación volumétrica de los modelos correspondientes a dichas estructuras encefálicas a partir de Amira ${ }^{\circledR}$. Esto permitió la visualización y manipulación de los datos originales, ilustrando las principales estructuras encefálicas afectadas por trastornos neuropsicológicos, a partir de la integración de los modelos $3 \mathrm{D}$ en planos axiales, coronales y sagitales multimodales, representando aspectos morfológicos y relaciones de vecindad con otras estructuras.

Finalmente, se diseñó un cuasiexperimento para analizar la eficacia de la visualización de neuroimágenes con volúmenes embebidos en la identificación/visualización de estructuras encefálicas profundas. 


\section{Material y métodos}

\subsection{PARTICIPANTES}

Para la adquisición de neuroimágenes y generación volumétrica de estructuras encefálicas se exploraron 14 sujetos de ambos sexos con un rango de edad comprendido entre los 21 y 43 años $(M=33, S D=4,3)$, sin historia de trastornos endocrinos, metabólicos o psiquiátricos, previa soicitud de pruebas neuroradiológicas. Se excluyeron aquellos casos cuyos resultados sugirieron presencia de enfermedades neurológicas.

Las exploraciones se llevaron a cabo, previo consentimiento informado, en los servicios de Radiodiagnóstico y Medicina Nuclear de los siguientes centros hospitalarios nacionales: Hospital Clínico Universitario de Salamanca, Hospital Universitario Rio Hortega de Valladolid, Clínica Universitaria de Navarra, Hospital 12 de Octubre de Madrid y Hospital Clínico de Barcelona.

Para el estudio empírico sobre la eficacia de la visualización volumétrica, la muestra estuvo formada por un total 80 participantes procedentes de diferentes universidades y centros hospitalarios españoles. La mitad se consideraron principiantes en neurociencias: estudiantes de $5^{\circ}$ curso de licenciatura en Psicología $(n=20)$ y estudiantes de $5^{\circ}$ curso de licenciatura en Medicina ( $\mathrm{n}=20)$; y la mitad, expertos en neurociencias: neuropsicólogos $(\mathrm{n}=20)$ y neuroanatomistas $(\mathrm{n}=20)$. La composición de cada uno de los grupos respecto al sexo estuvo formada por un 50\% de mujeres y 50\% hombres. En el caso de los expertos, se excluyeron participantes con una experiencia inferior 5 años y superior a 10 años. En la Tabla 3.1 aparecen los estadísticos descriptivos relativos a la edad, aptitud visoespacial y años de experiencia para la condición experimental (visualización volumétrica o combinada 2D/3D) y control (visualización convencional 2D).

Tabla 3.1. Medias y desviaciones típicas en edad, aptitud visoespacial y años de experiencia según condición.

\begin{tabular}{llllll}
\hline & & \multicolumn{2}{c}{ Visualización 2D } & \multicolumn{2}{c}{ Visualización 2D/3D } \\
\cline { 3 - 6 } & & $\mathrm{M}$ & $\mathrm{SD}$ & $\mathrm{M}$ & $\mathrm{SD}$ \\
\hline \multirow{2}{*}{ Principiantes } & Edad & 24,45 & 1,92 & 24,11 & 1,73 \\
& Aptitud visoespacial & 22,08 & 3,71 & 21,23 & 3,97 \\
\hline \multirow{2}{*}{ Expertos } & Edad & 36,41 & 3,41 & 37,31 & 3,74 \\
& Aptitud visoespacial & 19,12 & 2,48 & 20,42 & 4,05 \\
& Experiencia (años) & 7,13 & 2,53 & 7,41 & 1,82 \\
\hline
\end{tabular}




\subsection{APARATOS}

- Unidad de RM de 1.5 T marca Philips Intera Medical Systems, para la adquisición de imágenes morfológicas de RM.

- Unidad de PET marca Philips Medical Systems, para la adquisición de imágenes funcionales PET ${ }^{18} \mathrm{~F}$-FDG y PET ${ }^{18} \mathrm{~F}$-DOPA.

- Unidad de SPECT gamma cámara modelo Orbiter-Nco de la marca Siemens, con un colimador de baja energía y alta resolución, dotado de un cabezal rotatorio, para la adquisición de imágenes SPECT.

\subsection{SOFTWARE}

Empleado en la generación volumétrica de estructuras encefálicas:

- Research Systems Inc. Visible Human Male CD Version 2.0 de la National Library of Medicine de EEUU, bajo licencia autorizada número HW1-020645 para uso con fines docentes y de investigación. Se utilizó para la obtención de imágenes anatómicas de cadáver.

- Amira Version 5.3® Visage Imaging GmbH. Se empleó como el desarrollo informático de referencia para la segmentación y reconstrucción $3 \mathrm{D}$ de las estructras encefálicas indicadas.

- Voxel-Man-3D-Navigator Brain and Skull Version 1.1® Part 1: Brain and Skull, Verlag Electronic Media. Se empleó para la reconstrucción 3D de la estructura ósea del cráneo, superficie de la corteza cerebral y elementos vasculares.

Utilizado en el estudio empírico sobre la eficacia de la visualización combinada 2D y 3D:

- Se diseñó una aplicación informática para la presentación controlada de estímulos en las dos condiciones de visualización: imagen convencional 2D e imagen combinada 2D/3D (Figura 3.1), el registro de los tiempos de respuesta y la precisión de las respuestas en formato .xls. Se empleó lenguaje de programación HTML (HyperText Markup Language) y PHP (Hypertext Preprocessor) en el lado del servidor (Figura 3.2), JavaScript en el lado del cliente (Figura 3.3) y hojas de estilo CSS (Cascading Style Sheets) para el maquetado de contenidos (Figura 3.4). El lenguaje para las base de datos raíz (condicion2D.sql y condicion3D.sql) fue MySQL (Structured Query Language). Se descartó $E$-Prime ${ }^{\circledR}$ por no proporcionar un sistema adecuado para el registro de respuestas en una sección determinada de la pantalla, requerido en tareas de identificación y localización. 


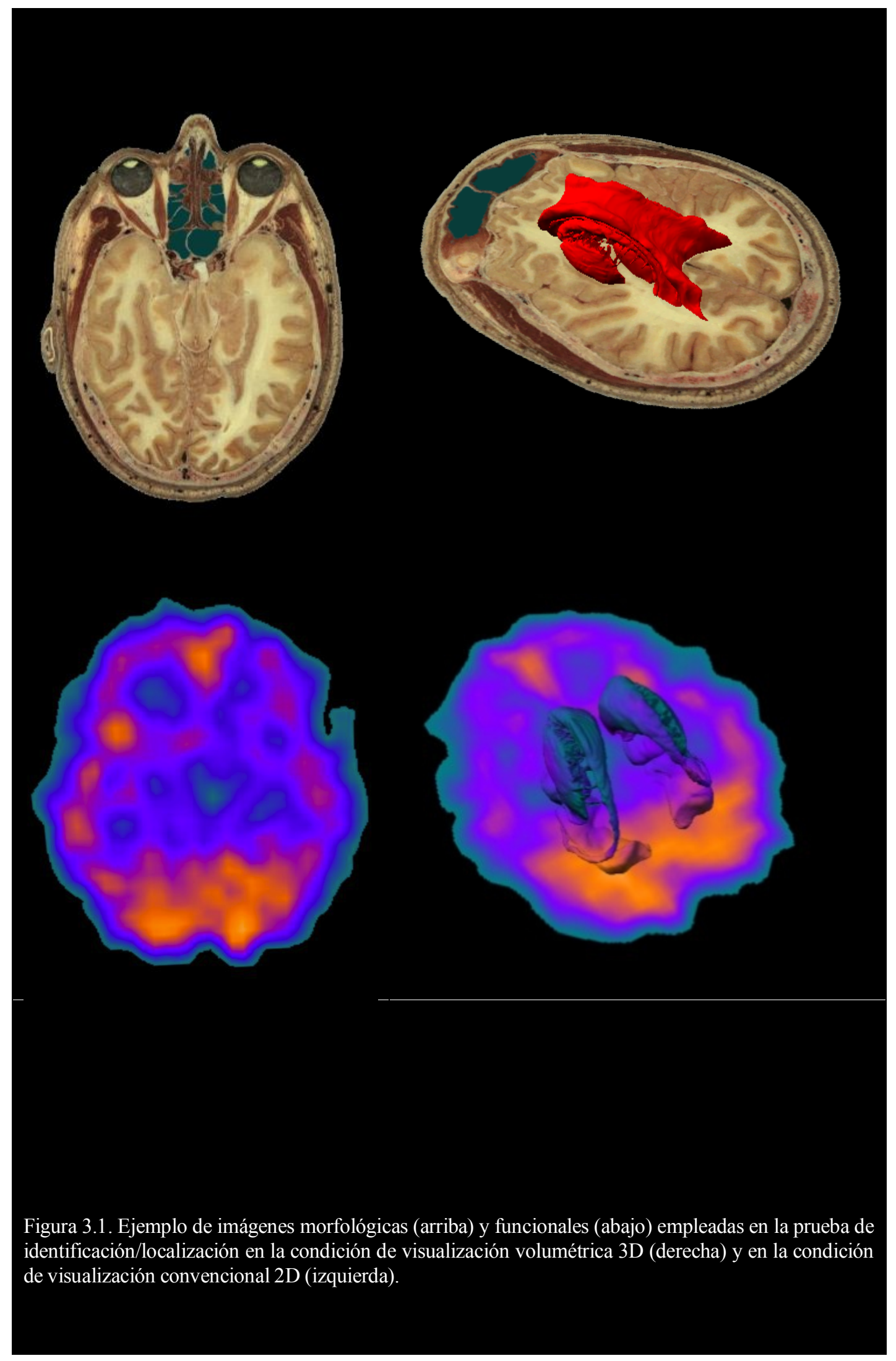




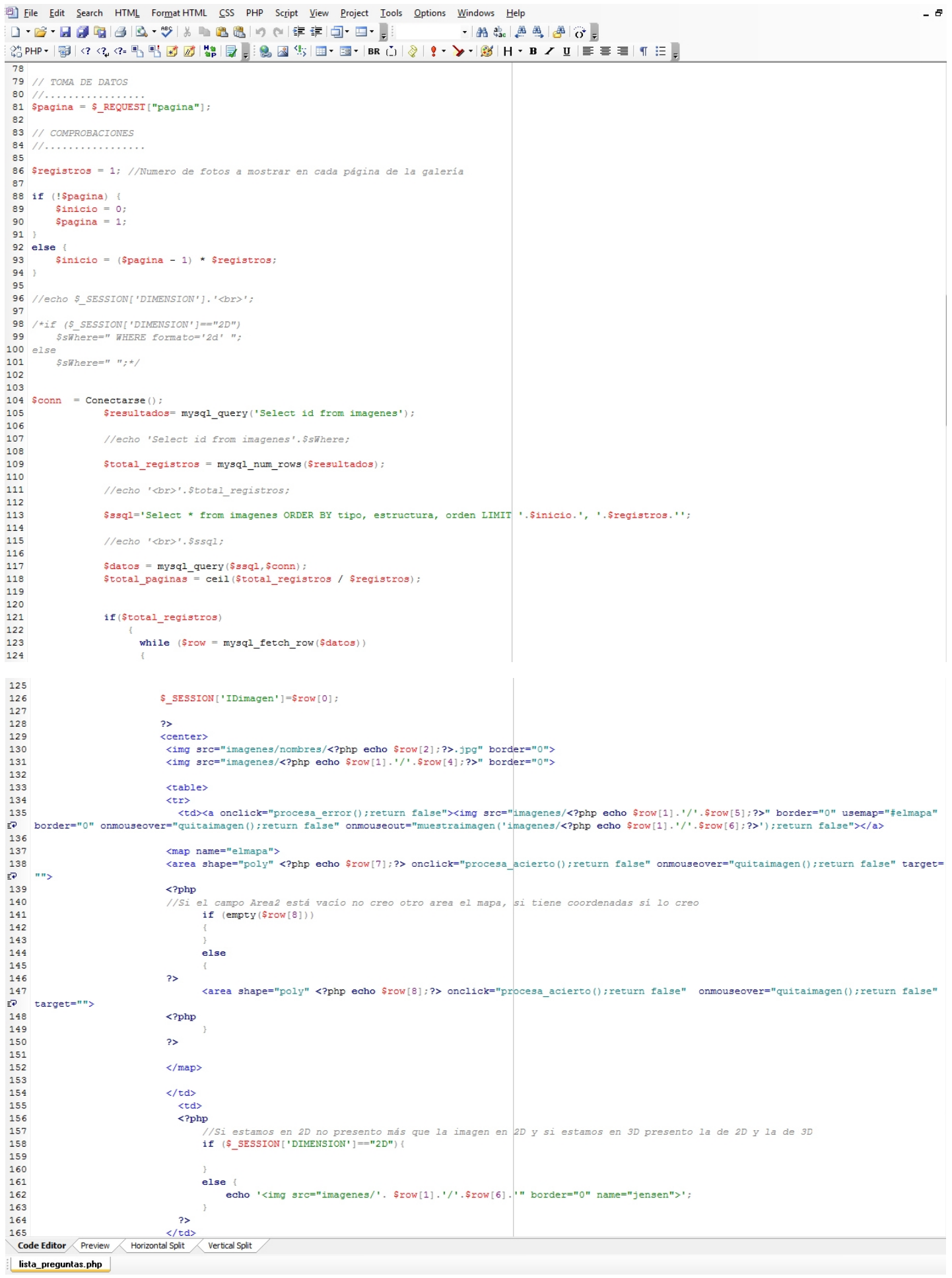

Figura 3.2. Código fuente en lenguaje HTML y PHP. 


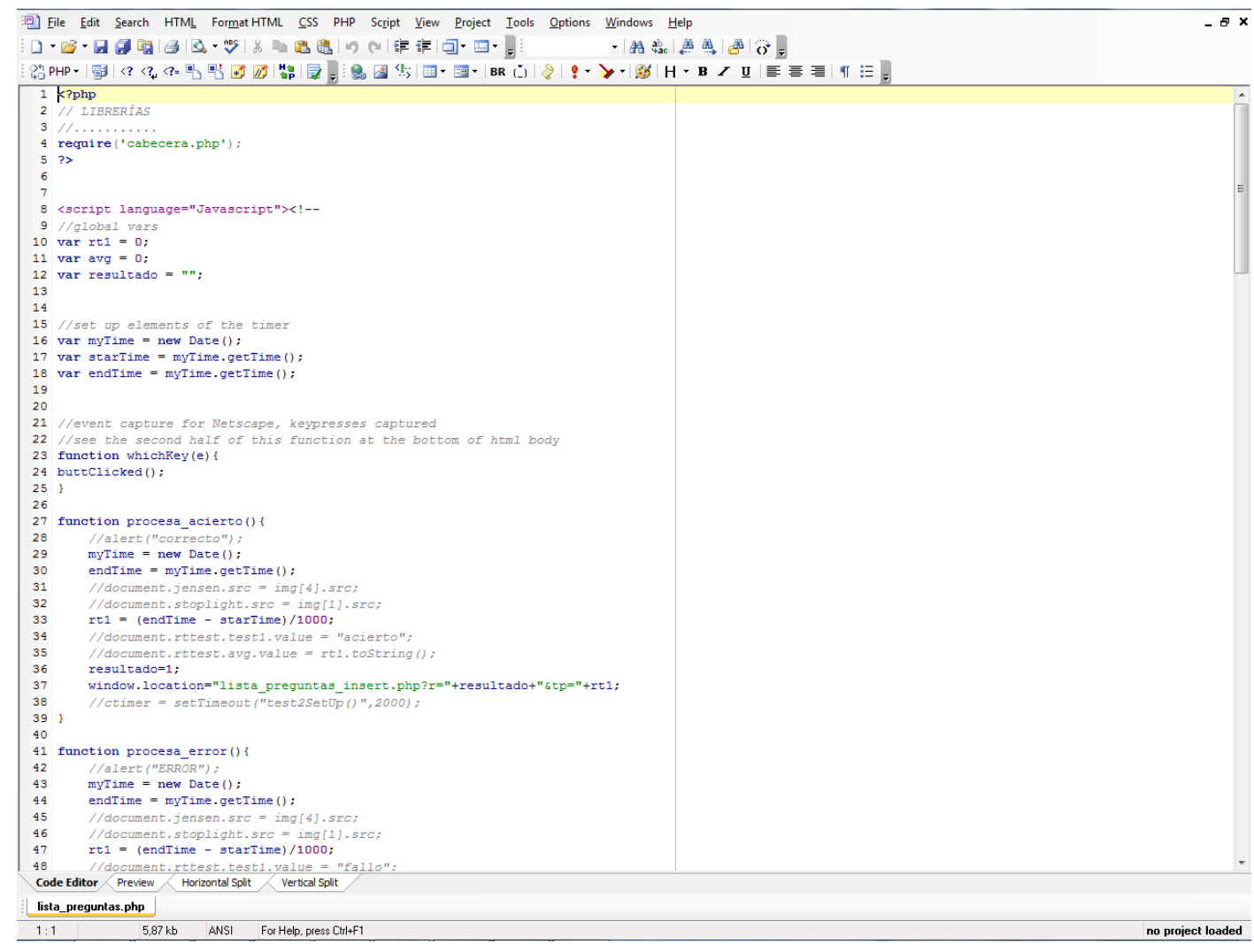

Figura 3.3. Código JavaScript.

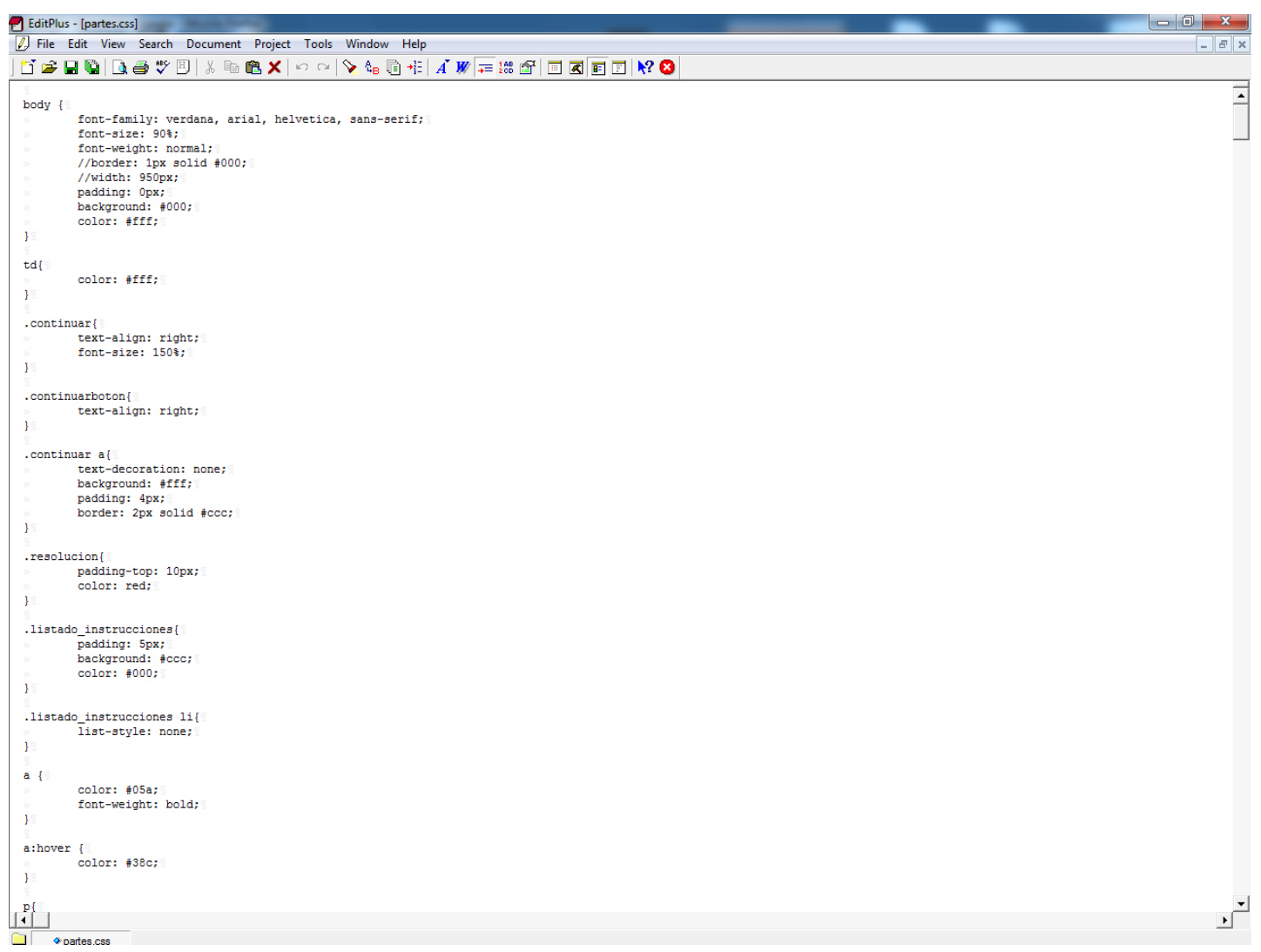

Figura 3.4. Hojas de estilo (CSS). 
- Se utilizó una selección de 36 imágenes morfológicas anatómicas de alta resolución obtenidas a partir de las Hi1001 hasta Hi1160, originales de 576x768 px obtenidas a partir del Visible Human Male CD Versión 2.0 de la National Library of Medicine de EEUU, bajo licencia autorizada número HW1-020645 para uso con fines docentes y de investigación.

- Paralelamente, se empleó una selección de imágenes funcionales axiales, sagitales y coronales obtenidas a partir de PET ${ }^{18} \mathrm{~F}$-FDG, PET ${ }^{18} \mathrm{~F}$-DOPA adquiridas mediante Unidad PET marca Philips Medical Systems y SPECT, en una unidad SPECT gamma cámara modelo Orbiter-Nco de la marca Siemens, con un colimador de baja energía y alta resolución, dotado de un cabezal rotatorio.

- Para la generación volumétrica (no probabilística) de estructuras encefálicas profundas se utilizó Amira Version 5.3® Visage Imaging GmbH. Fueron las siguientes: hipocampo, núcleo caudado, putamen, amígdala, tálamo y núcleo subtalámico.

- La adaptación de tamaño y formato de las imágenes se realizó mediante Pixresizer Software version 2.0.4®. El formato final fue jpg de 380 píxeles de ancho optimizados para la presentación en resoluciones de pantalla 800 x 600 píxel.

- La delimitación del área de respuesta para la localización de la estructura diana de cada tarea se realizó con Image Mapper Versión 1.0巴. Dicha área se definió a partir de coordenadas (x-y) establecidas para cada una de las imágenes empleadas, que oscilaron de 50 a 500 coordenadas según la estructura.

- La prueba se acompañó de una encuesta de satisfacción para la condición de visualización $2 \mathrm{D} / 3 \mathrm{D}$, dirigida a evaluar la percepción subjetiva de los usuarios respecto al valor formativo de la visualización combinada 2D/3D. Constó de tres afirmaciones a responder según el grado de acuerdo en una escala de 5 puntos tipo Likert, siendo las opciones de respuesta: totalmente en desacuerdo (1), parcialmente en desacuerdo (2), ni en desacuerdo ni de acuerdo (3), parcialmente de acuerdo (4) y totalmente de acuerdo (5). Los ítems fueron los siguientes "Los modelos 3D me han facilitado la identificación/localización de las estructuras encefálicas", "La visualización conjunta 2D/3D me ha facilitado la identificación/localización de estructuras encefálicas de las secciones", "Recomendaría utilizar la visualización combinada 2D/3D para la enseñanza/aprendizaje de neuroanatomía".

- La prueba utilizada para la evaluación de la aptitud de visualización de objetos y sus representaciones fue una versión computarizada del Test de Yela (1969), basado en una tarea de desarrollo de superficies. Para ello se digitalizaron los ítems originales diseñados para la aplicación en papel y lápiz y adaptaron las instrucciones para su aplicación, a través de un navegador. Constó de 12 figuras que contenían la 
representación gráfica de un cuerpo geométrico (con letras en algunas de sus caras y aristas) y el desarrollo de su superficie (con números del 1 al 5 en algunas de sus caras y aristas). La tarea consistió en determinar qué letras del volumen se corresponden con los números del desarrollo. El tiempo máximo de aplicación fue de 14 minutos. La puntuación directa (PD) se obtuvo por el número de contestaciones correctas o aciertos siguiendo la plantilla de corrección, siendo la PD máxima 60. El coeficiente de confiabilidad original del test, calculado por el procedimiento de las dos mitades, fue de 0,97 (Yela, 1969). En la Figura 3.5 aparece un ejemplo de los ítems del test (ver ANEXO I).
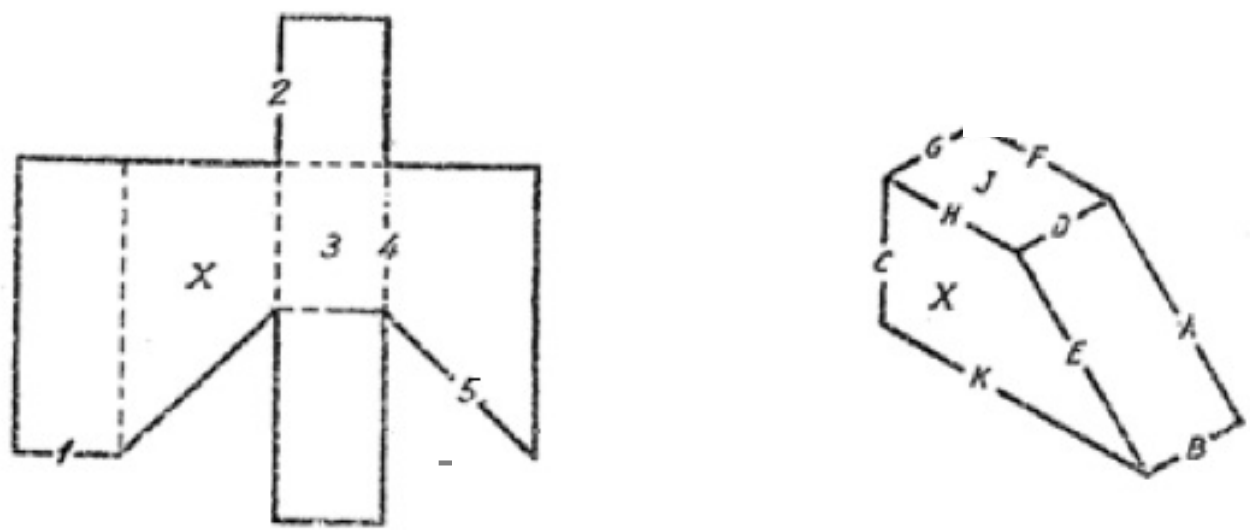

Figura 3.5. Ejemplo de ítem de desarrollo de superficies empleado en el test de aptitud visoespacial. Las figuras del test original pueden consultarse en el ANEXO I. 


\subsection{DISEÑO Y PROCEDIMIENTO}

\section{Estudio bibliométrico}

Para valorar la relevancia de la neuroimagen como estrategia en el estudio de la relación entre estructuras encefálicas y conducta, se analizó la producción científica en el área de neuroimagen, neurociencias y conducta según científicos, instituciones y países a nivel mundial, utilizando los datos relativos al número de publicaciones y citas para el periodo comprendido entre el 1 de enero de 2000 y el 1 de enero de 2011 según la información disponible a través del Institute for Scientific Information (ISI).

\section{Revisión bibliográfica}

Para la selección de estructuras encefálicas a generar volumétricamente, se revisaron las bases de datos bibliográficas accesibles en ISI, facilitada por la Fundación Española para Ciencia y Tecnología (FECYT) y el Ministerio de Ciencia e Innovación (MICINN) a través de la Biblioteca de la Universidad de Salamanca.

Se utilizaron dos filtros de búsqueda. En un primer momento, se emplearon como palabras clave Brain Imaging. Los registros resultantes fueron depurados considerándose sólo aquellos bajo las siguientes categorías: Neurología Clínica, Neuroimagen, Radiología, Medicina Nuclear e Imageniería Médica, Psiquiatría y Psicología Clínica. En un segundo momento, se filtraron los resultados incorporando un segundo término de búsqueda correspondiente a cada uno de los trastornos considerados en este trabajo. Finalmente, se realizó la selección final en función del contenido del título y palabras clave de los registros obtenidos.

La clasificación de las enfermedades neurológicas se basó en la National Library of Medicine Classification del NIH de EEUU (National Institute of Health [NIH], 2010) y los trastornos psiquiátricos y del desarrollo en el DSM-IV-TR de la American Psychiatric Association (American Psychiatric Association, 2000).

El sistema de citas y referencias en este trabajo se basa en las normas y convenciones establecidas por la American Psychological Association, dada su trascendencia internacional como guía estándar de estilo de publicación en Psicología, tal y como aparecen recogidas en la $6^{\mathrm{a}}$ edición de su Publication Manual of the American Psychological Association (American Psychological Association, 2010).

La selección final de las estructuras encefálicas cuyos volúmenes se generaron en 3D se realizó según su relevancia en las principales enfermedades neurológicas y trastornos psiquiátricos, en base a los resultados de la literatura revisada. 


\section{Adquisición de neuroimágenes}

Se han empleado neuroimágenes provenientes de cadáver (VHP,) de servicio de Radiología (RM) y de Medicina Nuclear (SPECT y PET).

Las imágenes utilizadas del VHP corresponden a criosecciones seriadas del encéfalo humano efectuadas en el plano axial, procedentes de un varón, obtenidas a $1 \mathrm{~mm}$ de espesor y una resolución de $0.3 \mathrm{~mm}$ por píxel (px). Del total de 2.878 imágenes comprimidas en formato JPG que componen la colección completa, se utilizaron las primeras 160 imágenes de alta resolución (Hi1001 a Hi1160) con un tamaño de 576x768 px cada una, correspondientes a las secciones de la cabeza en su formato y orientación originales (Figura 3.6).

Para la adquisición de imágenes RM se utilizó un equipo de 1.5 T, marca Philips Medical Systems y el protocolo de adquisición consistió en secuencias de la cabeza en el plano axial, coronal y sagital, con los siguientes parámetros: Repetition Time $=412$; Echo Time $=6.4$; Inversion Time $=300 ;$ Thickness $=1.6 \mathrm{~mm}$; Slice Spacing $=0.8 \mathrm{~mm} ;$ Matrix $=276 \times 276 ;$ Flip Angle $=90^{\circ}$. Las imágenes fueron potenciadas en T1 (Figura 3.7) y el formato de los ficheros de datos originales fue DICOM. Se obtuvieron vóxeles cúbicos de $0.8 \mathrm{~mm}$ y dimensiones de 276x276x200 px. Por motivos de seguridad, se confirmó que los sujetos no llevasen marcapasos o materiales ferromagnéticos durante la exploración.

Las imágenes de PET fueron obtenidas, exclusivamente, en el centro PET del Hospital de Navarra, que a su vez consta de tres subunidades vinculadas a diferentes etapas de la exploración:

Un ciclotrón de baja energía (10-18 MeV), para la aceleración de partículas y formación de isótopos radiactivos que fueron incorporados a moléculas más complejas para su uso como marcadores biológicos.

Un laboratorio de radioquímica donde se realizó el proceso de síntesis y marcado de dichas moléculas. Los radiofármacos administrados por personal cualificado fueron FDG (Figura 3.8) y DOPA (Figura 3.9), marcadas con ${ }^{18} \mathrm{~F}$, vía endovenosa, previa verificación de su pureza radioquímica, radiofarmacéutica y radionucleídica.

Una cámara de positrones, donde se detectaron las moléculas marcadas y su recorrido dentro del encéfalo. La cámara utilizada en nuestro estudio contenía varios anillos adyacentes con cristales detectores de centelleo, compuestos por bigermanato de bismuto, separados entre sí por septos metálicos que impidieron la detección de fotones procedentes de otros planos. La atenuación de la emisión radiactiva fue corregida mediante una máscara, a partir de la atenuación de otras fuentes externas de similar energía.

En la exploración PET, los sujetos mantuvieron un ayuno de doce horas previas a la exploración. Tras un período de espera de 45 minutos a partir de la administración del radiofármaco, fueron colocados en una camilla situada en la línea media de los detectores. La 
cámara exploró un campo de visión axial de $14.8 \mathrm{~cm}$, con una resolución espacial de $2 \mathrm{~mm}$ y una matriz de 128x128 px. La reconstrucción de imágenes tomográficas axiales, coronales y sagitales a partir de los datos recogidos, se realizó en la estación de trabajo asociada.

Las imágenes SPECT se obtuvieron utilizando una gamma cámara modelo Orbiter-Nco de Siemens, con un colimador de baja energía y alta resolución, dotado de un cabezal rotatorio. La amplitud del recorrido del arco fue de $360^{\circ}$ en sentido horario y la matriz empleada de $640 \mathrm{x}$ $640 \mathrm{px}$. El procedimento fue el siguiente:

En primer lugar, se procedió a la preparación del radiofármaco, en nuestro caso, Hexametil-propilen-amino-oxima (HM-PAO) bajo el nombre comercial de Ceretec ${ }^{\circledR}$, unido a hexa-Metazina de ${ }^{99 \mathrm{~m}}$ Tecnecio $\left({ }^{99 \mathrm{~m}} \mathrm{Tc}\right)$. Veinticuatro horas antes de la exploración se procedió a diluir el generador de Tc, con $10 \mathrm{ml}$ de cloruro sódico al 0,9\%. De aquí, se extrajeron entre 40-80 $\mathrm{mCi}$, completando hasta $5 \mathrm{ml}$ con cloruro sódico al $9 \%$. Con ello se obtuvo ${ }^{99 \mathrm{~m}} \mathrm{Tc}$ con una vida media de 6 horas. A continuación se introdujo en un vial de Ceretec ${ }^{\circledR}$ y se midió su actividad en un activímetro. La estabilidad de este radiotrazador fue de 20 minutos, a partir de los cuales su pureza radioquímica disminuyó a un $85 \%$.

En segundo lugar, se procedió a la preparación del sujeto, explicándole la importancia de mantenerse inmóvil, motivo por el que permaneció inmovilizado mediante sistemas de fijación en cabeza y brazos. Se administraron $300 \mathrm{mg}$ de perclorato potásico por vía oral, para disminuir la captación de pertecnectato por el tiroides y los plexos coroideos. Los sujetos se colocaron en decúbito supino y se les tomó una vía venosa en la vena mediana cubital. Permanecieron con los ojos abiertos en condiciones de reposo absoluto y aislamiento sonoro y lumínico durante un periodo comprendido entre 10 y 15 minutos. A continuación se les perfundió una embolada endovenosa de 20-25 mCi de HM-PAO ${ }^{99 \mathrm{~m}} \mathrm{Tc}$, procurando influir lo menos posible en su estado de reposo.

En tercer lugar, tras 5 minutos de espera para facilitar la difusión del radiotrazador, se procedió a la obtención de imágenes SPECT (Figura 3.10), obteniendo desde la posición 0, un total de 64 imágenes, con $5^{\circ}$ de rotación y 25 segundos de duración cada una. 

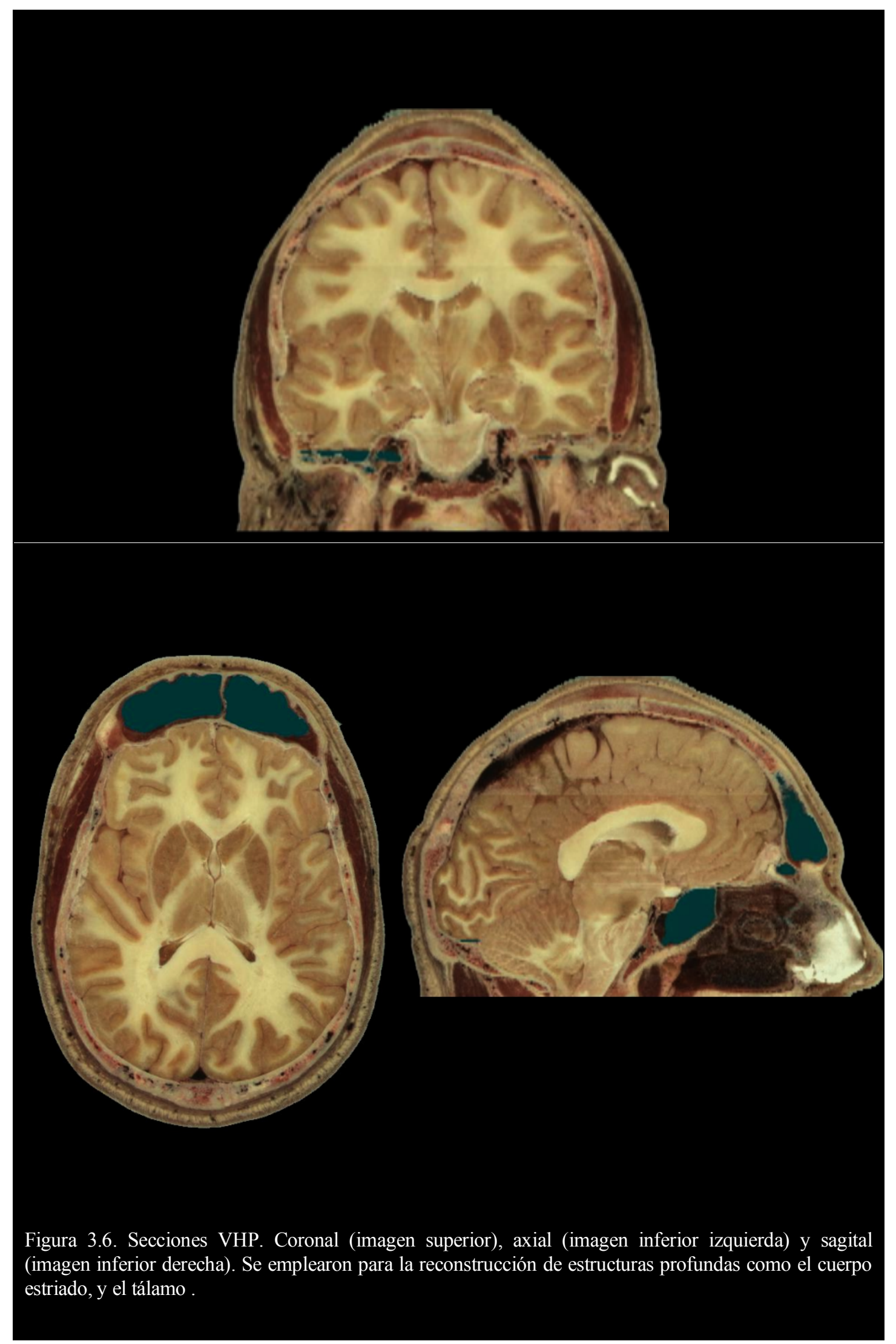


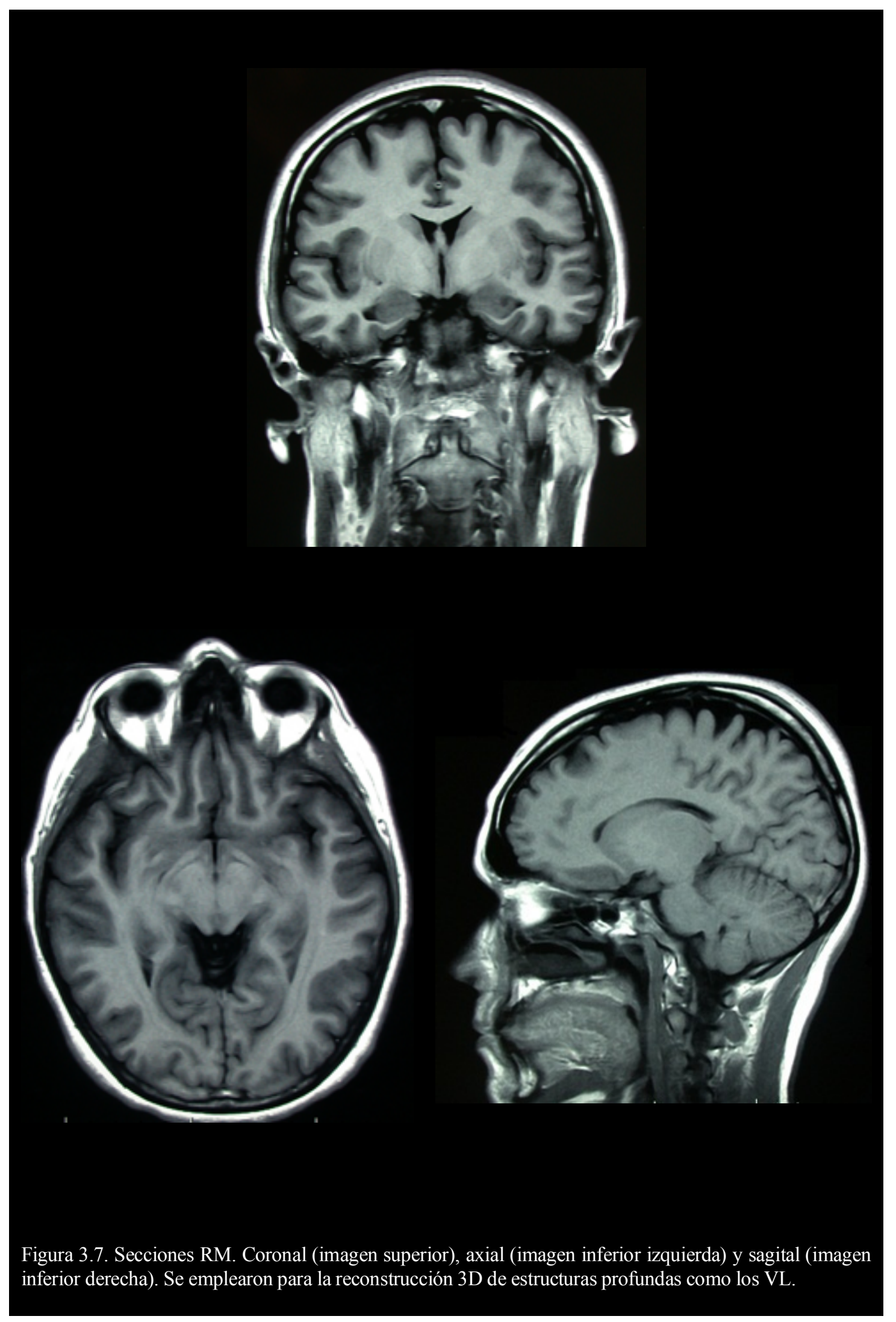




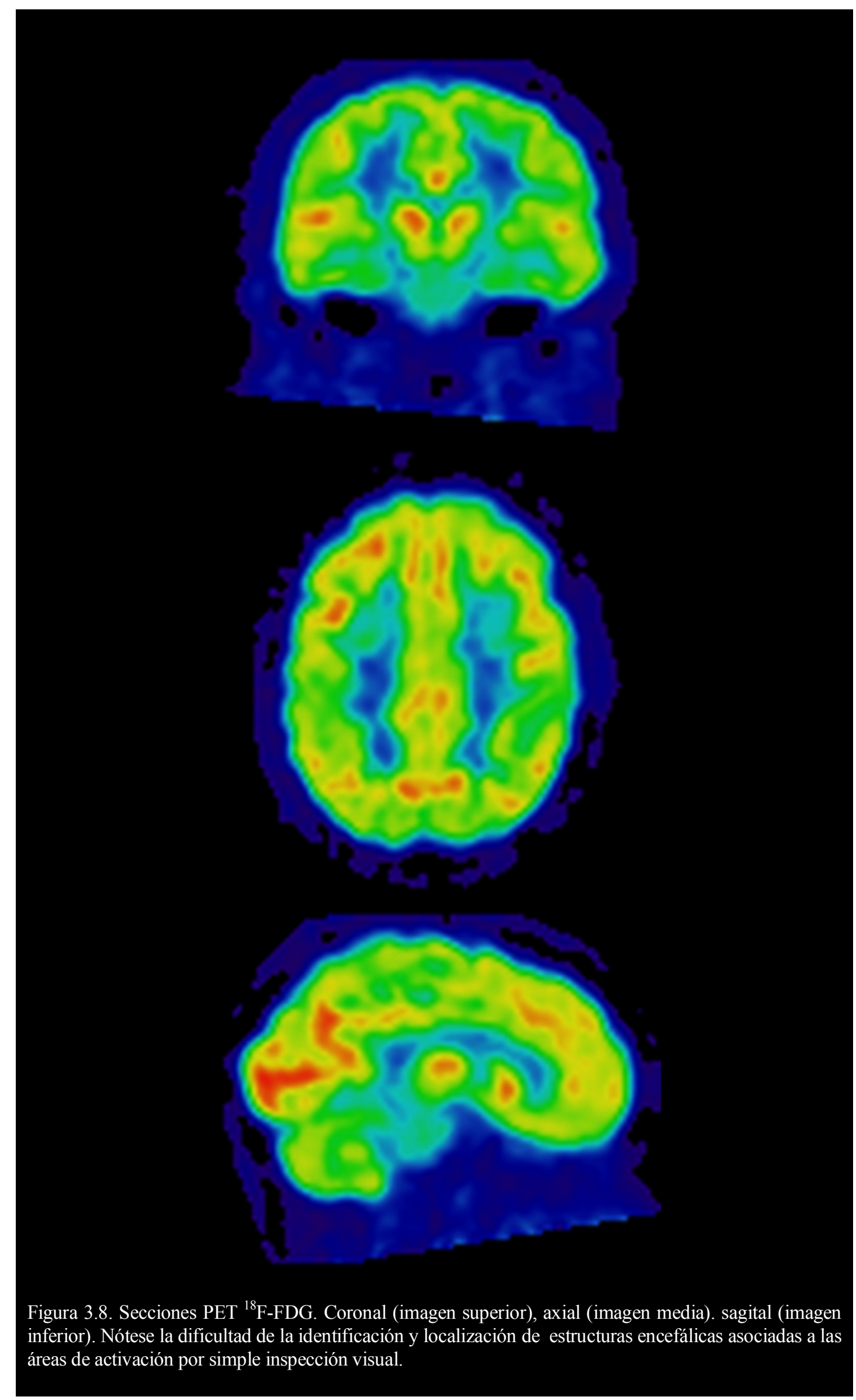




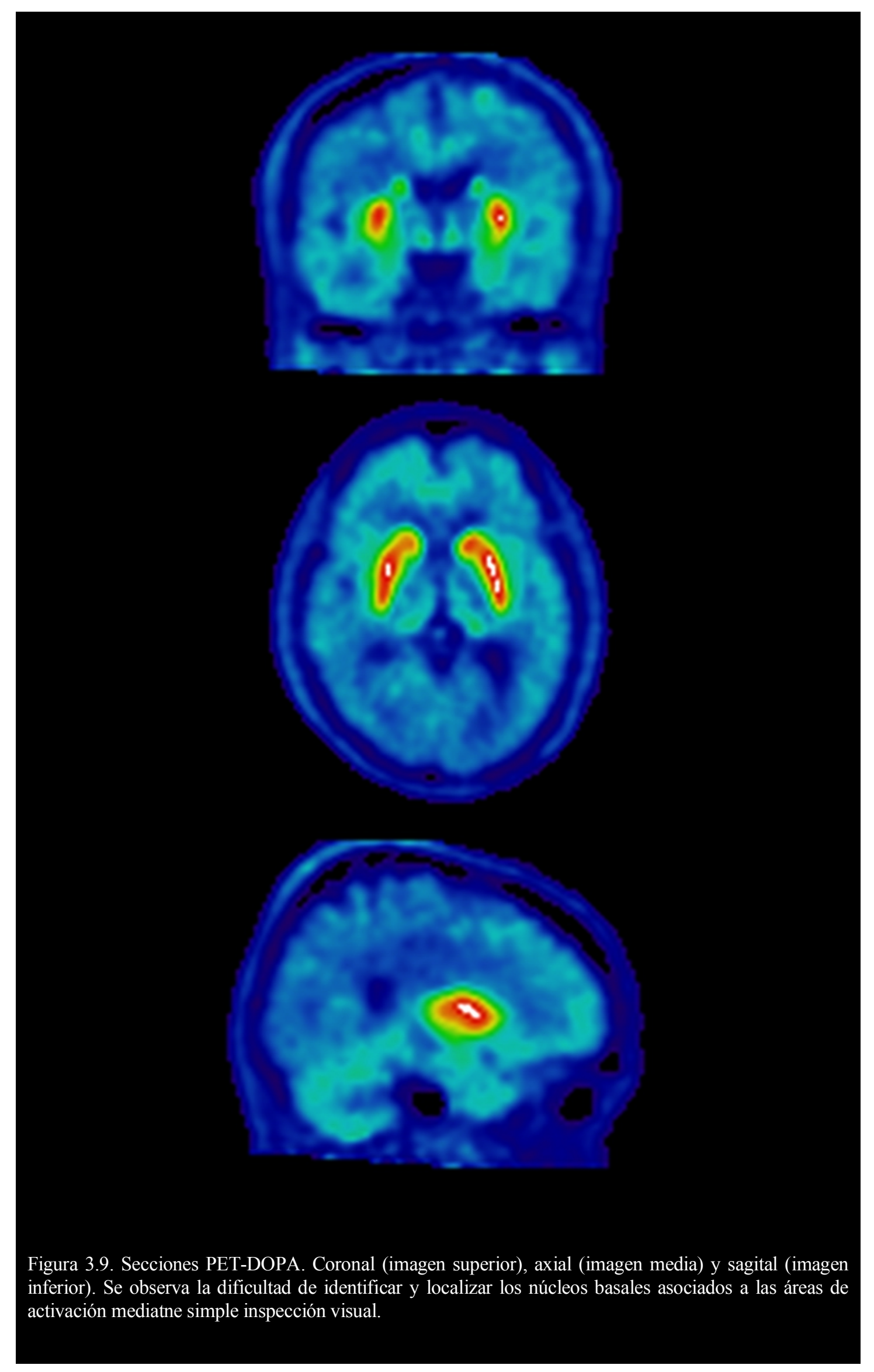




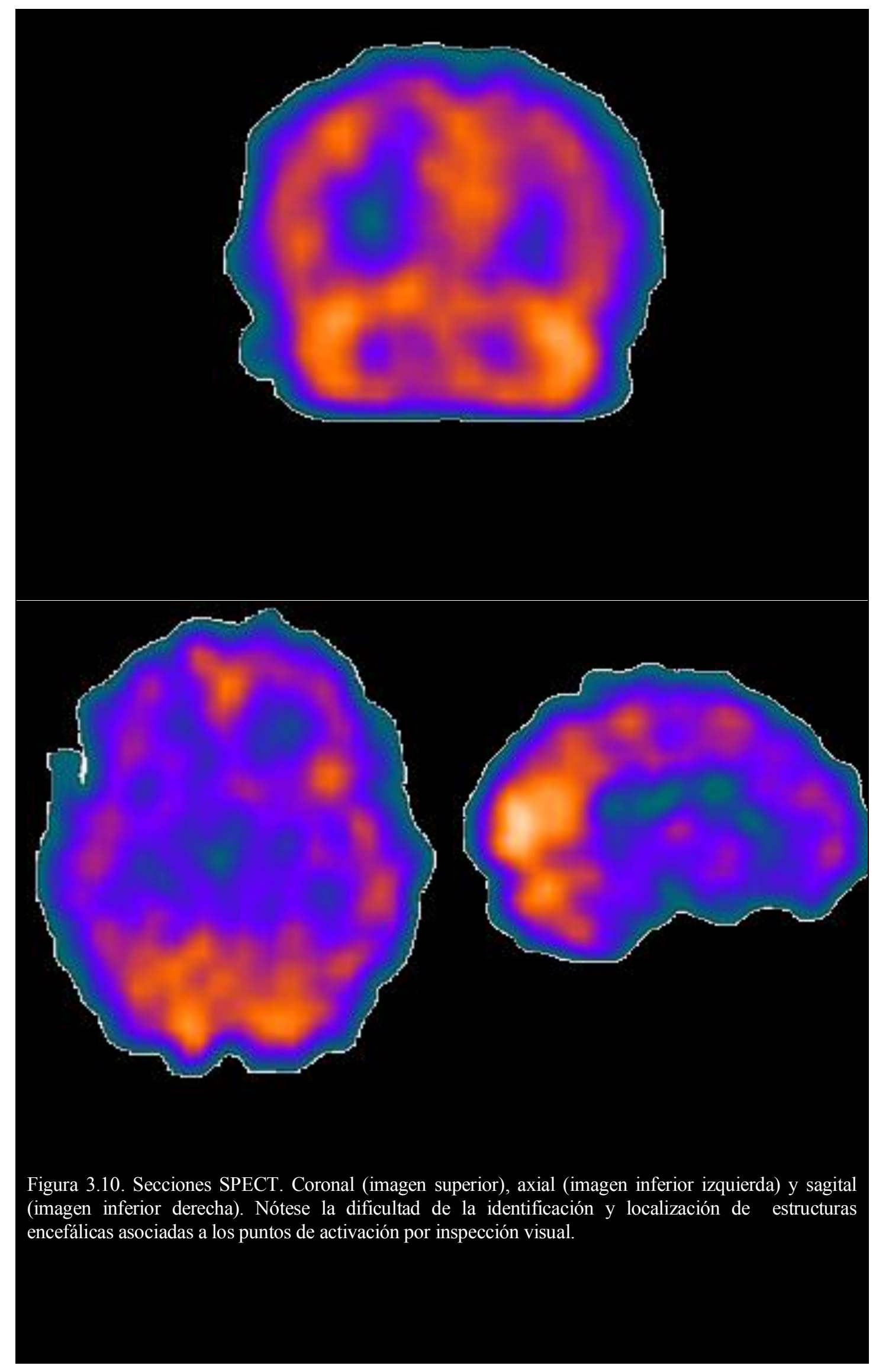




\section{Segmentación y delimitación de las Regiones de Interés (ROIs)}

Consistió en la identificación y delimitación lineal de las imágenes anatómicas y radiológicas adquiridas en regiones homogéneas respecto a algún criterio formal. En nuestro caso: el nivel de sustancia gris, brillo y contraste en correspondencia con las estructuras encefálicas previamente seleccionadas.

Se consideraron dos estrategias: segmentación binaria (binary segmentation), según la cual nos preguntamos si un vóxel determinado pertenece a las estructuras encefálicas seleccionadas, respondiendo de forma afirmativa o negativa; y segmentación ponderada (fuzzy segmentation) que consiste en asignar a cada vóxel una determinada probabilidad de pertenecer a una estructura concreta. La primera es característica de la estrategia de segmentación manual utilizada en este trabajo. La segunda, sólo resulta útil en la segmentación automática, donde se clasifica cada vóxel según su intensidad, independientemente de su localización, y se seleccionan valores umbral, superior e inferior, que delimitan un rango de intensidades determinado. En este caso, el proceso de renderizado del volumen se realiza directamente (renderizado directo del volumen, sin necesidad de un paso explícito de segmentación previa). Éste hubiera sido el método de elección para discriminar entre hueso o tejido muscular en TC o RM, pero nuestro trabajo se ha centrado en la generación volumétrica de tejido blando para la que no existen actualmente algoritmos que permitan reconstrucción automática, por lo que hemos empleado un proceso de segmentación manual basado en una estrategia de segmentación binaria. La segmentación automática nos hubiera conducido a clasificar incorrectamente tejidos blandos como grasa y sustancia blanca. Aparecerían varias estructuras encefálicas en una sola región (problema de subsegmentación), o una determinada estructura anatómica podría contener varias regiones segmentadas (problema de sobresegmentación).

La segmentación se basó en la delimitación manual, empleando el correspondiente editor de Amira ${ }^{\circledR}$ y supervisión por parte de un observador experto, aportando más robusted que los métodos de segmentación automática disponibles a través de algoritmos. El etiquetado se realizó de forma jerárquica. Inicialmente se diferenció entre sustancia blanca y gris. Posteriormente, se identificaron las estructuras corticales y subcorticales globales, sin considerar grupos nucleares, a partir del conocimiento neuroanatómico y organización espacial de las distintas estructuras utilizando como ayuda los landmarks.

El proceso de segmentación fue muy laborioso y exigente en cuanto a consumo de tiempo, al realizarse de forma individual para cada conjunto de datos y bajo la supervisicion de un anatomista. El hipocampo y el núcleo subtalámico fueron las estructuras más difíciles de delimitar. 


\section{Delimitación de bordes y etiquetado}

Posteriormente, se procedió a la detección de bordes relativos a las estructuras encefálicas profundas seleccionadas en base a su forma, tamaño y localización. En general, cuanto más rápido se produce el cambio de intensidad en la imagen, más fuerte es el borde. Un buen proceso de detección de bordes facilita la elaboración de las fronteras de las estructuras encefálicas 3D a modelar, con lo que el reconocimiento de objetos se facilita. Precisamente, dado que el cambio de intensidad o borde entre muchas de las estructuras que nos ocupan es difícilmente perceptible, por la falta de nitidez en sus límites, empleamos estrategias de segmentación manuales, en vez de algoritmos de segmentación automáticos. El suavizado de bordes sí se realizó de forma automática, a través del módulo de Amira ${ }^{\circledR}$ correspondiente, basándose en el promedio de los píxeles de una región.

El etiquetado de ROIs se realizó de forma bilateral identificando los diferentes ROIs con términos con sentido como "cuerpo_calloso", "ventrículo_lateral", o "putamen". El correcto etiquetado requiere cuidar la forma en la que se hayan escrito los nombres, incluyendo mayúsculas y minúsculas y asegurarse de que se hayan incluido todas ellas. Para ello, se creó un campo de etiquetado (LabelField) para cada uno de los conjuntos de datos con la lista completa de estructuras en orden jerárquico, a los que se les asignó un color diferente.

\section{Extracción de la superficie}

La visualización de volúmenes en ordenadores convencionales requiere un paso previo que consiste en la extracción de la superficie. Este paso reduce, significativamente, el peso de los datos y como resultado, también los tiempos de procesamiento requeridos para su visualización. Consiste en crear representaciones intermedias de la superficie en forma de mallas poligonales, asociadas a las estructuras encefálicas seleccionadas. Contienen la información a partir de la cual se van a renderizar las imágenes. En nuestro caso los elementos empleados para la composición de la superficie fueron triángulos (proceso denominado triangulación) (Figura 3.11). 

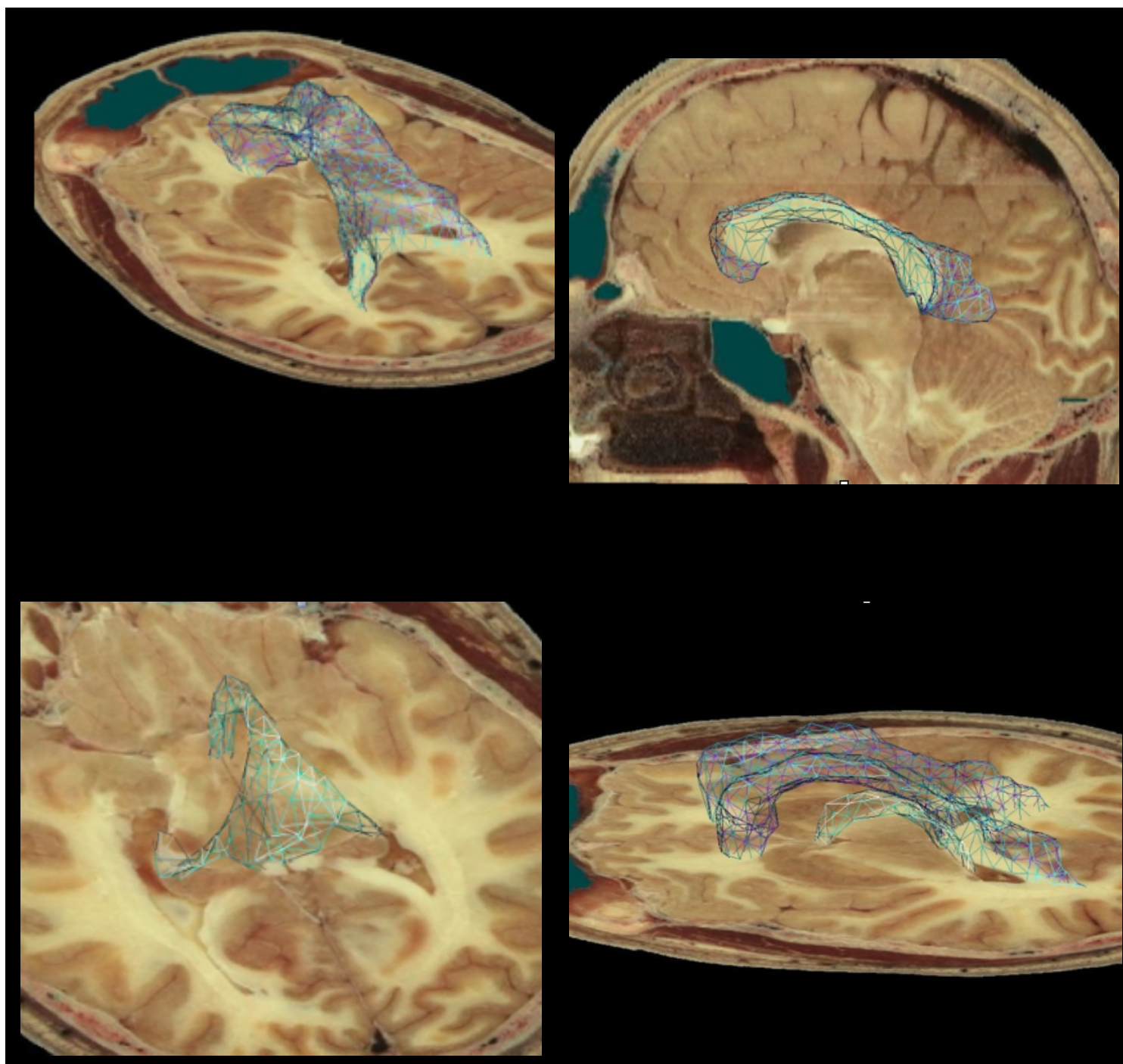

Figura 3.11. Estructura en malla triangular del cuerpo calloso, el fórnix, los VL y el tálamo. Se observa la composición de la superficie de la estructura en forma de triángulos embedidos en secciones axiales del VHP para distintas estructuras encefálicas. El cuerpo calloso (imágenes superiores), el fórnix (imagen media izquierda), el conjunto formado por el cuerpo calloso y el fórnix (imagen media derecha) y el conjunto VL y tálamo (imagen inferior). 


\section{Registro y fusión multimodal}

Consistió en la alineación de los ROIs en los tres planos de referencia y su transformación o edición, para comparar conjuntos de datos individuales. La alineación supuso la incorporación de los diferentes conjuntos de datos originales, adquiridos desde diferentes orientaciones, a un sistema de coordenadas común. El registro consiste en la comparación y ajuste de la posición y orientación de los conjuntos de datos correspondientes a imágenes de diferentes modalidades, hasta que la información mútua de los dos conjuntos de datos se maximiza. Para este proceso, se emplearon puntos de referencia, a partir de los cuales se calculó la transformación (rotación y traslación) que minimiza la suma de las distancias entre los centros de gravedad de las diferentes estructuras y permiten la máxima correspondencia entre los conjuntos de datos de las imágenes de cada modalidad.

Los puntos de referencia o landmarks, constituyen los parámetros que permiten alinear las secciones y adquirir las imágenes en los mismos ángulos. Se trata de puntos craneométricos, unidos por segmentos cortos y proyectados en los planos coronal, axial y sagital. Se emplearon los siguientes: nasal o nasión, en la parte anterior e inión en la parte posterior, y la línea órbitomeatal y el centro del conducto auditivo externo.

En nuestro trabajo empleamos la integración o registro de modelos 3D generados a partir de secciones radiológicas morfológicas y funcionales originales. Difiere del tradicional sistema de registro basado en la estandarización anatómica (o normalización espacial), consistente en la transformación de las imágenes obtenidas de un sujeto en un encéfalo estándar de referencia y, por otro lado, el corregistro, que consiste en la unión de imágenes de diferentes modalidades, pertenecientes a un mismo sujeto.

\section{Renderizado}

El renderizado del volumen consistió en la visualización de datos volumétricos a partir de imágenes médicas correspondientes a las diferentes estructuras encefálicas, mediante la aplicación de color y textura.

El renderizado directo del volumen consiste en la visualización directa de la superficie de una estructura encefálica, a partir de los datos del volumen. En este caso, la visualización resulta de la aplicación de un sofisticado algoritmo denominado Proyección de Máxima Intensidad, según el cual, se asignan parámetros de emisión y absorción de luz a cada punto del volumen. Esta simulación del paso de luz a través del volumen, hace posible mostrar los datos desde cualquier dirección sin construir modelos poligonales intermedios. Este sistema es adecuado para visualizar el interior de pequeños vasos como en la TC o RM angiografía, sin necesidad de segmentación, aunque podría fallar en vasos sanguíneos especialmente pequeños. 
El problema del renderizado directo del volumen es que al evitar decisiones binarias, las las imágenes resultantes son muy suaves, casi transparentes y difíciles de interpretar. Además, el renderizado directo del volumen es lento en comparación con la extracción de superficies, porque las operaciones de ponderación y sombreado se tienen que realizar para muchos vóxeles en cada rayo y la gran cantidad de datos que requiere manejar, simultáneamente, demanda el uso de ordenadores con potentes tarjetas de aceleración de gráficos.

En este trabajo se prefirió el sistema de renderizado basado en la extracción de superficies mediante la técnica de isosuperficies, que representa una determinada estructura encefálica con puntos de valor constante dentro de un volumen, por ejemplo, en el caso de datos volumétricos de TC, valores de intensidad constante en medidas $\mathrm{UH}$.

El algoritmo utilizado fue Marching Cubes que permitió la extracción de mallas poligonales de una isosuperficie a partir de vóxeles. Requiere dividir el espacio en vóxeles formados por los valores de intensidad de los 8 vértices del vóxel (cubo), correspondientes a los datos volumétricos originales. El algoritmo recorre cada uno de los vóxeles y, si una o más esquinas del vóxel tiene valores menores que el isovalor especificado, y una o más esquinas tienen valores mayores que el isovalor, sabemos que el vóxel forma parte de la isosuperficie. Posteriormente, determinando qué lados del vóxel son intersectados por la isosuperficie, podemos crear polígonos triangulares que dividirán el vóxel en regiones que están dentro de la isosuperficie y otras que están fuera. Como el cubo está formado por 8 lados, existen $2^{8}$ (256) maneras distintas en las que la isosuperficie puede atravesar el vóxel y delimitan hasta 15 tipos de polígonos triangulares del vóxel por la isosuperficie. Finalmente, conectando los polígonos triangulares de cada uno de los vóxeles que se encuentran en la frontera de la isosuperficie, se obtiene una representación mallada de la isosuperficie con el isovalor buscado. Se trata de un algoritmo rápido pero que no muestra el interior del objeto, así que las disecciones no aportarían ninguna información adicional, por lo que no son consideradas en este trabajo.

El procedimiento de elaboración de modelos en malla a partir del algoritmo Marching Cubes va seguido de la aplicación de determinados algoritmos con la intención de simplificarlos y suavizarlos.

El guiado visual acompañó todo el proceso, lo que requirió de la visualización simultánea del modelo de superficie y de los planos de la neuroimagen de referencia. Como hemos mencionado, se emplearon como landmarks estructuras fácilmente identificables de forma visual y puntos craneométricos. Finalmente, se obtuvo un fichero en formato DirectX del modelo de superficie definitivo de la estructura a reconstruir.

En las Figuras 3.12 y 3.13 se observa la representación de distintos modelos en malla triangular para distintas estructuras encefálicas antes de la generación volumérica final. La creación de estos contornos 3D con una forma de visualización más simple, como los modelos en malla o alambre, permitió reducir la demanda de recursos en los ordenadores. 

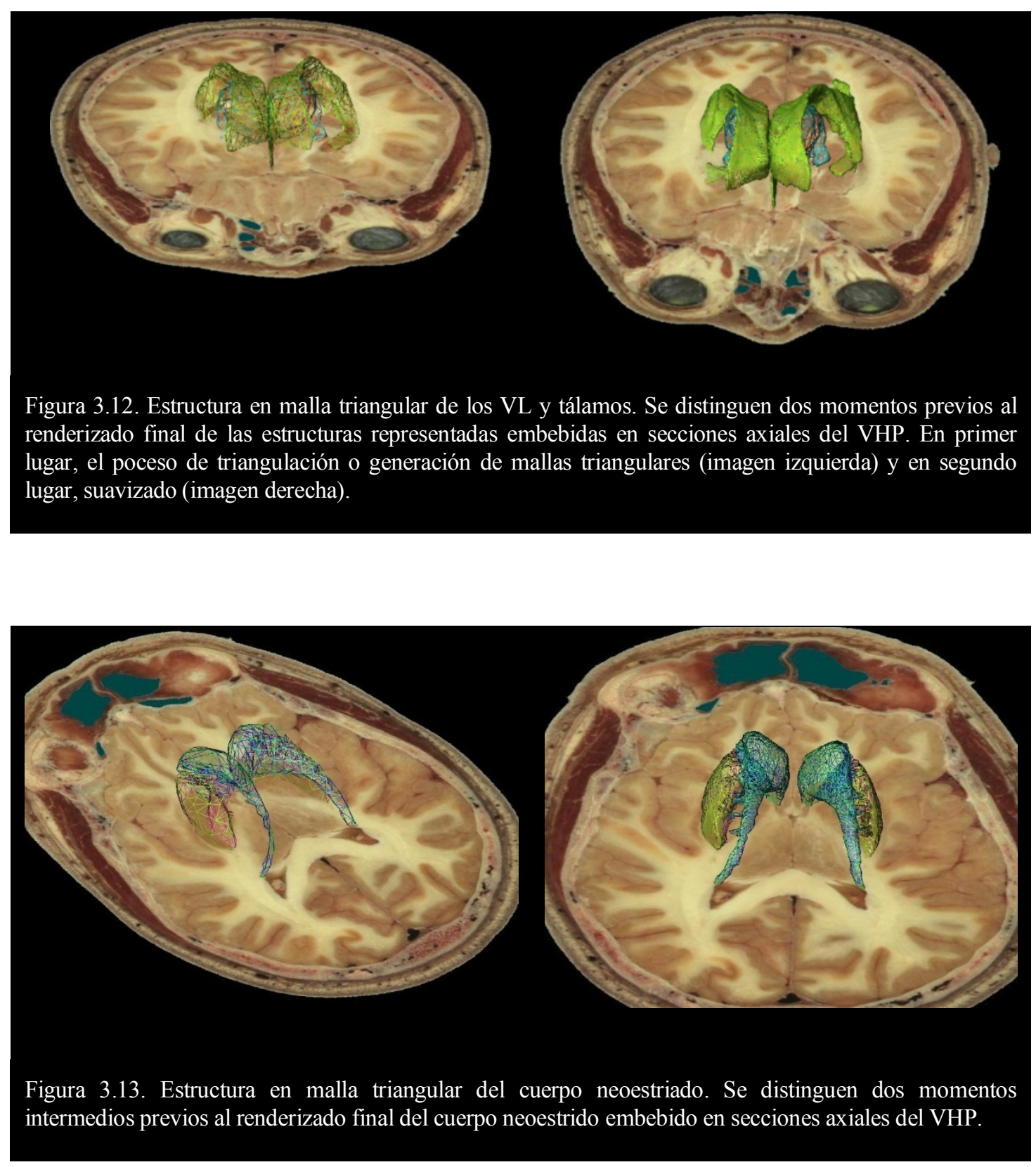

La herramienta empleada durante el proceso de segmentación, edición de superficies, suavizado libre de intersecciones, registro, creación de modelos poligonales y mallas volumétricas necesarias, para la simulación avanzada de los volúmenes reconstruidos y el renderizado final fue Amira ${ }^{\circledR}$. Dichos volúmenes fueron verdaderas representaciones de las características y variaciones morfológicas de un sujeto determinado. 


\section{Estudio empírico sobre la eficacia de la visualización volumétrica}

Se diseñó un cuasiexperimento de dos condiciones intersujeto para prevenir efectos de práctica tales como aprendizaje o fatiga durante el cambio de condición de visualización. El grupo control completó una tarea de identificación/localización de estructuras encefálicas profundas en secciones convencionales 2D. En la condición experimental se emplearon las mismas secciones con generaciones volumétricas de varias estructuras encefálicas profundas embebidas en ellas.

Las variables dependientes (VD) fueron: rendimiento o nivel de ejecución, definido como el porcentaje de aciertos, tiempo de respuesta (TR) y grado de certeza subjetivo en la respuesta estimada en una escala de 0 a 10.

Se controlaron variables relacionadas con el individuo: sexo, formación y aptitud visoespacial; y variables relacionadas con la tarea: modalidad de la neuroimagen y dificultad de las estructuras diana a identificar. En ambos grupos se incluyeron el mismo número de secciones en el plano axial, coronal y sagital para cada estructura a identificar.

Inicialmente se procedió a la generación volumétrica de las estructuras encefálicas a utilizar mediante Amira ${ }^{\circledR}$, como se describió previamente. Se comenzó con la segmentación interactiva de las neuroimágenes y delimitación de las regiones de interés (ROIs) para cada estructura. El sistema de renderizado fue por extracción de superficies y se emplearon landmarks para el registro final.

Los participantes fueron asignados de forma aleatoria al grupo control de visualización convencional (2D) y al grupo experimental de visualización volumétrica (2D/3D). La realización del experimento y recogida de datos se realizó mediante un navegador web, a través de una aplicación diseñada para este fin y donde el ratón fue el dispositivo empleado para la recogida de datos que se almacenaron en dos ficheros "resultados_2D.xls" y "resultados_3D.xls", posteriormente, integrados en un archivo "datos.sav" de SPSS.

La dificultad, baja o alta, de las estructuras a identificar/localizar, se estableció por consenso según el criterio de tres neuroanatomistas de las Universidades de Barcelona, Madrid y Salamanca que actuaron como jueces expertos. Se consideraron estructuras encefálicas profundas con alta dificultad de identifiación/localización: amígdala, hipocampo y núcleo subtalámico; y estructuras con baja dificultad de identificación/localización: núcleo caudado, tálamo y núcleo putamen.

La prueba se aplicó íntegramente de forma computarizada a través de internet. Se comenzó con la presentación de instrucciones y un ítem a modo de ejemplo, como adaptación a aspectos de la tarea:lectura de pantallas, procedimiento de respuestas, tipo de tareas que se van a solicitar y forma de responder a modo de ejemplo. La prueba constó de 36 ítems presentados de forma aleatoria, para evitar posibles efectos del orden de presentación. La duración total de las 
sesiones fue de, aproximadamente, 15 minutos. Tras un descanso de 5 minutos, se procedió a la evaluación computarizada de la aptitud visoespacial de los participantes a partir de un test de desarrollo de superficies estandarizado.

Los datos se analizaron con SPSS (Statistical Package for the Social Sciences) versión 18.0 para Windows. En primer lugar, se calcularon los descriptivos de tendencia central y dispersión para las variables analizadas según condición. Posteriormente, se analizó el coeficiente de correlación de Pearson para las variables edad y porcentaje de aciertos. El efecto principal de la condición de visualización se analizó a través de una prueba t de Student. El efecto de la condición de visualización según el nivel de formación se calculó mediante un ANOVA (análisis de varianza) univariante. El análisis del efecto según la modalidad de la neuroimagen y dificultad de las estructuras a identificar/localizar en cada condición experimental se realizó mediante un ANOVA de medidas repetidas. El nivel de significación para las pruebas fue del $95 \%$. 



\section{Resultados}

En primer lugar, presentaremos los resultados del estudio bibliométrico realizado sobre la producción científica en Neuroimagen dentro del contexto de la investigación en neurociencias y conducta. Estos resultados reflejan la relevancia de los hallazgos de las técnicas de diagnóstico por imagen en el estudio de la relación entre estructuras y función del encéfalo y funciones neuropsicológicas. En segundo lugar, nos centraremos en la implicación de determinadas estructuras encefálicas profundas (referidas en el apartado 1.1) en las enfermedades neurológicas y trastornos psiquiátricos (para ampliar información, consultar el apartado 1.6), en base a los resultados de la extensa revisión bibliográfica desarrollada, dirigida a analizar estudios que han empleado técnicas morfológicas y funcionales (técnicas descritas en el apartado 1.2). En tercer lugar, describiremos las características morfológicas y relaciones de vecindad de los volúmenes generados, correspondientes a las estructuras encefálicas seleccionadas por su relevancia clínica, embebidas en secciones morfológicas y funcionales. No se pretende ofrecer un atlas exhaustivo de todas las estructuras encefálicas, sino de aquéllas clínicamente relevantes, en base a los resultados de los estudios revisados que proponen su implicación en las enfermedades neurológicas y trastornos indicados. Finalmente, presentaremos los resultados obtenidos en el estudio empírico realizado dirigido a analizar la efectividad de la visualización combinada 2D/3D en la interpretación de neuroimágenes.

\subsection{RELEVANCIA ACTUAL DE LA NEUROIMAGEN EN NEUROCIENCIA Y CONDUCTA}

En la última década, los dos países líderes en el estudio de la relación entre el encéfalo y el comportamiento normal y patológico, según el número de investigaciones publicadas en revistas de impacto y citas asociadas a sus principales centros de investigación, han sido EEUU con 126.115 publicaciones y 3.075 .762 citas y Reino Unido con 24.844 publicaciones y 612.210 citas. Sólo el Instituto Max Planck en Alemania y la Universidad McGill en Canadá destacan como centros más prolíficos ajenos a EEUU y Reino Unido (Tabla 4.1). España ocuparía el undécimo lugar con 9.285 publicaciones y 137.782 citas.

Los autores más sobresalientes de estos países cuentan con más de 10.000 citas cada uno en el periodo referido (Tabla 4.2). 
Tabla 4.1. Instituciones más relevantes en el campo de neurociencia y conducta.

\begin{tabular}{lll}
\multicolumn{1}{c}{ Institución } & Publicaciones & Citas \\
\hline University of Harvard (EEUU) & 6.748 & 240.014 \\
University College of London (Reino Unido) & 5.941 & 184.612 \\
Johns Hopkins University (EEUU) & 4.450 & 137.109 \\
University of California (San Francisco, EEUU) & 3.290 & 117.904 \\
University of California (Los Ángeles, EEUU) & 4.168 & 112.869 \\
Max Planck Institute (Alemania) & 3.532 & 112.863 \\
University of Columbia (EEUU) & 3.706 & 110.578 \\
University of Yale (EEUU) & 3.352 & 108.662 \\
University of California (San Diego, EEUU) & 3.185 & 100.780 \\
University of Stanford (EEUU) & 2.639 & 97.371
\end{tabular}

Tabla 4.2. Autores más relevantes en el campo de neurociencia y conducta.

\begin{tabular}{lcrl}
\multicolumn{1}{c}{ Autores } & Publi. & Citas & \multicolumn{1}{c}{ Centro de investigación } \\
\hline F.H. Gage & 122 & 14.116 & Salk Institute of Biological Studies \\
T.W. Robbins & 234 & 13.272 & University of Cambridge \\
R.J. Dolan & 185 & 13.231 & Trust Centre for Neuroimaging (UCL) \\
M.P. Mattson & 223 & 12.039 & Lab. Neuroscience National Institute on Aging (NIH) \\
K.J. Friston & 171 & 12.030 & Trust Centre for Neuroimaging (UCL) \\
J.Q. Trojanowski & 206 & 11.717 & University of Pennsylvania \\
V.M.Y. Lee & 187 & 11.672 & University of Pennsylvania \\
D.R. Weinberger & 187 & 11.672 & Clinical Brain Disorders Branch (NIMH) \\
R.C. Malenka & 83 & 10.640 & University of Standford \\
A.J. Thompson & 218 & 10.090 & University of Cambridge \\
\hline
\end{tabular}

La mitad de estos autores destacan por sus aportaciones en neuroimagen. Especialmente, R.J. Dolan con 86 publicaciones específicas en neuroimagen, A.J. Thompson, con 63 publicaciones, ocuparía el sexto lugar y K.J. Friston, a continuación, con 55 publicaciones, D.R. Weinberger, con 22 publicaciones, ocuparía el puesto sesenta y cuatro en 
cuanto a productividad en neuroimagen, y V.M.Y. Lee, el puesto 91 con 19 publicaciones en neuroimagen.

Neuroimage resultó la revista más relevante en neuroimagen, con una cuota del 11,22\% del total de las publicaciones en el campo de neurociencia y conducta en la última década. La segunda revista más importante en neuroimagen, Neurology, también supone el 4,41\% de las publicaciones en neurociencia y conducta (Tabla 4.3).

Tabla 4.3. Revistas y número de publicaciones en neuroimagen, neurociencia y conducta

\begin{tabular}{lrlr}
\hline \multicolumn{2}{c}{ Neuroimagen: Revista $/ N^{o}$ publicaciones } & Neurociencias y Conducta: Revista/N ${ }^{\circ}$ publicaciones \\
\hline Neuroimage & 1272 & Journal of neuroscience & 13.740 \\
Neurology & 500 & Neurology & 8.238 \\
Journal of neuroscience & 373 & Neuron & 3.273 \\
American Jorunal of neuroradiology & 333 & Proc. Nat. acad. Sci.USA & 3.459 \\
Brain & 277 & Brain research & 12.280 \\
Cerebral cortex & 264 & Nature neuroscience & 2.093 \\
Human brain mapping & 253 & Journal of neurochemistry & 6.918 \\
Neuroradiology & 251 & Journal of neurophysiology & 6,829 \\
Biological psychiatry & 248 & Neuroimage & 5.168 \\
Movement disoders & 238 & Neuroscience & 7.794 \\
Neuroreport & 230 & European journal of neuroscience & 6.264 \\
Psychiatry research imaging & 200 & Science & 767 \\
Journal of cognitive neuroscience & 184 & Biological psychiatry & 3.143 \\
Journal of neuroimaging & 165 & Nature & 784 \\
Brain research & 164 & Neuroscience letters & 10.555 \\
Journal of neurology & 163 & Brain & 2.564 \\
Annals of neurology & 148 & Annals of neurology \\
Archives of neurology & 141 & Journal of comparative neurology \\
Neuron & 134 & Neuroreport & 2.332 \\
\hline & & & 4.368 \\
\hline & & 5.717 \\
\hline
\end{tabular}

La evolución anual del número de revisiones (Figura 4.1) y de artículos (Figura 4.2) en Neuroimagen durante la última década, ofrece otro indicador objetivo de su acelerado ritmo de crecimiento, ilustrando la importancia, novedad y proyección de esta área en la investigación actual en neurociencia y conducta. El $56,6 \%$ de las revisiones de la última década se han realizado en los últimos 3 años (el 91,40\% publicadas en inglés y sólo el 1,04\% en castellano). 


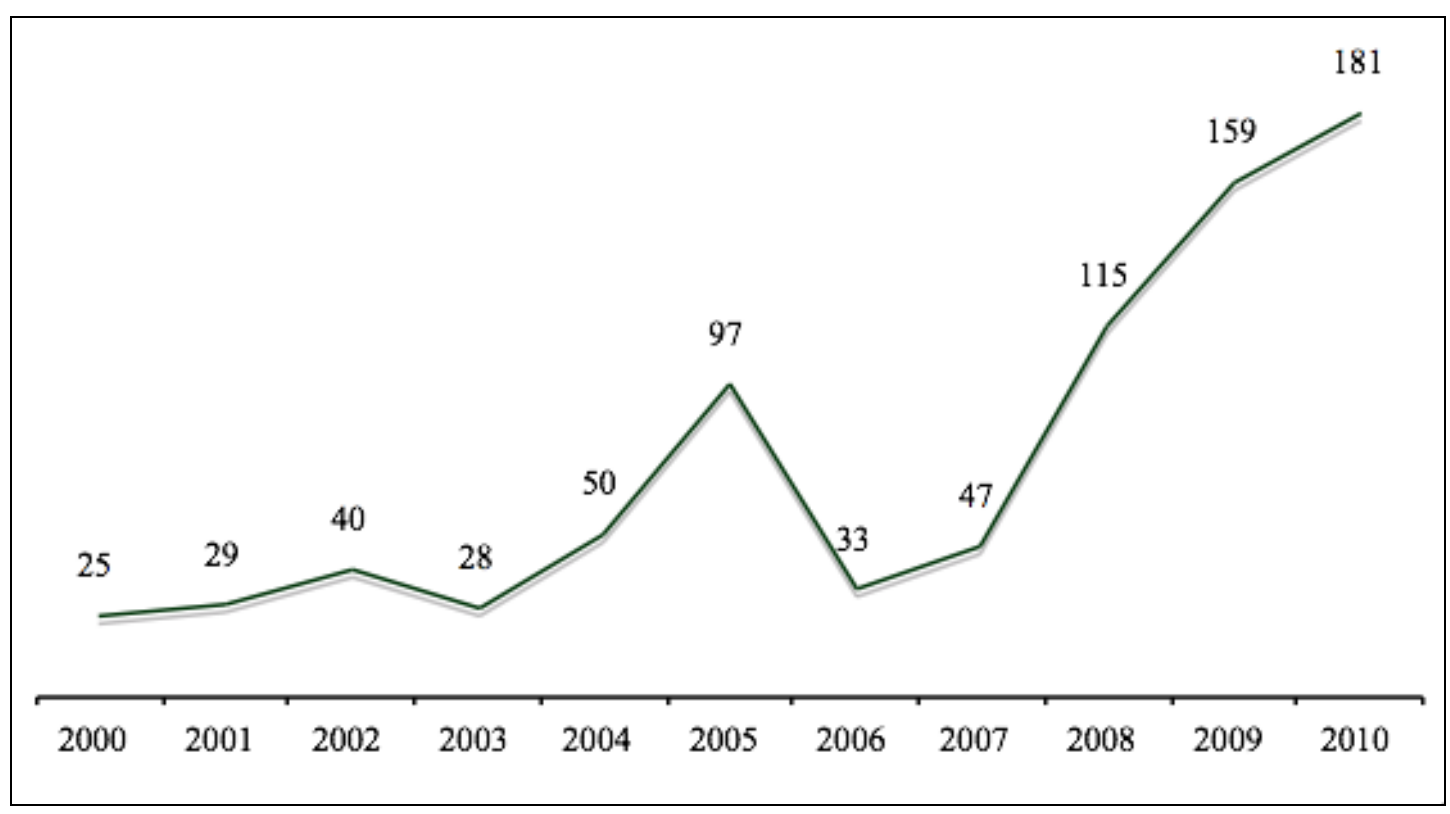

Figura 4.1. Evolución del número de artículos de revisión en Neuroimagen.

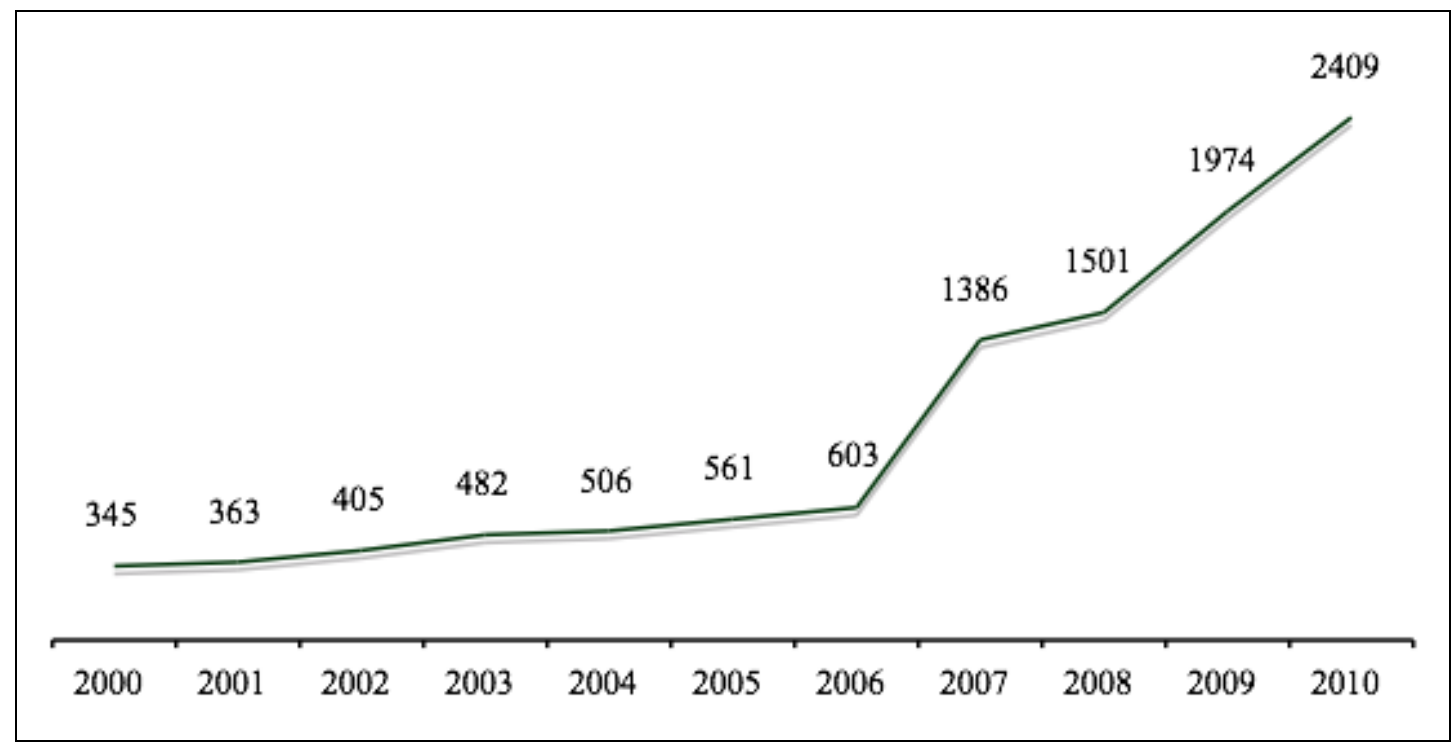

Figura 4.2. Evolución del número de artículos en Neuroimagen. 


\subsection{ESTRUCTURAS ENCEFÁLICAS IMPLICADAS EN TRASTORNOS NEUROPSICOLÓGICOS}

De los 804 artículos de revisión registrados bajo los términos "brain imaging" en las bases de datos del ISI en la última década, se seleccionaron aquéllos incluidos bajo las categorías Neurología Clínica, Neuroimagen, Radiología, Medicina Nuclear, Imaginería médica, Psiquiatría, Psicología Clínica, Anatomía y morfología, que aparecen en la Tabla 4.4. Se presentan el número de revisiones por categoría (no excluyentes entre sí) y el porcentaje respecto al total de 804 artículos.

Tabla 4.4. Número y porcentaje de revisiones en brain imaging según categoría.

\begin{tabular}{lrr}
\hline \multicolumn{1}{c}{ Categoría } & \multicolumn{2}{c}{$N^{o}$} \\
\hline Neurología Clínica & 226 & 45,2 \\
Neuroimagen & 61 & 12,2 \\
Radiología, Medicina Nuclear e imaginería médica & 258 & 51,6 \\
Psiquiatría & 100 & 20,0 \\
Psicología Clínica & 5 & 1,0 \\
Anatomía y morfología & 2 & 0,4 \\
\hline
\end{tabular}

Se excluyeron artículos cuyos títulos y palabras clave no hacían referencia al estudio de estructuras encefálicas implicadas en las enfermedades neurológicas y trastornos psiquiátricos considerados en el apartado introductorio (apartado 1.6) o que no habían empleado las técnicas de diagnóstico por imagen descritas (apartado 1.2). Paralelamente, se incluyeron artículos mencionados en las referencias de los artículos seleccionados, y considerados pertinentes en base al contenido de su título.

A continuación se presentan los resultados del análisis de los artículos seleccionados, destacando aquellas estructuras encefálicas macroscópicas propuestas como sustrato biológico de las enfermedades y trastornos señalados por la literatura revisada. Por lo tanto, estos estudios ofrecen evidencia a favor e la implicación de dichas estructuras en las funciones neuropsicológicas afectadas en una de las condiciones clínicas referidas.

Por facilitar la interpretación de los datos, se ha omitido la modalidad morfológica o funcional de las técnicas empleadas para la obtención de los resultados en cada estudio. Para un análisis de estas características, consultar los apartados introductorios 1.2 y 1.6.

En la Tabla 4.5 se incluyen los resultados de los artículos revisados relativos a estructuras encefálicas macroscópicas implicadas en enfermedades neurológicas y en la Tabla 4.6, aquéllos relativos a las estructuras implicadas en trastornos psiquiátricos y del desarrollo. 
Tabla 4.5. Estructuras encefálicas implicadas en enfermedades neurológicas según la literatura.

Hipocampo: Jack et al., 2000; Kogure et al., 2000; Ebmerirer et al., 2005; Becker et al., 2006; Henry-Feugeas, 2007; Lowndes \& Savage, 2007; Rabinovici et al., 2007; Ravinovici et al., 2008; Fennema-Notestine et al., 2009; Morra et al., 2009; Schroeter et al., 2009; Apostolova et al., 2010; Guo et al., 2010

Amigdala: Buckner et al., 2000; Mungas et al., 2002; Kawas, 2003; Ebmerirer et al., 2005; Ramani et al., 2006; Henry-Feugeas, 2007; Eldaief \& Dougherty, 2008,

Alzheimer Persson et al., 2008; Fennema-Notestine et al., 2009; Schroeter et al., 2009

Cuerpo calloso: Tomimoto et al., 2004; Ramani et al., 2006; Chua et al., 2008; Guo et al., 2010; Di Paola et al., 2010; Pitel et al., 2010; Seoung et al., 2010; Serra et al., 2010

VL: Carmichaelet al., 2007; Wang et al., 2008

Fórnix: Copenhaver et al., 2006; Kantarci et al., 2010 ; Pievani et al., 2010

Cuerpo estriado (*globo pálido): Eidelberg \& Edwards, 2000; Obeso et al., 2004; Olanow, 2004; Piccini \& Brooks, 2006; Obeso et al., 2008; Sharma \& Ebadi, 2008;

Yu \& Neimat, 2008*; Janke, 2009; Jubault et al., 2009; Pavase \& Brooks, 2009;

Bronstein et al., 2010

Sustancia negra: Eidelberg \& Edwards, 2000; Obeso et al., 2004; Piccini \&

Parkinson Brooks, 2006; Obeso et al., 2008; Janke, 2009; Jubault et al., 2009; Pavase \&

Brooks, 2009; Berg et al. 2005; Bronstein et al., 2010

Núcleo subtalámico: Visser-Vandewalle et al., 2005; Anatonelli et al., 2010;

Chereau et al., 2010; Feher et al., 2010; Wylie et al., 2010; Boon et al., 2011;

Rodríguez-Oroz et al. 2011

Tálamo: Schulde et al., 2003; Zivadinov \& Cox, 2007; Ghaffar \& Feinstein, 2007; Rashid \& Miller, 2008; Moore et al., 2009; Trovar-Moll et al., 2009;

Esclerosis Rocca et al., 2010; Yokoyama, et al., 2010; Zhou et al., 2010

Múltiple Cuerpo estriado: Calabrese et al., 2010; Paseve et al., 2010; Yokoyama, et al., 2010 
Tabla 4.6. Estructuras encefálicas implicadas en trastornos psiquiátricos y del desarrollo según la literatura.

GCA: Thakkar et al., 2008; Thakkar et al., 2008; Di Martino et al., 2009; Agam et al., 2010; Forbes et al., 2010; Noriuchi et al., 2010; Chan et al., 2011

Amígdala: Sparks et al., 2002; Amaral, 2003; Schumann et al., 2004; Schultz, 2005; Munson et al., 2006; Schumann \& Amaral, 2006; Skuse, 2006; Arehart-Treichel, 2007; Amaral \& Corbett, 2008; Blair, 2008; Brun et al., 2009; Mosconi et al., 2009; Ulay et al., 2009; Dziobek et al., 2010;

Autismo Green et al., 2010; Kim et al., 2010; Kleinhans et al., 2010; Monk et al., 2010; Neuhaus et al., 2010; Verhoeven et al., 2010

Cuerpo estriado (núcleo caudado): Stanfield et al., 2008; Thakkar et al., 2008; Brun et al., 2009; Langen et al., 2009; Forbes et al., 2010; Qiu et al., 2010; Verhoeven et al. 2010

Tálamo: Brun et al., 2009; Verhoeven et al., 2010; Tamura et al., 2010 Cuerpo calloso: Kilian et al., 2008; Stanfield et al., 2008; Casanova et al., 2009; Brun et al., 2009; Noriuchi et al., 2010; Verhoeven et al., 2010

$V L$ :Wright et al., 2000; Antonova et al., 2004; DeLisi et al., 2004; Strasser, Lilyestrom et al., 2005; Pol et al. 2008; Czechowska et al. 2009; Wexler et al. 2009; Puri et al. 2010; McDonald et al. 2006; Kempton et al., 2010; Rosa et al. 2010 ; Tanskanen et al. 2010

CPF-DL: Callicott et al., 2000; Jansma et al, 2001; Riehemann et al., 2001; Bunney et al., 2003; Niznikiewicz et al., 2003; Antonova et al., 2004; Heinz et al., 2004; Hill et al., 2004; Hulshoff Pol et al., 2004; Hulshoff Pol et al., 2006; Iritani, 2007; Kalus et al., 2008; Kéri, 2008; Lawrie et al., 2008; Venkatasubramanian et al., 2008; Fornito et al., 2009; Kawada et al., 2009; Esquizofrenia McDonald et al., 2009; Ragland et al., 2009; Farzan et al., 2010; Fung et al., 2010; Rosso et al., 2010; Sismanlar et al., 2010; Zavitsanou et al., 2010; Heinz et al., 2011; Lesh et al., 2011

GCA: Yücel et al., 2003; Haznedar et al., 2004; Fujiwara et al., 2007; Fornito et al., 2009; Costain, Crawley, Mikulis, Brzustowicz, Chow, \& Bassett, 2010; Ellison-Wright \& Bullmore, 2010; Jung et al., 2010; Patel et al., 2010; Pomarol-Clotet et al., 2010; Smieskova et al., 2010; White et al., 2010; Lesh et al., 2011

Hipocampo : Seidman et al., 2003; Niznikiewicz et al., 2003; Antonova et al., 2004; Achim \& Lepage, 2005; Honea et al., 2005; Iritani, 2007; Kalus et 
al., 2008; McDonald et al., 2009; Javadapaour et al., 2010; Koolschijn et al., 2010; Mamah et al., 2010; Rimol et al., 2010; Sismanlar et al., 2010; Witthaus et al., 2010

Cuerpo calloso:

Burns et al., 2003; Niznikiewicz, Kubicki, \& Shenton, 2003; Buchsbaum et al., 2005; Kubicki et al., 2005; Meyer-Lindenberg et al., 2005; Stephan et al., 2006; Uchino et al., 2006; Kubicki et al., 2007; Lawrie et al., 2008; Szeszko et al., 2008; Walterfang et al., 2008; Puri, 2010

Tálamo: Clinton \& Meador-Woodruff, 2004; Crespo-Facorro et al., 2007 ; Byne et al., 2009; Coscia et al., 2009; Qui et al., 2009; Ellison-Wright \& Bullmore, 2010; Moghaddam, 2010

Núcleos basales: Mitelman et al., 2009 (putamen); Levitt et al., 2009 (caudado)

Amigdala: Kim et al., 2004; Adolphs et al., 2005; Deckersbach et al., 2006; Brewin, 2008

Trastorno Hipocampo: Newport \& Nemeroff, 2000; Sapolsky, 2003; Ruiz, 2004; Estrés Deckersbach et al., 2006; Tupler \& De Bellis, 2006; Gilbertson et al., 2007

Postraumático GCA: Frannk et al., 2004; Das et al., 2005; Etkin et al., 2006; Shin \& Liberzon, 2010; Van Tol et al., 2010

CPF y cuerpo estriado (núcleo lenticular y caudado)

Trastorno López-Ibor Alcocer et al., 2000; Van den Heuvel et al., 2005; Lipsman et al., Obsesivo Compulsivo 2007; Menzies et al., 2007; Christian et al., 2008; Menzies et al., 2008; Radua $\&$ Mataix-Cols, 2009; Bear et al., 2010; Radua et al., 2010; Rotge et al., 2010; Van den Heuvel et al., 2010

$C P F$ (CPF-DL y GCA) : Frank et al., 2004; Cavedini et al., 2006; Friederich et al., 2007; Pieters et al., 2007; McCormick et al., 2008; Redgrave et al., 2008; Anorexia $\quad$ Kaye et al., 2009; Van Den Eynde \& Treasure, 2009; Van Kuyck et al., 2009; Nerviosa Zastrow et al., 2009; Castro-Fornieles et al., 2010; Joos et al., 2010; Miyake et al., 2010; Miyake et al., 2010

Amigdala: Friederich et al., 2007; Miyake et al., 2010

$C P F-D L$ :

Deckersbach et al., 2006; Maletic et al., 2007; Serene et al., 2007; Clark et al., 2009; Cook et al., 2009; Takahashi et al., 2009; Portella et al., 2009; Cooney et 


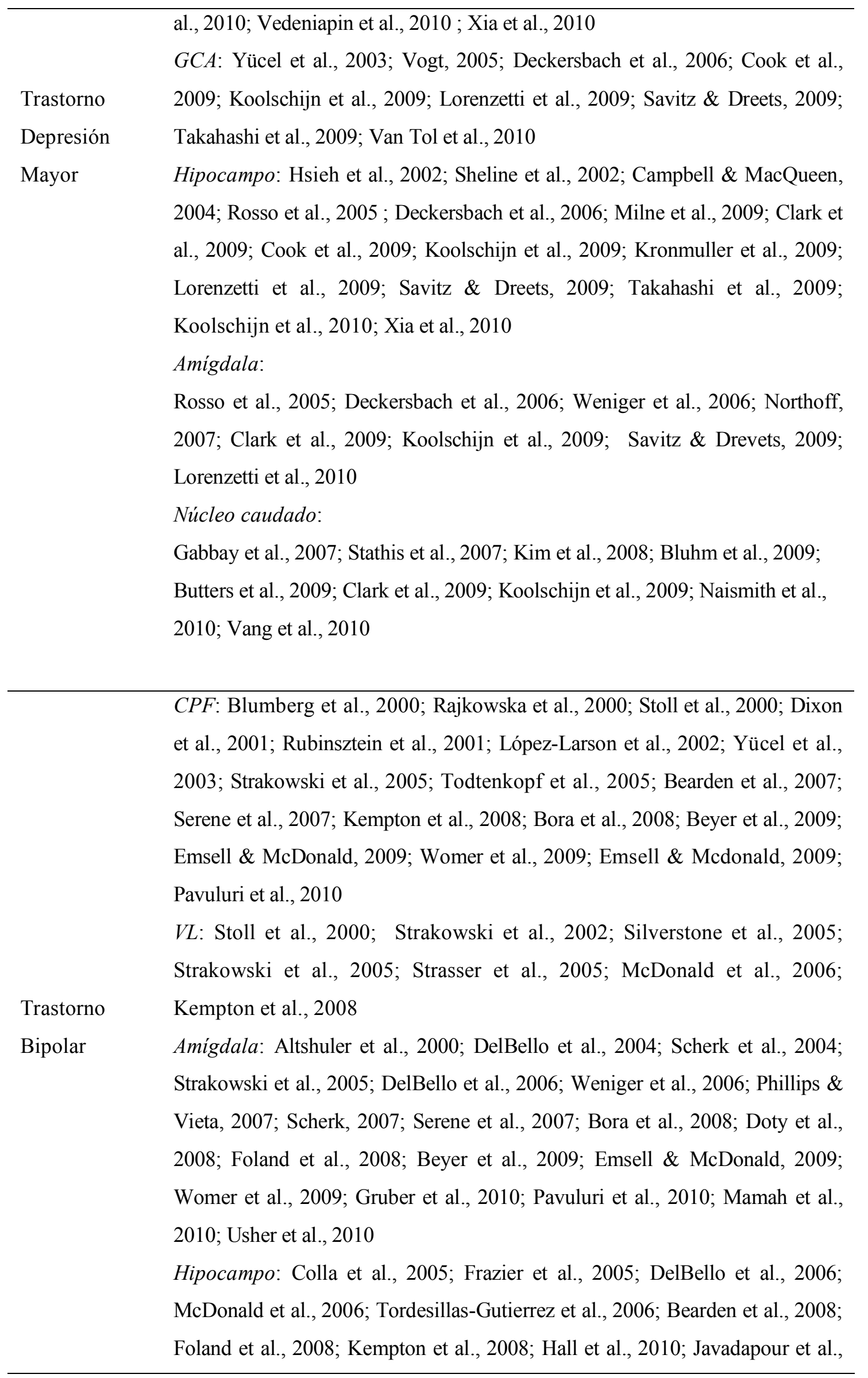


Trastorno $\quad C P F$ : Blumberg et al., 2000; Rajkowska et al., 2000; Stoll et al., 2000; Dixon Bipolar et al., 2001; Rubinsztein et al., 2001; López-Larson et al., 2002; Yücel et al., 2003; Strakowski et al., 2005; Todtenkopf et al., 2005; Bearden et al., 2007; Serene et al., 2007; Kempton et al., 2008; Bora et al., 2008; Beyer et al., 2009; Emsell \& McDonald, 2009; Womer et al., 2009; Emsell \& Mcdonald, 2009; Pavuluri et al., 2010

$V L$ : Stoll et al., 2000; Strakowski et al., 2002; Silverstone et al., 2005; Strakowski et al., 2005; Strasser et al., 2005; McDonald et al., 2006; Kempton et al., 2008

Amígdala: Altshuler et al., 2000; DelBello et al., 2004; Scherk et al., 2004; Strakowski et al., 2005; DelBello et al., 2006; Weniger et al., 2006; Phillips \& Vieta, 2007; Scherk, 2007; Serene et al., 2007; Bora et al., 2008; Doty et al., 2008; Foland et al., 2008; Beyer et al., 2009; Emsell \& McDonald, 2009; Womer et al., 2009; Gruber et al., 2010; Pavuluri et al., 2010; Mamah et al., 2010; Usher et al., 2010

Hipocampo: Colla et al., 2005; Frazier et al., 2005; DelBello et al., 2006; 


\subsection{MORFOLOGÍA DE LAS ESTRUCTURAS ENCEFÁLICAS GENERADAS VOLUMÉTRICAMENTE}

A continuación, se ofrece un análisis descriptivo de las principales características morfológicas a nivel macroscópico, y de las relaciones de vecindad de cada una de las estructuras generadas volumétricamente, por su relevancia clínica.

Dichos volúmenes no corresponden a esquemas o representaciones probabilísticas, sino a verdaderas representaciones de las características morfológicas y espaciales de cada estructura. Los modelos 3D se presentan embebidos en secciones morfológicas y funcionales que conforman un sistema de coordenadas que facilitan la ubicación de los detalles anatómicos a nivel macroscópico de los volúmenes generados (Figura 4.3). Se incluyen muestras iconográficas de los modelos 3D de estructuras independientes, para facilitar la exploración de detalles anatómicos, y como parte de un grupo de estructuras, para ilustrar las relaciones de vecindad.

Para la facilitar la presentación lógica de las generaciones volumétricas relativas a las estructuras encefálicas profundas reseñadas, hemos seguido una trayectoria caudo-rostral. Comenzaremos por una descripción preliminar del tronco encefálico, cerebelo y hemisferios cerebrales. Sin embargo, el eje central de nuestro trabajo se ha dirigido a la generación volumétrica de estructuras diencefálicas, telencefálicas, el sistema ventricular y el fórnix y cuerpo calloso, entendidos como unidades macroscópicas. Tronco encefálico y cerebelo parecen estar menos implicados en procesos cognitivos superiores, y la corteza de los hemisferios es susceptible de segmentación automática y renderización directa del volumen. Un análisis más exhaustivo de las fibras de asociación y comisurales merecerían consideración en futuras investigaciones, empleando RM TDI.

Se incluye el renderizado directo del volumen del cráneo y de las arterias carótidas a partir de imágenes TC desde el VoxelMan ${ }^{\circledR}$ (Figura 4.7).

\subsubsection{Tronco encefálico y cerebelo}

La generación volumétrica del tronco encefálico consistió en el modelado del bulbo raquídeo, la protuberancia y el mesencéfalo. La visualización volumétrica del tronco encefálico y cerebelo aparecen integrados en secciones RM y del VHP (Figura 4.4).

En la Figura 4.4 se aprecia el ensanchamiento característico del tronco encefálico a nivel protuberancial y el origen aparente del trigémino a este nivel. En un nivel superior, por encima del mesencéfalo, se observan los cuerpos mamilares a ambos lados de la línea media .A nivel inferior, en el bulbo raquídeo se pueden identificar las pirámides bulbares. En la representación 
de los modelos 3D embebidos en secciones SPECT, se puede observar la cara superior del cerebelo (Figura 4.4).

Según los resultados de la literatura revisada, pocos trastornos psiquiátricos se han asociado con estas estructuras, a excepción del autismo o el vermis en el TB.

\subsubsection{Estructuras diencefálicas}

Se desarrollaron generaciones volumétricas bilaterales del tálamo y el núcleo subtalámico. Para facilitar la identificación y visualización de estas estructuras mediales, se ha omitido la representación del hemisferio cerebral izquierdo en algunas de las imágenes seleccionadas.

El tálamo es una estructura bilateral de forma ovalada y unos $3 \mathrm{~cm}$ de longitud que ocupa, aproximadamente, el 80\% del diencéfalo (Figura 4.5). La parte medial del tálamo delimita la pared lateral del tercer ventrículo, y la parte más anterior se caracteriza por ser más estrecha y redondeada, definiendo el límite posterior del orificio interventricular. La conexión intertalámica no resulta visible desde las vistas seleccionadas.

En base a la revisión realizada, se considera una estructura clínicamente relevante en enfermedades neurológicas como la EM y trastornos psiquiátricos como esquizofrenia y autismo, principalmente, asociado a una reducción significativa del volumen.

El núcleo subtalámico es especialmente difícil de localizar y delimitar en secciones unimodales tradicionales. Este núcleo, también conocido como cuerpo de Luys, tiene forma de lente biconvexa y se sitúa próximo al tálamo en una posición inferior y lateral, dentro de la cápsula interna, sin contacto con la luz ventricular. En la Figura 4.6 puede observarse su posición respecto al tálamo en la sección axial del VHP en la que aparece embedido.

Varios estudios revisados han propuesto la implicación del núcleo subtalámico en la EP, consistente con su participación en la integración de la función motora somática como núcleo motor extrapiramidal.

\subsubsection{Estructuras telencefálicas}

Dentro del telencéfalo se representaron, para cada hemisferio cerebral, los diferentes giros, surcos que los delimitan y los núcleos basales, a excepción del claustro o antemuro por la ausencia de implicación en trastornos neuropsicológicos, en base a la literatura revisada. Además, se representaron los grupos de fibras comisurales clínicamente más relevantes en las patologías consideradas según la literatura: el cuerpo calloso y el fórnix (Figura 4.7). 


\subsubsection{Giros}

$C P F$

En base a los resultados de los estudios analizados, el CPF, especialmente la región del CPF-DL y el GCA, han sido las áreas más relevantes desde el punto clínico en las enfermedades neurológicas (Tabla 4.5), considerándose un sustrato biológico común en los trastornos psiquiátricos seleccionados, como se aprecia en la información resumida en la Tabla 4.6.

Estos resultados son coherentes con el papel del CPF en funciones cognitivas superiores como toma de decisiones, atención, habilidades sociales, resolución de problemas, planificación, etc. Los trabajos revisados han encontrado alteraciones morfológicas y funcionales en los siguientes trastornos psiquiátricos: autismo, esquizofrenia, TEPT, TOC, AN, TDM, TB y TDAH. La degeneración más amplia del córtex cerebral, se ha asociado a demencia como la EA.

La generación volumétrica de los giros de la superficie de los hemisferios cerebrales permite distinguir la región correspondiente al CPF-DL (Figura 4.7) en secciones RM (Figura 4.8), SPECT (Figura 4.9), y el giro cingulado en secciones SPECT (Figuras 4.9 y 4.16 ) y VHP (Figura 4.9). Esta estructura también aparece en la Figura 4.4, donde se puede observar su localización en la superficie medial de los hemisferios cerebrales, rodeando la parte rostral del encéfalo y cuerpo calloso. Según la revisión realizada, la región del GCA, junto a la región del CPF-DL, han sido las áreas prefrontales más implicadas en trastornos psiquiátricos.

Desde el punto de vista anatómico, la visualización de estas reconstrucciones permite identificar la fisura longitudinal cerebral caracterizada por una profunda hendidura interhemisférica en la línea media (Figuras 4.7 y 4.8) y el surco parietoccipital (imágen superior izquierda de la Figura 4.9) o perpendicular interno en el margen superior medial de los hemisferios, unos cinco centímetros anteriores al polo occipital, discurriendo hacia posiciones basal y anterior en dicha superficie medial hasta encontrarse con la cisura calcarina, y que en algunos hemisferios cerebrales, continúa brevemente en la superficie lateral del hemisferio. La cuña o cuneus, sería el área triangular del córtex ,delimitado por el surco parietoccipital en la parte superior, por la fisura calcarina en la parte inferior y por el margen medial superior en la parte posterior. El surco parietoccipital interno delimita el lóbulo occipital desde una vista medial, y la región dorsal del giro cingulado, inmediatamente superior al cuerpo calloso (Figura 4.9).

En la Figura 4.8 también es visible el Surco de Silvio que se encuentra en las superficies laterales de los hemisferios, delimitando el área correspondiente al lóbulo temporal del lóbulo frontal y parietal, divididos a su vez, por el Surco de Rolando.

\section{Hipocampo}

El hipocampo es una estructura encefálica bilateral que se define por una elevación curva que se extiende a lo largo del suelo del asta temporal de los VL, en la cara medial de los 
hemisferios cerebrales (Figuras 4.20 y 4.21). Tiene forma de rodete semilunar, a modo de cola de un caballito de mar. La porción anterior del hipocampo es más ancha que el resto y su porción posterior contínua en el pilar del fórnix.

El hipocampo es una de las estructuras especialmente implicadas en EA, según los resultados de la revisión realizada, coherente con los síntomas clásicos de este tipo de demencia, tales como la pérdida de memoria y desorientación, y la participación de esta estructura en la formación/consolidación de recuerdos y navegación espacial. Sin embargo, trastornos psiquiátricos, especialmente en casos de esquizofrenia y trastornos del estado de ánimo como TDM y TB, también cursan con alteraciones en esta estructura.

\subsubsection{Núcleos basales}

La generación volumétrica y delimitación en imágenes 2D de estos complejos nucleares profundos, constituyó una tarea difícil por su dificultad de segmentación y número de secciones implicadas en el núcleo caudado.

Se desarrollaron modelos 3D bilaterales de los núcleos que conforman el cuerpo estriado y la amígdala, por su implicación en el control de movimientos, cognición y conducta emocional. Se omitió la representación del claustro por la ausencia de evidencia sobre su vinculación con trastornos neuropsicológicos e, incluso, su importancia biológica.

\section{Cuerpo estriado}

Se generaron volúmenes bilaterales independientes para el cuerpo estriado, formado por el núcleo caudado y el núcleo lenticular, compuesto, a su vez, del núcleo putamen y globo pálido.

La literatura revisada apoya la implicación del cuerpo estriado, como sustrato neuroanatómico, en trastornos neurológicos como EP y EM, y todos los trastornos psiquiátricos a excepción de AN.

\section{Núcleo caudado}

En la visualización volumétrica del núcleo caudado, embebido en secciones VHP y PET ${ }^{18}$ F-DOPA, puede diferenciarse la cabeza, el cuerpo y la cola, describiendo una morfología en forma de "C" (Figura 4.10). El núcleo caudado se sitúa adyacente a los VL, formando la pared lateral del asta anterior de los VL. La cabeza, de aspecto redondeado y mayor tamaño que el cuerpo y la cola, se sitúan en la región interventricular. El cuerpo sigue el contorno de cada uno de los VL. La cola, parte más larga y estrecha, continúa a partir del cuerpo en la región del extremo posterior del tálamo (Figuras 4.17 y 4.18), vuelve hacia la parte más rostral, a nivel del asta inferior del VL y termina en la parte anterior de la amígdala (Figura 4.21). 
Según los resultados de los estudios revisados, el cuerpo estriado sería una de las estructuras más implicadas en trastornos psiquiátricos como autismo, esquizofrenia, TEPT, TOC, TDM, TB y TDAH.

\section{Núcleo putamen}

El núcleo putamen es el núcleo basal de mayor tamaño y con una posición más lateralizada del núcleo lenticular. Su apariencia externa se caracteríza por estrías a través de las cuales discurre la cápsula interna $\mathrm{y}$, medialmente, se relaciona con el globo pálido. Estas características se distinguen en la representación 3D del núcleo putamen embebidas en secciones VHP (Figura 4.11).

En la generación volumétrica del cuerpo neoestriado (o simplemente estriado), formado por el núcleo caudado y núcleo putamen, destaca el aspecto estriado de la región de contacto que da lugar a su nombre, tal y como se observa en las Figuras 4.13, 4.14, 4.16, 4.17 y 4.18.

Las relaciones de vecindad entre el cuerpo neoestriado y el tálamo, se pueden observar en la Figura 4.16, con modelos 3D embebidos en secciones PET ${ }^{18}$ F-DOPA y en la Figura 4.17 en secciones PET ${ }^{18}$ F-FDG. En la Figura 4.18 se destacan las relaciones espaciales respecto al hemisferio cerebral derecho, tronco encefálico y cerebelo en secciones VHP.

Los estudios revisados destacan su implicación, junto con el núcleo caudado, en la esquizofrenia y TB.

\section{Globo pálido}

El núcleo globo pálido o cuerpo paleoestriado aparece representado de forma independiente en la Figura 4.12, también embebido en secciones del VHP, observándose su menor tamaño y posición más medial. Se han representado, de forma conjunta, el segmento interno o globo pálido interno y el segmento externo o globo pálido externo.

En la visualización volumétrica del núcleo lenticular o conjunto formado por el globo pálido y putamen, se observa la posición del segundo entre el núcleo globo pálido y la cápsula externa (Figura 4.15). Se aprecia la base convexa y ancha del núcleo lenticular dirigida lateralmente y una pared cóncava dirigida medialmente y situado anterolateral respecto al tálamo (Figuras 4.16, 4.17 y 4.18).

Se trata del núcleo implicado, según la literatura, en la EP.

\section{Amígdala}

Desde el punto de vista puramente anatómico, la amígdala constituye un conjunto de núcleos bilaterales con forma de almendra (Figura 4.19) localizados en el lóbulo temporal anteromedial, específicamente, anteriores al asta inferior de los VL en la zona medial del lóbulo 
temporal, cerca del uncus. En la Figura 4.21 se observan las relaciones de vecindad de la amígdala con el cuerpo estriado y otras estructuras del sistema límbico como el hipocampo.

A partir de los resultados de la bibliografía revisada, hemos encontrado numerosos estudios que sugieren alteraciones morfológicas y funcionales de la amígdala en trastornos neurológicos como la EA y psiquiátricos como el autismo, AN y trastornos del estado de ánimo como el TDM y el TB. Además, ha sido la estructura más consistentemente asociada con los trastornos de ansiedad. Estos resultados son congruentes con la relevancia de esta estructura en la codificación y procesamiento de material emocional desagradable, especialmente la percepción de miedo en situaciones sociales, respuesta a estímulos novedosos y respuesta de ansiedad.

\subsubsection{Sustancia blanca}

Se generaron volúmenes para dos conjuntos de fibras distintas: el cuerpo calloso (Figura 4.22) y el fórnix (Figuras 4.23 y 4.24), por su implicación en enfermedades neurológicas como EA y, especialmente trastornos psiquiátricos y del desarrollo, como el autismo, esquizofrenia y TDAH.

\section{Cuerpo calloso}

El cuerpo calloso consiste en un gran conjunto de fibras mielinizadas comisurales que conectan recíprocamente áreas del córtex de todos los lóbulos (a excepción de la parte del lóbulo temporal que se comunica a través de la comisura blanca anterior) (Figura 4.22), por lo que se trata de una estructura importante en la integración de información. Se localiza en el interior de la fisura interhemisférica. Alteraciones morfológicas en esta estructura se han asociado a diferentes trastornos como EA, autismo, esquizofrenia, TB y a niños con TDAH, especialmente el esplenio.

En la visión lateral del volumen 3D, se distinguen las partes del cuerpo calloso: el pico, la rodilla, el cuerpo y el rodete (Figura 4.22). En la vista basal, se observa la curvatura hacia el polo frontal de las fibras más anteriores correspondientes al forceps minor, al igual que la curvatura hacia el polo occipital de las fibras más posteriores, correspondientes al forceps mayor (Figura 4.22).

Las investigaciones revisadas sugieren la implicación de reducciones en el volumen del cuerpo calloso, especialmente en la parte anterior, en enfermedades neurológicas como EA, trastornos psiquiátricos como la esquizofrenia, y del desarrollo como el autismo y TDAH (en concreto el esplenio). 


\section{Fórnix o trígono cerebral}

El fórnix o trígono cerebral es un conjunto de fibras, intensamente mielinizadas en el telencéfalo, que se proyectan desde la formación hipocampal hasta el hipotálamo. Constituye el sistema eferente del hipocampo y define la parte superior o techo del diencéfalo. En su trayectoria hacia el hipocampo, se arquea rostralmente, superior al tálamo e inferior al cuerpo calloso, formando las columnas posteriores del fórnix (Figuras 4.23 y 4.24). Las dos columnas se juntan en la línea media para formar el cuerpo del fórnix (Figuras 4.23 y 4.24).

Desde el punto de vista clínico, y en base a la literatura revisada, hemos encontrado alteraciones en el fórnix en la EA.

\subsubsection{Sistema ventricular}

La generación volumétrica del sistema ventricular consistió en la reconstrucción 3D de todos los ventrículos y conductos que los comunican (Figura 4.25).

Los VL están separados por el septum pellucidum y se comunican, a través del foramen de Monro (que limita anteriormente con la columna anterior del fórnix y posteriormente con la parte anterior del tálamo), con el tercer ventrículo, una estrecha hendidura medial localizada inferior al cuerpo calloso, entre los dos tálamos y que definen sus paredes (Figuras 4.25 y 4.26). $\mathrm{Su}$ forma es irregular y el suelo está formado por el hipotálamo, la pared anterior, por la lámina terminalis y el techo, por el epéndimo. El tercer ventrículo se comunica a través del acueducto de Silvio o mesencefálico con el ventrículo IV, que se define por una cavidad de forma rómbica (Figura 4.25) localizada entre el bulbo raquído, la protuberancia y el cerebelo en la parte posterior (Figura 4.26).

En los volúmenes correspondientes de la Figura 4.26 se observa la alineación del sistema ventricular con el epéndimo y las distintas áreas que definen los VL: cuerpo, asta anterior, asta posterior y asta inferior a nivel de los lóbulos frontal, occipital y temporal respectivamente.

Desde una vista anterior se observa la disposición en "T" del sistema ventricular (Figuras 4.25 y 4.26), donde los brazos laterales corresponden a los VL y la extensión caudal al tercer ventrículo, que se comunica, a través del acueducto de Silvio, con el IV ventrículo (Figuras 4.25 y 4.26).

El alargamiento de los ventrículos ha sido la primera alteración de una estructura encefálica asociada con la progresión de la demencia en EA y en trastornos psiquiátricos como la Esquizofrenia y el TB. 

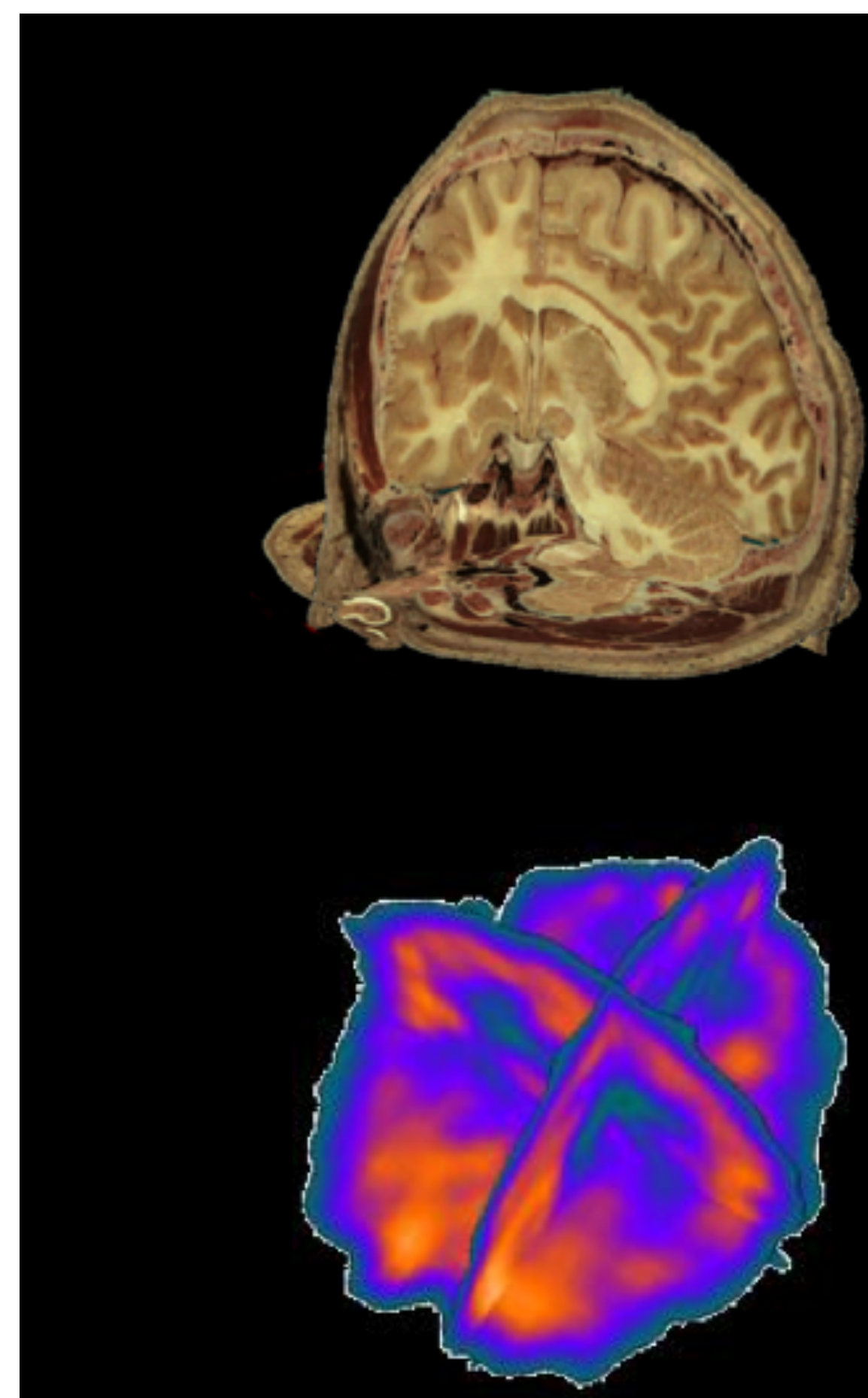

Figura 4.3. Secciones ortogonales VHP (imagen superior) y SPECT (imagen inferior). 

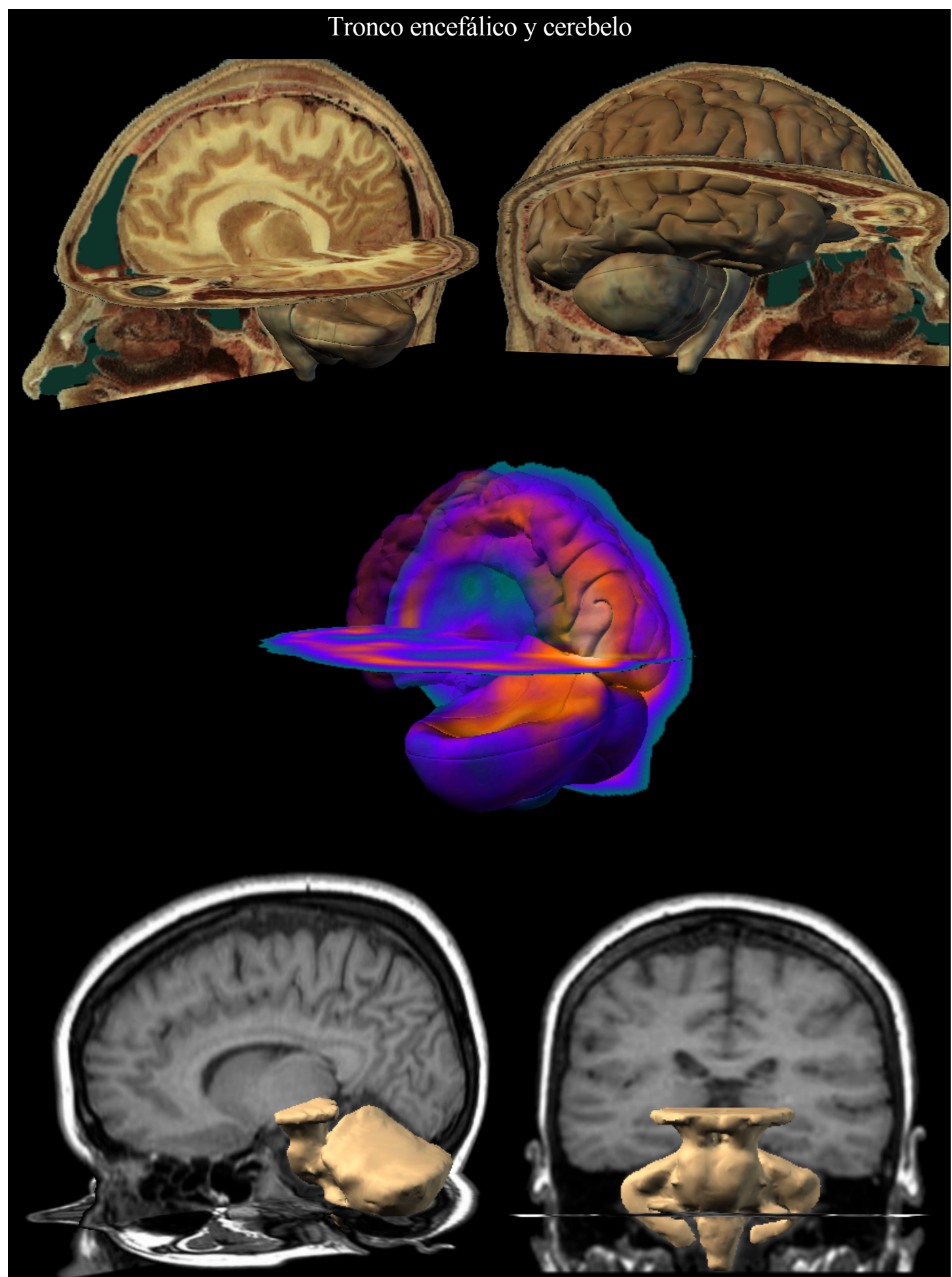

Figura 4.4. Visualización volumétrica del tronco encefálico y cerebelo. Se observan las características morfológicas y relaciones espaciales de las estructuras a partir de los modelos $3 \mathrm{D}$ embebidos en secciones VHP (imágenes superiores), SPECT (imagen media) y RM (imágenes inferiores). Se incluye la representación del hemisferio derecho embebido en VHP y SPECT. 


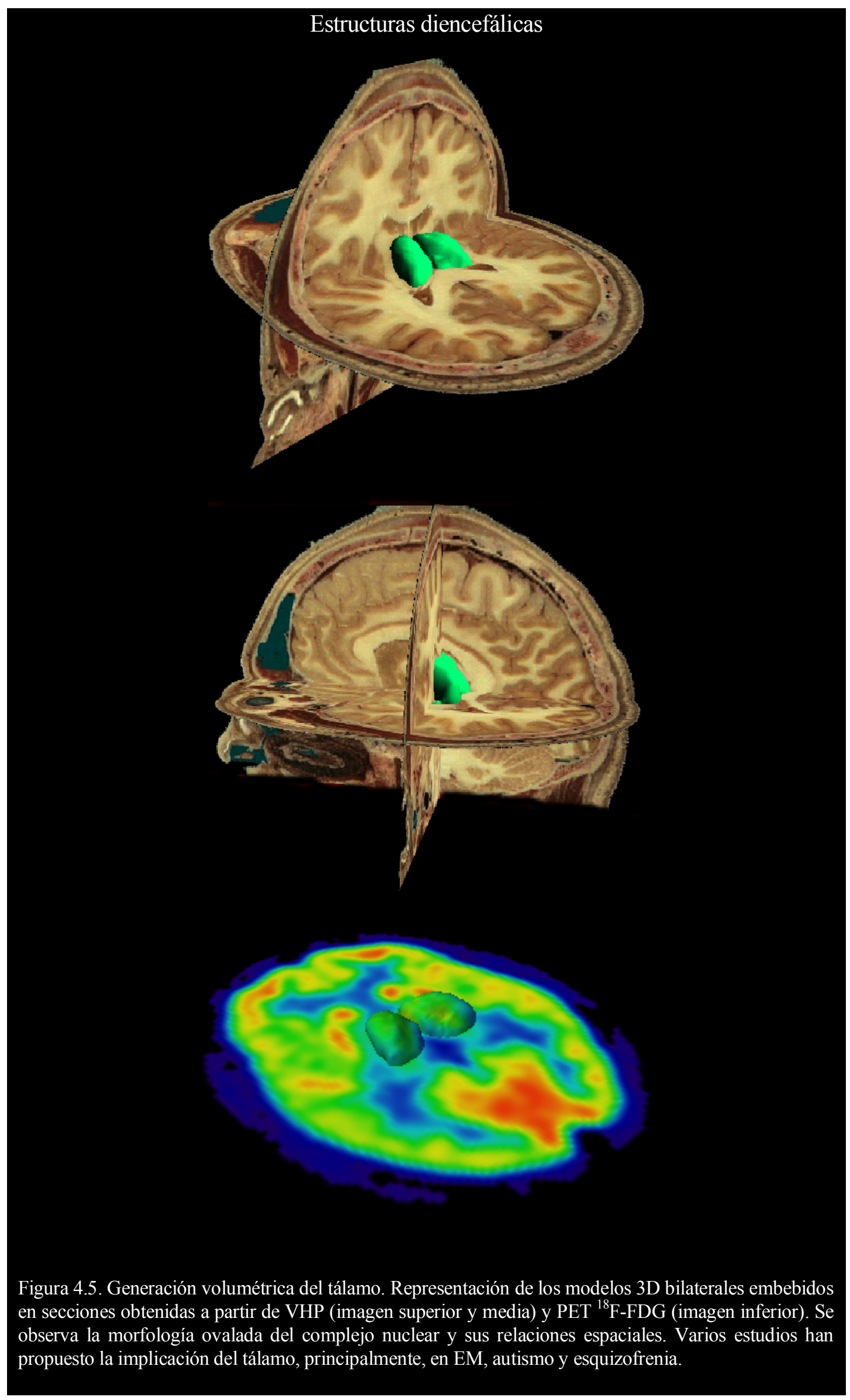




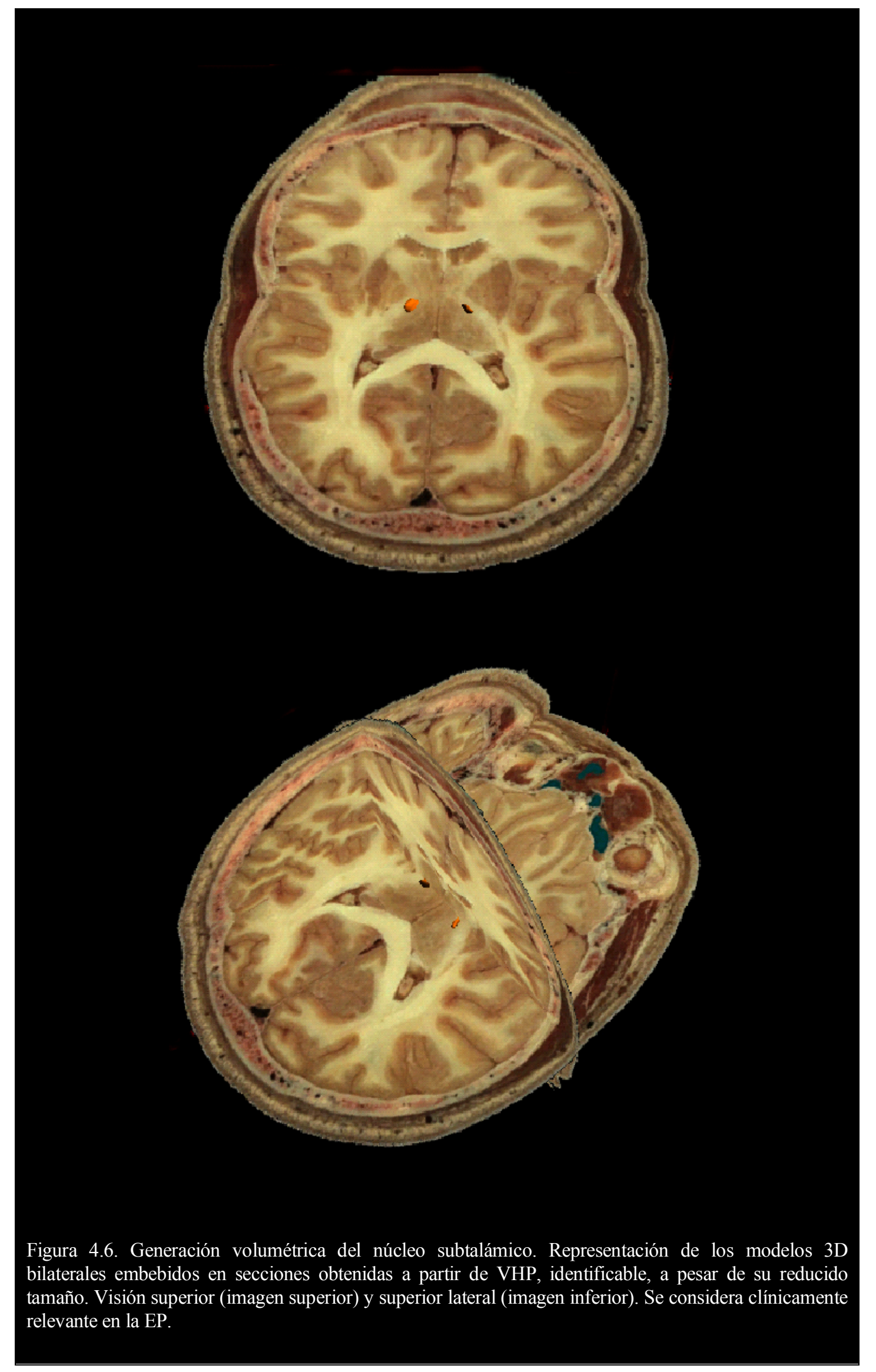

Figura 4.6. Generación volumétrica del núcleo subtalámico. Representación de los modelos 3D bilaterales embebidos en secciones obtenidas a partir de VHP, identificable, a pesar de su reducido tamaño. Visión superior (imagen superior) y superior lateral (imagen inferior). Se considera clínicamente relevante en la EP. 


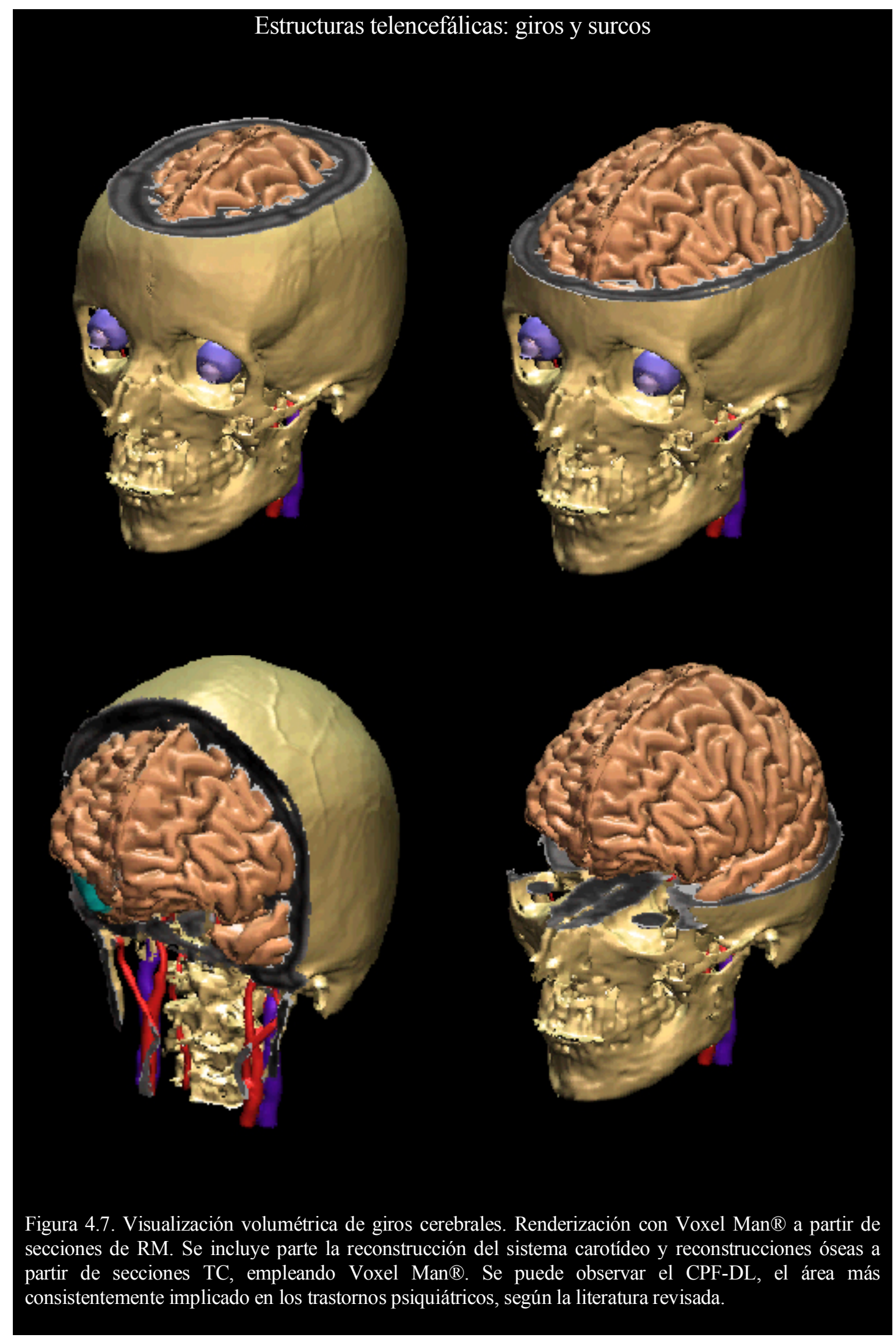




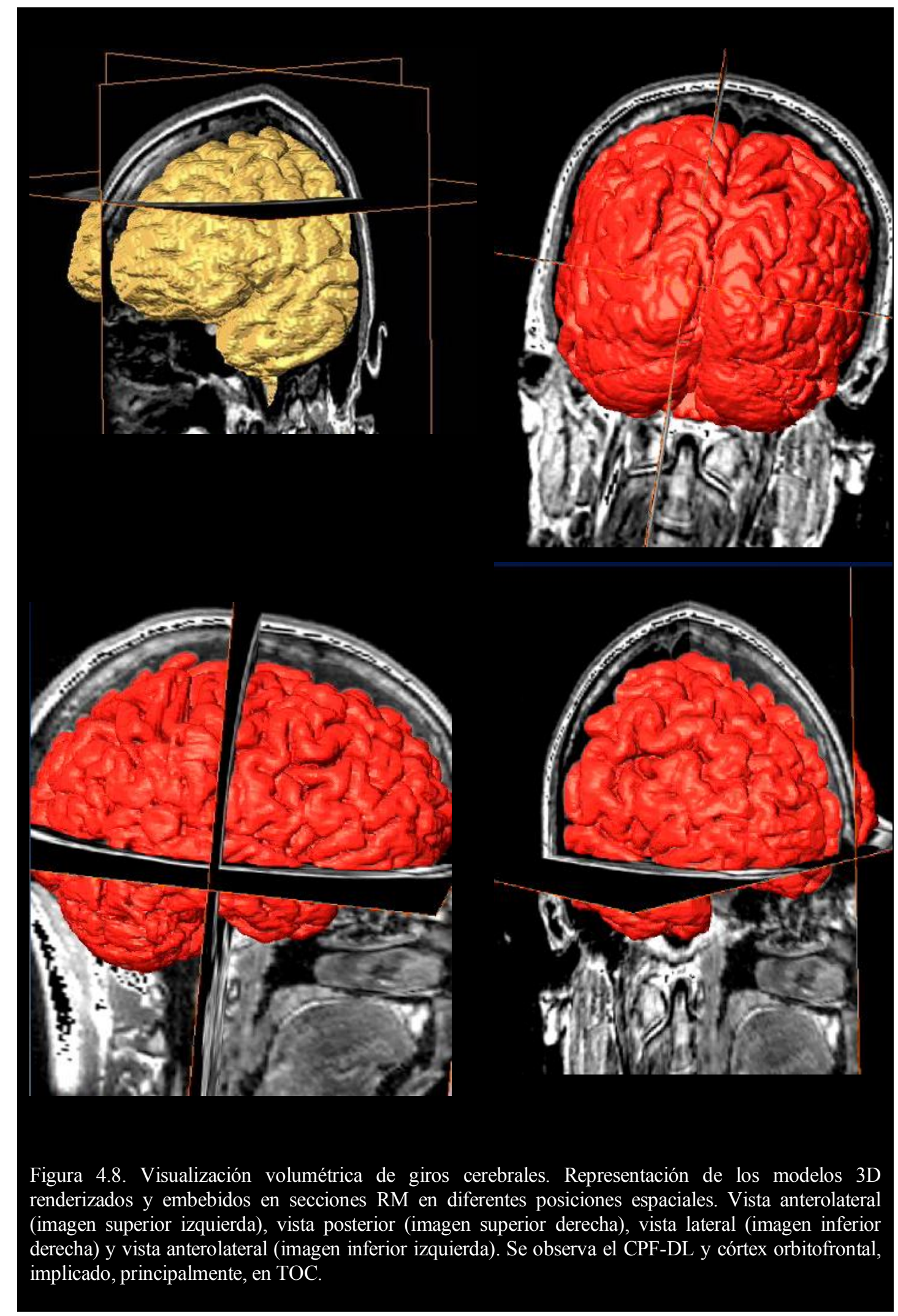




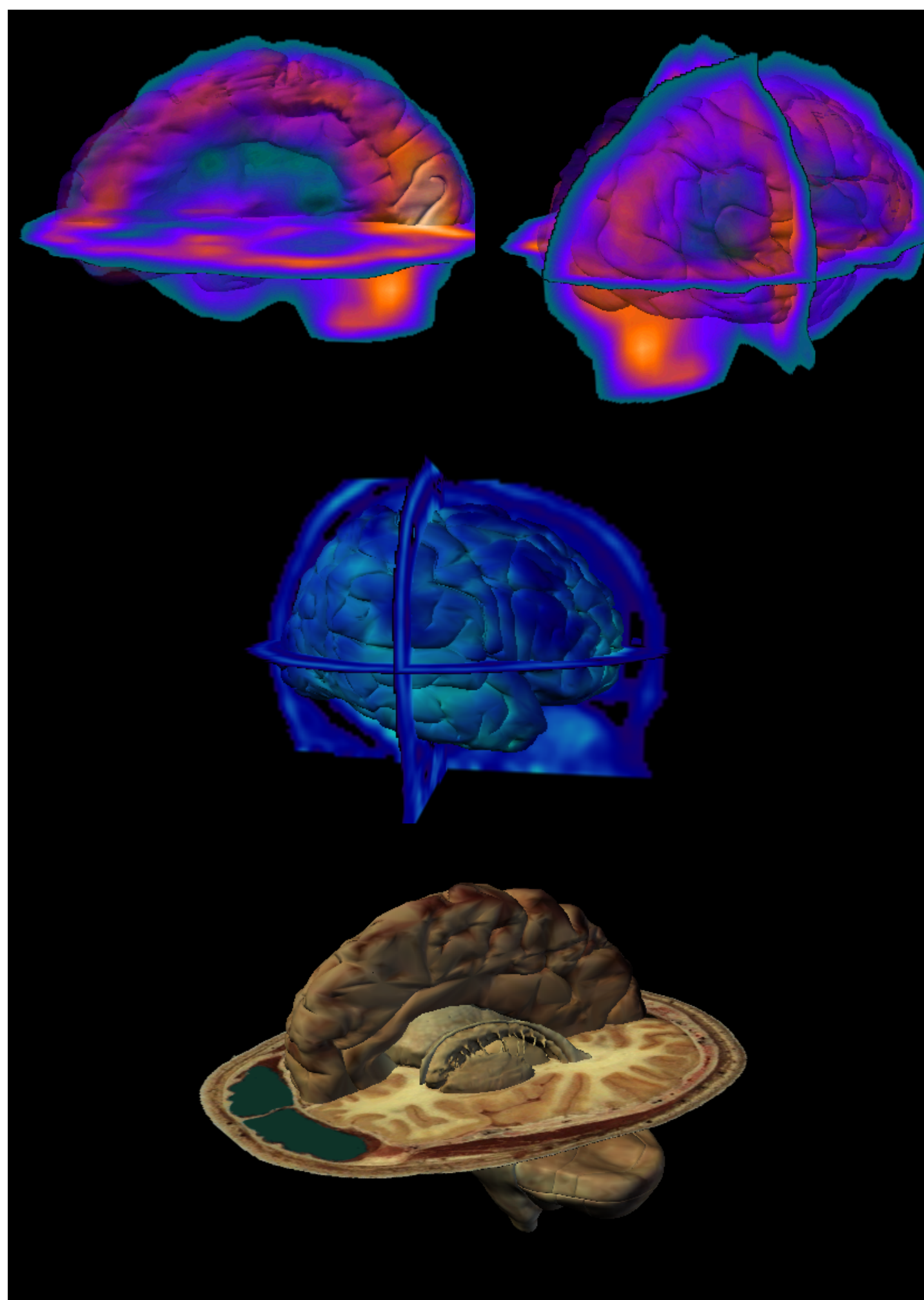

Figura 4.9. Visualización volumétrica de giros cerebrales. Representación 3D del hemisferio derecho embebido en secciones obtenidas a partir de SPECT (imágenes superiores), en secciones PET-DOPA (imagen media) y VHP (imagen inferior). En la cara medial del hemisferio derecho se observa el GCA, que constituye, junto con el CPF-DL, las regiones más relevantes, según la literatura revisada, en los trastornos psiquiátricos. También pueden observarse las relaciones de vecindad del GCA con el cuerpo calloso y núcleo estriado. 


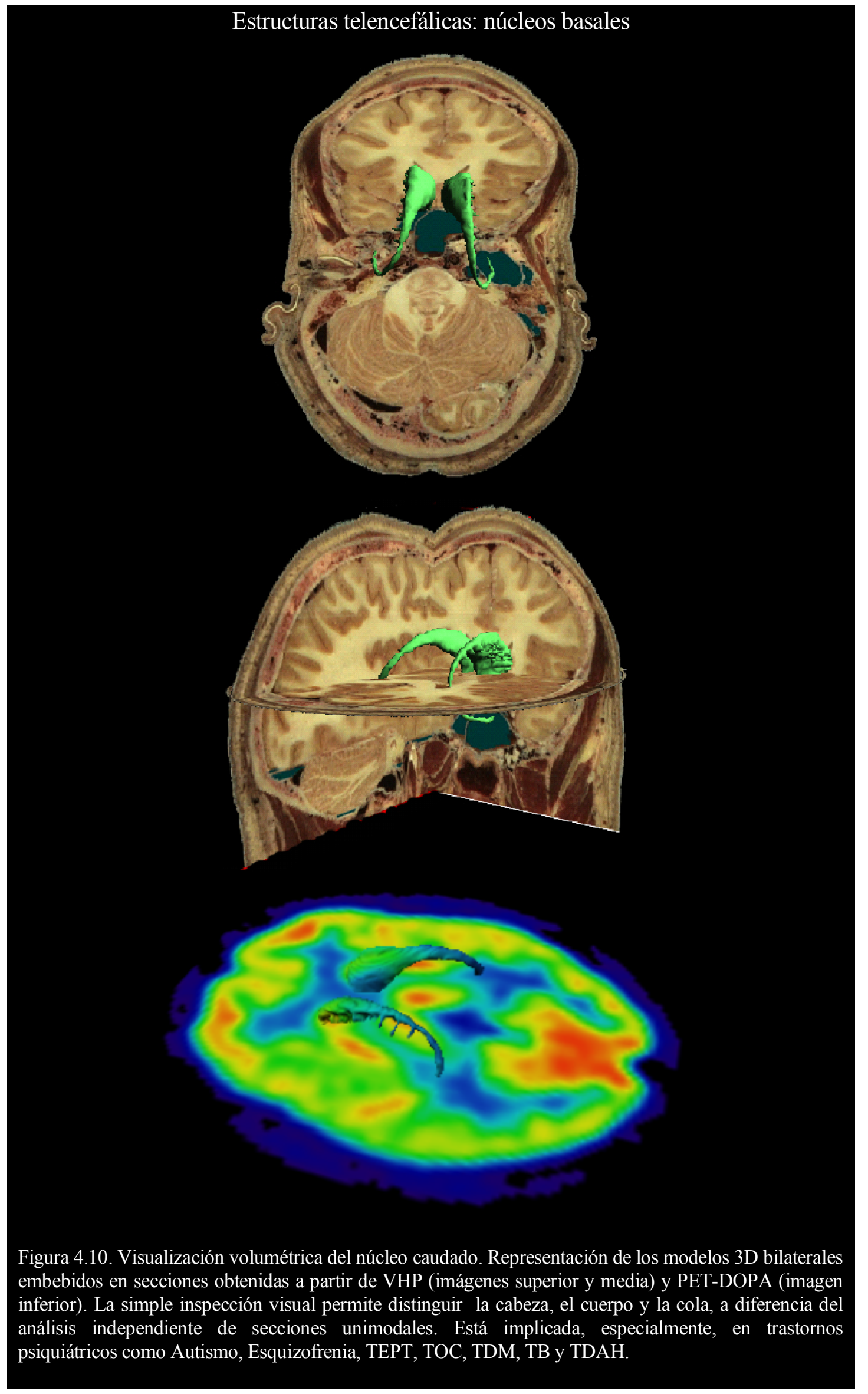




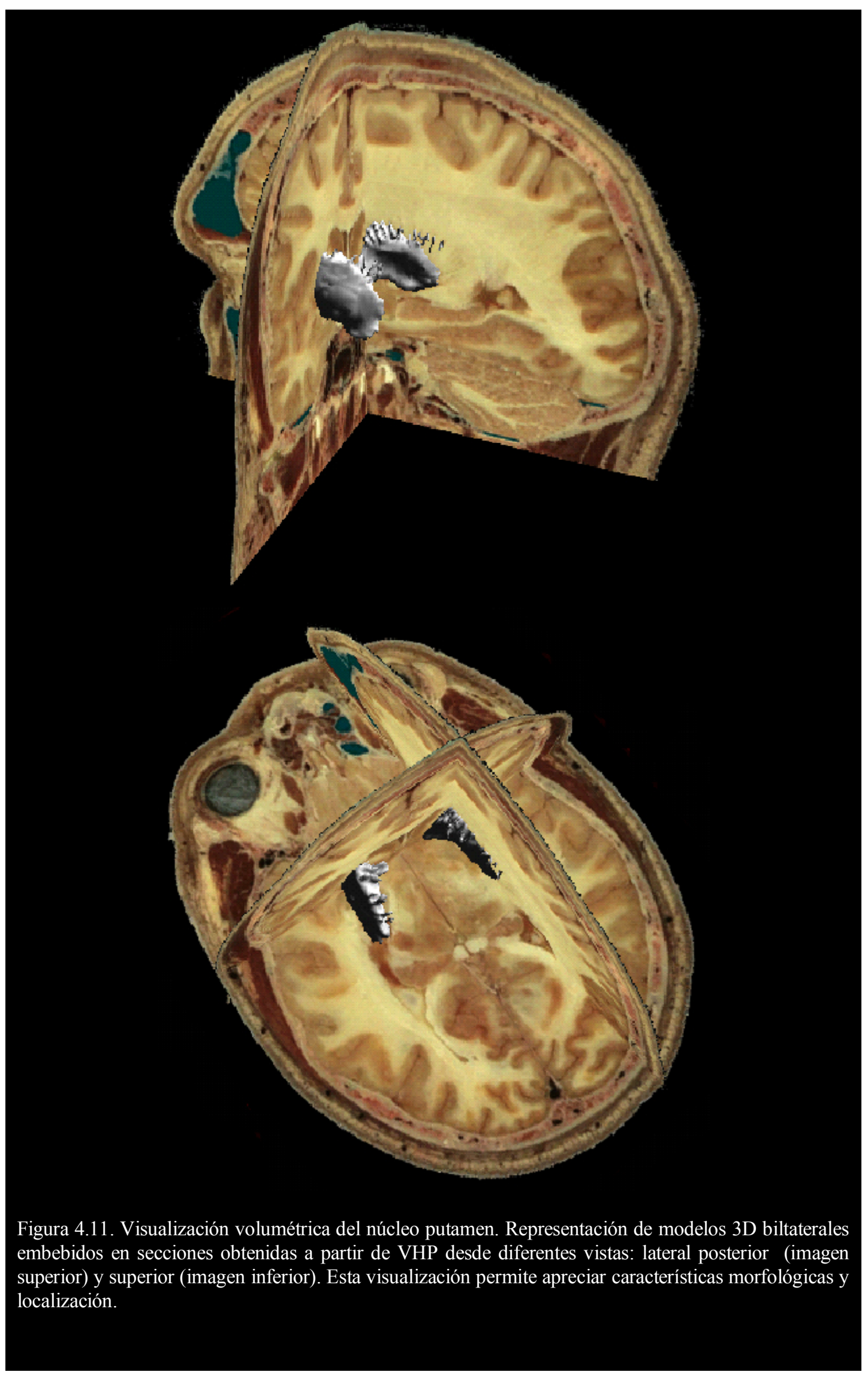

Figura 4.11. Visualización volumétrica del núcleo putamen. Representación de modelos 3D biltaterales embebidos en secciones obtenidas a partir de VHP desde diferentes vistas: lateral posterior (imagen superior) y superior (imagen inferior). Esta visualización permite apreciar características morfológicas y localización. 

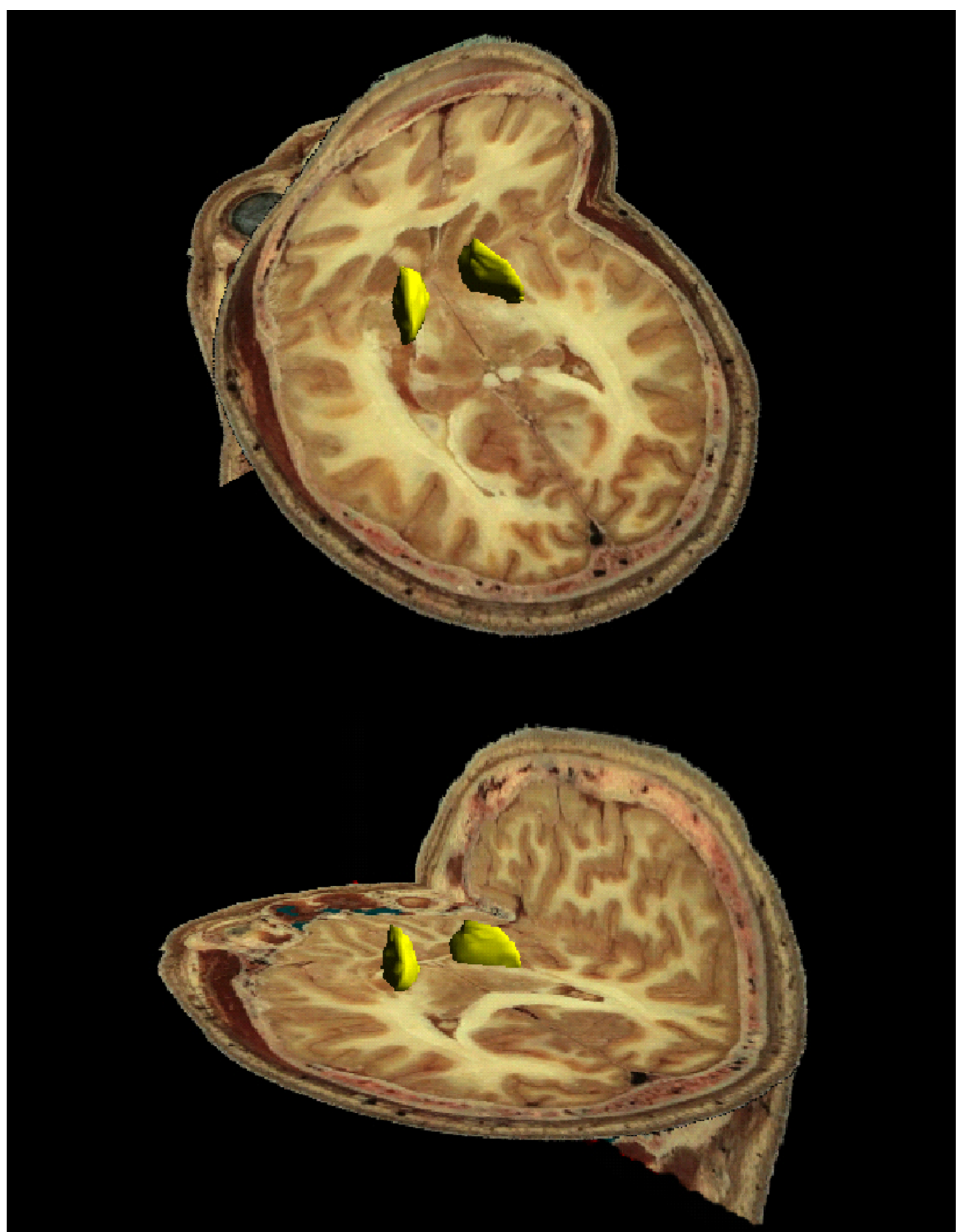

Figura 4.12. Visualización volumétrica del núcleo globo pálido. Representación de los modelos 3D bilaterales embebidos en secciones frontal y axial, obtenidas a partir de VHP. Vista superior posterior (imagen superior) y visión lateral posterior (imagen inferior). Como en casos anteriores se pueden apreciar aspectos morfológicos y espaciales, más completos que los obtenidos a partir de la inspección visual de secciones VHP individuales. Este núcleo estaría especialmente implicado en la EP, según la literatura revisada. 


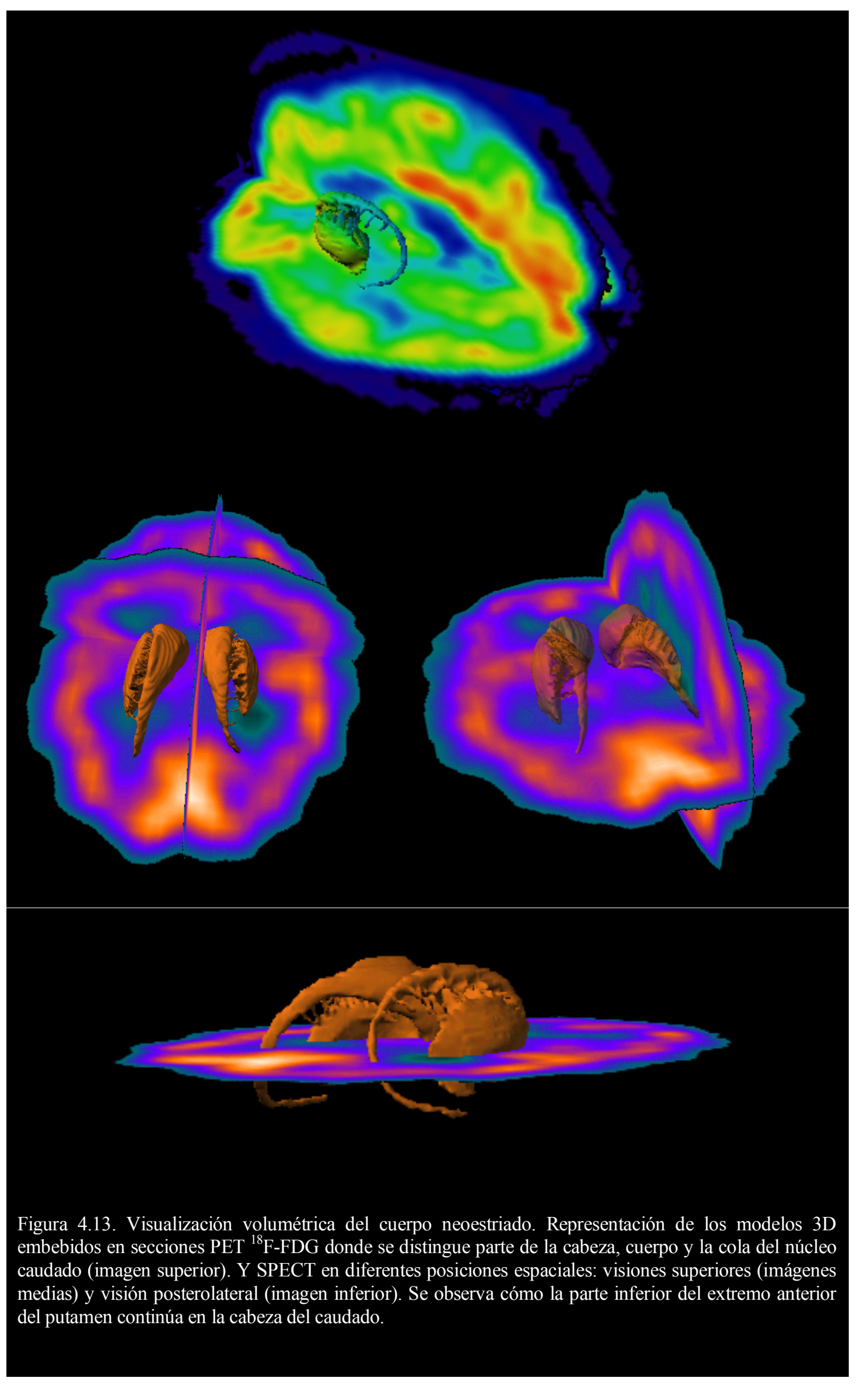




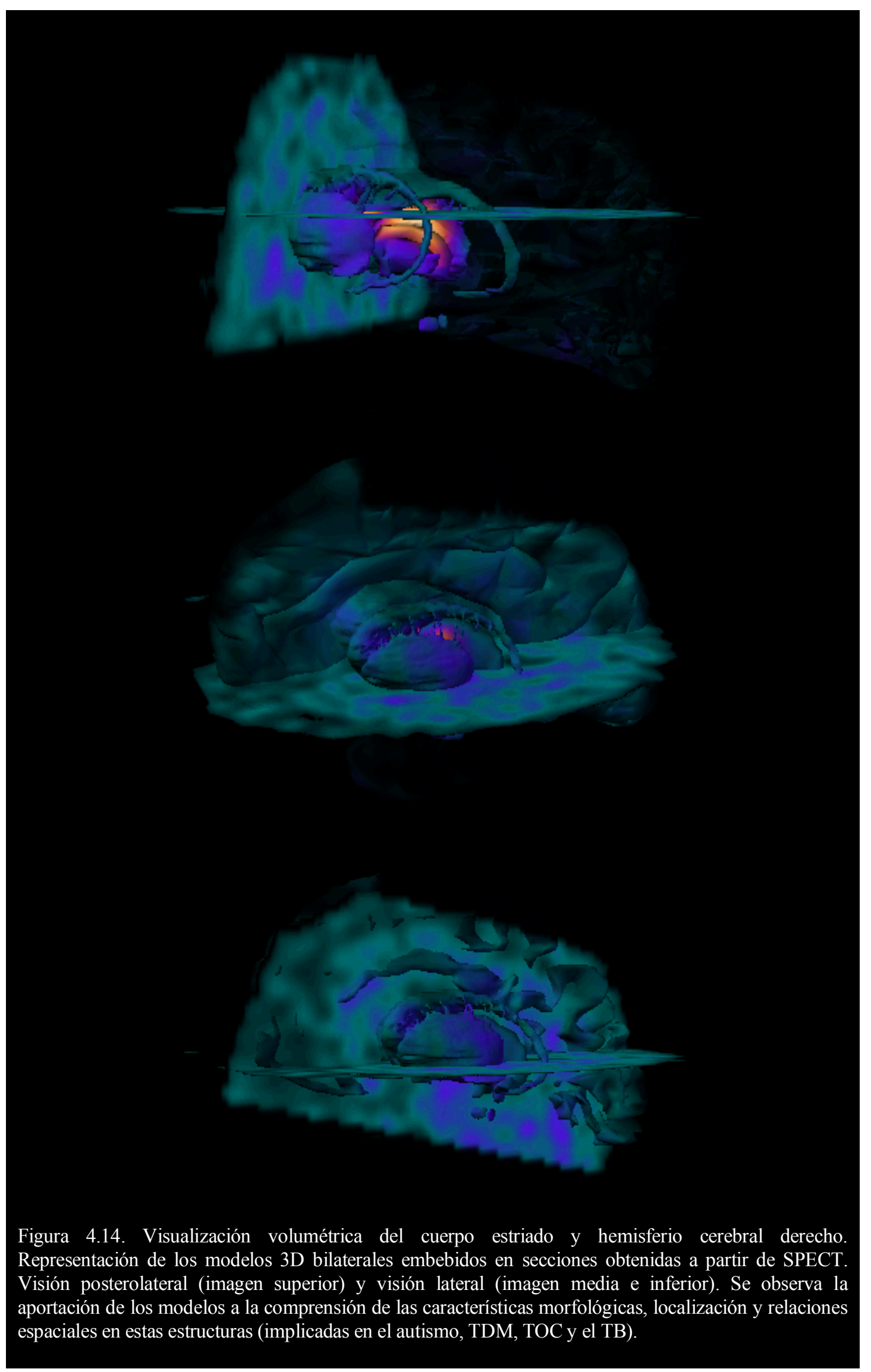




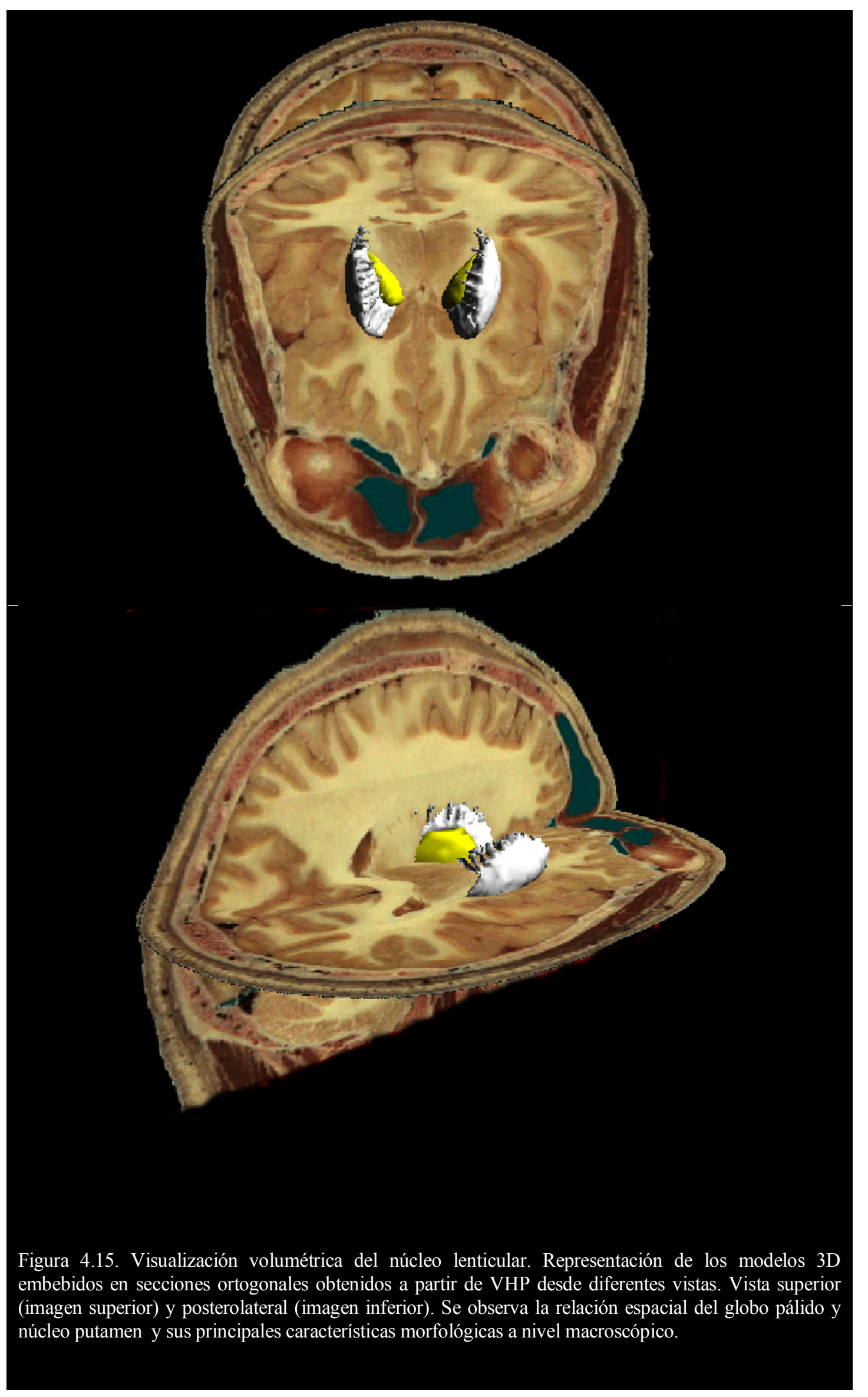

Visualización volumétrica del núcleo lenticular. Representación de los modelos 3D embebidos en secciones ortogonales obtenidos a partir de VHP desde diferentes vistas. Vista superior (imagen superior) y posterolateral (imagen inferior). Se observa la relación espacial del globo pálido y núcleo putamen y sus principales características morfológicas a nivel macroscópico. 


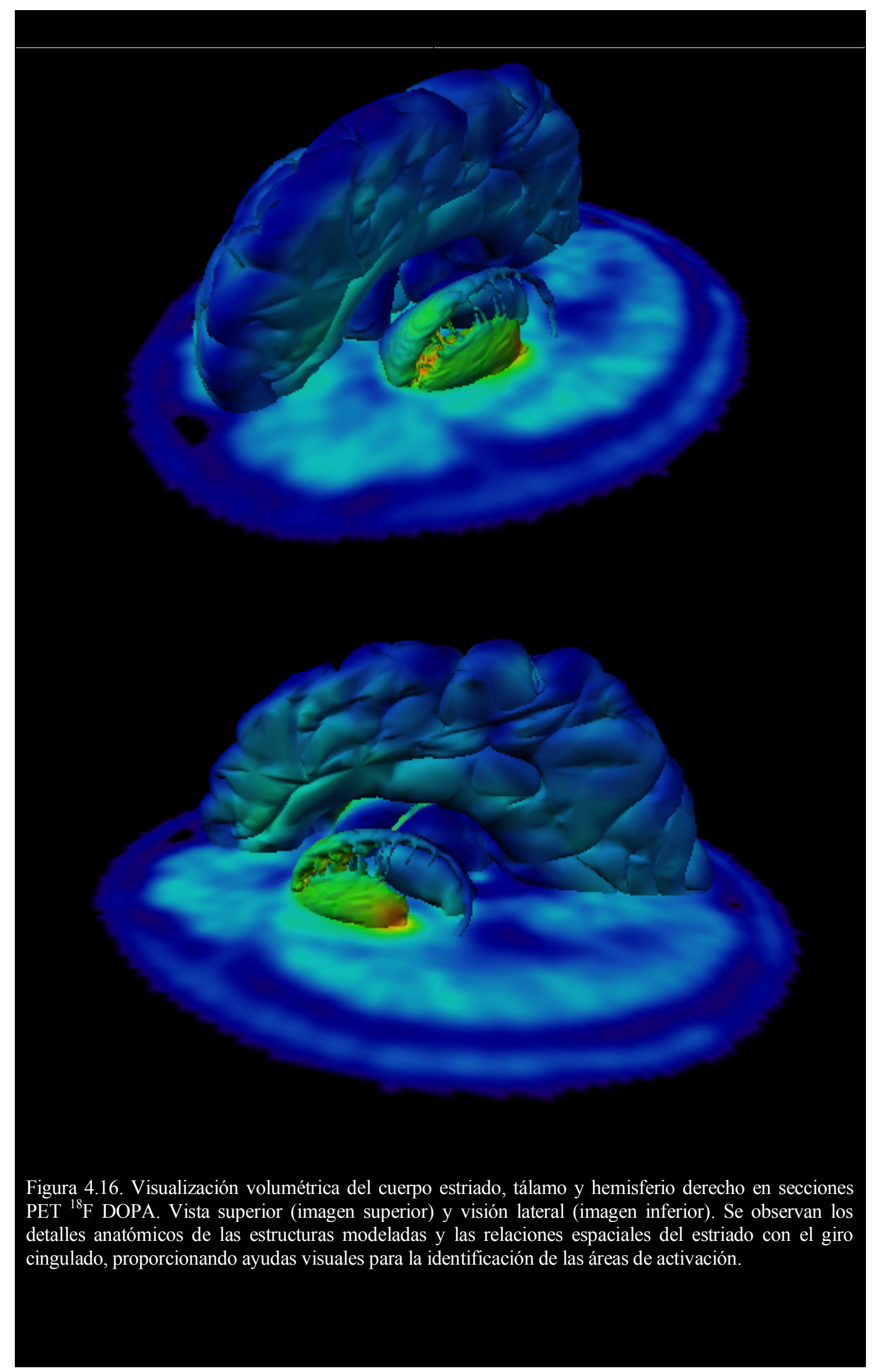




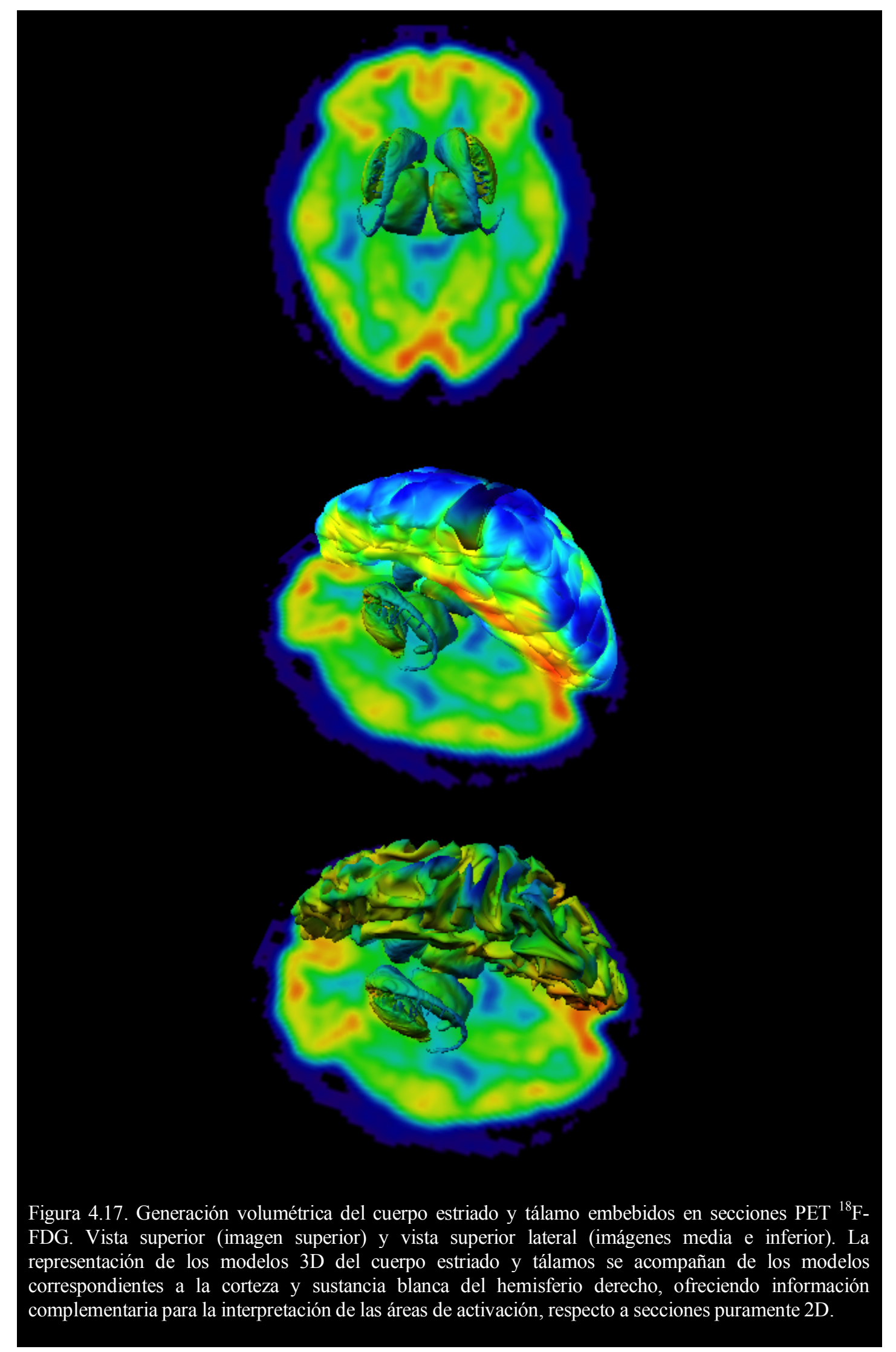




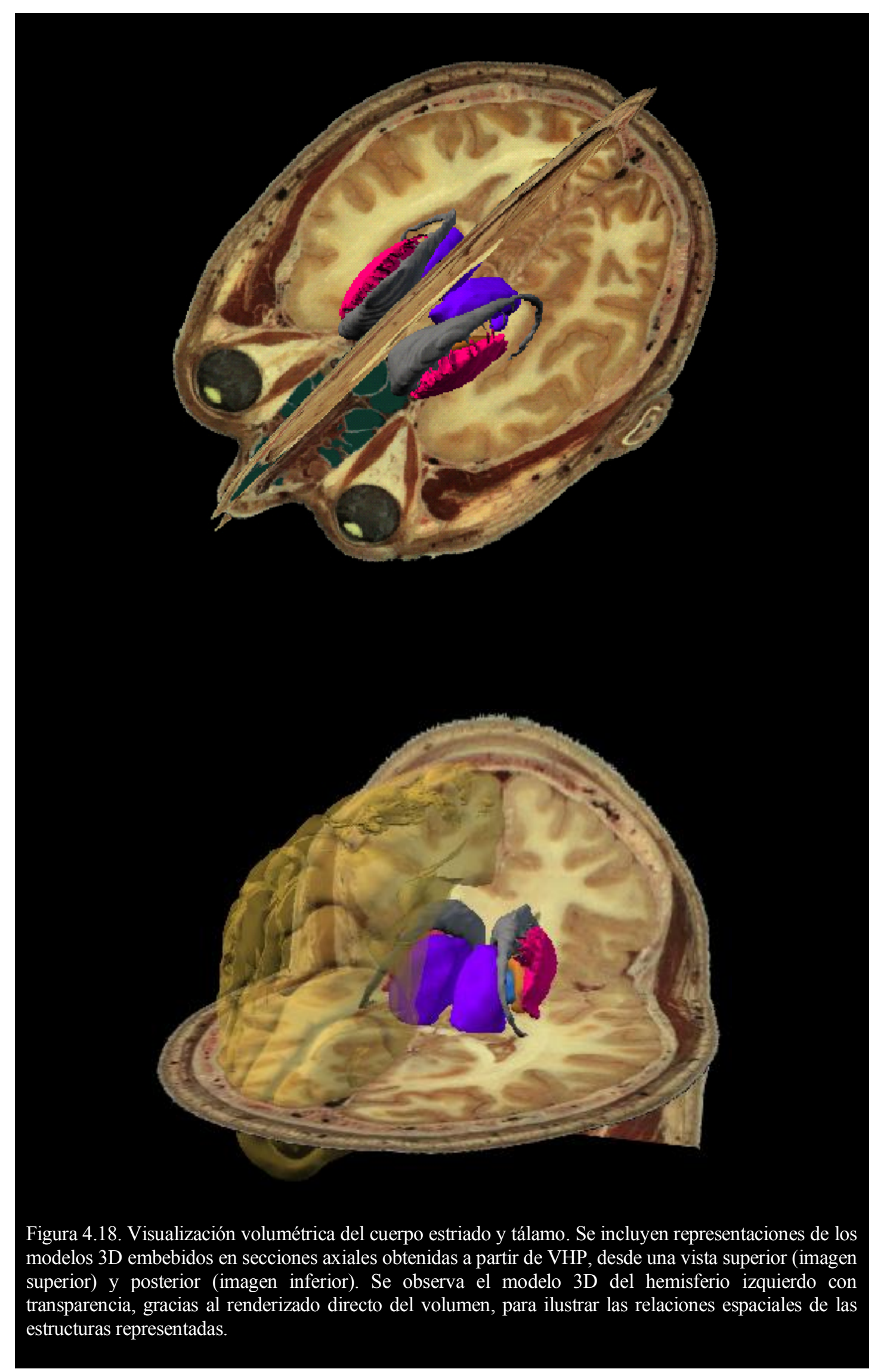



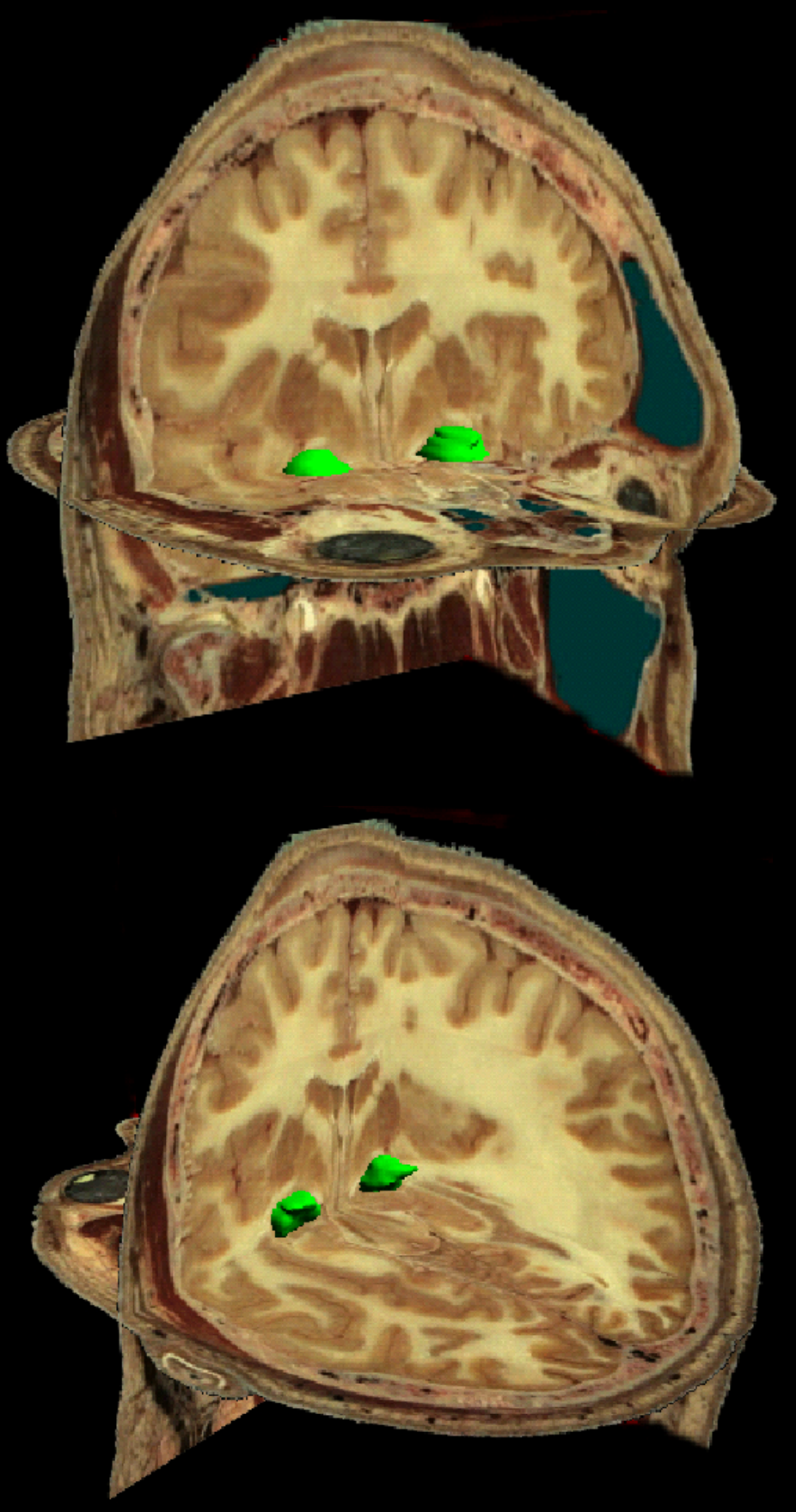

Figura 4.19.Visualización volumétrica de la amígdala. Representación de los modelos 3D bilaterales embebidos en secciones ortogonales obtenidas a partir de VHP desde diferentes vistas: anterolateral (imagen superior) y posterolateral (imagen inferior). Se observan con claridad detalles anatómicos a pesar de su pequeño tamaño, difícilmente replicable en base a la mera inspección visual de imágenes morfológicas convencionales 2D. La amígdala estaría implicada, principalmente, en EA, AN, TDM y TB. Además, un alargamiento bilateral, especialmente de la amígdala derecha, estaría asociado con el trastorno de autismo durante la infancia. 


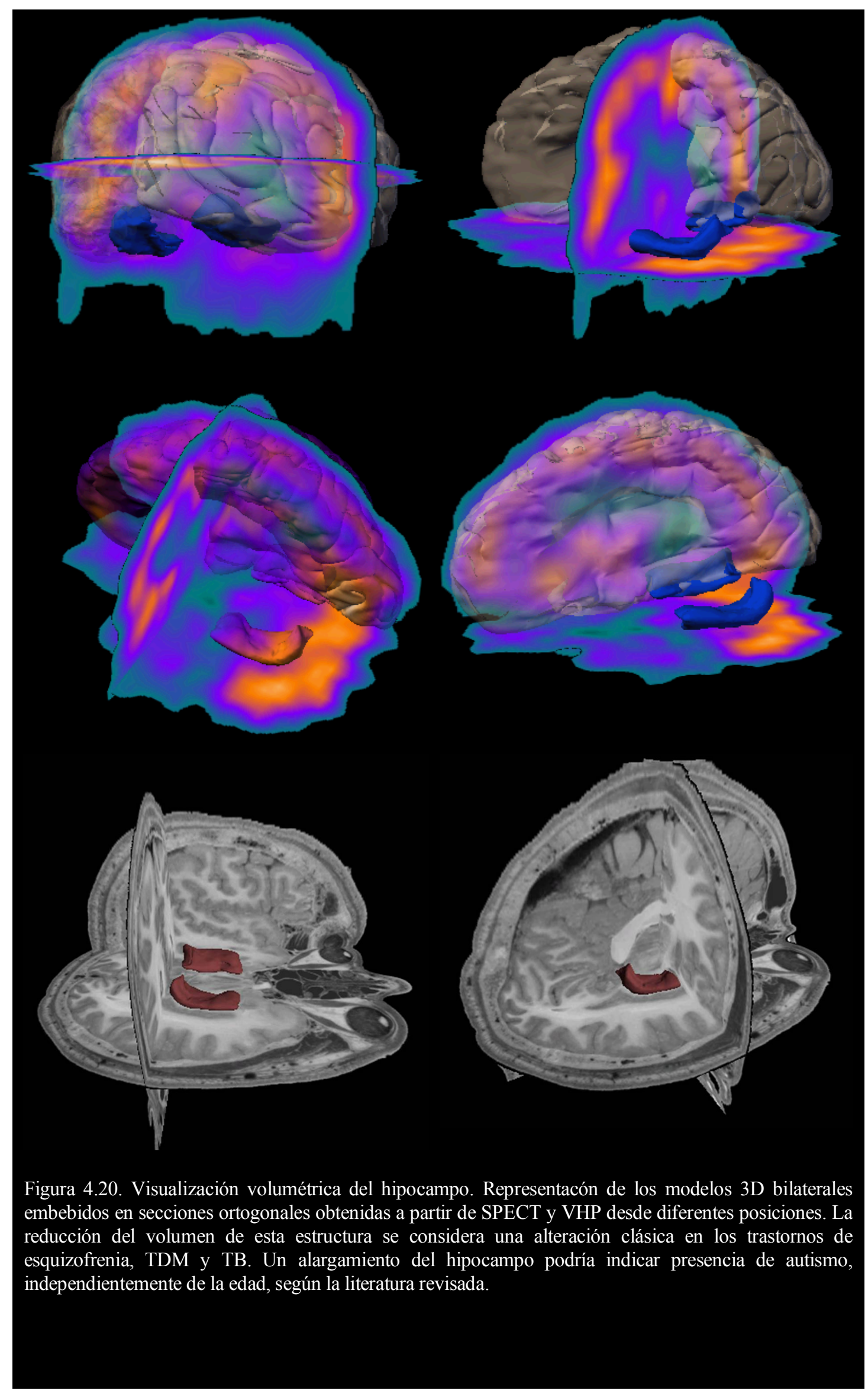




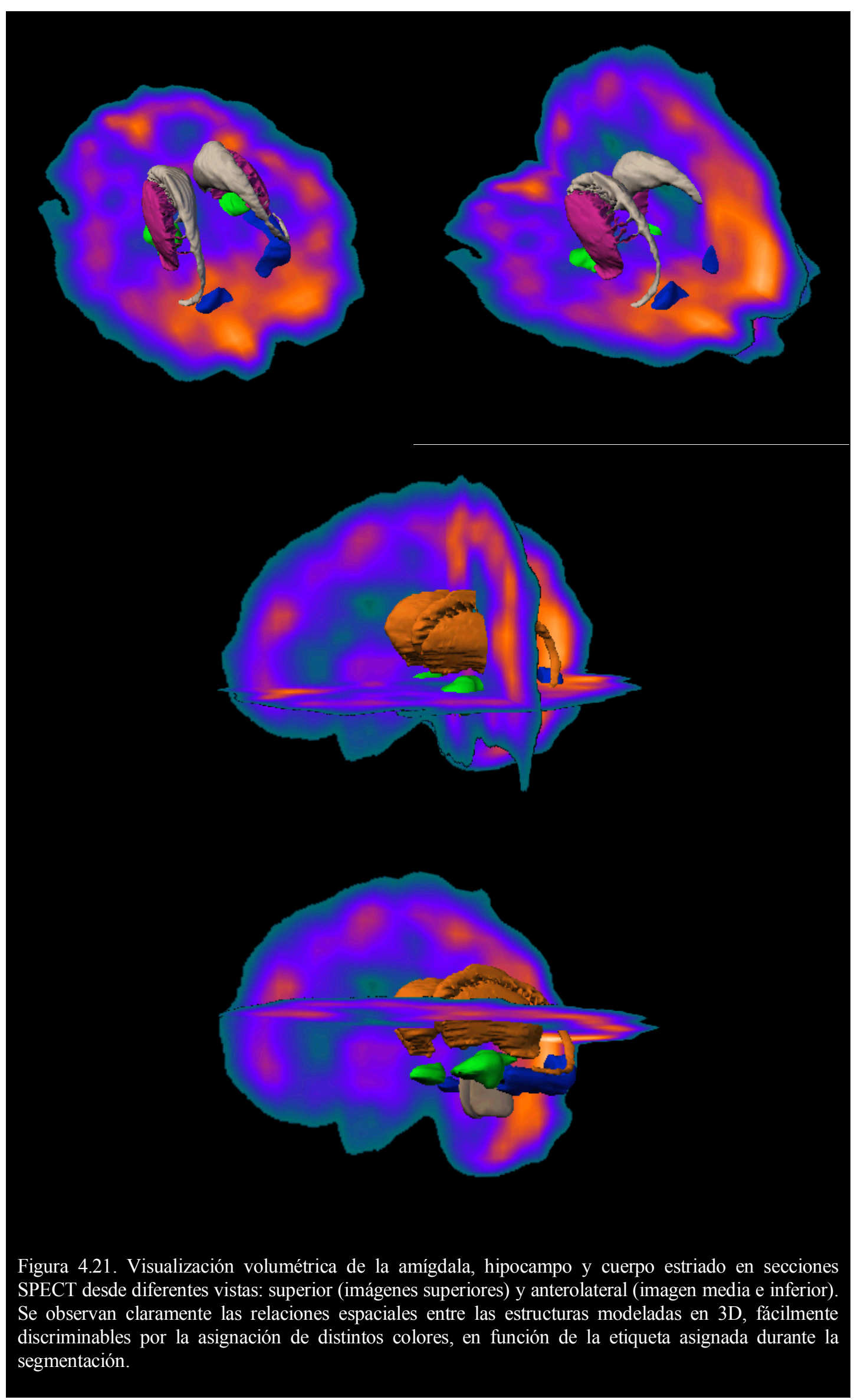




\section{Sustancia blanca}
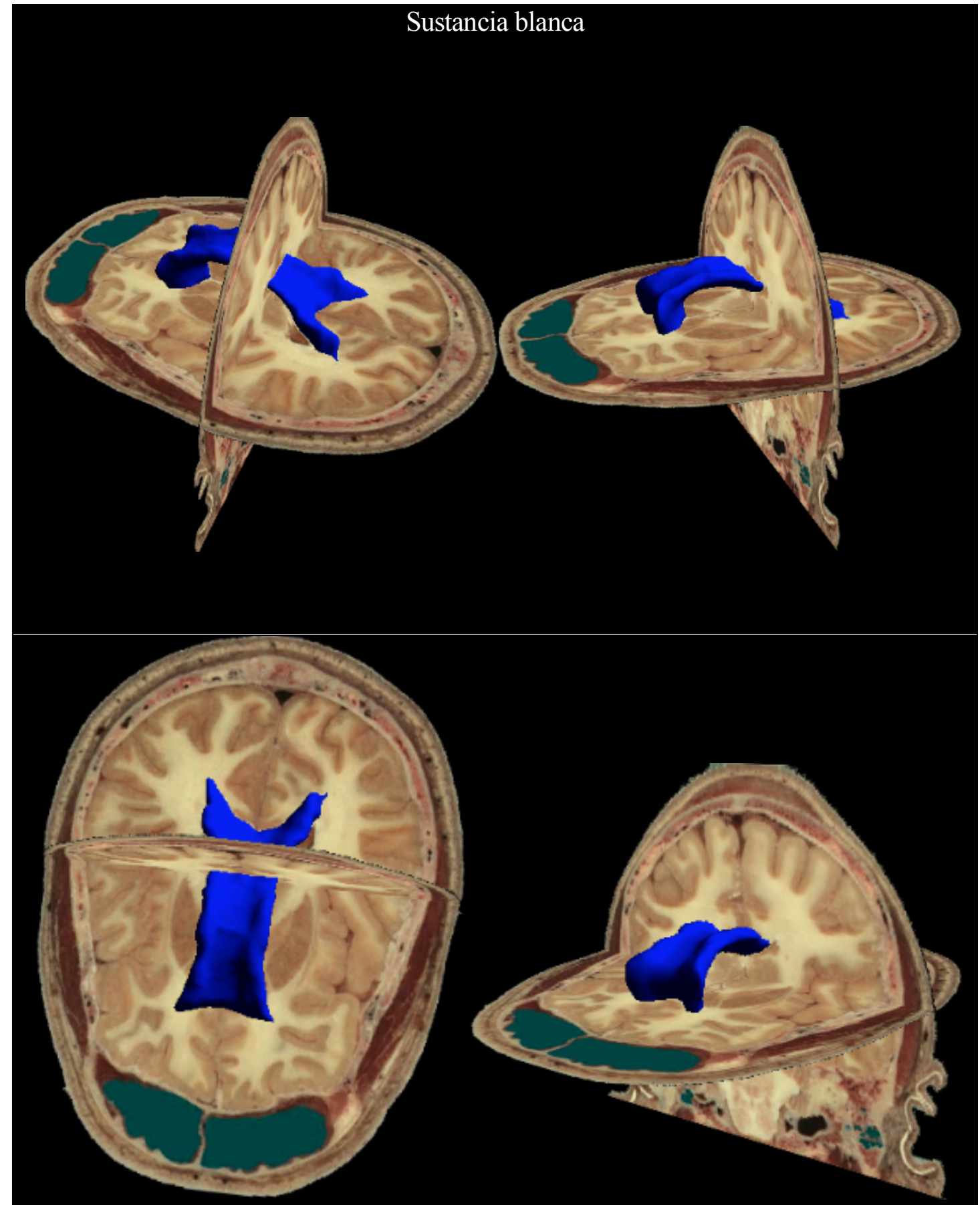

Figura 4.22. Visualización volumétrica del cuerpo calloso. Representación del modelo 3D embebido en secciones obtenidas a partir del VHP desde diferentes perspectivas: posterolateral (imagen superior izquierda), anterolateral (imágenes superior e inferior derecha), superior (imagen inferior izquierda). Se destaca la disposición espacial y apariencia a nivel macroscópico de este conjunto de fibras, considerado como una unidad anatómica. Se tata de una estructura, al igual que otras estructuras encefálicas profundas, implicada en trastornos psiquiátricos como autismo, esquizofrenia, TDAH, y enfermedades neurológicas como la EA, donde su volumen sería menor del esperado para poblaciones normales. 


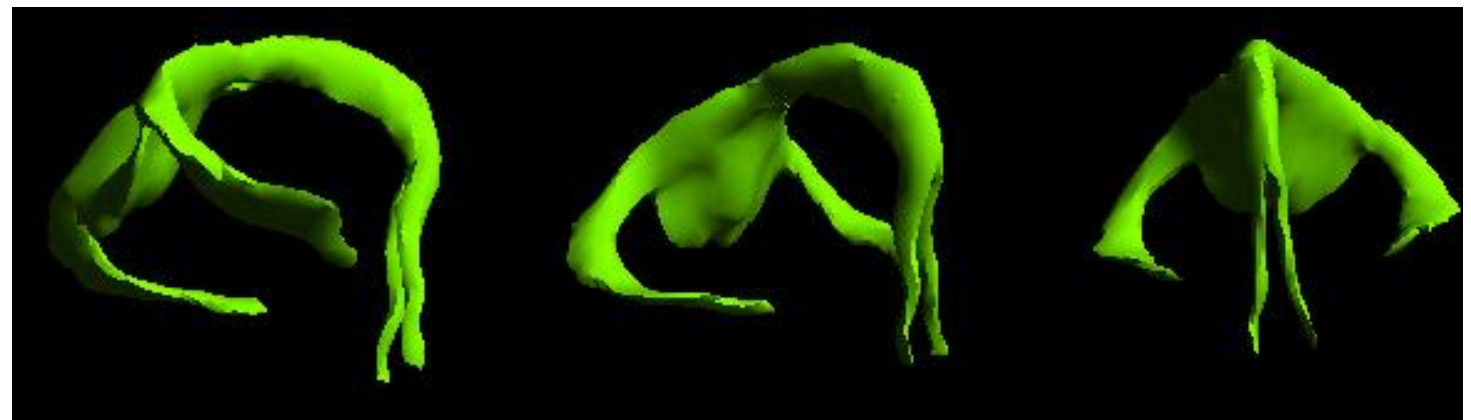

Figura 4.23. Renderización del modelo 3D del fórnix. Se observa la disposición en forma de lámina triangular con vértice anterior, base posterior y forma de bóveda, del conjunto formado por una porción central, o cuerpo de la que se desprenden dos columnas anteriores y dos posteriores que funcionan como pilares.

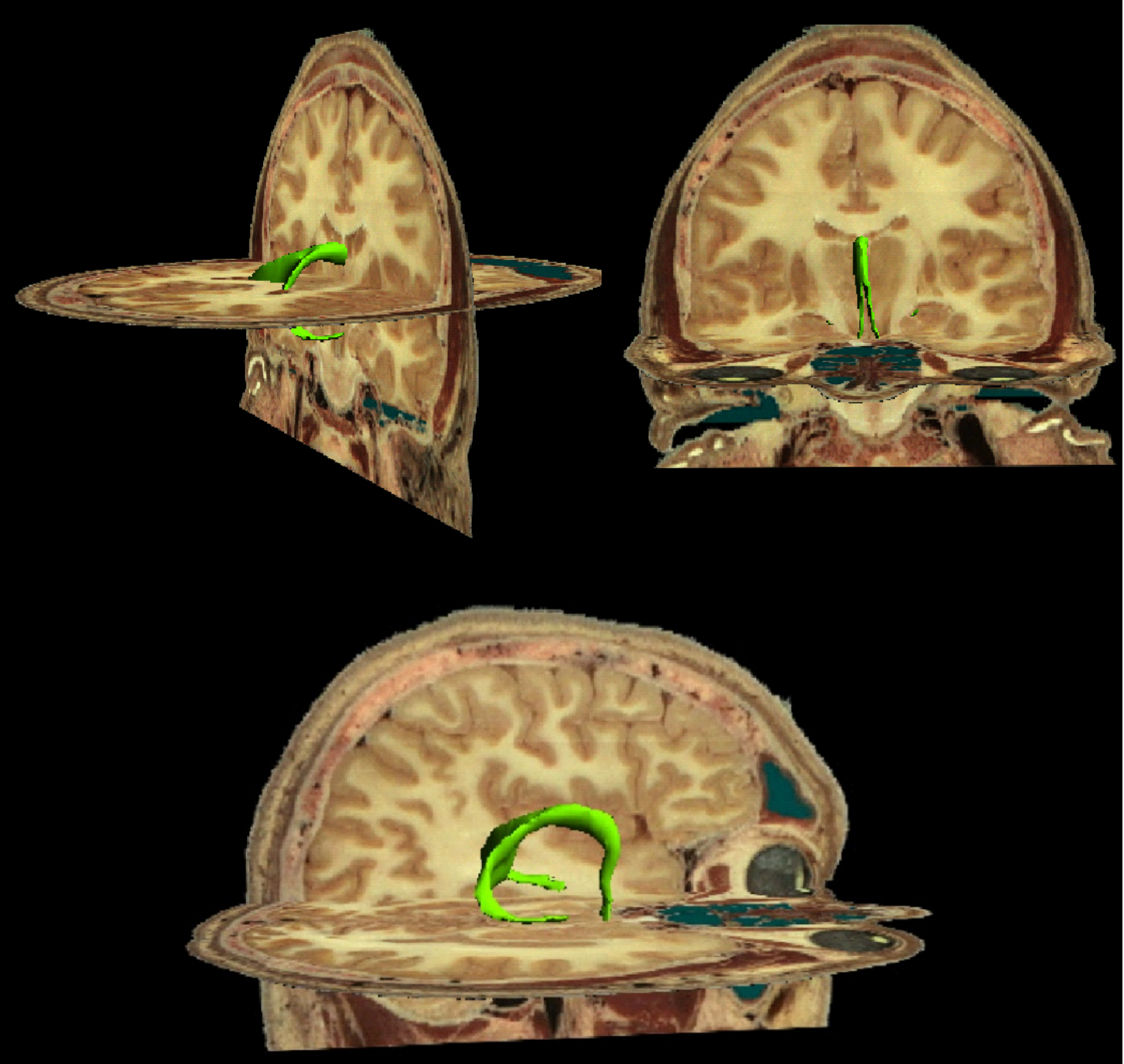

Figura 4.24. Visualización volumétrica del fórnix. Representación del modelo 3D embebido en secciones del VHP desde diferentes secciones. Vista posterolateral (imagen superior), vista anterior (imagen superior) y vista lateral (imagen inferior). Se evidencia la complejidad morfológica del fórnix, difícilmente comprensible a partir de secciones convencionales. El fórnix sería una de las estructuras implicadas en la EA. 


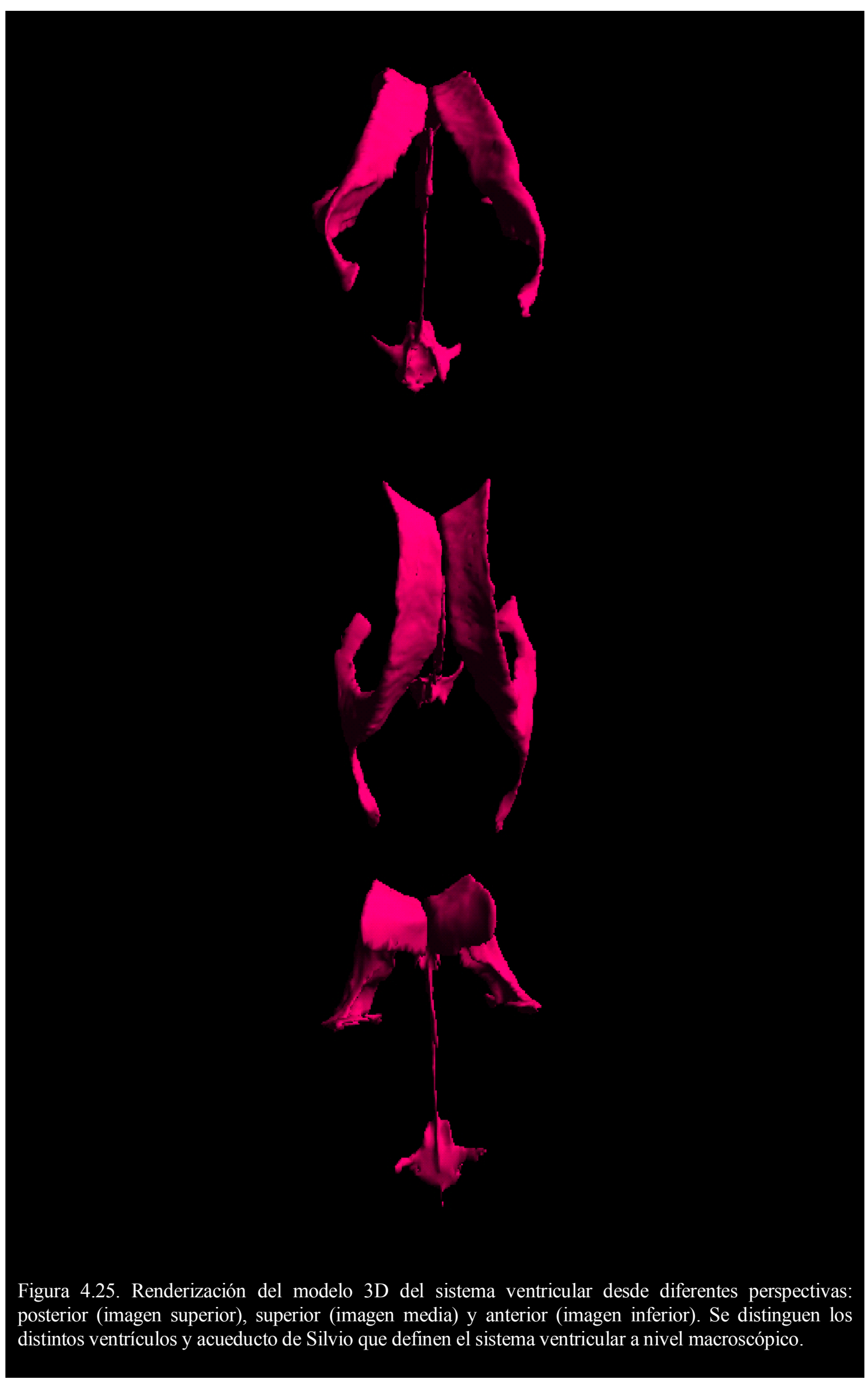




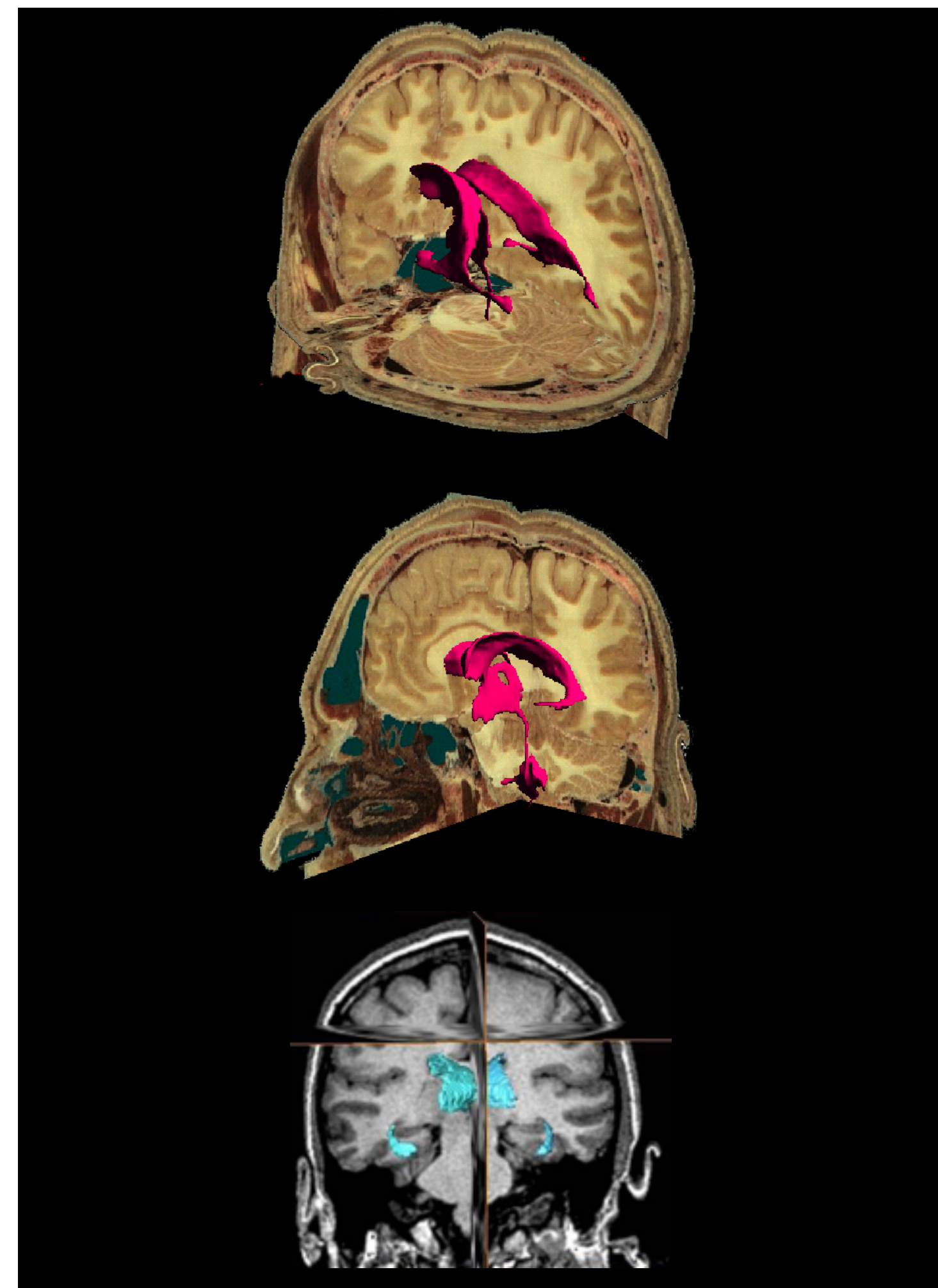

Figura 4.26. Visualización volumétrica del sistema ventricular. Representación de los modelos 3D embebidos en secciones obtenidas a partir de VHP desde vistas postero y anterolateral (imagen superior y media ) y RM desde una vista anterior (imagen inferior). El alargamiento de los VL podría representar un endofenotipo volumétrico de la esquizofrenia, aunque se trata de una alteraión inespecífica, presente en otros trastornos como el TB y EA. 


\subsection{EFICACIA DE LA VISUALIZACIÓN VOLUMÉTRICA 2D/3D EN LA INTERPRETACIÓN DE NEUROIMÁGENES}

Los grupos de comparación experimental y control fueron idénticos en el número de sujetos de cada nivel formativo y sexo. En cuanto a las puntuaciones en aptitud visoespacial, no se encontraron diferencias significativas entre el grupo control $(\mathrm{M}=21,14, \mathrm{SD}=3,38) \mathrm{y}$ experimental $(\mathrm{M}=20,08, \mathrm{SD}=2,95), \mathrm{t}_{(78)}=1,71, \mathrm{p}>0,05$ (n.s); ni se encontraron diferencias en las puntuaciones obtenidas en aptitud espacial según el sexo, hombres $(\mathrm{M}=20,80, \mathrm{SD}=3,59)$ y mujeres $(M=20,59, \mathrm{SD}=2,95), \mathrm{t}_{(78)}=0,29, \mathrm{p}>.05$ (n.s).

En la Tabla 4.7 se recogen los estadísticos descriptivos en el test de aptitud visoespacial, según los grupos de formación de la muestra.

Tabla 4.7. Medias y desviaciones típicas en aptitud visoespacial para los diferentes grupos.

\begin{tabular}{llllll}
\hline Condición visualización & Est. $5^{\circ}$ Psic. & Est. $5^{\circ}$ Med. & Neuropsicología & Neuroanatomía \\
\cline { 1 - 2 } \cline { 5 - 6 } Convencional 2D & $\mathrm{M}=22,50$ & $\mathrm{M}=20,20$ & $\mathrm{M}=21,09$ & $\mathrm{M}=20,80$ \\
& $\mathrm{SD}=4,30$ & $\mathrm{SD}=2,48$ & $\mathrm{SD}=4,22$ & $\mathrm{SD}=2,09$ \\
Volumétrica 2D/3D & $\mathrm{M}=21,01$ & $\mathrm{M}=19,20$ & $\mathrm{M}=20,30$ & $\mathrm{M}=19,80$ \\
& $\mathrm{SD}=3,39$ & $\mathrm{SD}=2,66$ & $\mathrm{SD}=3,34$ & $\mathrm{SD}=2,48$ \\
\hline
\end{tabular}

Se calculó el coeficiente de correlación producto-momento de Pearson para evaluar la relación entre la edad y el porcentaje de aciertos totales obtenidos. Se encontró una correlación positiva entre las dos variables, $\mathrm{r}=0,56, \mathrm{p}<0,01$. En general, se encontró una fuerte correlación positiva entre la edad y el porcentaje de aciertos total. Una mayor edad correlacionó con un aumento en el porcentaje de aciertos.

Se realizaron las correspondientes pruebas $t$ de muestras independientes para comparar el porcentaje de aciertos, tiempo de respuesta y grado de confianza en la respuesta para la tarea de identificación/localización en las condiciones de visualización convencional 2D y visualización volumétrica $2 \mathrm{D} / 3 \mathrm{D}$.

En primer lugar, se encontró una diferencia significativa en el porcentaje de aciertos totales en la condición de visualización volumétrica $(\mathrm{M}=41,09, \mathrm{SD}=17,32)$ y visualización convencional $(\mathrm{M}=25,37, \mathrm{SD}=15,40) ; \mathrm{t}_{(78)}=4,68, \mathrm{p}<0,01$. Estos resultados señalan que la visualización de generaciones volumétricas embebidas en neuroimagenes tiene un efecto sobre el porcentaje de aciertos en la interpretación de neuroimágenes. En concreto, nuestros resultados sugieren que el porcentaje de aciertos de los participantes expuestos a la condición de 
visualización volumétrica, aumentó respecto a los participantes expuestos a visualización convencional 2D.

En segundo lugar, se encontró una diferencia significativa en el tiempo de respuesta en la condición de visualización volumétrica $(\mathrm{M}=6752, \mathrm{SD}=825)$ y visualización convencional $(\mathrm{M}=$ $8059, \mathrm{SD}=1101) ; \mathrm{t}_{(72)}=5,95, \mathrm{p}<0,01$. Los datos sugieren que la visualización de generaciones volumétricas embebidas en neuroimagenes tiene un efecto sobre el tiempo de respuesta para la tarea propuesta. En concreto, nuestros resultados sugieren que en los participantes expuestos a la condición de visualización volumétrica, el tiempo de respuesta disminuyó respecto a los participantes expuestos a visualización convencional 2D.

En tercer lugar, se encontró una diferencia significativa en el grado de confianza en la respuesta para la condición de visualización volumétrica $(\mathrm{M}=6,48, \mathrm{SD}=1,56)$ y visualización convencional $(\mathrm{M}=4,90, \mathrm{SD}=1,96) ; \mathrm{t}{ }_{(78)}=3,96, \mathrm{p}<0,01$. Estos resultados indican que la visualización de generaciones volumétricas embebidas en neuroimagenes tiene un efecto sobre el grado de confianza en la respuesta. En concreto, nuestros resultados sugieren que para los participantes expuestos a la condición de visualización volumétrica, el grado de confianza en la corrección de su respuesta aumentó respecto a los participantes expuestos a visualización convencional 2D.

Posteriormente, se realizaron ANOVAs (Analysis of Variance) para el análisis del efecto de la condición de visualización sobre el nivel de ejecución de los participantes según su nivel de formación, modalidad de la neuroimagen presentada y dificultad de la estructura a identificar en la tarea.

Se realizó un ANOVA intersujetos para comparar los efectos de la condición de visualización sobre el porcentaje de aciertos, según nivel de formación de los participantes. Se encontró un efecto significativo de la condición de visualización, $F_{(1,76)}=38,43, p<0,01$, y del nivel de formación, $\mathrm{F}_{(1,76)}=55,23, \mathrm{p}<0,01$, pero no de la interacción entre ambos, $\mathrm{F}_{(1,76)}=0,54$, $\mathrm{p}>0,05$, (n.s.). En conjunto, estos resultados indican que tanto la condición de visualización volumétrica, como un alto nivel de formación tienen un efecto significativo sobre el el porcentaje de aciertos en la tarea de identificación/localización de estructuras encefálicas profundas. Es interesante destacar que la mejora en la condición de visualización volumétrica 2D/3D respecto al porcentaje de aciertos fue superior en el grupo de principiantes (aumentando el porcentaje de aciertos un $19,40 \%$, frente a un aumento del $11,04 \%$ en el grupo de expertos. En la Figura 4.27 aparecen representados los porcentajes de aciertos en la condición de visualización 2D y volumétrica 2D/3D según el nivel de formación bajo (principiantes) y alto (expertos). 


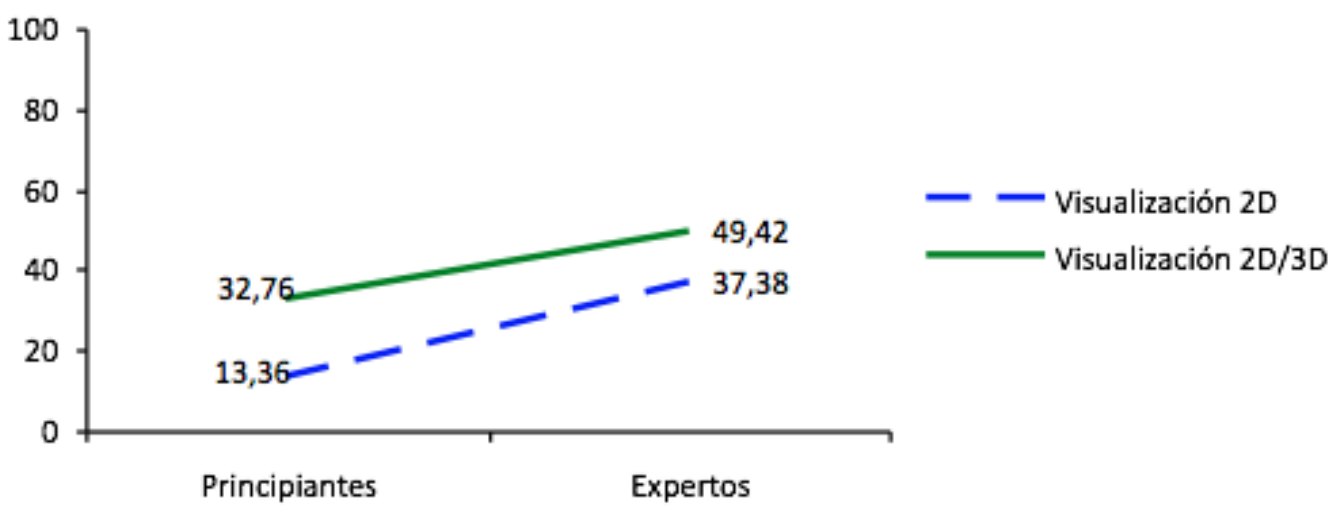

Figura 4.27. Porcentaje de aciertos en las condiciones de visualización volumétrica 2D/3D y convencional 2D según nivel de formación.

Se realizó un ANOVA de medidas repetidas para comparar los efectos de la condición de visualización sobre el porcentaje de aciertos totales en la tarea de identificación/localización de estructuras, según la modalidad de la neuroimagen a interpretar (morfológica o funcional). Se encontró un efecto significativo de la condición de visualización $\mathrm{F}_{(1,78)}=53,51, \mathrm{p}<0,01$, y de la modalidad de la imagen a interpretar $\mathrm{F}_{(1,78)}=16,59, \mathrm{p}<0,01$. La interacción resultó no significativa, $\mathrm{F}_{(1,78)}=0,92, \mathrm{p}>0,05$ (n.s.). Estos resultados sugieren que la condición de visualización tuvo efecto sobre las dos modalidades de neuroimágenes, tanto morfológicas como funcionales, de forma que los participantes expuestos a la visualización volumétrica mejoraron el porcentaje de aciertos en la interpretación de neuroimágenes morfológicas y funcionales, respecto a la condición de visualización convencional 2D. Este beneficio fue superior en la interpretación de neuroimágenes funcionales, aumentando un $21,56 \%$ el porcentaje de aciertos, respecto a la mejora asociada a la interpretación de neuroimágenes morfológicas de un 17,46\%. En la Figura 4.28 aparecen representados los porcentajes de aciertos en la condición de visualización 2D y volumétrica 2D/3D según la modalidad de las neuroimágenes.

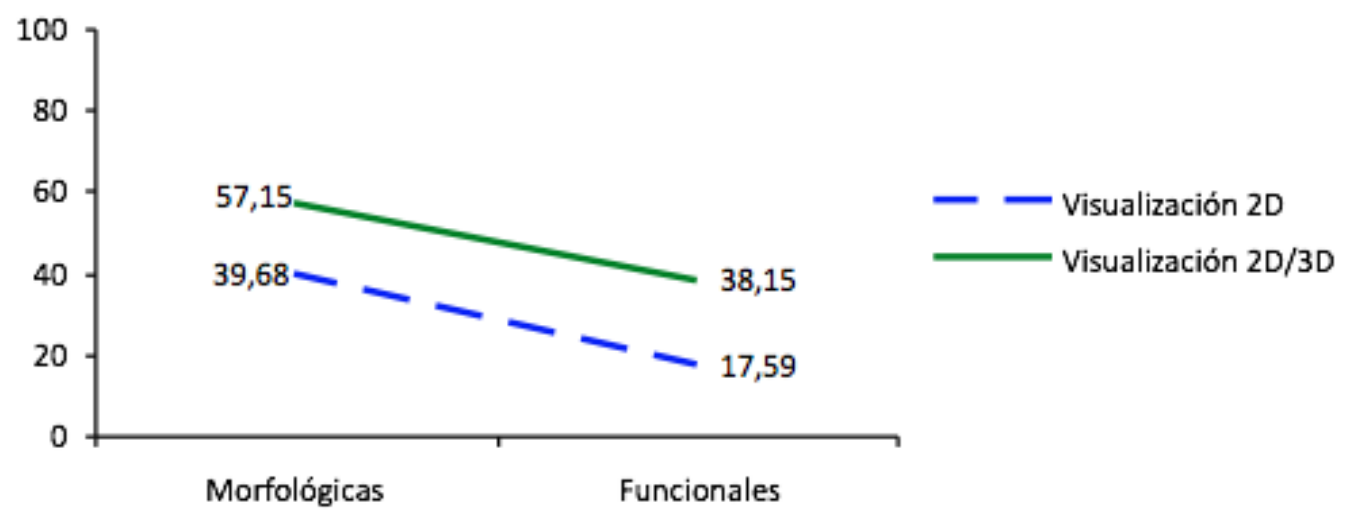

Figura 4.28. Porcentajes de aciertos en las condiciones de visualización volumétrica 2D/3D y convencional 2D según la modalidad de las neuroimágenes. 
Se realizó un segundo ANOVA de medidas repertidas para comparar los efectos de la condición de visualización sobre el porcentaje de aciertos según la dificultad (baja o alta) de la estructura encefálica a interpretar. Se encontró, nuevamente, un efecto significativo de la condición de visualización $\mathrm{F}_{(1,78)}=125,18, \mathrm{p}<0,01$, y de la dificultad de la imagen a interpretar, $\left(\mathrm{F}_{(1,78)}=21,91, \mathrm{p}<0,01\right.$. Sin embargo, en esta ocasión la interacción resultó significativa, $\mathrm{F}_{(1,78)}$ $=7,84, \mathrm{p}<0,05$. Estos resultados sugieren que el efecto de la condición de visualización sobre el porcentaje de aciertos varió según la dificultad de la estructura a identificar. En concreto, nuestros resultados sugieren que los participantes expuestos a la visualización volumétrica mejoraron el porcentaje de aciertos en la identificación/localización de estructuras encefálicas difíciles, pero no se encontró este beneficio en la interpretación de estructuras clasificadas como fáciles, aunque también aumentaron los porcentajes de aciertos en la condición de visualización volumétrica. En la Figura 4.29 aparecen representados los porcentajes de aciertos en la condición de visualización 2D y volumétrica 2D/3D según la dificultad de las estructuras encefálicas.

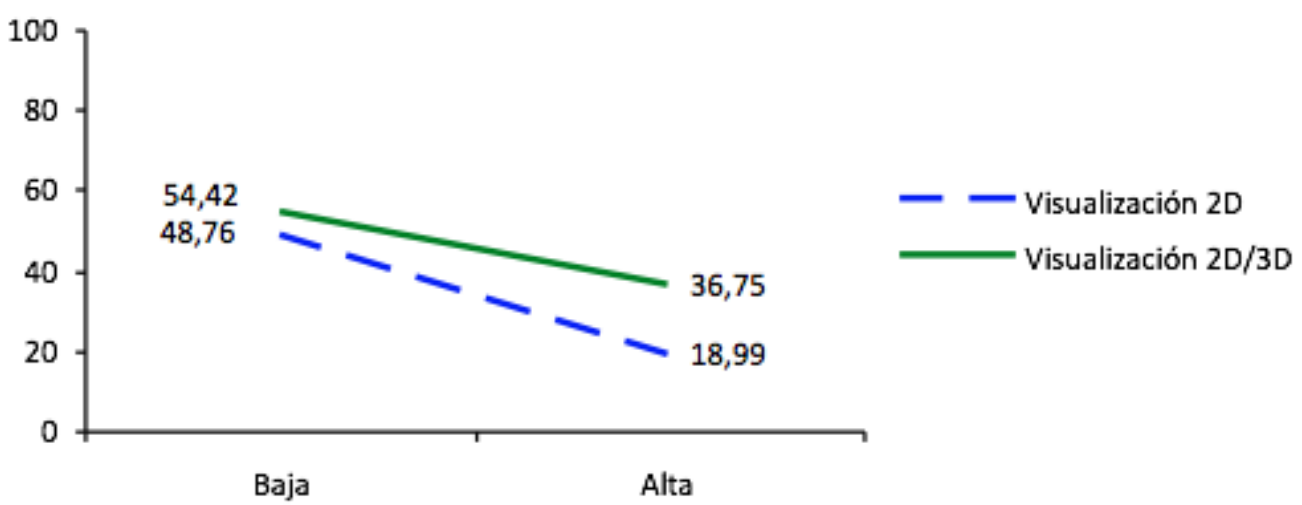

Figura 4.29. Porcentajes de aciertos en las condiciones de visualización volumétrica 2D/3D y convencional 2D según la dificultad de las estructuras a identificar.

Finalmente, los valores promedio obtenidos en los ítems de la escala de satisfacción aplicada al grupo experimental, modalidad de visualización combinada $2 \mathrm{D} / 3 \mathrm{D}$, fueron los siguientes: para al primer ítem, relativo a la utilidad de las generaciones volumétricas embebidas, $\mathrm{M}=3,5, \mathrm{SD}=0,82$; para el segundo, sobre la percepción de utilidad de la visualización conjunta 2D/3D de secciones con modelos embebidos, $\mathrm{M}=4,1, \mathrm{SD}=0,45$; para el tercero, sobre la oportunidad de recomendar este sistema de visualización para la enseñanza/aprendizaje de neuroanatomía, $\mathrm{M}=4,3, \mathrm{SD}=0,61$. En general, los resultados obtenidos indican un alto nivel de satisfacción y percepción de utilidad del sistema de visualización volumétrico. 


\section{Discusión}

La neuroanatomía es una parte relevante de las neurociencias Supone un lenguaje común, cuyo nivel de conocimiento ha caído drásticamente en los últimos años, en parte por la falta de oportunidades de interactuar directamente con la anatomía real objeto de estudio (Older, 2004; Rizzolo et al., 2006; Rizzolo \& Stewart, 2006; Turney, 2007). Sin embargo, las universidades no se pueden permitir formar neuropsicólogos, cuya carrera profesional va a durar décadas, sin una adecuada formación en neuroanatomía. Contenidos que deben ser considerados, no sólo en la formación de neuropsicólogos, sino también de psiquiatras, psicólogos y otros profesionales sanitarios (Bullmore, Fletcher, \& Jones, 2009), por el interés de los pacientes y de una óptima atención sanitaria (Sugand, Abrahams, \& Khurana, 2010). Los resultados de este trabajo han cuantificado, de forma objetiva, la distancia que existe entre estudiantes de Psicología y Medicina, Neuropsicológos y Neuroanatomistas, en la interpretación de neuroimágenes.

Tradicionalmente, el conocimiento sobre neuroanatomía se ha presentado en libros y atlas en soporte papel (Young, 2001; Kalat, 2003; Purves, 2004; Standring, 2005; Afifi \& Bergman, 2006; Haines, 2006; Puelles, 2008; Rubin, M., \& Safdieh, 2008) o en formato digital, tanto en soporte CD-ROM, como web (Scarabino et al., 2006; Crossman \& Neary, 2007; Duane, 2008; Soper, 2008; Woolsey et al., 2008; Barr, 2009; Nowinski, Thirunavuukarasuu, Volkau, Marchenko, \& Runge, 2009; Snell, 2009). Sin embargo, todos ellos han seguido basándose en el paradigma tradicional caracterizado por texto impreso, acompañado de imágenes 2D. Los resultados de estre trabajo ofrecen una aproximación más novedosa al estudio de estructuras encefálicas profundas, a partir de su generación volumétrica.

Actualmente, los avances de las nuevas tecnologías definen la base de la educación moderna y nos han brindado la posibilidad de desarrollar nuevos recursos como los modelos 3D informatizados, que ofrecen una estrategia más versátil para la representación del conocimiento espacial de la neuroanatomía humana, sin perder el conocimiento descriptivo clásico declarativo, que puede incluirse como atributo de los modelos 3D (Chumley-Jones, Dobbie, \& Alford, 2002; Cantillon, Irish, \& Sales, 2004; Guttmann, Drake, \& Trelease, 2004; Hansen, 2008; Nowinski et al., 2009; Nowinski, Thirunavuukarasuu et al., 2009).

La creciente aplicación de estas técnicas ha supuesto la acumulación de un ingente volumen de datos, y por lo tanto, la necesidad de considerar cómo almacenarlos. Cualquier método de almacenamiento, incluso en formato digital, resulta inútil, a menos que se disponga de formas eficaces de acceso a la información. Los modelos 3D, como los generados en este trabajo, permiten dar respuesta a esta necesidad, al constituir verdaderos sistemas de navegación que permiten resumir y visualizar, simultáneamente, información contenida en múltiples secciones seriadas $2 \mathrm{D}$. 
Estos logros de las técnicas de neuroimagen morfológicas y funcionales, condición sine qua non para la consecución de los objetivos planteados en nuestro estudio, se pueden clasificar en tres categorías: nuevos métodos de adquisición de datos, nuevos métodos para el análisis/procesamiento de datos y nuevas aplicaciones (Monchi, Benali, Doyon, \& Strafella, 2008).

Hoy disponemos de múltiples técnicas de diagnóstico por imagen que permiten la adquisición de datos desde diferentes modalidades. El enfoque multimodal de nuestro trabajo ha incorporado modalidades de imágenes biomédicas morfológicas, RM potenciadas en T1 y secciones de cadáver del VHP, y funcionales, SPECT y PET. A diferencia de otros, centrados en datos unimodales, principalmente RM (Hammers et al., 2003; Heckemann, Hajnal, ljabar, Rueckert, \& Hammers, 2006; Shattuck et al., 2008).

En este trabajo, las generaciones volumétricas se han basado en sujetos sanos, a diferencia de otros estudios que han desarrollado reconstrucciones 3D de determinadas patologías neurológicas, como la atrofia cerebral en enfermos con EA, a partir de secciones RM obtenidas de la base de datos pública del Alzheimer's Disease Neuroimaging Initiative, tumores, entre otros (Bach et al., 2004; Belitz, Rohr, Müller, \& Wagenkncht, 2006; Hua, Lee, Ho, Leow yanovsky, \& Gutmn, 2008; Khotanlou, 2008).

Dentro de los avances en el análisis y procesamiento de datos, destacaremos las estrategias o métodos especiales de procesamiento de imágenes, también denominadas transformaciones imagen-imagen, que han permitido la generación volumétrica o visualización 3D desarrollada en este trabajo.

La segmentación manual o interactiva ha aportado robusted durante el proceso de generación volumétrica y es considerado un estándar en la interpretación de datos de neuroimagen, actualmente (Khotanlou, 2008; Shattuck et al., 2008). La segmentación automática nos hubiera permitido segmentar conjuntos de datos a gran escala con la menor intervención por nuestra parte. Sin embargo, la selección de los parámetros de segmentación deberían haberse realizado, igualmente, de forma manual y con sumo cuidado, para garantizar resultados óptimos.

Se está trabajando en algoritmos y modelos deformables de segmentación automática (Sharma \& Aggarwal, 2010) pero, hasta la fecha, y en base a los trabajos revisados, no hemos encontrado ningún algoritmo que pueda segmentar de forma robusta diferentes estructuras encefálicas en imágenes biomédicas de distintos conjuntos de datos, especialmente, en el caso de presencia de patologías o cuando las formas de las estructuras no son suaves, como sucede en nuestro trabajo. Amira ${ }^{\circledR}$ ha sido la herramienta empleada para aplicar la estrategia de segmentación manual o interactiva basada en las capacidades de reconocimiento de un observador entrenado (Olabarriaga \& Smeulders, 2001; Takanashi, Lum, Meyer, Ma, Hamann, \& Olson, 2001). 
Las principales dificultades en la tarea de segmentación de las imágenes empleadas se han debido al hecho de trabajar con gran cantidad de datos, la presencia de artefactos debidos al movimiento del sujeto y la falta de definición en los tejidos blandos de las estructuras a representar. Estas dificultades son comunes a las encontradas por otros autores durante el proceso de segmentación en caso de patologías (Bach Cuadra et al., 2004; Belitz et al., 2006; Khotanlou, 2008). Como solución, la segmentación se apoyó en el conocimiento previo sobre las relaciones espaciales entre las estructuras a modelar. Automatizar el proceso de segmentación permitiría que varios casos pudieran ser manejados con la misma precisión, de forma rápida y sin afectar variables como la fatiga. El problema es que las técnicas de segmentación de imágenes médicas disponibles, son dependientes de la modalidad de imagen y la parte del cuerpo estudiada. Es decir, no existe un algoritmo universal para todas las imágenes médicas (Sharma \& Aggarwal, 2010).

A diferencia de otros trabajos, hemos empleado un enfoque probabilístico, al considerar que no existe un único encéfalo representativo de la población, ni un método simple de representar las distintas variaciones existentes. Esta es una característica diferencial respecto a otros estudios dirigidos a la construcción de atlas estandarizados o normalizados (Chumley-Jones et al., 2002; Cantillon et al., 2004; Guttmann et al., 2004; Hansen, 2008) y que suponen diferentes métodos de tratamiento de imágenes. Los atlas normalizados se han empleado para intentar resolver el problema de las reconstrucciones asociado al uso de diferentes escalas, resoluciones espaciales, métodos de organización, estudio de las diferencias individuales y variabilidad en el tiempo de las estructuras reconstruidas (Toga, 2005). Estos atlas se han basado en un sistema de coordenadas de referencias, generalmente, el atlas de Talairach y Tournoux (1988), sobre el que comparar los datos obtenidos en diferentes individuos, pero resulta un enfoque inadecuado para los propósitos de nuestro trabajo. La normalización de los datos supone distorsionar los originales, como sucedió con el atlas probabilístico desarrollado por el Internacional Consortium for Brain Mapping (Mazziotta, Toga, Evans, Fox, \& Lancaster, 1995). Para este fin, normalmente se emplean algoritmos de transformación lineal (linear scaling) que consisten en estirar o contraer hasta ajustar la forma y posición de un determinado encéfalo al de Talairach, que sigue siendo el sistema de referencia o normalización más empleado para presentar coodenadas y ha sido útil en la planificacion de abordajes quirúrgicos. El problema es que el atlas de Talairach sólo consta de un hemisferio, al asumir simetría interhemisférica y no incluye el tronco encefálico ni el cerebelo. Además, se vuelve progresivamente más impreciso en regiones más variables, como el córtex, o en regiones asimétricas entre los dos hemisferios, como algunas áreas temporales. Otro problema asociado, tiene que ver con la ausencia de imágenes del encéfalo original empleado en su construcción del atlas, por lo que no permite emplear sistemas de registro para mapear el encéfalo de un individuo concreto, directamente. Los atlas estandarizados o probabilísticos tienden a minimizar el problema de las diferencias individuales y 
la variabilidad de las estructuras en el tiempo. Se basa en medias grupales y requiere emplear grandes poblaciones, de forma que su nivel de precisión mejora a medida que aumenta el tamaño de la muestra e incorpora nuevos datos.

Las generaciones volumétricas de este trabajo reflejan las características morfológicas y espaciales de los casos explorados, frente a los esquemas o representaciones de valores probables característicos de los atlas probabilísticos. Esta tarea ha supuesto un trabajo exigente para la identificación y delimitación de estructuras con alta variabilidad interindividual en sus características morfológicas o espaciales, especialmente, surcos y giros, pero permite mejorar significativamente, la capacidad de análisis y la sensibilidad de información tradicional de las técnicas de diagnóstico por imagen, en la detección de trastornos neuropsicológicos.

Los avances en las técnicas de diagnóstico por imagen también han ampliado el número de estructuras encefálicas que pueden ser exploradas y valoradas de forma no invasiva, como se aprecia en la multiplicidad de estructuras reconstruidas en este trabajo. Se ha progresado desde radiografias simples, que mostraban las distintas estructuras como sombras superpuestas en la película, a secciones neuroanatómicas sin superposiciones y con una precisión sin precedentes, con la aparición de las modalidades tomográficas como TC, RM y PET y, finalmente, a la reconstrucción 3D gracias al registro de secciones paralelas.

Los resultados del estudio bibliométrico y de la revisión bibliográfica desarrollada en este trabajo, confirman el interés actual por la aplicación de las nuevas técnicas de diagnóstico por imagen al estudio de la relación entre el encéfalo humano y el comportamiento humano, especialmente, los trastornos psiquiátricos (Lyoo \& Renshaw, 2002; Dougherty \& Rauch, 2004; Pozo, 2004; Abou-Saleh, 2006; Pearlson, \& Calhoum, 2007; Dager, Corrigan, Richards, \& Posse, 2008; Fleck, Nandagopal, Cerullo, Eliassen, DelBello, Adler, \& Strakowski, 2008; Renshaw, 2008; Sava \& Yurgelun-Todd, 2008; Théberge, 2008; Hendler et al., 2009). Consistentemente, ha aumentado el espacio dedicado a este campo de estudio en los manuales de neuropsicología más recientes (Halligan, Kischka, \& Marshall, 2010; Kolb, \& Whishaw, 2010), si bien el trastorno por esquizofrenia sigue siendo el trastorno psiquiátrico paradigmático y que más atención ha recibido (Ellison-Wright \& Bullmore, 2009; Kircher, Leube, \& Habel, 2009; Kyriakopoulos \& Frangou, 2009).

Uno de los problemas que hemos encontrado a la hora de seleccionar las estructuras implicadas en los diferentes trastornos, con importantes efectos neuropsicológicos han sido los diferentes tamaños de muestra empleados, generalmente grupos cautivos, los diversos criterios de selección de la muestra y las distintas técnicas de neuroimagen utilizadas en los estudios. En general, las estructuras encefálicas más relevantes han sido el CPF, especialmente la región del CPF-DL y la región del GCA: el cuerpo estriado, el hipocampo, la amígdala y los VL. En el caso específico de los trastornos psiquiátricos caracterizados por un comportamiento socioemocional complejo, a partir de los resultados de las investigaciones revisadas, hemos encontrado un 
denominador común neuroanatómico, asociado al área prefrontal-estriada (Blumberg et al., 2000; Womer et al., 2009; Carlson, Singh, Zarate, Drevets, \& Manji, 2006; Emsell \& McDonald, 2009).

En concreto, los estudios de neuroimagen revisados sugieren que el CPF-DL (áreas $9 \mathrm{y}$ 46 de Brodmann) localizado en los giros frontales superior y medio juega un papel crítico en la planificación de conductas, junto con el caudado, que participa según el nivel de complejidad.

Sin embargo, no hemos encontrado estudios que confirmen la utilidad diagnóstica o predicción de la respuesta al tratamiento de pacientes a partir de estos hallazgos, al menos, en el caso de trastornos psiquiátricos.

Finalmente, en cuanto a las nuevas aplicaciones de las imágenes médicas, la generación volumétrica de estructuras encefálicas no sólo ofrece imágenes visualmente sofisticadas, sino que en base a los resultados obtenidos, pueden considerarse una forma más eficiente de representación de las características morfológicas y espaciales respecto a la visualización convencional. Son potentes fuentes de información aplicables a contextos formativos y clínicos, al permitir su integración con imágenes multimodales.

En contextos formativos, los recursos para la formación en neuroanatomía han evolucionado intensamente desde el siglo XVI, cuando Vesalio introdujo la disección como estrategia pedagógica obligatoria para el aprendizaje de anatomía. Los modelos 3D, como los que se presentan en este trabajo, no sólo han potenciado los recursos del sistema pedagógico tradicional, si no que lo han renovado, ofreciendo una visión más completa de las características anatómicas (Reidenberg \& Laitman, 2002; McLachlan, 2004; McLachlan, Bligh, Bradley, \& Searle, 2004; McLachlan \& Patten, 2006; Turner, 2007; Sugand et al., 2010). Estos recursos mantienen como eje vertebral el énfasis en el uso de ayudas visuales, más allá de las simples ilustraciones de los libros de texto, sin pretender sustituir o negar los beneficios de la disección tradicional como recurso docente (Parker, 2002; Gundermann \& Wilson, 2005; Rizzolo et al., 2006; Rizzolo \& Stewart, 2006; Burton \& Underwood, 2007), aunque con la desventaja de ser poco accesible, dado el escaso número de sujetos disponibles, especialmente, para los estudiantes de las Facultades de Psicología.

Las generaciones volumétricas desarrolladas se enmarcarían dentro de estas nuevas estrategias pedagógicas visuales que permiten la activación y revisión de contenidos neuroanatómicos (O’Byrne, Patry, \& Carnegie, 2008; McNulty, Sonntag, \& Sinacore, 2009; Nowinski et al., 2009; Sugand et al., 2010). Además, dado el carácter digital de los desarrollos volumétricos, pueden integrarse en entornos de simulación virtual, para el entrenamiento en abordajes quirúrgicos.

Los modelos de plástico merecen consideración a parte, como recursos visuales. Modelan a la perfección los órganos humanos como el encéfalo y tienen una forma impecable y 
un color coordinado. Sin embargo, al igual que las ilustraciones de los libros de texto, no muestran la variabilidad biológica de cada caso, que resulta de interés clínico. En una reciente investigación se encontró que los alumnos deprivados de contacto con el cuerpo humano real, tuvieron más dificultades para apreciar cualquier variación biológica (Gillingwater, 2008).

Como resultado de la importancia de las técnicas de diagnóstico por imagen como herramientas de diagnóstico clínico, es necesario mejorar la habilidad para interpretar imágenes médicas, y las generaciones volumétricas, contribuyen a este fin (Miles, 2005; Gundermann \& Wilson, 2005). En las exploraciones morfológicas, las estructuras encefálicas aparecen en imágenes, en escalas de gris de diferentes secciones ortogonales, de forma muy diferente respecto a su apariencia real en 3D. Esta diferencia requiere que el neuropsicólogo, realice una traslación mental compleja importante, que requiere de un entrenamiento muy especializado. Otros clínicos como neurólogos, radiólogos, internistas, etc. pasan a través de dicho entrenamiento, sin embargo, no sucede así en el caso de neuropsicólogos, psicólogos o psicólogos clínicos, lo que implica mayor probabilidad de errores a la hora de realizar estas operaciones. La utilidad de los modelos 3D radica, principalmente, en su carácter digital que incorporan dichas reconstrucciones a aplicaciones multimedia.

En general, el nivel de aprendizaje está directamente correlacionado con el nivel de implicación del estudiante, y las ayudas de aprendizaje visuales e interactivas suponen un incentivo, además de mejorar la retención a largo plazo (Miles, 2005; Windsor, Diener, \& Zoha, 2008), garantizando el conocimiento necesario para identificar estructuras encefálicas clínicamente relevantes, como las desarrolladas en este estudio. Aumentar la participación y atención de los alumnos redunda en una mejor comprensión de las características morfológicas y relaciones espaciales entre dichas estructuras. Es una de las habilides básicas en neuroanatomía (Juanes et al., 2002).

Desde el punto de vista de la investigación, la fusión de técnicas de diagnóstico por imagen morfológicas y funcionales ha contribuido a mejorar el estudio de las bases neuronales de la conducta humana normal y patológica, destacando la participación conjunta de diferentes estructuras encefálicas, a modo de circuitos.

En base a los resultados de la revisión bibliográfica realizada, la amígdala es una estructura central en la respuesta de ansiedad y trastornos asociados (ver referencias en Tabla 4.6). Un estudio multimodal RM y RMf, en el que se presentaron caras emocionales y neutras durante diferente tiempo de exposición, haciéndolas perceptibles o no (enmascaramiento), como era esperado, los tiempos de reacción fueron más largos en la condición emocional, pero también se descubrió que existen dos áreas dentro de la amígdala, que responden de forma diferencial al tiempo de exposición, gracias a la superposición de imágenes RMf y RM (Etkin, Klemenhagen, Dudman, Rogan, Hen, Kandel, \& Hirsch, 2004). La amígdala basal lateral se activó en la condición de enmascaramiento y la amígdala dorso lateral durante la presentación explícita; la 
primera estuvo modulada por diferencias individuales en ansiedad-rasgo (Etkin et al., 2004). En un estudio posterior, se encontró que el GCA también participa en el control de emociones modulando la actividad de la amígdala (Etkin et al., 2006).

Otro ejemplo, relacionado con la aportación de las técnicas de diagnóstico por imagen al estudio de las bases biológicas de la conducta humana, tiene que ver con el estudio de las estructuras implicadas en mentir. Cuando se han comparado las áreas de activación en RMf asociadas a la condición "decir la verdad" y "mentir" ante la tarea de responder a una pregunta, se ha encontrado una mayor activación en el giro frontal medio, una estructura asociada con la toma de decisiones y elaboración de juicios morales complejos (Greene et al., 2001; Hirsch, 2005). Precisamente, la misma estructura encefálica que Harlow, después del estudio del caso de Phineas Gage, sugirió como sustrato biológico de la moralidad.

Sin embargo, la contribución de las técnicas de diagnóstico por imagen al estudio de distintos trastornos neuropsicológicos no ha sido homogénea en cuanto a la nitidez con que ilustran las estructuras encefálicas implicadas. En el campo de los tratornos psiquiátricos, las técnicas de neuroimagen morfológicas han sido las más empleadas en contextos clínicos, mientras que las funcionales, se han restringido a contextos de investigación (Pozo, 2004; Ciumas, Montavont, \& Ryvlin, 2008; Eldaief \& Dougherty, 2008).

En el estudio de los trastornos neurológicos, la RM se ha convertido en una herramienta clave en su diagnóstico y tratamiento, en presencia de alteraciones agudas en el estado mental, signos neurológicos, TCE relevante o epilepsia (Weinberger, 1984; Krzyzkowiak, 1993; Mueller, Rufer, Moergeli, \& Bridler, 2006; Khotanlou, 2008), y para establecer la pérdida de volumen en estructuras del lóbulo temporal medial y el hipocampo en casos de EA, como predictores del deterioro cognitivo leve en EA (Jack et al., 2000; Mungas et al., 2002).

Recientemente, las imágenes biomédicas también se han empleado en el estudio de trastornos psiquiátricos, especialmente en la esquizofrenia, con la intención de identificar cambios y/o alteraciones en estructuras encefálicas asociadas. Sin embargo, a partir de la revisión realizada en este trabajo, las alteraciones encontradas son sutiles, inespecíficas, y variables, luego los datos obtenidos a partir de técnicas de diagnóstico por imagen no pueden emplearse de forma exclusiva en el diagnóstico de trastornos psiquiátricos (Pozo, 2004; Erhart, Young, Marder, \& Mintz, 2005; Eldaief \& Dougherty, 2008; Brammer, 2009). Por ejemplo, las alteraciones en el hipocampo son comunes al TB y Esquizofrenia (Rimol et al. 2010; Hall et al. 2010; Mamah et al., 2010; Javadapour, et. 2010)

Se asume que los trastornos psiquiátricos están asociados a alteraciones en determinadas estructuras encefálicas, y que las técnicas de neuroimagen son útiles para su estudio, pero se sigue discutiendo cuál es la naturaleza de estas alteraciones, al menos a nivel macroscópico. 
Hasta la fecha, y en base a la investigación revisada, la aplicación clínica de las técnicas de neuroimagen en el estudio de trastornos psiquiátricos se ha extendido, aunque limitándose a descartar condiciones médicas o neurológicas que pudieran mimetizar trastornos psiquiátricos, ya que con frecuencia, los síntomas psiquiátricos son los primeros signos de una patología neurológica (Weinberger, 1984), pero actualmente, no permite el diagnóstico psiquiátrico o elección de tratamiento (Ciumas et al., 2008).

Los dos problemas metodológicos más importantes en el estudio de trastornos psiquiátricos a través de técnicas de diagnóstico por imagen son: en primer lugar, la dificultad en controlar características de la muestra como: comorbilidad, medicación u otras diferencias inter o intraindividuales (Holler et al., 2009). Por ejemplo, en estudios realizados con pacientes del espectro autista con RM se ha encontrado que la edad influía en el tamaño de la amígdala y la edad, junto con el Cociente Intelectual en el tamaño del vermis (Stanfield et al., 2008). En segundo lugar, el problema de la sobresimplificación en cuanto a la localización de funciones cerebrales en estructuras anatómicas específicas. La tarea de la localización de funciones cognitivas superiores es complicada porque la mayor parte de las estucturas encefálicas participan en múltiples procesos, y la mayoría de los tests neuropsicológicos y funciones cognitivas evaluadas a través de ellos, no se localizan estrictamente en estructuras encefálicas específicas (Mateus et al., 2009). Por ejemplo, en el estudio de los patrones de activación PET en pacientes con EA frente al patrón de envejecimiento, se encontró que el patrón de activación depende de la interacción entre la fase del paciente y la dificultad o demandas específicas de la tarea (Almkvist, 2000).

En contextos clínicos como la planificación quirúrgica es necesario comprender y localizar estructuras encefálicas 3D complejas y las diferencias individuales propias de cada caso. Sin embargo, la "reconstrucción mental" de estructuras encefálicas a partir de las imágenes biomédicas $2 \mathrm{D}$ es extremadamente difícil y depende del entrenamiento e imaginación del clínico observador (Duncan \& Ayache, 2000; Olabarriaga \& Smeulders, 2001; Pommert et al., 2002).

La visualización de modelos 3D permite crear una perspectiva visual más realista y precisa de las distintas estructuras encefálicas, que las imágenes biomédicas convencionales de las deferentes modalidades en 2D. En cirugía craneo-facial o traumatologia, la generación volumétrica se ha convertido, desde hace años, en parte de los procedimientos estándar preoperatorios (Altobelli et al., 1993).

La visualización volumétrica ofrece información más completa para definir las características morfológicas macroscópicas y relaciones espaciales de estructuras encefálicas, que pueden estar implicadas en los distintos trastornos neuropsicológicos (Toga \& Thomson, 2000). Supone un apoyo para la visualización o monitorización de casos clínicos que requieren disponer de información anatomofuncional individualizada para la toma de decisiones diagnósticas y quirúrgicas, por parte de estudiantes y profesionales en 
neurociencias (Atlas et al., 1996). La visualización volumétrica optimiza la correlación anatomofuncional entre las distintas estructuras encefálicas y las imágenes biomédicas, especialmente funcionales, que aunque cada vez nos ofrece más información sobre la actividad cerebral, no ofrece indicadores claros de la localización de los datos, especialmente, si consideramos la variabilidad interindividual en la anatomía del encéfalo, y con más intensidad en funciones cognitivas (Brett, Johnsrude, \& Owen, 2002).

La integración o fusión de imágenes biomédicas morfológicas y funcionales ha demostrado ser útil en el diagnóstico y tratamiento de tumores cerebrales. Por ejemplo, en el caso de un hombre de 32 años con un GBM localizado en el lóbulo frontal izquierdo, atendido por el Centro Médico de la Universidad de Columbia, Program for Imaging and Cognitive Sciences, al que pertenece el Premio Nobel Eric Kandel, se utilizaron tareas de lenguaje y habla antes de la cirugía para localizar las estructuras del encéfalo asociadas al lenguaje anexas al tumor. Fusionando neuroimágenes obtenidas a partir de RM y RMf se localizó la activación del área posterior adyacente al tumor durante tareas relacionadas con el habla, y la información se consideró relevante en la planificación de la intervención que, finalmente, no mostró déficits relacionados con el habla (Hirsch et al., 2000).

La fusión de imágenes morfológicas y funcionales con volúmenes, supone un avance más, facilitando la detección de sutiles diferencias entre las estructuras encefálicas representadas, difícilmente perceptibles a través de la exploración visual directa de secciones $2 \mathrm{D}$, especialmente en el caso de las imágenes biomédicas 2D funcionales, donde es difícil realizar una interpretación cualitativa apropiada de los puntos de activación mediante inspección visual. Por ejemplo, en secciones PET (Olabarriaga \& Smeulders, 2001).

En este trabajo, la integración de volúmenes y secciones de imágenes biomédicas, se ofrece como una alternativa al registro o superposición de secciones funcionales y radiológicas 2D desarrolladas por la Universidad de Harvard, en los ejemplos descritos en la introducción de este trabajo (Johnson \& Becker, 2010).

En el ámbito de la cirugía, las reconstrucciones 3D permiten representar escenarios y entornos de simulación para la planificación de abordajes quirúrgicos. Este hecho supone un avance cualitativo respecto a las intervenciones tradicionales, que se han basado en los mismos principios desde hace cientos de años, consistentes en el acceso mecánico directo al lugar de intervención como medio para la visualización de las estructuras encefálicas a intervenir. Las manos han controlado los instrumentos de intervención y los ojos han permitido obtener retroalimentación sobre el efecto de las intervenciones. En este escenario, la pérdida de visualización de la estructura encefálica a tratar y del control mecánico o pérdida de retroalimentación táctil, suponen una dificultad añadida.

Los modelos 3D en contextos de simulación, aumentan las posibilidades de visualización y reducen la invasividad de las intervenciones. Esta ventaja resulta, especialmente 
importante, en la planificación de abordajes quirúrgicos en neurocirugía donde se requiere la delimitación precisa de elementos estructurales y funcionales del encéfalo. En radioterapia, el creciente uso de imágenes de TC y RM en el diagnóstico y planificación de intervenciones, requiere la identificación y localización de las distintas estructuras diana, por lo que la segmentación y visualización 3D será de especial interés.

En los últimos años, ha sido posible combinar la visualización volumétrica con sistemas de realidad virtual que permiten al clínico "planear" a través de las estructuras en cuestión, o incluso tocarlas, incluyendo simulación de la resistencia y textura de distintas superficies de tejidos o retroalimentación háptica (haptic feedback technology) de vital importancia en el caso de detección de tumores (Howell, Conatser, Williams, Burns, \& Eland, 2008). La integración de visualización volumétrica con realidad aumentada, donde se superponen los mundos virtual y real para guiar al cirujano durante la intervención y robótica, en su aplicación a contextos quirújicos, se denomina cirugía asistida por ordenador, conocido bajo el acrónimo anglosajón CIST (computer-assisted surgery o computer integrated surgery and therapy). Lo novedoso de esta tecnología radica en la aplicación de visualizaciones volumétricas, no sólo en la planificación quirúrgica, sino en la propia ejecución de intervenciones quirúrgicas a través de sistemas de visualización 3D (Caramella \& Bartolozzi, 2002). Hasta el momento se han desarrollado cientos de cirugías e intervenciones basadas en este tipo de reconstruciones 3D, incluyendo neurocirugía, operaciones de próstata, hígado, abdominales y cardiovasculares (Morikawa et al., 2009; Tokuda et al., 2010).

En relación a las investigaciones futuras, el desarrollo de las técnicas de diagnóstico por imagen no invasivas seguirá siendo una herramienta clave, tanto en la investigación básica en neurociencias y aplicada al ámbito formativo y clínico, como en las áreas del diagnóstico clínico, y en la planificación de abordajes quirúrgicos. La integración multimodal seguirá siendo una estrategia útil para mejorar la resolución espacio-temporal de las diferentes modalidades, ya que reflejan procesos distintos (señales electrofisiológicas, hemodinámicas...), pero íntimamente relacionados (He \& Liu, 2008). Resulta útil en la valoración de riesgos en sujetos individuales (Juanes, Prats, et al., 2001; Juanes et al., 2001).

En el futuro, el número y calidad de las imágenes médicas seguirá aumentando día a día, al igual que sus aplicaciones formativas y clínicas, de forma que contaremos con más datos que demandarán programas informatizados capaces de almacenar y procesar tal cantidad de información. Paralelamente, los especialistas como neuropsicólogos, entre otros, tendrán que ser más eficientes en el análisis de dichas imágenes que les permitan identificar áreas sospechosas en distintas estructuras encefálicas, potencialmente asociadas a trastornos neuropsicológicos, como las señaladas en este trabajo. Por ejemplo, en la evaluación de pacientes con EA, tumores cerebrales, ACVs, etc. 
Investigaciones futuras seguirán trabajando en el análisis de parámetros y algoritmos que permitan la segmentación automática en imágenes biomédicas con mayor fiabilidad, algo que resulta inaccesible actualmente.

En lo relativo a la aplicación de imágenes funcionales SPECT y PET en el diagnóstico y clasificación de trastornos psiquiátricos, cada vez se están haciendo más comunes; sin embargo, es necesario seguir investigando hasta recoger datos suficientes que avalen su aplicabilidad diagnóstica, o predicción de los efectos terapéuticos. En este sentido, en un estudio con 253 pacientes con síntomas psiquiátricos, los resultados obtenidos a partir de la exploración RM modificó el tratamiento del 15\% de los casos (Erhart et al., 2005).

En el ámbito quirúrgico, las intervenciones mínimamente invasivas requerirán la generación volumétrica de estructuras encefálicas para la visualización y manipulación de las imágenes médicas, especialmente funcionales. Antes de la intervención quirúrgica, los datos tendrán que ser segmentados y preparados para la reconstrucción $3 \mathrm{D}$, y su posterior traslado a escenarios quirúrgicos o entornos de simulación, que servirán de apoyo en la planificación de intervenciones. En un futuro, los modelos se podrán actualizar durante la intervención, de forma que se podrán obtener modelos 3D más ajustados. Sin embargo, aún queda mucho trabajo que hacer en el área de la generación de algoritmos de segmentación automáticos fiables.

Los navegadores o tecnologías de neuronavegación ofrecen al cirujano información útil para la planificación de abordajes quirúrgicos precisos hacia la lesión diana, además de definir las estructuras neurovasculares que la rodean. La incorporación de datos funcionales como RMf a estas tecnologías ayuda a reducir el riesgo de afectar estructuras relevantes durante cirugías tales como biopsias, drenajes ventriculares, localización de un tumor, valoración de estructuras neurovasculares adyacentes a tumores... (Ganslandt, Behari, Gralla, Fahlbusch, \& Nimsky, 2002).

Cuando hablamos de la aplicación de los resultados obtenidos a partir de técnicas de diagnóstico por imagen en el estudio de trastornos psiquiátricos, tenemos que distinguir entre hallazgos de investigación y aquéllos de utilidad clínica. A pesar de que puede haber importantes hallazgos en el área, es posible que no sean aplicables al contexto clínico en un paciente concreto. Generalmente, estos hallazgos se han referido a datos medios grupales y puede que no sean extrapolables a cada uno de los casos del grupo inicial a los que se pretende generalizar los resultados. Sin embargo, la neuroimagen es una estrategia potencialmente útil en el campo de la Psiquiatría o Psicopatología para la mejora del diagnóstico, selección de tratamientos más adecuados y predicción de los resultados de las intervenciones (Glenda \& MacQueen, 2010). Por ejemplo, un estudio reciente discriminó correctamente pacientes depresivos de controles con un nivel de sensibilidad del $84 \%$ y una especificididad del $88 \%$ en base a la información obtenida a partir de RMf (Ecker et al., 2010) Futuras investigaciones tendrán que ir un paso más allá y discriminar, no sólo respecto a encéfalos sanos, sino entre distintos estados patológicos. Por 
ejemplo, si se trata de un episodio depresivo mayor o un TB, o si los síntomas son parte del comienzo de un cuadro de Esquizofrenia inducido por sustancias, etc.

Los resultados de las referencias bibliográficas revisadas en este trabajo coinciden en destacar la importancia de determinadas estructuras encefálicas, especialmente, en el caso de los trastornos psiquiátricos. Sin embargo, no se trata de alteraciones específicas de cada diagnóstico, ni los resultados son consistentes en los estudios revisados. Como ejemplo de la falta de especificidad, varios estudios de RM han encontrado una reducción en el volumen del hipocampo en pacientes con trastorno por depresión mayor, que se ha asociado a un peor pronóstico (Hsieh et al., 2002; Frodl et al., 2008; MacQueen, Yücel, Taylor, Macdonald, \& Joffe, 2008; McKinnon et al., 2009). Sin embargo, el volumen del hipocampo también se ha encontrado reducido en otras patologías como trastorno por estrés postraumático En otra serie de estudios, en este caso empleando RMf, han encontrado una relación entre la actividad del GCA y la respuesta a la medicación antidepresiva y terapia cognitivo conductual y casos de TDM, pero también en trastornos de ansiedad (Bryant, Felmingham, Kemp, Das, Hughes, Peduto, \& Williams, 2008; Nitschke, Sarinopoulos, Oathes, Johnstone, Whalen, Davidson, \& Kalin, 2009). Otros estudios sugieren la implicación de otras estructuras encefálicas, como la amígdala, que predijo la resolución de síntomas en pacientes con TDM (Canli et al., 2005; Fu et al., 2008; DeRubeis, Siegle, \& Hollon, 2008). En la mayoría de las investigaciones revisadas sobre Esquizofrenia, se han hallado alteraciones en el CPF, sin embargo, algunos autores han encontrado, igualmente, alteraciones funcionales en el CPF-DL en sujetos sanos (Callicott et al., 2003) y, otros autores, han encontrado inconsistencias (Michael et al., 2010), que confirman la heterogeneidad característica de este trastorno. Actualmente se discute si esta variabilidad representa diferentes extremos de un único continuo o si podrían diferenciarse trastornos independientes dentro de este grupo (Galderisi \& Maj, 2009). Incluso, se discute si podría conceptualizarse como un trastorno neurodegenerativo (Rund, 2009).

Un problema a resolver por futuras investigaciones dirigidas al estudio de las estructuras encefálicas implicadas en trastornos psiquiátricos y, en concreto, a la aplicabilidad de las técnicas de neuroimagen, tiene que ver con la alta prevalencia de trastornos del estado de ánimo y ansiedad, que podría dificultar la integración de estas técnicas en la práctica clínica habitual, dado el alto coste que supondría incluir estas pruebas en la rutina diaria.

En base a la evolución de los últimos años y al énfasis del plan estratégico del National Institute of Mental Health (NIMH) de EEUU en la personalización de la atención psiquiátrica en función a las respuestas individuales como área prioritaria de investigación (Insel, 2009; Malhi, \& Lagopoulos, 2008; Brammer, 2009), se espera un aumento significativo en la investigación y aplicación clínica de la neuroimagen en Psiquiatría durante los próximos años (Malhi \& Lagopoulos, 2008; Glenda, \& MacQueen, 2010), lo que requerirá un aumento de las demandas en profesionales como psiquiatras, psicólogos clínicos y neuropsicólogos en lo relativo a la 
comprensión de la información contenida en la imágenes médicas, además de las indicaciones, limitaciones y principios de las distintas técnicas.

La interpretación de neuroimágenes es un aspecto central en la formación de muchos profesionales en neurociencias. El avance en los sistemas de adquisición y procesamiento de imágenes morfológicas y funcionales contribuye a aumentar sus aplicaciones en el ámbito de la formación médica y en el diagnóstico clínico. Sin embargo, la dificultad en la interpretación de neuroimágenes, especialmente funcionales $\mathrm{y}$, a la hora de identificar o localizar estructuras encefálicas profundas, obliga a considerar formas de optimizar el rendimiento en estas tareas.

La generación volumétrica de modelos supone una propuesta prometedora, reduciendo las demandas cognitivas asociadas a la reconstrucción mental de las estructuras encefálicas y sus potenciales secciones. Algunos autores han propuesto la mejora de la comprensión de características morfológicas como una de las características asociadas a los modelos 3D (Cockburn, \& McKenzie, 2002).

Dos estudios recientes, han propuesto la utilidad de la visualización volumétrica, aunque sin realizar un estudio empírico sistemático. En el primero, se encontró que los estudiantes de Medicina que contaron con recursos de formación visuales en formato digital a través de ordenador puntuaron significativamente por encima de aquellos que no accedieron al contenido online en los exámenes sobre anatomía (McNulty et al., 2009). En segundo, los alumnos de Medicina de primer año que acompañaron sus clases magistrales con un tutorial de neuroanatomía 3D, no sólo consideraron interesante la herramienta, sino que obtuvieron puntuaciones significativamente más altas en el examen final, especialmente en las tareas de mayor dificultad (Venali, Deveze, Lallemant, Guevara, \& Mondain, 2010), sin embargo no se trataron de estudios empíricos sistemáticos como el que presentamos en este trabajo.

Consistentemente, los resultados de nuestro estudio ofrecen apoyo empírico a favor de la visualización volumétrica como estrategia más efectiva en tareas de identificación y localización de estructuras encefálicas como las propuestas: núcleos basales y el tálamo; y que constituye uno de los aspectos centrales en la interpretación de neuroimágenes morfológicas y funcionales. Estos resultados son coherentes con otros estudios aplicados de la visualización 3D en contextos formativos que subrayan el mayor atractivo visual y mayor grado de realismo vinculado a las representaciones (Novak, 2003; McLachlan et al., 2008; Silén et al., 2008; Hamza-Lup \& Thompson, 2009; Venali et al., 2010).

Los resultados de nuestro estudio apoyaron la eficacia de la visualización volumétrica en la interpretación de neuroimágenes respecto a la visualización convencional, pero también sugiere un beneficio respecto al nivel de confianza en las respuestas. Paralelamente, la disminución del tiempo asociado a las respuestas parece consistente con la mayor facilidad en la identificación/localización de la estructura diana. 
En base a los resultados obtenidos se destaca la importancia de este tipo de visualización en la elaboración de recursos docentes en estudiantes de neurociencias, que se beneficiaron especialmente de la visualización volumétrica 2D/3D. Sin embargo, también mejoró la interpretación de neuroimágenes en profesionales o expertos en neurociencias, sugiriendo la utilidad de este tipo de ayudas visuales en el desempeño profesional. Al igual que sucedió en los estudios reseñados, los participantes expuestos a la condición de visualización volumétrica 2D/3D mostraron un alto nivel de satisfacción con este sistema de visualización y lo consideraron de gran utilidad a nivel formativo.

La principal aportación de este trabajo ha sido la generación volumétrica de estructuras encefálicas internas a partir de imágenes médicas de RM y VHP y la evaluación empírica de su eficacia en la interpretación de neuroimágenes. El tratamiento digital de imágenes 2D ha permitido su segmentación y renderizado de modelos 3D, cuya visualización ofrece información más completa y realista de las estructuras respecto a las imágenes médicas 2D. La integración de las reconstrucciones $3 \mathrm{D}$ con secciones $2 \mathrm{D}$ convencionales, especialmente funcionales, mejoran la sensibilidad en la detección de las características morfológicas y relaciones espaciales de estructuras encefálicas profundas, constituyendo una herramienta valiosa en el ámbito formativo mejorando la comprensión de la neuroanatomía e interpretación de imágenes y una prometedora estrategia en el diagnóstico, valoración y planificación de intervenciones quirúrgicas.

La visualización volumétrica mejora la localización de estructuras encefálicas profundas difíciles de identificar en neuroimágenes morfológicas y especialmente, funcionales, implicadas en enfermedades neurológicas y trastornos psiquiátricos con importantes efectos neuropsicológicos. En el caso de las alteraciones encontradas en los trastornos psiquiátricos, generalmente han sido alteraciones sutiles, inespecíficas y relativamente inconsistentes, que afectan a estructuras límbicas y prefrontales íntimamente relacionadas con sistemas de respuesta al estrés; por lo que la relevancia clínica de estas alteraciones en su diagnóstico resulta insuficiente, actualmente.

Los beneficios de la visualización volumétrica no se limitan a la interpretación de neuroimágenes en estudiantes de Medicina y Psicología, sino también en expertos, mejorando su rendimiento en la interpretación de neuroimágenes.

Futuras investigaciones deberían controlar variables psicológicas como el criterio de decisión a la hora de responder, conservador o liberal, tal y como se definen en la Teoría de Detección de Señal, que podrían influir en las diferencias encontradas en el nivel de confianza en la respuesta. También deberían estudiar sistemáticamente el valor diagnóstico de la visualización 3D en la interpretación de procesos patológicos en neuroimagen, afianzando los resultados de estudios que sugieren el interés de las reconstrucciones 3D en contextos clínicos (Perandini et al., 2010; Rosenkrantz, Neil, Kong, Melamed, Babb, Taneja \& Taouli, 2010). 


\section{Conclusiones}

Después de analizar las estructuras encefálicas implicadas en los trastornos neuropsicológicos considerados, desarrollar su generación volumétrica, integrar dichas reconstrucciones en secciones encefálicas morfológicas y funcionales y, finalmente, analizar empíricamente la eficacia de la visualización volumétrica en la interpretación de neuroimágenes, hemos llegado a las siguientes conclusiones:

$1^{\text {a }}$. La generación volumétrica de estructuras encefálicas ofreció una representación de las características anatómicas y relaciones espaciales, más realista que los mapas estadísticos paramétricos e ilustraciones de los atlas de neuroanatomía disponibles actualmente, proporcionando información valiosa en procesos diagnósticos y quirúrgicos de enfermedades neurológicas.

$2^{\mathrm{a}}$. El renderizado 3D de estructuras encefálicas profundas requirió un minucioso y exhaustivo proceso de segmentación manual, de secciones seriadas originales de cadáver del Visible Human Proyect y de Resonancia Magnética potenciadas en T1 y la generación de mallas tetraédricas independientes mediante el software Amira ${ }^{\circledR}$.

$3^{\text {a }}$. La visualización de volúmenes embebidos en secciones multimodales mejoró la identificación de estructuras difíciles de localizar, como el hipocampo y la amígdala, redujo los tiempos de respuesta y aumentó el grado de confianza.

$4^{\mathrm{a}}$. Las diferencias en el rendimiento entre la condición de visualización volumétrica y visualización convencional no dependieron de la aptitud visoespacial o sexo de los participantes.

$5^{\text {a }}$. La visualización volumétrica de estructuras encefálicas fue más beneficiosa para los estudiantes de Psicología y Medicina que para profesionales, especialmente en la interpretación de imágenes funcionales.

$6^{\mathrm{a}}$. Los resultados del estudio bibliométrico y revisión bibliográfica evidenciaron un aumento del número de estudios dirigidos al análisis de diferencias volumétricas encefálicas en el estudio de trastornos neuropsicológicos, e inespecificidad e inconsistencia en las estructuras encefálicas implicadas. 


\section{Referencias}

Abate, A. F., Nappi, M., Riccio, D., \& Sabatino, G. (2007). Image: Information and Control 2D and 3D face recognition: A survey. Pattern Recognition Letters, 28(14), 1885-1906.

Abella, H. A. (2009). Report from SNM: PET imaging of brain chemistry bolsters characterization of dementias. Psychiatric Times.

Abi-Dargham, A., \& Laruelle, M. (2005). Mechanisms of action of second generation antipsychotic drugs in schizophrenia: insights from brain imaging studies. European Psyquiatry, 20, 15-27.

Abou-Saleh, M. T. (2006). Neuroimaging in psychiatry: an update. Journal of Psychosomatic Research, 61, 289-293.

Abramowitz, J., Tylor, S., \& McKay, D., (2009). Obsessive-compulsive disorder. Lancet, 374(9688), 491499.

Achim, A. M., \& Lepage, M. (2005). Episodic memory-related activation in schizophrenia: meta-analysis. British Journal of Psychiatry British, 187, 500-509.

Ackerman, M. J. (1998). The visible human project. Proceedings of the IEEE, 86, 504-511.

Ackerman, M. J. (2000). Accessing the Visible Human Project. D-Lib Magazine, 3.

Ackerman, M. J. (2002). The visible human project moves from data to knowledge. Lekar a Technika, $33(1), 4-8$.

Ackerman, M. J., Spitzer, V. M., Scherzinger, A. L., \& Whitlock, D. G. (1995). The Visible Human data set: an image resource for anatomical visualization. Medinfo, 8(2), 1195-1198.

Ackerman, M. J., \& Yoo, T. S. (2003). The Visible Human data sets (VHD) and Insight Toolkit (ITk): experiments in open source software. American Medical Informatic Association Annual Symposium Proceedings, 773.

Adolphs, R. (2001). The neurobiology of social cognition. Current Opinion in Neurobiology, 11, 231-239.

Adolphs, R., Gosselin, F., Buchanan, T. W., Tranel, D., Schyns, P., \& Damasio, A. R. (2005). A mechanism for impaired fear recognition after amygdala damage. Nature, 433, 68-72.

Afifi, A. K., \& Bergman, R. A. (2006). Neuroanatomía funcional. McGraw-Hill Interamericana. Agam, Y., Joseph, R. M., Barton, J. J. S., \& Manoach, D. S. (2010). Reduced Cognitive Control of Response Inhibition by the Anterior Cingulate cortex in Autism Spectrum Disorders. Neuroimage, $52(1), 336-347$.

Ajioka, M. (1995). Outline of VOXEL-MAN: an interactive 3-D atlas for teaching and studying anatomy, radiology and surgery. Online Kensaku, 16(3), 116-119. 
Alcaráz, M. (2003). Bases fisicas y biológicas del radiodiagnóstico médico. Murcia: Universidad de Murcia.

Alheid, G. F., Milsom, W. K., \& McCrimmon, D. R. (2004). Pontine influences on breathing: an overview. Respiratory Phisiology and Neurobiology, 143(2-3), 105-114.

Almkvist, O. (2000). Functional brain imaging as a looking-glass into the degraded brain: reviewing evidence from Alzheimer disease in relation to normal aging. Acta Psychologica, 105(2-3), 255-277.

Altobelli, D. E., Kikinis, R., Mulliken, J. B., Cline, H., Lorensen, W., \& Jolezz, F. (1993). ComputerAssisted Three Dimensional Planning in Craniofacial Surgery. Plastic and reconstructive surgery, 92(4), 576-586.

Altshuler, L., Bartzokis, G., Grieder, T., Curran, J., Jimenez, T., Leight, K., . . Mintzab, J. (2000). An MRI study of temporal lobe structures in men with bipolar disorder or schizophrenia. Biological Psychiatry, $48(2), 147-162$.

Amaral, D. G. (2002). The primate amygdala and the neurobiology of social behavior: implications for understanding social anxiety. Biological Psychiatry, 52, 11-17.

Amaral, D. G., Bauman, M. D., Capitanio, J. P., Lavenex, P., Mason, W. A., Mauldin-Jourdain, M. L., \& Mendoza, S. P. (2003). The amygdala: is it an essential component of the neural network for social cognition? Neuropsychologia, 41, 517-522.

Amaral, D. G., Capitanio, J. P, Jourdain, M., Mason, W. A, Mendoza S. P., \& Prather, M. (2003). The amygdala: is it an essential component of the neural network for social cognition? Neuropsychologia, $41,235-240$.

Amaral, D. G., \& Corbett, B. A. (2008). The Amygdala, Autism and Anxiety. En G. Bock \& J. Goode (Eds), Autism: Neural Basis and Treatment Possibilities. Chichester, UK: John Wiley \& Sons.

American Psychiatric Association. (2000). Diagnostic and statistical manual of mental disorders (Revised 4th ed.). Washington, D.C.: American Psychiatric Association.

American Psychological Association. (2010). Publication Manual of the American Psychological Association (6th ed.). Washington, D.C.: American Psychological Association.

Anderson, A. K., Christoff, K., Panitz, D., DeRosa, E., \& Gabrieli, J. D. (2003). Neural correlates of the automatic processing of threat facial signals. Journal of Neuroscience, 23, 5627-5633.

Anderson, A. K., \& Sobel, N. (2003). Dissociating intensity from valence as sensory inputs to emotion. Neuron, 39, 581-583.

Anderson, R. H., \& Cook A. C. (2006). Visible human projects special issue. Clinical Anatomy, 19(8), 776776.

Anatonelli, F., Ray, N., \& Strafella, A. P. (2010). Imaging Cognitive and Behavioral Symptoms in Parkinson's Disease. Expert Review of Neurotherapeutics, 10(12), 1827-1838. 
Antonova, E., Sharma, T., Morris, R., \& Kumari, V. (2004). The relationship between brain structure and neurocognition in schizophrenia: a selective review. Schizophrenia Research, 70(2-3), 117-145.

Apostolova, L. G., Morra, J. H., Green, A. E., Hwang. K. S., Avedissian, C., Woo, E., . . Thompson, P. M. (2010). Alzheimer's Disease Neuroimaging Initiative. Automated 3D mapping of baseline and 12month associations between three verbal memory measures and hippocampal atrophy in 490 ADNI subjects. Neuroimage, 51(1), 488-99.

Arehart-Treichel, J. (2007). Autism's Social Impairment Related to Amygdala Size. Psychiatric News, 42(2), 17.

Arehart-Treichel, J. (2011). Which Disorders Rank Highest in Misery Meter? Psychiatric News, 46(2), 29.

Arnott, S. R. Binns, M. A., Grady, C. L., \& Alain. C. (2004). Assessing the auditory dual-pathway model in humans. Neuroimage, 22(1), 401-408.

Arnsten, A. F. T. (2006). Fundamentals of attention-deficit/hyperactivity disorder: Circuits and Pathways. Journal of Clinical Psychiatry, 67, 7-12.

Arnsten, A. F. T. (2009). Towards a New Understanding of Attention-Defitic Hyperactivity Disorder Pathophysiology. An Important Role for Prefrontal Cortex Dysfunction. Central Nervous System Drugs, 23, 33-41.

Aron, A. R., Durston, S., Eagle, D. M., Logan, G. D., Stinear, C. M., \& Stuphorn, V. (2007). Converging evidence for a fronto-basal-ganglia network for inhibitory cognition. Journal of neuroscience, 31(44), $11860-11864$.

Assaf, Y., \& Pasternak, O. (2008). Diffusion tensor imaging (DTI)-based white matter mapping in brain research: A review. Journal of molecular neuroscience, 34(1), 51-61.

Atlas, S. W., Howard, R. S., Maldijian, J., Alsop, D., Detre, J. A., Listerud, J., . . Stecker, M. (1996). Functional Magnetic Resonance Imaging of Regional Brain Activity in Patients with Intracerebral Gliomas: Findings and Implications for Clinical Management. Neurosurgery, 38(2), 329-338.

Bach Cuadra, B., Pollo, C., Bardera, A., Cuisenaire, O., \& Thiran, J. P. (2004). Atlas-based segmentation of pathological brain MR images using a model of lesion growth. IEEE Transactions on Medical Imaging, 23, 1301-1314.

Baerson, K. M. (1991). NLM's Visible Human Project to aid medical care training. Federal Computer Week, 21(32).

Bakshi, R. (2005). Magnetic Resonance Imaging Advances in Multiple Sclerosis. Journal of Neuroimaging, 15, 5-9.

Bankman, I. (2000). Handbook of Medical Imaging: Processing and Analysis. Burlington: Elsevier Saunders.

Bao, F., Sun, Y. K., Tian, X. L., \& Tang, Z. (2008). 3D head reconstruction and color visualization of Chinese Visible Human. Lecture Notes in computer Science, 1987, 262-269. 
Bargall, N. (2004). Utilidad de la resonancia magnética en contraste de fase en el diagnóstico de las patologías relacionadas con trastorno en la circulación del líquido cefalorraquideo. Tesis. Universidad de Barcelona.

Barkley, G. L., \& Baumgartner, C. (2003). MEG and EEG in epilepsy. Journal of Clinical Neurophysiology, 20(3), 163-178.

Barr, M. L. (2009). The human nervous system: An anatomical Viewpoint. Philadelphia: Lippincott Williams y Wilkins.

Bear, R. E., Fitzgerald, P., Rosenfeld, J. V., \& Bittar, R. G. (2010). Neurosurgery for obssesive-compulsive disorder: contemporary approaches. Journal of Clinical Neuroscience, 17(1), 1-5.

Bearden, C. E. Glahn, D. C., Caetano, S., Olvera, R. L., Fonseca, M., Najt, P., . . Soares, J. C. (2007). Evidence for disruption in prefrontal cortical functions in juvenile bipolar disorder. Bipolar Disoders, $9(1), 145-159$.

Bearden, C. E., Thompson, P. M., Dutton, R .A., Frey, B. N., Peluso, M. A. M., Nicoletti, M., . . Soares, J. C. (2008). Three-dimensional mapping of hippocampal anatomy in unmedicated and lithium-treated patients with bipolar disorder. Neuropsychopharmacology, 33(6), 1229-1238.

Becker, J. T., Davis, S. W., Hayashi, K. M., Meltzer, C. C., Toga, A. W., López, O. L., \& Thompson, P. M. (2006). Three-Dimensional Patterns of Hippocampal Atrophy in Mild Cognitive Impairment. Archives of Neurology, 63, 97-101.

Belitz, H., Rohr, K., Müller, H., \& Wagenknecht, G. (2006).First Results of an Automated Model-Based Segmentation System for Subcortical Structures in Human Brain MRI Data. Procedings IEEE International Symposium on Biomedical Imaging: From Nano to Macro, 6-9, 402-405.

Berg, D., Merz, B., Reiners, K., Naumann, M., \& Becker, G. (2005). Five-year follow-up study of hyperechogenicity of the substantia nigra in Parkinson's disease. Movement Disorders. 20, 345-383.

Berger, A., Kofman, O., Livneh, U., \& Henik, A. (2007). Multidisciplinary perspectives on attention and the development of self-regulation. Progress in Neurobiology, 82(5), 256-286.

Besada, C., Funes, J. Sinay, V., y Santa Cruz, D. (2005). Esclerosis múltiple: valor de la distribución topográfica de las lesiones en RM. LI Congreso Argentino de Radiología.

Beyer, J. L., Kuchibhatla, M., Payne, M. E., Macfall, J., Cassidy, F., \& Krishnan, K. R. (2009). Gray and White matter brain volumes in older adults with bipolar disorder. International Journal of Geriatric Psychiatry, 24(12), 1445-1452.

Bisiach, E., \& Luzzatti, C. (1978). Unilateral neglect of representational space. Cortex, 14(1), 129-13.

Blair, R. J. (2008). Fine cuts of empahty and the amygdala: dissociable deficits in psychopaty and autism. Quarterly Journal of Experimental Psychology, 61(1), 157-170.

Bluhm, R., Williamson, P., Lanius, R., Theberge, J., Densmore, M., Bartha, R., . . Osuch, E. (2009). Resting state default-mode network connectivity in early depression using a seed region of interest 
analysis: Decreased connectivity with caudate nucleus. Psychiatry and Clinical Neurosciences, 63(6), 754-761.

Blumberg, H. P., Stern, E., Martínez, D., Ricketts, S., de Asis, J., White, T., . . Silbersweig, D. A. (2000). Increased anterior cingulate and caudate activity in bipolar mania. Biological Psychiatry, 48, $1045-$ 1052.

Bonilha, L., Montenegro, M. A., Cendes, F., \& Li, L. M. (2004). The role of neuroimaging in the investigation of patients with single seizures, febrile seizures, or refractory partial seizures. Medical Science Monitor, 10(3), 40-46.

Boon, P., Dandachi-FitzGerald, B., Dutis, A., Temel, Y., Visser-Vandewalle, V., \& van den Hout, M. (2011). Modification of emotional states by bilateral stimulation of the subthalamic nucleus in patient with Parkinson's disease. Journal of Neurology, Neurosurgery and Psychiatry, 82(1), 117-118.

Bora, E., Vahip, S., \& Akdeniz, F. (2008). The role and importance of cognitive symptoms in bipolar disorder. Turk Psikiyatri Dergisi, 19(1), 81-93.

Brabec, J., Rulseh, A., Hoyt, B., Vizek, M., Horinek, D., Hort, J., \& Petrovicky, P. (2010). Volumetry of the human amygdala. An anatomical study. Psychiatry Research. Neuroimaging, 182(1), 67-72.

Brambilla, P., Harenski, K., Nicoletti, M., Sassi, R. B., Mallinger, A. G., Frank, E., . . Soares, J. C. (2003). MRI investigation of temporal lobe structures in bipolar patients. Journal of Psychiatric Research, 37, $287-295$.

Brammer, M. (2009). The role of neuroimaging in diagnosis and personalized medicine. Current position and likely future directions. Dialogues in Clinical Neuroscience, 11, 389-396.

Bremner, J. D., Randall, P, Scott TM, Bronen, R. A., Seibyl, J. P. Southwick, S. M., Delaney, R. C., McCarthy, G., . . Innis, R. B. (1995). MRI-based measurement of hippocampal volume in combatrelated posttraumatic stress disorder. American Journal of Psychiatry, 152, 973-981.

Brett, M., Johnsrude, I. S., \& Owen, A. M. (2002). The problem of functional localization in the human brain. Nature Reviews Neuroscience, 3, 243-249.

Brewin, C. R. (2008). What is it that a neurobiological model of PTSD must explain? Progress in Brain Research, 167, 217-228,

Broca, P. (1861). Sur le siège de la faculté du langage articulé. Anatomical Society of Paris, 2(6), 355.

Brodmann, K. (1909). Brodmann's 'Localisation in the Cerebral Cortex'. London: Smith-Gordon.

Bronstein, J. M., Tagliati, M., Alterman, R. L., Lozano, A. M., Volkmann, J., Stefani, S.,. . DeLong, M. R. (2010). Deep Brain Stimulation for Parkinson Disease: An Expert Consensus and Review of Key Issues. Archives of Neurology, doi:10.1001/archneurol.2010.260

Brown, M. A., \& Semelka, R. C. (2003). MRI: Basic Principles and Applications. Chichester: Wiley.

Brown, S., Martínez, M. J., \& Parsons, L. M. (2006). The neural basis of human dance. Cerebral Cortex, 16(8), 1157-1167. 
Brun, C. C., Nicolson, R., Lepore, N., Chou, Y., Vidal, C., Devito, T. J., . . Thompson, P. M. (2009). Mapping Brain Abnormalities in Boys with Autism. Human Brain Mapping, 30(12), 3887-3900.

Bryant, R. A., Felmingham, K., Kemp, A., Das, P., Hughes, G., Peduto, A., \& Williams, L. (2008). Amygdala and ventral anterior cingulate activation predicts treatment response to cognitive behaviour therapy for post-traumatic stress disorder. Psychological Medicine, 38, 555-561.

Buchsbaum, M. S., Friedman, J., Buchsbaum, B. R., Chu, K.W., Hazlett, E. A., Newmark, R., .. . Gorman, J. (2006). Diffusion tensor imaging in schizophrenia. Biological Psychiatry, 60(11), 1181-1187.

Buckner, R., Snyder, A., Sanders, A., Raichle, M., \& Morris, J. (2000). Functional brain imaging of young, nondemented, and demented older adults. Journal of Cognitive Neuroscience, 12, 224-234.

Bullmore, E., Fletcher, P., \& Jones, P. B. (2009). Why psychiatry can't afford to be neurophobic. British Journal of Psychiatry, 194, 293-295.

Bunney, B. G., Bunney, W. E., Stein, R., \& Potkin, S. G. (2003). Cortical pathology in schizophrenia: a review of data from the dorsolateral prefrontal cortex. Current Opinion in Psychiatry, 16(2), 9-14.

Bush, G., Valera, E. M., \& Seidman, L. J. (2005). Functional neuroimaging of attention-deficit/ hyperactivity disorder: a review and suggested future directions. Biological Psychiatry, 57(11), 12731284.

Bushberg, J. T., Seivert, A., Leidholdt, E. M., \& Boone, J. M. (2002). The Essential Physics of Medical Imaging. Lippincotto Williams and Wilkins.

Burke, C., \& Patrias, K. (2007). Visible Human Project. Current bibliographies in medicine.

Burke, R. E. (2007). Sir Charles Sherrington's: The integrative action of the nervous system: a centenary appreciation. Brain, 130(4), 887-894.

Burns, J., Job, D., Bastin, M. E., Whalley, H., Macgillivray, T., Johnstone, E. C., \& Lawrie, S. M. (2003). Structural disconnectivity in schizophrenia: A diffusion tensor magnetic resonance imaging study. British Journal of Psychiatry, 182, 439-443.

Burton, J. L., \& Underwood, J. (2007). Clinical, educational, and epidemiological value of autopsy. Lancet, $369,1471-1480$.

Butters, M. A., Aizenstein, H. J., Hayashi, K. M., Meltzer, C. C., Seaman, J., Reynolds, C. H., .. . Becker, J. T. (2009). Three-Dimensional Surface Mapping of the Caudate Nucleus in Late-Life Depression. American Journal of Geriatric Psychiatry, 17(1), 4-12.

Buxton, R. B. (2009). Introduction to Functional Magnetic Resonance Imaging: Principles and Techniques. Cambridge: Cambridge University Press.

Byne, W., Hazlett, E. A., Buchsbaum, M. S., \& Kemether, E. (2009). The thalamus and schizophrenia: current status of research. Acta Neuropathologica, 117, 367-368.

Cabeza, R., \& Kingstone, A. (2001). Handbook of Functional Neuroimaging of Cognition. The MIT Press. 
Cabrero, F. J. (2002). Fundamentos fisicos y técnicos del diagnóstico por imagen. Salamanca: Universidad de Salamanca.

Cabrero, F. J. (2004). Imagen radiológica. Principios fisicos e instrumentación. Barcelona: Masson.

Calabrese, M., Rinaldi, F., Grossi, P., Mattisi, I., Bernardi, V., Favaretto, A., . . Gallo, P. (2010). Basal Ganglia and Frontal/parietal Cortical Atrophy is Associated with Fatigue in Relapsing Remitting Multiple Sclerosis. Multiple Sclerosis, 16(10), 1220-1228.

Caltech (2009). The Human Brain Project. Acceso el 15 de diciembre de 2009 de http://www.gg.caltech.edu/hbp/

Callicott, J. H., Bertolino, A., Mattay, V. S., Langheim, F. J. P., Duynl, J., Coppola, R., . . Weinberger, D. R. (2000). Physiological dysfunction of the dorsolateral prefrontal cortex in schizophrenia revisited. Cerebral Cortex, 10,1078-1092.

Callicott, J. H., Egan, M. F., Mattay, V. S. Bertolino, A., Bone, A. D., Verchinksi, B., \& Weinberger, D. R. (2004). Abnormal fMRI response of the dorsolateral prefrontal cortex in cognitively intact siblings of patients with schizophrenia. American Journal of Psychiatry, 161, 1145.

Campbell, P. (2010). A decade for psychiatric disorders. Nature, 463, 9.

Campbell, S., \& MacQueen, G. (2004). The role of Hippocampus in the pathophysiology of major depression. Journal of Psyquiatry and Neuroscience, 29(6), 417-426.

Campbell, B., Rosse, C., \& Brinkely, J. F. (2001). The Virtual Anatomy Lab: a hands-on anatomy learning environment. Study Heatlh Technology Information, 81, 85-87.

Cano, M., Bezdudnaya, T., Swadlow, H. A., \& Alonso, J. M. (2006). Brain state and contrast sensitivity in the awake visual thalamus. National Neuroscience, 9(10), 1240-1242.

Cantillon, P., Irish, B., \& Sales, D. 2004. Using computers for assessment in medicine. British Medical Jorunal, 329, 606-609.

Canli, T., Cooney, R. E., Goldin, P., Shah, M., Sivers, H., Thomason, M. E., . . Gotlib, I. H. (2005). Amygdala reactivity to emotional faces predicts improvement in major depression. Neuroreport,16, $1267-1270$.

Cao, Q. J., Sun, L. Gong, G. L., Lv, YT., Cao, X. H., Shuai, L., . . Wang, Y. F. (2010). The macrostructural and microstructural abnormalities of corpus callosum in children with attention deficit/hyperactivity disoder: A combined morphometric and diffusion tensor MRI study. Brain Research, 1310, 172-180.

Caramella, D., \& Bartolozzi, C. (2002). 3D Image Processing: techniques and clinical applications. Berlin: Springer-Verlag.

Carlson, P. J., Singh, J. B., Zarate, C. A., Drevets, W. C., \& Manji, H. K. (2006). Neural circuitry and neuroplasticity in mood disorders: insights for novel therapeutic targets. NeuroRX, 3(1), 22-41. 
Carmichael, O. T., Kuller, L. H., López, O. L., Thompson, P. M., Dutton, R. A., Lu, A., . . Becker, J. T. (2007). Cerebral ventricular changes associated with transitions between normal cognitive impairment, and dementia. Alzheimer Disease and Associated Disorders, 21(1), 14-24.

Carrasco, X., López, V., \& Aboitiz, F. (2005). Frontal and executive dysfunction is a central aspect of ADHD. Behavioral and Brain Sciences, 28(3), 427-433.

Carrera, E., \& Bogousslavsky, J. (2006). The thalamus and behavior: effects of anatomically distinct strokes. Neurology, 66(12), 1817-1823.

Carrió, I., González, D., Estorch, M., Canessa, J., Mitjavila, M., \& Massardo, T. (2003). Medicina nuclear. Aplicaciones clínicas. Barcelona: Masson.

Carroll, L. (1960). Alice's Adventures in Wonderlalnd. New York: Norton \& Company.

Casanova, M. F., El-Baz, A., Mott, M., Mannheim, G., Hassan, H., Fahmi, R., . . Farag, A. (2009). Reduced Gyral Window and Corpus Callosum Size in Autism: Possible Macroscopic Correlates of a Minicolumnopathy. Journal of Autism and Developmental Disorders, 39(5), 751, 764.

Cascio, C. J., Gerig, G., \& Piven, J. (2007). Diffusion tensor imaging: Application to the study of the developing brain. Journal of the American Academy of Child and Adolescent Psychiatry, 46(2), 213223.

Castro-Fornieles, J., García, A. I., Lázaro, L., Andrés-Perpina, S., Falcon, C., Plana, M. T., \& Bargallo, N. (2010). Prefrontal metabolites in short-term weight-recovered adolescent anorexia nervosa patients. Progress in Neuro-Psychopharmacology \& Biological Psychiatry, 34(6), 1049-1053.

Catani, M. (2006). Diffusion tensor magnetic resonance imaging tractography in cognitive disorders. Current Opinion in Neurology,19, 599-606.

Cattaneo, L., Cucurachi, L., Chierici, E., \& Pavesi, G. (2006). Pathological yawning as a presenting symptom of brain stem ischaemia in two patients. Journal of Neurology and Neurosurgical Psychiatry, 77(1), 98-100.

Cavedini, P., Zorzi, C., Bassi, T., Gorini, A., Baraldi, C., Ubbiali, A. \& Bellodi, L. (2006). Decisionmaking functioning as a predictor of treatment outcome in anorexia nervosa. Psychiatry Research, $145(2-3), 179-187$.

Chamberlain, S. R., Menzies, L., Hampshire, A., Suckling, J., Fineberg, N. A., del Campo, N., . . Sahakian, B. J. (2008). Orbitofrontal dysfunction in patients with obsessive-compulsive disorder and their unaffected relatives. Science, 321(5887), 421-422.

Chamberlain, S. R., Robbins, T. W., \& Sahakian, B. J, (2007), The neurobiology of attentiondeficit/hyperactivity disorder. Biological Psychiatry, 61(12), 1317-1319.

Chan, A. S., Han, Y. M. Y., Leung, W. W. M., Leung, C., Wong, V. C. N., \& Cheung, M. C. (2011). Abnormalities in the anterior cingulate cortex associated with attentional and inhibitory control deficits: A neurophysiological study on children with autism spectrum disorders. Research in Autism Spectrum Disorders, 5(1), 254-266. 
Charil, A., \& Filippi, M. (2007). Inflammatory demyelination and neurodegeneration in early multiple sclerosis. Journal of Neurological Sciences, 259, 7-14.

Chen, Y., Zhang, J., Heng, P. A., \& Deshen, X. (2008). Chinese Visible Human Brain image sementation. First International Congress on Image and Signal Processing, 3, 639-643.

Chereau, I., De Chazeron, I., Rieu, I., Derost, P. P., Lemaire, J. J., \& Durif, F. (2010). Eating Disorders and Deep Brain Stimulation of the Subthalamic Nucleus in Parkinson's Disease. European Neuorpsychopharmacology, 20(3), 562-563.

Cherkasova, M. V., \& Hechtman, L. (2009). Neuroimaging in Attention-Deficit Hyperactivity Disorder: Beyond the Frontostriatal Circuitry. Canadian Journal of Psychiatry, 54(10), 651-664.

Choi, S. H., Jeong, J. H., Cho, S., Chung, M. S., Huh, H. D., Kim, W. C., . . Ki, C. H. (2008). Construction of a High-quality Voxel Model VKH-Man Using Serially Sectioned Images from Visible Korean Human Projeet in Korea. Journal of Nuclear Science and Technology, 5, 179-182.

Choi, M. Y., \& Sutherland, G. R.(2009). Surgical Performance in a Virtual Environment. On the Horizon, $17,345-355$.

Christian, C. J., Lencz, T., Robinson, D. G., Burdick, K. E., Ashtari, M., Malhotra, A. K., ... Szesko, P. R. (2008). Gray matter structural alterations in obsessive-compulsive disorder: Relationship to neuropsychological functions. Psychiatric Research: Neuroimaging, 164, 123-131.

Chua, T. C., Wen, W., Slavin, M. J., \& Sachdev, P. S. (2008). Diffusion tensor imaging in mild cognitive impairment and Alzheimer-s disease: a review. Current Opinion in Neurology, 21(1), 83-92.

Chumley-Jones, H. S., Dobbie, A., \& Alford, C. L. (2002). Web-based learning: Sound educational method or hype? A review of the evaluation literature. Academic Medicine, 77, 86-93.

Chung, M. S., Kim, J. Y., Hwang, W. S., \& Park, J. S. (2002). Visible Korean human: another trial for making serially sectioned images. Proceedings of the Society of Photo-Optical Instrumentation Engineers, 4681, 171-183.

Ciumas, C., Montavont, A., \& Ryvlin, P. (2008). Magnetic resonance imaging in clinical trials. Current Opinion in Neurology, 21(4), 431-436.

Clark, L, Chamberlain, S. R., \& Sahakian, B. J. (2009). Neurocognitive mechanisms in depression: implications for treatment. Annual Review of Neuroscience, 32, 57-74.

Clatz, O., Sermesant, M., Bondiau, P. Y., Delingette, H., Warfield, S. K., Malandain, G., \& Ayache, N. (2005). Realistic simulation of the 3D growth of brain tumors in MR images coupling diffusion with mass effect. IEEE Transactions on Medical Imaging, 24(10): 1334-1346.

Clinton, S. M., \& Meador-Woodruff, J. H. (2004). Thalamic dysfunction in schizophrenia: neurochemical, neuropathological, and in vivo imaging abnormalities. Schizophrenia Research, 69(2-3), 237-253.

Cockburn, A., \& McKenzie, B. (2002). Evaluating the Effectiveness of Spatial Memory in 2D and 3D Physical and Virtual Environments. Proceedings of ACM CHI'2002 Conference on Human Factors in Computing Systems, 203-210. 
Colla, M., Schubert, F., Heidenreich, J., Seifert, F., Bubner, M., Bajbouj, M., \& Heuser, I. (2005). Proton MR spectroscopy at 3 tesla in the hippocampus of lithium-treated euthymic bipolar patients. Biological Psychiatry, 57(8), 132-132.

Commowick, O. (2007). Design and use of anatomical atlases for conformal radiotherapy planning. Tesis. Université de Nice-Sophia Antipolis.

Cook, I. A., Hunter, A. M., Abrams, M., Siegman, B., \& Leuchter, A. F. (2009). Midline and right frontal brain function as a physiologic biomarker of remission in major depression. Psyquiatry ResearchNeuroimaging, 174(2), 152-157.

Cooney, R. E., Joormann, J., Eugene, F., Dennis, E. L., \& Gotlib, I. H. (2010). Neural correlates of rumination in depression. Cognitive Affective \& Behavioral Neuroscience, 10(4), 470-478.

Copenhaver, B. R., Rabin, L.A., Saykin, A. J. Roth, R. M., Wishart, H. A., Flashman, L. A., . . Mamourian, A. C. (2006) The Fornix and Mammillary Bodies in Older Adults with Alzheimer's Disease, Mild Cognitive Impairment, and Cognitive Complaints: A Volumetric MRI Study. Psychiatry Research. Neuroimaging, 147(2-3), 93-103.

Coscia, D. M., Narr, K. L., Robinson, D. G., Hamilton, L. S., Sevy, S., Burdick, K. E., . . Szeszko, P. R. (2009). Volumetric and shpae analysis of the thalamus in first-episode schizophrenia. Human Brain Mapping, 30(4), 1236-1245.

Costain, G., Ho, A., Crawley, A. P., Mikulis, D. J., Brzustowicz, L. M., Chow, E. W. C., \& Bassett, A. S. (2010). Reduced gray matter in the anterior cingulate gyrus in familial schizophrenia: A preliminary report. Schizophrenia Research, 122, 81-84.

Crespo-Facorro, B., Roiz-Santianez, R., Pelayo-Teran, J. M., Rodríguez-Sánchez, J. M., Pérez Iglesias, R., González-Blanch, C., . . Vázque-Barquero, J. L. (2007). Reduced thalamic volume in first-episode non-affective psychosis: correlations with clinical variables, symptomatology and cognitive functioning. Neuroimage, 35, 1613-1623.

Crick, F. (1994). The Astonishing Hypothesis: The Scientific Search for the Soul. Nueva York: Scribner.

Critchley, H. D, Mathias, C. J., \& Dolan, R. J. (2002). Fear conditioning in humans: the influence of awareness and autonomic arousal on functional neuroanatomy. Neuron, 33, 653-663.

Crossingham, J. L., Jenkinson, J., Woolridge, N., Gallinger, S., Tait, G. A., \& Multon, C. A. E. (2009). Interpreting three-dimensional structures from two-dimensional images: a web-based interactive 3D teaching model of surgical liver anatomy. International Hemato Pancreato Biliary Journal, 11(6), 523-528.

Crossman, A. R., \& Neary, D. (2007). Neuroanatomía: Texto y atlas en color. Elservier Masson.

Curatolo, P., Paloscia, C., D’Agati, E., Moavero, R., \& Pasini, A. (2009). The neurobiology of attention deficit/hyperactivity disorder. European Journal of Pediratric Neurology, 13, 299-304. 
Czechowska, Y. M., Bodnar, M., Mala, A., \& Lepage, M. (2009). Lateral Ventricle Volumes as a Neural Marker of Short-Term Clinical Outcome in First Episode Schizophrenia. Schizophrenia Bulletin, 35(1), 211-212.

Czisch, M., Wehrle, R., Kaufmann, C., Wetter, T. C., Holsboer, F., Pollmacher, T., \& Auer, D. P. (2004). Functional MRI during sleep: BOLD signal decreases and their electrophysiological correlates. European Journal of Neuroscience, 20, 566-574.

D’Agati, E., Casarelli, L., Pitzianti, M. B., \& Pasni, A. (2010). Overflow movements and white matter abnormalities in ADHD. Progress in Neuro-Psychopharmacology \& Biological Psychiatry, 34(3), 441445.

Dager, S. R., Corrigan, N. M., Richards, T. L., \& Posse, S. (2008). Research applications of magnetic resonance spectroscopy to investigate psychiatric disorders. Top Magnetic Resonance Imaging, 18(2), $81-96$.

Dale, A. M., \& Halgren, E. (2001). Spatiotemporal mapping of brain activity by integration of multiple imaging modalities. Current Opinion of Neurobiology, 11, 202-208.

Dapretto, M., Davies, M. S., Pfeifer, J. H., Scott, A. A., Sigman, M., Bookheimer, S. Y., \& Iacoboni, M. (2006). Understanding emotions in others: Mirror neuron dysfunction in children with autism spectrum disorders. Nature Neuroscience, 9(1): 28-30.

Das, P., Kemp, A. H., Liddell, B. J., Brown, K. J., Olivieri, G., Peduto, A., . . Williams, L. M. (2005). Pathways for fear perception: modulation of amygdala activity by thalamo-cortical systems. Neuroimage, 26, 141-148.

Das, R. R., Seshadri, S., Beiser, A. S., Kelly-Hayes, M., Au, R., Himali, J. J., . . Wolf, P.A. (2008). Prevalence and correlates of silent cerebral infarcts in the Framingham offspring study. Stroke, 39(11), 2919-2935.

Deb, S., Lyons, I., Koutzoukis, C., Ali, I., \& McCarthy, G. (1999). Rate of psychiatric illness one year after traumatic brain injury. American Journal of Psychiatry, 156, 374-378.

Deckersbach, T., Dougherty, D. D., \& Rauch, S. L. (2006). Functional imaging of mood and anxiety disorders. Journal of Neuroimaging, 16, 1-10.

DeFelipe, J., Fernández-Gil, M. A., Kastanauskaite, A., Bote, R. P., Presmanes, Y. G., \& Ruiz, M. T. (2007). Macroanatomy and microanatomy of the temporal lobe. Seminars in Ultrasound, CT and MR, $28(6), 404-415$.

DelBello, M. P., Adler, C. M., \& Strakowski, S. M. (2006). The neurophysiology of childhood and adolescent bipolar disorder. CNS Spectrums, 11(4), 298-311.

DelBello, M. P., Zimmerman, M. E., Mills, N. P., Getz, G. E., \& Strakowski, S. M. (2004). Magnetic resonance imaging analysis of amygdala and other subcortical brain regions in adolescents with bipolar disorder. Bipolar Disorders, 6, 43-52.

Delgado, M. T., Martínez-Morillo, M., y Otón, C. (2002). Manual de radiología clínica. Madrid: Harcourt. 
DeLisi, L. E., Sakuma, M., Maurizio, A. M., Reija, M, \& Hoff, A. L. (2004). Cerebral ventricular change over the first 10 years after the onset of schizophrenia. Psychiatry Research, 130(1), 57-70.

Del Zoppo, G. J. (2006). Stroke and neurovascular protection. New England Medicine, 354, 553-555.

DeRubeis, R. J., Siegle, G. J., \& Hollon, S. D. (2008). Cognitive therapy versus medication for depression: treatment outcomes and neural mechanisms. National Review of Neuroscience, 9, 788-796.

Dev, P., \& Senger, S. (2005). The Visible Human and Digital Anatomy Learning Initative. Studies in Health Technology and Informatics, 111, 108-114.

Di Martino, A., Ross, K., Uddin, L. Q., Sklar, A. B., Castellanos, F. X., \& Milham, M. P. (2009). Functional Brain Correlates of Social and Nonsocial Processes in Autism Spectrum Disorders: An Activation Likelihood Estimation Meta-Analysis. Biological Psyquiatry, 65(1), 63-74.

Di Paola, M., Di Lulio, F., Cherubini, A., Blundo, C., Casini, A. R., Sancesario, G., . . Saplletta, G. (2010). When, where, and how the corpus callosum changes in MCI and AD. A mulmodal RMI study. Neurology, 74(14), 1136-1142.

Dixon, T.A., Morris, R. G., Bullmore, E. T., Brammer, M. J., Williams, S. C. R., Sharma, T., .. McGuire, P. K. (2001). Differential frontal activation in schizophrenia and bipolar illness during verbal fluency. Journal of Affective Disorders, 66(2), 111-121.

Doolittle, N.D. (2004). State of science in brain tumor classification. Seminars in Oncology Nursing, 20, 224-230.

Doty, T. J., Payne, M. E., Steffens, D. C., Beyer, J. L., Krishnan, K. R. R., \& Labar, K. S.(2008). Agedependent reduction of amygdala volume in bipolar disorder. Psychiatry Research. Neuroimaging, 163(1), 84-94.

Dou, W., Ruan, S., Chen, Y., Bloyet, D., \& Constans, J. M. (2007). A framework of fuzzy information fusion for segmentation of brain tumor tissues on MR images. Image and Vision Computing, 25, 164171.

Dougall, N. J., Brugginks, S., \& Ebmeier, K. P. (2004). Systematic review of the diagnostic accuracy of 99mTc-HMPAO-SPECT in dementia. American Journal of Geriatric Psychiatry, 12(6), 554-570.

Dougherty, D. D., \& Rauch, S. L. (2004). Brain imaging in psychiatry. Essentials of Neuroimaging for Clinical Practice. Arlington: American Psychiatric Publishing.

Duan, H., Tan, O., Jia, C., \& Lu, W. (2001). Segmentation and labeling of visible human dataset based on atlas. Chinese Journal of Biomedical Engineering, 20(3), 248-253.

Duane, E. H. (2008). Neuroanatomy: an atlas of structures, sections, and systems $\left(7^{\text {th }} \mathrm{ed}\right)$. Philadelphia: Williams y Wilkins.

Duncan, J. S., \& Ayache, N. (2000). Medical image analysis: Progress over two decades and the challenges ahead. IEEE Transactions on Pattern Analysis and Machine Intelligence, 22, 85-105. 
Dziobek, I., Bahnemann, M., Convit, A., \& Heekeren, H. R. (2010). The Role of the Fusiform-Amydala System is the Pathophysiology of Autism. Archives of General Psychiatry, 67(4), 397-405.

Ebmeier, K. P., Donahey, C., \& Dougall, N. J. (2005). Neuroimaging in dementia. Neuroimaging, 67, 4372

Ecker, C., Rocha-Rego, V., Johnston, P., Mourao-Miranda, J., Marquiand, A., Daly, E. M., ... Murphy, D. G. (2010). Investigating the predictive value of whole-brain structural MR scans in autism: a pattern classification approach. Neuroimage, 49, 44-56.

Editorial. (2010). Combating Schizophrenia. Nature, 468, 133.

Eldaief, M., \& Dougherty, D. (2008). Advances in Neuroimaging: Impact on Psychiatric Practice. Tools to Identify Psychiatric Disease Through Regional Brain Abnormalities, Psychiatric Times, 25(11), 1-5.

Eichenbaum, H., Yonelinas, A. P., \& Ranganath, C. (2007). The medial temporal lobe and recognition memory. Annual Review of Neuroscience, 30, 123-152.

Eidelberg, D., \& Edwards, C. (2000). Functional brain imaging of movement disorders. Neurological Research, 22(3), 305-312.

Ellison-Wright, I., \& Bullmore, E. (2009). Meta-analysis of difussion tensor imaging studies in schizophrenia. Schizophrenia Research, 10881(3), 3-10.

Ellison-Wright, I., \& Bullmore, E. (2010). Anatomy of Bipolar Disorder and Schizophrenia: A MetaAnalysis. Schizophrenia Research, 117(1), 1-12.

Emsell, L., \& McDonald, C. (2009). The estructural neuroimaging of bipolar disorder. International Review of Psyquiatry, 21(4), 297-313.

Emond, V., Joyal, C., \& Poissant, H. (2009). Structural and functional neuroanatomy of attention-deficit hyperactivity disorder (ADHD). Encephale-Revue de Psychiatrie Clinique Biologique et Therapeutique, 35(2), 107-114.

Engel, J. (2006). Report of the ILAE Classification Core Group. Epilepsia, 47, 1558-1568.

Erhart, S. M., Young, A. S., Marder, S. R., \& Mintz, J. (2005). Clinical utility of magnetic resonance imaging radiographs for suspected organic syndromes in adult psychiatry. Journal of Clinical Psychiatry, 66, 968-973.

Estévez, M. E., Lindgren, K. A., \& Bergethon, P. R. (2010). A novel three-dimensional tool for teaching human neuroanatomy. Anatomical Sciences Education, 3(6), 309-317.

Etkin, A, Egner, T. Peraza, D. M., Kanderl, E. C., \& Hirsch, J. (2006). Resolving emotional conflict: A role for the rostral anterior cingulate cortex in modulating activity in the amygdale, Neuron, 52(6) 11211121.

Etkin, A., Klemenhagen, K. C., Dudma, J. T., Rogan, M. T., Hen, R., Kandel, E. R., \& Hirsch, J. (2004). Individual Differences in Trait Anxiety Predict the Response of the Basolateral Amygdala to Unconsciously Processed Fearful Faces. Neuron, 44(6), 1043-1055. 
Farzan, F., Barr, M. S., Levinson, A. J., Chen, R., Wong, W., Fitzgerald, P. B., \& Daskalakis, Z. J. (2010). Evidence for Gamma Inhibition in the Dorsolateral Prefrontal Cortex of Patients with Schizophrenia. Brain, 133(5), 1505-1514.

Feher, G., Balas, I., Komoly, S., Doczi, T., Janszky, J., Aschermann, Z., . . Kovacs, N. (2010). Analysis of Antiparkinsoninan Drug Reduction After Bilateral Subthalamic Deep Brain Stimulation. Clinical Neuroscience, 63(9-10), 314-319.

Fennema-Notestine, C., Hagler, D. J., McEvoy, L. K., Fleisher, A. S., Wu, E. H., Karow, D.S., \& Dale, A.M. (2009). Structural MRI biomarkers for preclinical and mild Alzheimer's disease. Human Brain Mapping, 30(10), 3238-3253.

Fisher, R. S., Van Emde Boas, W., Blume, W., Elger, C., Genton, P., Lee, P., \& Engel, J. (2005). Epileptic seizures and epilepsy. Definitions proposed by the International League againstEpilepsy (ILAE) and the International Bureau for Epilepsy (IBE). Epilepsia, 46, 470-472.

Fleck, D. E., Nandagopal, J., Cerullo, M. A., Eliassen, J. C., DelBello, M. P., Adler, C. M. \& Strakowski, S. M. (2008). Morphometric magnetic resonance imaging in psychiatry. Top Magnetic Resonce Imaging, 19(2), 131-142.

Foland, L. C., Altshuler, L. I., Sugar, C. A., Lee, A. D., Leow, A. D. Townsend, J., . . Thompsom, P. M. (2008). Increased volume of the amygdala and hippocampus in bipolar patients treated with lithium. Neuroreport, 19(2), 221-224.

Forbes, C. E., \& Grafman, J. (2010). The Role of the Human Prefrontal Cortex in Social Cognition and Moral Judgment. Annual Review of Neurosicience, 33, 299-324.

Fornito, A., Yücel, M., Dean, B., Wood, S. J., \& Pantelis, C. (2009). Anatomical Abnormalities of the Anterior Cingulate Cortex in Schizophrenia: Bridging the Gap Between Neuroimaging and Neuropathology. Schizophrenia Bulletin, 35(5), 973-993.

Fornito, A., Yücel, M., \& Pantelis, C. (2009). Reconciling neuroimaging and neuropathological findings in schizophrenia and bipolar disorder. Current Opinion in Psychiatry, 22(3), 312-319.

Forsgren, L., Beghi, E., Oun, A., \& Sillanpää, M. (2005). The epidemiology of epilepsy in Europe - a systematic review. European Journal of Neurology, 12, 245-253.

Frackowiak, R. (2003). Human Brain Function. USA: Academic Press.

Frank, G. K., Bailer, U. F., Henry, S., Wagner, A., \& Kaye, W. H. (2004). Neuroimaging studies in eating disoders. CNS Spectrums, 9(7), 539-548.

Frankle, W. G. (2007). Neuroreceptor imaging studies in schizophrenia. Harvard review of psychiatry, 15, 212-232.

Frankle, W. G., \& Laruelle, M. (2002). Neuroreceptor imaging in psychiatric disorders. Annals of Nuclear Medicine, 16, 437-446. 
Frazier, J. A., Chiu, S. F., Breeze, J. L., Makris, N., Lange, N., Kennedy, D. N. . . Biederman, J. (2005). Structural brain magnetic resonance imaging of limbic and thalamic volumes in pediatric bipolar disoder. American Journal of Psychiatry, 162(7), 1256-1265.

Friederich, H. C., Uher, R., Brooks, S., Giampietro, V., Brammer, M., Williams, S. C., . . Campbell, I. C. (2007). I'm not as slim as that girl: neural bases of body shape self-comparison to media images. Neuroimage, 37(2), 674-81.

Fritsch, G. T., \& Hitzig, E. (1870). On the electrical excitability of the cerebrum.

Frodl, T., Jager, M., Smajstrlov, I., Born, C., Bottlender, R., Palladino, T., . . Meisenzahl, E.M. (2008). Effect of hippocampal and amygdala volumes on clinical outcomes in major depression: a 3-year prospective magnetic resonance imaging study. Journal Psychiatry of Neuroscience, 33, 423-30.

Frohman, E. M., Racke, M. K., \& Raine, C. (2006). Multiple sclerosis-The plaque and its pathogenesis. New England Journal of Medicine, 354(9), 942-955.

Fu, C. H., Williams, S. C., Cleare, A. J., Scott, J., Mitterschiffthaler, M. T., Walsh, N. D., . . Murray, R. M. (2008). Neural responses to sad facial expressions in major depression following cognitive behavioral therapy. Biological Psychiatry, 64, 505-512.

Fujiwara, H., Hirao, K., Namiki, C., Yamada, M., Shimizu, M., Fukuyama, H., Hayashi, T., \& Murai, T. (2007). Anterior cingulate pathology and social cognition in schizophrenia: A study of gray matter, white matter and sulcal morphometry. Neuroimage, 36, 1236-1245.

Fung, S. J., Sivagnanasndaram, S., \& Weickert, C. S. (2010). Markers of Synaptic Pasticity are Reduced in the Dorsolateral Prefrontal Cortex of Patients with Schizophrenia. Schizophrenia Research, 117(2-3), 255-256.

Gabbay, V., Hess, D. A., Liu, S., Babb, J. S., Klein, R. G., \& Gonen, O. (2007). Lateralized Caudate Metabolic Abnormalities in Adolescent Major Depressive Disorder: A Proton MR Spectroscopy Study. American Journal of Psychiatry, 164, 1881-1889.

Galderisi, S., \& Maj, M. (2009). Deficit schizophrenia: An overview of clinical, biological and treatment aspects. European psychiatry, 24(8), 493-500.

Gall, F. J., \& Spurzheim, J. C. (1810). Anatomie und Physiologie des Nervensystems im Allgemeinen und des Gehirns insbesondere. Paris: Schoell.

Ganslandt, O., Behari, S., Gralla, J., Fahlbusch, R., \& Nimsky, C. (2002). Neuronavigation: concept, techniques and applications, Neurology, 50(3), 244-255.

Gazzaniga, M. S. (2005). Forty-five years of split-brain research and still going. National Review of Neuroscience, 6(8), 653-659.

Ghaffar, O., \& Feinstein, A. (2007). The neuropsychiatry of multiple sclerosis: a review of recent developments. Current Opinion in Psychiatry, 20(3), 278-285. 
Gilbertson, M., Williston, S., Paulus, L., Lasko, N., Gurvits, T., Shenton M. E., . . Orr, S. (2007).

Configural cue performance in identical twins discordant for posttraumatic stress disorder: Theoretical implications for the role of hippocampal function. Biological Psychiatry, 62, 513-520.

Gillingwater, T. H. (2008). The importance of exposure to human material in anatomical education: A philosophical perspective. Anatomical Science Education, 1, 264-266.

Glascher, J., \& Adolphs, R. (2003). Processing of the arousal of subliminal and supraliminal emotional stimuli by the human amygdala. Journal of Neuroscience, 23(10), 274-282.

Glass, R.M. (2010). Mental health vs. mental disorders. Journal of the American Medical Association, 303, 1978-1979.

Glenda, M., \& MacQueen, M. D. (2010). Will there be a role for neuroimaging in clinical psychiatry? Journal of Psychiatry Neuroscience, 35(5), 291-293.

Glickstein, M. (2007). What does the cerebellum really do?. Current Biology, 17(19), 824-827.

Glickstein, M., \& Berlucchi, G. (2008). Classical disconnectioni studies of the corpus callosum. Cortex, 44(8), 914-927.

Goodman, M., Richardson, M., Bush, L., Mulcahy, H., \& Chew, F. (2009). Interactive 3D CT for Teaching Anatomy and Pathology in Complex. American Journal of Roentgenology, 192(5).

Google (2011). Body Browser. Acceso el 8 de enero de 2011 en http://bodybrowser.googlelabs.com/body.html.

Grahn, J. A., Parkinson, J. A., \& Owen, A. M. (2008). The cognitive functions of the caudate nucleus. Progress in Neurobiology, 86, 141-155.

Grauke, L., \& Richardson, M. (2010). Interactive 3D CT Models for Teaching Anatomy and Pathology in Common Hand and Wrist Trauma. American Journal of Roentgenology, 19(5), 482.

Greene, J. D., Sommerville, R. B., Nystrom, L. E., Darley, J. M., \& Cohen, J. D. (2001). An fMRI investigation of emotional engagement in moral Judgment. Science, 293, 2105-2108.

Green, S. A., \& Ben-Sasson, A. (2010). Anxiety Disorders and Sensory Over-Responsivity in Children with Autism Spectrum Disorders: Is there a Causal Relationship? Journal of Autism and Developmental Disorders, 40(12), 1495-1504.

Gruber, O. Tost, H., Henseler, I., Schmael, C., Scherk, H., Ende, G., . . Rietshel, M. (2010). Pathological Amydala Activation During Working Memory Performance: Evidence from a Pathophysiological Trait Marker in Bipolar Affective Disorder. Human Brain Mapping, 31(1), 115-125.

Guillaume, S., Sang, C. N. T., Jaussent, I., Raingeard, I., Bringer, K., Joliant, F., \& Courtet, P. (2010). Is Decision Making Really Impaired in Eating Disorders? Neuropsychology, 24(6), 808-812.

Guo, X. J., Wang, Z. Q., Lic, K. C., Li, Z. Y., Qi, Z. G., Jin, Z., . . Chen, K. W. (2010). Voxel-based assessment of gray and white matter volumes in Alzheimer's disease. Neuroscience Letters, 468(2), 146-150. 
Gunderman, R. B., \& Wilson, P. K. (2005). Exploring the human interior: The roles of cadaver dissection and radiologic imaging in teaching anatomy. Academic Medicine, 80, 745-749.

Guttmann, G. D, Drake, R. L., \& Trelease, R. B. (2004). To what extent is cadaver dissection necessary to learn medical gross anatomy? A debate forum. Anatomical Record, 281B, 2-3.

Haines, D. E. (2006). Fundamental Neuroscience for Basic and Clinical Applications. Livingstone: Elsevier Saunders.

Hajek, T., Carrrey, N., \& Alda, M. (2005). Neuroanatomical abnormalities as risk factors for bipolar disorder. Bipolar disoder, 7(5), 393-403.

Halperin, J. M., \& Schulz, K. P. (2006). Revisiting the role of the prefrontal cortex in the pathophysiology of attention-deficit/hyperactivity disoder. Psychological Bulletin, 132(4), 560-581.

Hall, K., Whalley, H. C., Marwick, K., McKirdy, J., Sussmann, J., Romaniuk, L., . . Lawrie, S. W. (2010). Hippocampal function in schizophrenia and bipolar disoder. Psychological Medicine, 40(5), 761-770.

Halligan, P. W., Kischka, U., \& Marshall, J. C. (2010). Handbook of Clinical Neuropsychology. Oxford: Oxford University Press.

Hammers, A., Allom, R., Koepp, M. J., Free, S. L., Myers, R., Lemieux, L., . . Duncan, J. S. (2003). Three-dimensional maximum probability atlas of the human brain, with particular reference to the temporal lobe. Human Brain Mapping, 19 (4), 224-247.

Hamza-Lup, F. G., \& Thompson, T. (2009). Interactive 3D User Interfaces for Neuroanatomy Exploration. International Conference on Web Information Systems and Technologies, 130, 23-26.

Hansen, M. M. (2008). Versatile, immersive, creative and dynamic virtual 3-D healthcare learning environments: A review of the literature. Medical Internet Journal, 10, 26.

Hardan, A. Y., Muddasani, S., Vemulapalli, M., Keshavan, M. S., \& Minshew, N. J. (2006). An MRI Study of Increased Cortical Thickness in Autism. American Journal of Psychiatry, 163(7): 1290-1292.

Hariri, A. R., Mattay, V. S., Tessitore, A., Fera, F., \& Weinberger, D. R. (2003). Neocortical modulation of the amygdala response to fearful stimuli. Biological Psychiatry, 53, 494-501.

Harlow, J. M. (1848). Passage of an iron rod through the head. Boston Medical and Surgical Journal, 39, 389-393.

Harlow, J. M. (1869). Recovery from the passage of an iron bar through the head. Publications of the Massachusetts Medical Society, 2, 327-347.

Hayman, G. N., Fuller, J. E., Cavazos, J. E., Pfleger, M. J., Meyers, C. A., \& Jackson, E. F. (1998). The hippocampus: Normal anatomy and pathology. American Journal of Roentgenology, 171(4), 11391146.

Haznedar, M. M., Buchsbaum, M. S., Hazletta, E. A., Shihabuddina, L., Newa, A., \& Sievera, L. J. (2004). Cingulate gyrus volume and metabolism in the schizophrenia spectrum. Schizophrenia Research, 71, 249-262. 
He, B., \& Liu, Z. (2008). Multimodal Functional Neuroimaging: Integrating Functional MRI and EEG/MEG, IEEE Reviews in Biomedical Engineering, 1, 23-40.

Hechtman, L. (2009). Comorbidity and Neuroimaging in Attention-Deficit Hyperactivity Disorder. Canadian Journal of Psychiatry, 54(10), 649-650.

Heckemann, R. A., Hajnal, J. V., Ijabar, P., Rueckert, D., \& Hammers, A. (2006). Automatic anatomical brain MRI segmentation combining label propagation an decision fusion. Neuroimage, 33 (1), 115-126.

Heinz, A., Braus, D. F., Romero, B. Gallinat, J., Puls, I., Juckel, G., \& Weinberger, D. R. (2004). Genetic and pharmacological effects on prefrontal cortical function in schizophrenia, Nervenarzt , 75(9), 845852 .

Hendler, T., Bleich-Cohen, M., \& Sharon, H. (2009). Neurofunctional view of psychiatry: clinical brain imaging revisited. Current Opinion in Psychiatry, 22(3), 300-305.

Heng, P. A. (2007). Advances in visible human based virtual medicine. Lecture Notes in Computer Science, 4561, 623-632.

Heng, P. A., Zhang, S. X., Xie, Y. M., Wong, T. T., Chui, Y. P., \& Cheng, C. Y. (2006).Photorealistic virtual anatomy based on Chinese Visible Human data.. Clinical Anatomy, 19(3), 232-239.

Henry-Feugeas, M. C. (2007). MRI of the "Alzheimer síndrome”. Journal of Neurology, 34, 220-227.

Herman, J. P., Ostrander, M. M., Mueller, N. K., \& Figueiredo, H. (2005). Limbic system mechanisms of stress regulation: hypothalamo-pituitary-adrenocortical axis. Progress in Neuropsychopharmacology and Biological Psychiatry, 29(8), 1201-1213.

Hill, K., Mann, L., Laws, K. R., Stephenson, C. M. E., Nimmo-Smith, I., \& McKenna, P. J. (2004). Hypofrontality in schizophrenia: a meta-analysis of functional imaging studies. Acta Psychiatrica Scandinavica, 110(4), 243-256.

Hirsch, J. (2005). Functional Neuroimaging. Basic and Clinical Neurosciences. 27th Annual Postgraduate Review Course. Columbia University.

Hirsch, J., Ruge, M. I., Kim, K. H. S., Correa, D. D., Victor, J. D., Relkin, N. R., . . Gutin, P. H. (2000). An Integrated Functional Magnetic Resonance Imaging Procedure for Preoperative Mapping of Cortical Areas Associated with Tactile, Motor, Language, and Visual Functions, Neurosurgery, 47, 711-722.

Höhne, K. H., Pflesser, B., Pommert, A., Priesmeyer, K. Riemer, M., Schiemann, T., . . Schumacher, U. (2003). Voxel-Man 3D Navigator: Inner Organs. Regional, Systemic and Radiological Anatomy. Springer-Verlag Electronic Media: Heidelberg.

Holler, Y., Kronbichler, M., Zeller, A., Klein, S., Hinterhuber, H., Golaszewski, S., \& Ladurner, G. (2009). Contribute of functional magnetic resonance imaging to the understanding of psychiatric disorders. Neuropsychiatrie, 23,84-90. 
Honea, R., Crow, T. J., Passingham, D., \& Mackay, C. E. (2005). Regional deficits in brain volume in schizophrenia: A meta-analysis of voxel-based morphometry studies. American Journal of Psychiatry, 162(12), 2233-2245.

Howell, J. N., Conatser, R. R., Williams, R. L., Burns, J. M., \& Eland, D. C. (2008). The virtual haptic back: A simulation for training in palpatory diagnosis. BMC Medical Education, 8, 14.

Hua, X, Lee, S., Ho, A., Leow, A., Yanovsky, I., \& Gutmn, B. (2008). 3D characterization of brain atrophy in Alzheimer's disease and mild cognitive impairment using tensor-based morphometry, Neuroimage, 41(1), 19-34.

Hubbard, E. M. (2007). Neurophysiology of synesthesia. Current Psychiatry Reports, 9(3), 193-199.

Hubbard, E. M., \& Ramachandran, V. S. (2005). Neurocognitive mechanisms of synesthesia. Neuron, $3(48), 509-520$.

Huettel, S. A., Song, W. A., \& Mc Carthy, G. (2004). Functional Magnetic Resonance Imaging. Sunderland: Sinauer Associates.

Hui, F., Cavazos, J. E., \& Tien, R. D. (1997). Hippocampus. Normal magnetic resonance imaging anatomy with volumetric studies. Neuroimaging Clinics of North America, 7(1), 11-17.

Hulshoff Pol, H. E., Brans, R. G., van Haren, N. E., Schnack, H. G., Langen, M., Baare, W. F., . . Kahn, R. S. (2004). Gray and white matter volume abnormalities in monozygotic and same-gender dizygotic twins discordant for schizophrenia. Biological Psychiatry, 55, 126-130.

Hulshoff Pol, H. E., Schnack, H. G., Mandl, R. C., Brans, R. G., Van Haren, N. E., Baare, W.F., . . Kahn, R. S. (2006). Gray and white matter density changes in monozygotic and same-sex dizygotic twins discordant for schizophrenia using voxelbased morphometry. Neuroimage, 31, 482-488.

Husken, M., Brauckmann, M., Gehlen, S., \& Von der Malsburg, C. (2005). Strategies and Benefits of Fusion of 2D and 3D Face Recognition. Computer Vision and Pattern Recognition, 174-174.

Hutchinson, A. D., Mathias, J. L., \& Banich, M. T. (2008). Corpus callosum morphology in children and adolescents with attention deficit hyperactivity disorder: a meta-analytic review. Neuropsychology, $22(3), 341-349$.

Hsieh, M. H., McQuoid, D. R., Levy, R. M., Payne, M. E., MacFall, J. R., \& Steffens, D. C. (2002). Hippocampal volume and antidepressant response in geriatric depression. International Journal of Geriatric Psychiatry, 17, 519-525.

Insel, T. R. (2009). Translating scientific opportunity into public health impact: a strategic plan for research on mental illness. Archives of General Psychiatry, 66, 128-133.

Insel, T. R., \& Wang, P. S. (2010). Rethinking mental illness. Journal of the American Medical Association, 303(19), 1970-1971.

Irani, F., Platek, S. M., Bunce, S., Ruocco, A. C., \& Chute, D. (2007). Functional near infrared spectroscopy (fNIRS): an emerging neuroimaging technology with important applications for the study of brain disorders. The Clinical Neuropsychologist, 21(1), 9-37. 
Iritani, S. (2007). Neuropathology of schizophrenia: a mini review. Neuropathology, 27(6), 604-608.

Jack, C. R., Petersen, R. C., Xu, Y., O’Brien, P. C., Smith, G. E., Ivnik, R., J., . . Kokmen, E. (2000). Rates of hippocampal atrophy correlate with change in clinical status in aging and AD. Neurology, 55, 484489.

Jack, C. R., Lowe, V. J., Senjem, M. L., Weigand, S. D., Kemp, B. J., Shiung, M. M., . . Petersen, R. C. (2008). 11C PiB and structural MRI provide complementary information in imaging of Alzheimer-s disease and amnestic mild cognitive impairment. Brain, 131(3), 665-680.

Janke, K. (2009). Parkinson's disease: neuroimaging and clinical studies on cognition and depression. Tesis. University of Groningen.

Jansma, J. M., Ramsey, N. F., Slagter, H. A., \& Kahn, R. S. (2001). Functional anatomical correlates of controlled and automatic processing. Journal of Cognitive Neuroscience, 13, 730-743.

Javadapour, A., Malhi, G. S., Ivanovski, B., Chen, X. H., Wen, W., \& Sachdev, P. (2010). Hippocampal Volumes in Adults With Bipolar Disorder. Journal of Neuropsychiatry and Clinical Neurosciences, $22(1), 55-62$.

Jezzard, P., Matthews, P., \& Smith, S. (2001). Functional Magnetic Resonance Imaging: An Introduction to Methods. Cambridge: Oxford University Press.

Jiang, T. Z., Liu, Y., Shi, F., Shu, N., Liu, B., Jiang, J. F., \& Zhou, Y. (2008). Multimodal Magnetic Resonance Imaging for Brain Disorders: Advances and Perspectives. Brain imaging and behaviour, 2(4), 249-257.

Johnson, K. A., \& Becker, J. A. (2010). The Whole Brain Atlas. Acceso el 23 de febrero de 2010 desde http://www.med.harvard.edu/AANLIB/home.html

Johnstone, E. C., Crow, T. J., Frith, C. D., Husband, J., \& Kreel, L. (1976). Cerebral ventricular size and cognitive impairmente in chronic schizophrenia. Lancet, 2(7992), 924-926.

Joos, A., Kloppel, S., Hartmann, A., Glauche, V., Tuscher, O., Perlov, E., . . van Elst, L. T. (2010). Voxelbased Morphometry in Eating Disorders: Correlation of Psycopathology with Grey Matter Volume. Psychiatry Research-Neuroimaging, 182(2), 146-151.

Juanes, J. A., Cabrero, F. J., Riesco, J. M., Blanco, E., Velasco, M. J., Vázquez, R., \& Prats, A. (2001). Computerized model for the integration of data associated with the human brain. European Journal of Anatomy, 5, 133-138.

Juanes, J. A., Prats, A., Lagándara, M. L. \& Riesco, J. M. (2003). Application of the "Visible Human Project" in the field of anatomy: a review. European Journal of Anatomy, 7, 147-159.

Juanes, J. A., Prats, A., Riesco, J. M., Blanco, E., Velasco, M. J., Cabrero, F. J., \& Vázquez, R. (2001). Computerized model for the integration and neurosurgical evaluations. Journal of Anatomy, 5, 133-138. Juanes, J. A., Riesco, J. M., Blanco, E., Velasco, M. J., Vázquez, R., \& Prats, A. (2002). Technique for the volumetric reconstruction of anatomical structures. Joint meeting of the British Association of Clinical Anatomists and the Spanish Anatomical Society. 
Jubault, T., Brambati, S. M., Degroot, C., Kullmann, B., \& Strafella, A. P., (2009).Regional brain stem atrophy in idiopathic Parkinson's disease detected by anatomical MRI. PlosOne, 4(12), 8247-8249.

Jung, W. H., Jang, J. H., Byun, M. S., An, S. K., \& Kwon, J. S. (2010). Structural Brain Alterations in Individuals at Ultra-high Risk for Psychosis: A Review of Magnetic Imaging Studies and Future Directions. Journal of Korean Medical Science, 35(12), 1700-1709.

Jurado, M. B., \& Rosselli, M. (2007). The elusive nature of executive functions: a review of our current understanding. Neuropsychology Review, 17(3), 213-233.

Kalat, J. W. (2003). Biological Psychology (8th Ed). New York: Thomson Wadsworth.

Kalus, P., Falkai, P., \& Heinz, A. (2008). Structural and functional brain changes in schizophrenic disorders. Indications of early neuronal developmental disturbances? Nervenarzt, 79(3), 275-284.

Kantarci, K., Avula, R., Senjem, M. L., Samikoglu, A. R., Zhang, B., Weigand, S. D., . . Petersen, R. C. (2010). Dementia with Lewy bodies and Alzheimer disease Neurodegenerative patterns characterized by DTI. Neurology, 74(22), 1814-1821.

Kandel, E. R., Schwartz, J. H., \& Jessel, T. M. (2000). Principios de Neurociencia (4 ed.). Madrid: McGraw Hill.

Kawada, R., Yoshizum, M., Hirao, K., Fujiwara, H., Miyata, J., Shimizu, M., . . Murai, T. (2009). Brain volume and dysexecutive behavior in schizophrenia, Progress in neuro-psychopharmacology \& biological psychiatry, 33(7), 1255-60.

Kawas, C.H. (2003). Early Alzheimer's disease. New England Journal of Medicine, 349, 1056-1063.

Kaye, W. (2008). Neurobiology of anorexia and bulimia nervosa. Physiology \& Behavior, 94(1), 121-135.

Kaye, W. H., Fudge, J. L., \& Paulus, M. (2009). New insights into symptoms and neurocircuit function of anorexia nervosa. Nature Reviews Neuroscience, 10(8), 573-584.

Kellinghaus, C., \& Luders, H. O. (2004). Frontal lobe epilepsy. Epileptic Disorders, 6(4), 223-239.

Kempton, M. J., Geddes, J. R., Ettinger, U., Williams, S. C. R., \& Grasby, P. M. (2008). Meta-analysis, database, and meta-regression of 98 structural imaging studies in bipolar disorder. Archives of General Psychiatry, 65(9), 1017-1032.

Kempton, M. J., Stahl, D., Williams, S. C. R., \& De Lisi, L. E. (2010). Progressive Lateral Ventricular Enlargement in Schizophrenia: A Meta-analysis of Longitudinal MRI Studies. Schizophrenia Research, $120(1-3), 54-62$.

Kéri, S. (2008). Interactive memory systems and category learning in schizophrenia. Neuroscience and biobehavioral reviews, 32(2), 206-218.

Kerr, J., Ratiu, P., \& Sellberg, M. (1996). Volume rendering of visible human data for an anatomical virtual environment. Studies in Health Technology and Informatics, 29, 352-70.

Khotanlou, H. (2008). 3D brain tumors and internal brain structures segmentattion in MR images. Tesis. Ecole Nationale Superieure des Telecommunications . 
Kieling, C., Goncalves, R. R. F., Tannock, R., \& Castellanos, F. X. (2008). Neurobiology of attention déficit hyperactivity disorder. Child and Adolescent Psyquiatric Clinics of North America, 17(2), 285294.

Kiernan, V. (1994). A slice of life on the Internet: Visible Human Project. New Scientist, 3, 144-145.

Kilian, S., Brown, W. S., Hallam, B. J., Mc Mahon, W., Lu, K., Johnson, M., . . Lainhart, J. (2008). Regional callosal morphology in autism and macrocephaly. Developmental Neuropsychology, 33(1), 74-99.

Kim, A. J., Hamilton, J. P., \& Gotlib, I. H. (2008). Reduced caudate gray matter volume in women with major depressive disorder. Psychiatry Reserach. Neuroimaging, 164(2), 114-122.

Kim, B. N., Lee, J. S., Shin, M. S., Cho, S. C., \& Lee, D. S. (2002). Regional cerebral perfusion abnormalities in attention déficit/hyperactivity disorder- Statistical parametric mapping analysis. European Archives of Psyquiatry and Clinical Neuroscience, 252(5), 219-225.

Kim, H., Somerville, L.H., Johnstone, T., Alexander, A., \& Whalen, P. J. (2003). Inverse amygdala and medial prefrontal cortex responses to surprised faces. Neuroreport ,14, 2317-2322.

Kim, H., Somerville, L. H., Johnstone, T., Polis, S., Alexander, A. L., Shin, L. M., \& Whalen, P. J. (2004). Contextual modulation of amygdala responsivity to surprised faces. Journal of Cognitive Neuroscience, $16,1730-1745$.

Kim, J., Choi, C., De, S., \& Srinivasan, M. A. (2007). Virtual surgery simulation for medical training using multi-resolution organ models. International Journal of Medical Robotics, 3(2), 149-158.

Kim, J. E., Lyoo, I. K., Estes, A. M., \& Renshaw, P. F. (2010). Amydalar Enlargement in 6 to 7 Year Old Children With Autism Spectrum Disorder. Archives of General Psychiatry, 67(11), 1187-1197.

Kiral, Y., \& Kiray, S. J. (2007). Traumatic brain injury and delayed sequelae: A review - Tramatic brain injury and mild traumatic brain injury (conclusion) are precursors to later-onsest brain disorders, including early-onset dementia. The scientific world journal, 7, 1768, 1776.

Kircher, T., Leube, D., \& Habel, U. (2009). Functional magnetic resonance tomography in patients with schizophrenia: neural correlates of symtoms, cognition and emotion. Nervenarzt, 80(9), 1103-1116.

Kleinhans, N. M., Richards, T., Weaver, K., Johnson, L. C., Greenson, J., Dawson, G., \& Aylward, E. (2010). Association Between Amygdala Response to Emotional Faces and Social Anxiety in Autism Spectrum Disorders. Neuropsychologia, 48(12), 3665-3670.

Kogure, D., Matsuda, H., Ohnishi, T., Asada, T., Uno, M., Kunihiro, T., .. Takasaki, M. (2000). Longitudinal Evaluation of Early Alzheimer's Disease Using Brain Perfusion SPECT. Journal of Nuclear Medicine, 41, 1155-1116.

Kolb, B., \& Whishaw, I. Q. (2010). An Introduction to Brain and Behavior. New York: Worth Publichers. Konomovic, M. D., Klunk, W. E., Abrahamson, E. E., Mathis, C. A., Price, J. C., Tsopelas, N. D., . . Lopresti, B. J. (2008). Post-mortem correlates of in vivo PiB-PET amyloid imagin in a typical case of Alzheimer's disease. Brain, 131(6), 1630-1645. 
Koolschijn, P. C., Van Haren, N. E., Cahn, W., Schnack H. G., Janssen J., Klumpers, F., . . Kahn R. S. (2010). Hippocampal volume change in schizophrenia. Journal of Clinical Psychiatry, 71(6), 737-744. Epub 2010 Jan 12

Koolschijn, P. C., Van Haren, N. E., Lensvelt-Mulders, G. J., Hulshoff Pol, H. E., \& Kahn, R. S. (2009). Brain Volume Abnormalities in Major Depressive Disorder: A Meta Analysis of Magnetic Resonance Imaging Studies. Human Brain Mapping, 30(11), 3719-1735.

Koponer, S., Taiminen, T., Portin R., Himanen, L., Isoniemi, H., Heinonen, H., . . Tenovuo, O. (2002). Axis I and Axis II psychiatric disorders after traumatic brain injury. American Journal of Psychiatry, 159, $1315-21$

Kotsopoulos, I. A., van Merode, T., Kessels, F. G., de Kron, M. C., \& Knottnerus, J. A. (2002). Systematic review and meta-analysis of incidence studies of epilepsy and unprovoked seizures. Epilepsia, 43, 1402-1409.

Krain, A. L., \& Castellanos, F. X. (2006). Brain development and ADHD. Clinical Psychology Review, 26(4), 433-444.

Kronmüller, K. T., Pantel, J., Köhler, S., Giesel, F., Magnotta, V. A., Mundt, C., . . Schröder, J. (2008). Hippocampal volume and two year outcome in depression. British Journal of Psychiatry, 192, 472473.

Kronmüller, K. T., Schroder, J., Kohler, S., Gotz, B., Victor, D., Unger, J., . . Pantel, J. (2009). Hippocampal volume in first episode and recurrent depression. Psychiatry Research. Neuroimaging, $174(1), 62-66$.

Krzyzkowiak, W. (1993). Computer tomography in diagnosis of mental disorders. Psychiatr Polska, 27(3), 281-291.

Kubicki, M., McCarley, R., Westin, C. F., Park, H. J., Maier, S., Kikinis, R., . . Shenton, M. E. (2007). A review of diffusion tensor imaging studies in schizophrenia. Journal of Psychiatric Research, 41(1-2), 15-30.

Kubicki, M., Westin, C. F., Mc Carley, R. W., \& Shenton, M. E. (2005). The Application of DTI to Investigate White Matter Abnormalities in Schizophrenia. Annals of the New York Academy of Sciences, 1064, 134-48.

Kyriakopoulos, M., \& Frangou, S. (2009). Recent diffusion tensor imaging findings in early stages of schizophrenia. Current Opinion in Psychiatry, 22(2), 168-176.

Lado, F. A., Laureta, E. C., \& Moshe, S. L. (2002). Seizure-induced hippocampal damage in the mature and immature brain. Epileptic Disorders, 4(2), 83-97.

Lang, M. J., Greer, A. D., \& Sutherland, G. R.(2011). Intra-operative Robotics: NeuroArm. Acta Neurosurgica, 109(8), 231-236.

Lang, M. J., Kelly, J. J. P., \& Sutherland, G. R. (2011). A Moveable 3-Tesla Intra-operative MRI System. Neurosurgery. doi: 10.1227/NEU.0b013e3182045803 
Lang, M. J., \& Sutherland, G. R. (2010). Informatic Surgery: The Union of Surgeon and Machine. World Neurosurgery, 74(1), 118-120.

Lange, T., Indelicato, D. J., \& Rosen, J. M. (2000). Virtual reality in surgical training. Surgical oncology clinics of North America, 9(1), 61-79.

Langen, M., Schnack, H. G., Nederveen, H., Bos, D., de Jonge, M. V., van Engeland, H., \& Durston, S. (2009). Changes in the Developmental Trajectories of Striatum in Autism. Biological Psychiatry, 66(4), $327-333$.

Lassmann, H., Bruck, W., \& Lucchinetti, C. F. (2007). The immunopathology of multiple sclerosis: An overview. Brain Pathology, 17(2), 210-218.

Lawrie, S. M., McIntosh, A. M., Hall, J., Owens, D. G. C., \& Johnstone, E. C. (2008). Brain structure and function changes during the development of schizophrenia: The evidence from studies of subjects at increased genetic risk. Schizophrenia Bulletin, 34(2), 330-340.

Lesh, T. A., Niendam, T. A., Minzenberg, M. J., \& Carter, C. S. (2011). Cognitive Control Deficits in Schizophrenia: Mechanisms and Meaning. Neuropsychopharmacology, 36(1), 316-338.

Letteboer, M., Olsen, O., Dam, E., Willems, P., Viergever, M., \& Niessen, W. (2004). Sementation of tumors in magnetic resonance brain images using an interactive multiscale watershed algorithm. Academic Radiology, 11(10), 1125-1138.

Levitt, J. J., Styner, M., Niethammer, M., Bouix, S., Koo, M. S, Voglmaier, M. M., . . Shenton, M. E. (2009). Shape abnormalities of caudate nucleus in schizotypal personality disorder, Schizophrenia Research, 110, 127-139.

Levy, R., Cox, R. G., Hader, W. J., Myles, T., Sutherland, G.R., \& Hamilton, M. G. (2009). Application of High-Field Magnetic Resonance Imaging in Pediatric Neurosurgery. Journal of Neurosurgery: Pediatrics, 4, 467-474.

Lewis, S. G. J ., Dove, A., Robbins, T. W., Barker, R. A., \& Owen, A. M. (2004). Striatal contributions to working memory: a functional magnetic resonance imaging study in humans. European Journal of Neuroscience, 19(3), 755-760.

Lipsman, N., Neimat, J. S., \& Lozano, A. M. (2007). Deep brain stimulation for treatment-refractory obsessive-compulsive disorder: The search for a valid target. Neurosurgery, 61(1), 1-13.

Lisak, R. P. (2007). Neurodegeneration in multiple sclerosis: Defining the problem. Neurology, 68(22-3), $5-12$.

López-Larson, M. P., DelBello, M. P., Zimmerman, M. E., Schwiers, M. L., \& Strakowski, S.M. (2002). Regional prefrontal gray and white matter abnormalities in bipolar disorder. Biological Psychiatry, 52, 93-100.

López-Ibor Alcocer, M., Ortiz Alonso, T., Encinas Mejías, M., Fernández, A., Maestú, F., \& López-Ibor Aliño, J. (2000). New advances in neuroimaging in the diagnosis of obsessive-compulsive disorder. Actas Españolas De Psiquiatría, 28(5), 304-310. 
Lorenzetti, V., Allen, N. B., Fornito, A., \& Yücel, M. (2009). Structural brain abnormalities in major depressive disorder: A selective review of recent MRI studies. Journal of Afective Disorders, 117(1-2), 1-17.

Lorenzetti, V., Allen, N. B., Whittle, S., \& Yücel, M. (2010). Amygdala volumes in a simple of current depressed and remitted depressed patients and healthy controls. Journal of Affective Disorders, 120(13), 112-119.

Lowndes, M., Morris, J. F., \& Schubert, R. (1997). Use of the Voxel-Man dissectable atlas in teaching anatomy. Journal of Anatomy, 191(1), 127-128.

Lowndes, G., \& Savage, G. (2007). Early detection of memory impairment in Alzheimer's disease: a neurocognitive perspective on assessment. Neuropsychological Review, 17(3), 193-202.

Lyoo, I. K., \& Renshaw, P. F. (2002). Magnetic resonance spectroscopy: current and future applications in psychiatry research. Biological Psychiatry, 51(3), 195-207.

Luria, A. R. (1973). The Working Brain. Basic Books.

MacQueen, G. M., Yücel, K., Taylor, V. H., Macdonald, K., \& Joffe, R. (2008). Posterior hippocampal volumes are associated with remission rates in patients with major depressive disorder. Biological Psychiatry, 64, 880-883.

Maki, D. D., \& Griffiths, H. J. (1996). Voxel-Man. 1 Brain and skull. Radiographics, 16(3), 682.

Maldonado, A., Trampal, C. \& Ortega, F. (1998). Neuroimagen funcional. Indicaciones actuales de la PET en Neurologia. I congreso virtual de neurología.

Maletic, V., Robinson, M., Oakes, T., Iyengar, S., Ball, S. G., \& Russell, J. (2007). Neurobiology of depression: an integrated view of key findings. International Journal of Clinical Practice, 61(12) 20302040 .

Malhi, G. S., \& Lagopoulos, J. (2008). Making sense of neuroimaging in psyquiatry. Acta Psychiatrica Scandinavia, 117(2), 100-117.

Malhi, G. S., Valenzuela, M., Wen, W., \& Sachdev, P. (2002). Magnetic resonance spectroscopy and its applications in psychiatry. Australian and New Zealand Journal of Psychiatry, 36, 31-43.

Mamah, D., Wang, L., Csernansky, J. G., Rice, J. P., Smith, M., \& Barch, D. M. (2010). Morphometry of the hippocampus and amygdala in bipolar disorder and schizophrenia. Bipolar Disorders, 12(3), 341343.

Martínez-Montes, E., Valdes-Sosa, P. A., Miwakeichi, F., Goldman, R. I., \& Cohen, M. S. (2004). Concurrent EEG/fMRI analysis by multiway partial least squares. Neuroimage, 22, 1023-1034.

Mateus, M., Silva, C., Nogueiro, O., \& Redondo, J. (2009). Neuroimage in psyquiatry. What can we see?. European Psychiatry, 24(1), 694.

Matsuda, H. (2007). Role of neuroimaging in Alzheimer's disease, with emphasis on brain perfusion SPECT. Journal of Nuclear Medicine, 48(8), 1289-1300. 
Mazziotta, J. Toga, A., Evans, A., Fox, P., \& Lancaster, J. (1995). A probabilistic atlas of the human brain: theory and rationale for its development. NeuroImage, 2(2), 89-101.

McCormick, L. M., Keel, P. K., Brumm, M. C., Bowers, W., Swayze, V., Andersen, A., \& Andreasen, N. (2008). Implications of Starvation-Induced Change in Right Dorsal Anterior Cingulate Volume in Anorexia Nervosa. International Journal of Eating Disorders, 41(7), 602-610.

McDonald, A. W., Thermenos, H. W., Barch, D. M., \& Seidman, L. J. (2009). Imaging Genetic Liability to Schizophrenia: Systematic Review of fMRI Studies of Patients' Nonpsychotic Relatives. Schizophrenia Bulletin, 35(6), 1142-1162.

McDonald, C., Marshall, N., Sham, P. C., Bullmore, E. T., Schulze, K., Chapple, B., .. Quraishi, S. (2006). Regional brain morphometry in patients with schizophrenia or bipolar disorder and their unaffected relatives. American Journal of Psychiatry, 163(3), 478-487.

McKinnon, M. C., Yücel, K., Nazarov, A., \& MacQueen, G. M. (2009). A meta-analysis examining clinical predictors of hippocampal volume in patients with major depressive disorder. Journal of Psychiatry \& Neuroscience, 34, 41-54.

McLachlan, J. C., Bligh, J., Bradley, P., \& Searle, J. (2004). Teaching anatomy without cadavers. Medical Education, 38, 418-424.

McNally, M. A., Crocetti, D., Mahone, E. M., Denckla, M. B., Suskauer, S. J., \& Mostofsky, S. H., (2010). Corpus callosum segment circumference is associated with response control in children with attentiondeficit hyperactivity disoder (ADHD). Journal of Child Neurology, 25(4), 453-462.

McNamee, D. (1995). Visible Man available on disc. Lancet, 29(346), 302.

McNulty, J. A., Sonntag, B., \& Sinacore, J. M. (2009). Evaluation of computer-aided instruction in a gross anatomy course: A six-year study. Anatomical Science Education, 2, 2-8.

Meier, D. S., \& Guttmann, C. R. G. (2006). MRI time series modeling of MS lesion development. Neuroimage, 32(2), 531-537.

Méndez, M.F. (2009). The Neurobiology of Moral Behavior: Review and Neuropsychiatric Implications. CNS spectrums, 14(11), 608-620.

Menzies, L., Achard, S., Chamberlain, S. R. Fineberg, N., Chen, C. H., del Campo, N., . . Bullmore, E. (2007). Neurocognitive endophenotypes of obsessive-compulsive disorder. Brain, 130, 3223-3236.

Menzies, L., Chamberlain, S. R., Laird, A. R., Thelen, S. M., Sahakian, B. J., \& Bullmore, E. T. (2008). Integrating evidence from neuroimaging and neuropsychological studies of obsessive-compulsive disorder: the orbitofronto-striatal model revisited. Neuroscience and Biobehavioral Reviews, 32(3), $525-549$.

Meyer-Lindenberg, A. S., Olsen, R. K., Kohn, P. D., Brown, T., Egan, M. F., Weinberger, D. R., \& Berman, K. F. (2005). Regionally specific disturbance of dorsolateral prefrontal-hippocampal functional connectivity in schizophrenia. Archives of General Psychiatry, 62, 379-386. 
Michael, A. M., Baum, S. A., White, T., Demirci, O., Andreasen, N. C., Segall, J. M., .. Calhoun, V. D. (2010). Does function follow form?: Methods to fuse structural and functional brain images show decreased linkage in schizophrenia. Neuroimage, 49(3), 2626-2637.

Mikula, S., Stone, J. M., \& Jones, E. G. (2008). BrainMaps.org: Interactive High-Resolution Digital Brain Atlases and Virtual Microscopy. Brains, Minds y Media, 3, 1426-1432.

Miles, K. A. (2005). Diagnostic imaging in undergraduate medical education: An expanding role. Clinical Radiology, 60, 742-745.

Milne, A., MacQueen, G. M., Yücel, K. Soreni, N., \& Hall, G. B. (2009). Hippocampal metabolic abnormalities at first onset and with recurrent episodes of a major depressive disorder: A proton magnetic resonance spectroscopy study. Neuroimage, 47(1), 36-41.

Mitelman, S. A., Canfield, E. L., Chu, K. W., Brickman, A. M., Shihabuddin, L., Hazlett, E. A., \& Buchsbaum, M. S. (2009). Poor outcome in chronic schizophrenia is associated with progressive loss of volume of the putamen. Schizophrenia Research, 113(2-3), 241-245.

Miyake, Y., Okamoto, Y., Onoda, K., Kurosaki, M., Shirao, N., Okamoto, Y., \& Yamawaki, S. (2010). Brain Activation During the Perception of Distorted Body Images in Eating Disorders. Psychiatry Research. Neuroimaging, 181(3), 183-192.

Moghaddam, B. (2010). Dopamine in the Tahalamus: A Hotbed for Psychosis? Biological Psychiatry, $68(1), 3-4$.

Monchi, O., Benali, H., Doyon, J., \& Strafellas, A. P. (2008). Recent Advances in Neuroimaging Methods. Internacional Journal of Biomedical Imaging, 1-3.

Monk, C. S., Weng, S. J., Wiggins, J. L., Kurapati, N., Louro, H. M. C., Carrasco, M. . Lord, C. (2010). Neural Circuitry of Emotional Face Processing in Autism Spectrum Disorders. Journal of Psychiatry \& Neuroscience, 35(2), 105-114.

Moore, G. R. W., Vitali, A. M., Leung, E., Laule, C., Kozlowski, P., MacKay, A., L., \& Honey, C. R. (2009). Thalamic stimulation in multiple sclerosis: evidence for a "demyelinative thalamotomy"? Multiple Sclerosis, 15(11), 1311-1321.

Mori, S., Van Ziljl, P. C. (2002). Fiber tracking: principles and strategies. A technical review. Radiology Nuclear Medicine \& Medical Imaging, 15, 468-480.

Morikawa, S., Naka, S., Murakami, K., Kurumi, Y., Shiomi, H., Tani, T., . . Inubushi, T. (2009). Preliminary clinical experiences of a motorized manipulator for magnetic resonance image-guided microwave coagulation therapy of liver tumors. American Jorunal of Surgery. 198(3), 340-347.

Morra, J. H., Tu, Z., Apostolova, L. G., Green, A. E., Avedissian, C., Madsen, S. K., . . Thompson, P. M., (2009). The Alzheimer's Disease Neuroimaging Initiative. Automated mapping of hippocampal atrophy in 1-year repeat MRI data from 490 subjects with Alzheimer's disease, mild cognitive impairment, and elderly controls. Neuroimage, 45(1), 3-15. 
Mosconi, M. W., Cody-Hazlett, H., Poe, M. D., Gerig, G. Gimpel-Smith, R., \& Piven, J. (2009). Longitudinal study of amgydala volume and joint attention in 2 to 4 year old children with autism. Archives of General Psychiatry, 66, 509-516.

Mosely, M. E., \& Donnan, G., (2004). Multimodality Imaging: Introduction. Stroke, 35, 634-635.

Mueller, C., Rufer, M., Moergeli, H., \& Bridler, R. (2006). Brain imaging in psychiatry-a study of 435 psychiatric in-patients at a university clinic. Acta Psychiatrica Scandinavica, 114, 91-100.

Mungas, D., Reed, B. R., Jagust, W. J., DeCarli, C., Mack, W. J., Kramer, J. H., . . Chui, H. C. (2002). Volumetric MRI predicts rate of cognitive decline related to $\mathrm{AD}$ and cerebrovascular disease. Neurology, 59, 867-873.

Munson, J., Dawson, G., Abbott, R., Faja, S., Webb, S. J., Friedman, S. D., . . Dager, S. R. (2006). Amygdala volume and behavioral development in autism. Archives of General Psychiatry, 63(6), 686693.

Murray, E. A. (2007). The amygdala, reward and emotion. Trends in Cognitive Science, 12(5), 171-172.

Naismith, S. L., Lagopoulos, J., Ward, P. B., Davey, C. G., Little, C., \& Hickie, I. B. (2010). Fronto-striatal correlates of impaired implicit sequence learning in major depression: An fMRI study. Journal of Affective Disorders, 125(1-3), 256-261.

National Institute of Health [NIH]. (2010). National Library of Medicine Classification 2010. Acceso el 22 de diciembre de 2010 de http://www.nlm.nih.gov/class/nlmclassintro.html

National Institute of Neurological Disorders and Stroke [NINDS]. (2010). National Institute of Neurological Disorders and Stroke. Acceso el 17 de diciembre de 2010 de www.ninds.nih.gov/

Negoro, H., Sawada, M., Lida, J., Ota, T., Tanaka, S., \& Kishimoto, T. (2010). Prefrontal Dysfunction in Attention-Deficit/Hyperactivity Disorder as Measured by Near-Infrared Spectroscopy. Child Psychiatry \& Human Development, 41(2), 193-203.

Nente, F., Carrillo-Mezo, R., Mendez, M. F., \& Ramirez-Bermudez, J. (2007). Pathological hyperfamiliarity for others from a left anterior cingulate lesion. Journal of Neuropsychiatry Clinical Neuroscience, 19(3), 345-346.

Neuhaus, E., Beauchaine, T. P., \& Bernier, R. (2010). Neurobiological Correlates of Social Functioning in Autism. Clinical Psychology Review, 30(6), 733-748.

Newport, D., \& Nemeroff, C. (2000). Neurobiology of posttraumatic stress disorder. Current Opinion In Neurobiology, 10(2), 211-218.

Nieder, G., \& Nagy, F. (1996). A computer-assisted instructional program for sectional anatomy based on the National Library of Medicine's Visible Human Project (VHP) database. Federation of American Societies for Experimental Biology Journal, 10(3), 295.

Nielsen, F. A., (2009). Lost in localization: A solution with neuroinformatics 2.0?. Neuroimage, 48(1), 1113. 
Nitschke, J. B., Sarinopoulos, I., Oathes, D. J., Johnstone, T., Whalen, P. J., Davidson, R. J., \& Kalin, N. H. (2009). Anticipatory activation in the amygdala and anterior cingulate in generalized anxiety disorder and prediction of treatment response. American Journal of Psychiatry, 166, 302-310.

Niznikiewicz, M. A., Kubicki, M., \& Shenton, M. E. (2003). Recent structural and functional imaging findings in schizophrenia. Current opinion in psychiatry, 16(2), 123-147.

Noriuchi, M., Kikuchi, Y., Yoshiura, T., Kira, R., Shigeto, H., Hara, T., . . Kamio, Y. (2010). Altered White Matter tractional Anisotropy and Social Impairment in Children with Autism Spectrum Disorder. Brain Research, 1362, 141-149.

Northoff, G. (2007). Psychopathology and pathophysiology of the self in depression - neuropsychiatric hypothesis. Journal of Affective Disorders, 104(1-3), 1-14.

Northoff, G. (2010). Glutamate and the prefrontal cortex in the psychopathology of depression- a combined fMRI-MRS approach. European Neuropsychopharmacology, 20(3), 207-207.

Novak, J. D. (2003). The promise of new ideas and new technology for improving teaching and learning. Cell Biology Education, 2, 122-132.

Novelline, R. A. (2000). Fundamentos de radiología. Barcelona: Masson.

Nowinski, W. L., Thirunavuukarasuu, A., Ananthasubramaniam, A., Chua, B. C., Qian, G., Nowinska, N. G., . . Volkau, I., (2009). Automatic testing and assessment of neuroanatomy using a digital brain atlas: method and development of computer- and mobile-based applications. Anatomical Sciences Education, 2(5), 244-52.

Nowinski, W. L., Thirunavuukarasuu, A., Volkau, I., Marchenko. Y., \& Runge, V. M. (2009). The Cerefyl Atlas of Cerebral Vasculature (CD-ROM). New York: Thieme Medical Publishers.

Obeso, J. A., Rodríguez-Oroz, M., Benitez-Temino, B., Belsa, F. J., Guridi, J., Marin, C., \& Rodríguez, M. (2008). Functional organization of the basal ganglia: therapeutic implications for Parkinson's disease. Moviment Disorders, 23(3), 548-559.

Obeso, J. A., Rodríguez-Oroz, M., Marin, C., Alonso, F., Zamarbide, I., Lanciego, J. L., \& Rodríguez-Diaz, M. (2004). The origin of motor fluctuations in Parkinson's disease: Importantce of dopaminergic innervation and basal glanglia circuits. Neurology, 62(1), 17-30.

O’Byrne, P. J., Patry, A., \& Carnegie, J. A. (2008). The development of interactive online learning tools for the study of anatomy. Medical Teacher, 30, 260-271.

Olabarriaga, S. D., \& Smeulders, A. W. M. (2001). Interaction in the segmentation of medical images: A survey. Medical Image Analysis, 5, 127-142.

Olanow, C. W. (2004). The scientific basis of the current treatment of Parkinson's disease. Annual Review of Medicine, 55, 41 .

Older, J. (2004). Anatomy: a must for teaching the next generation. Surgeon, 2(2), 79-90.

Pallen, M. (1996). The Visible Human. British Medical Journal, 26(313), 1068. 
Pandya, S., Motkoski, J. W., Serrano-Almeida, C., Greer, A. D., Latour, I., \& Sutherland, G. R.(2009). Advancing Neurosurgery with Image-Guided Robotics. Journal of Neurosurgery, 111, 1141-1149.

Park, J. S., Chung, M. S., Hwang, S. B., Lee, Y. S., Har, D. H., \& Park, H. S. (2005). Visible Korean human: improved serially sectioned images of the entire body. IEEE Transactions on Medical Imaging, 24(3), 352-360.

Park, J. S., Chung, M. S., Hwang, S. B., Shin, B. S., \& Park, H. S. (2006). Visible Korean Human: Its techniques and applications. Clinical Anatomy, 19(3), 216-224.

Parker, L. M. (2002). Anatomical dissection: Why are we cutting it out? Dissectionin undergraduate teaching. Australian \& New Zealand Journal of Surgery, 72, 910-912.

Paseve, N., Metta, V., Bose, S. K., Chaudhuri, K. R., \& Brooks, D. J. (2010). Fatigue and Parkinson's disease is linked to striatal and limbic serotonergic dysfunction. Brain, 133(11), 3434-3443.

Patel, N. H., Vyas, N. S., Puri, B. K., Nijran, K. S., \& Al-Nahhas, A. (2010). Positron Emission Tomography in Schizophrenia: A New Perspective. Journal of Nuclear Medicine, 51(4), 511-520.

Pavese, N., \& Brooks, D. J. (2009). Imaging neurodegeneration in Parkinson's disease. Biochimica Et Biophysica Acta-Molecular Basis of Disease, 1792(7), 722-729.

Pavuluri, M. N., Passarotti, A. M., Harrai, E. M., \& Sweeney, J. A. (2010). Enhanced Prefrontal Function With Pharmacotherapy on a Response Inhibition Task in Adolescent Bipolar Disorder. Journal of Clinical Psychiatry, 71(1), 1526-1534.

Pearlson, G. D., \& Calhoun, V. (2007). Structural and functional magnetic resonance imaging in psychiatric disorders. Canadian Journal of Psychiatry-Revue Canadienne De Psychiatrie, 52(3), 158166.

Penfield, W. G., \& Rasmussen T. (1952). The Cerebral Cortex of Man. New York: Macmillan.

Perandini, S., Faccioli, N., Zaccarella, A., Re, T., \& Mucelli, R. P. (2010). The diagnostic contribution of CT volumetric rendering techniques in routine practice. Indian Journal of Radiology Imaging, 20(2), 92-97.

Perlov, E., Phillipsen, A., Matthies, S., Direling, T., Maier, S., Bubl, E., . . Tebartz Van Elst, L. (2009). Spectroscopiec findings in attention-deficit/hyperactivity disorder: Review and meta-analysis. World Journal of Biological Psyquiatry, 10(5), 355-365.

Persson, J., Lind, J., Larsson, A., Ingvar, M., Sleegers, K., Van Broeckhoven, C., . . Nyberg, L. (2008). Altered deactivation in individuals with genetic risk for Alzheimer's disease. Neuropsychologia, 46, 1679-1687.

Pessoa, L. (2008). On the relatioship between emotion and cognition. National Review of Neuroscience, 9(2), 148-158.

Petropoulos, H., Friedman, S. D., Shaw, D. W. W., Artru, A. A., Dawson, G., \& Dager, S. R. (2006). Gray matter abnormalities in autism spectrum disorder revealed by T2 relaxation. Neurology, 67(4), 632-636. 
Phan, K. L., Wager, T., Taylor, S. F., \& Liberzon, I. (2002). Functional neuroanatomy of emotion: a metaanalysis of emotion activation studies in PET and fMRI. Neuroimage, 16, 331-348.

Phillips, M. L., \& Vieta, E. (2007). Identifying functional neuroimaging biomarkers of biopolar disorder: toward DSM-V. Schizophrenia Bulletin, 33(4), 893-904.

Piccini, P., \& Brooks, D. J. (2006). New developments of brain imaging for Parkinson's disease and related disorders. Movement Disorders, 21(12), 2035-2041.

Pieters, G. L. M., de Bruijin, E. R. A., Maas, Y., Hulstijin, W., Vandereycken, W., Peuskens, J. \& Sabbe, B. G. (2007). Action monitoring and perfectionism in anorexia nervosa. Brain and Cognition, 63(1), 42-50.

Pievani, M., Agosta, F., Pagani, E., Canu, E., Sala, S., Absinta, M., \& Fillippi, M. (2010). Assessment of White Matter Tract Damage in Mild Cognitive Impairment and Alzheimer's Disease. Human Brain Mapping, 31(12), 1862-1875.

Pillay, H. K. (1994). Cognitive load and mental rotation: structuring orthographic projection for learning and problem solving. Instructional Science, 22, 91-113.

Pitel, A. L., Chanraud, S., Sullivan E. V., \& Pfefferbaum, A. (2010). Callosal microstructural abnormalities in Alzheimer's disease and alcoholism: same phenotype, different mechanisms. Psychiatry Research. Neuroimaging, 184(1), 49-56.

Pol, H. E. H., \& Kahn, R. S. (2008). What Happens After the First Episode? A Review of Progressive Brain Changes in Chronically Ill Patients with Schizophrenia. Schizophrenia Bulletin, 34(2), 354-366.

Polman, C. H., Wolinsky, J. S., \& Reingold, S. C. (2005). Diagnostic criteria for multiple sclerosis: 2005 revisions to the "McDonald criteria". Annals of Neurology, 58, 840-846.

Pomarol-Clotet, E., Canales-Rodríguez, E. J., Salvador, R., Sarro, S., Gomar, J. J., Vila, F. . . Capdevila, A. (2010). Medial Prefrontal Pathology in Schizophrenia as Revealed by Convergent Findings from Multimodal Imaging. Molecular Psychiatry, 15(8), 823-830.

Pommert, A., Höhne, H. H., Pflesser, B., Richter, E., Riemer, M., Schiemann, T., . . Tiede, U. (2001). Creating a high-resolution spatial/symbolic model of the inner organs based on the Visible Human. Medical Image Analysis, 5, 221-228.

Pommert, A., Tiede, U., \& Höhne, K. H. (2002). Volume Visualization. Brain Mapping: The Methods. Hamburg: Elseiver.

Portella, M. J., Morgan-Ferrando, R., \& Gómez-Anson, B. (2009). Prefrontal metabolic abnormalities in major depressive disorder: a proton magnetic resonance spectroscopy study. European Neuropsychopaharmacology, 19(3) 423-424.

Posner, M. I., Rothbart, M. K., Sheese, B. E., \& Tang, Y. (2007). The anterior cingulate gyrus and the mechanism of self-regulation. Cognitive, Affective and Behavioral Neuroscience, 7(4), 391-395. 
Powell, H. W. R., Koepp, J. M., Richardson, M. P., Symms, M. R., Thompson, P. J., \& Duncan, J. S. (2004). The application of functional MRI of memory in temporal lobe epilepsy: a clinical review. Epilepsia, 457, 855-863.

Pozo, M. A. (2004). Neuroimagen funcional: una ventana abierta al funcionamiento del cerebro. Revista de occidente, $272,5.23$.

Prats, A., \& Juanes, J.A. (2007). UB-Brain 2.0. Publicacions i Edicions Universitat de Barcelona.

Previc, F. H., (2006). The role of the extrapersonal brain systems in religious activity. Conscious and Cognition, 15(3), 500-539.

Proscia, N., Jaffe, T. A., Neville, A. M., Wang, C. L., Dale, B. M., \& Merkle, E. M. (2010). MRI of Pelvis in Women: 3D Versus 2D T2-Wighted Technique. American Journal of Roentgnology, 195(1), 254259.

Puelles, L. (2008). Neuroanatomía. Editorial Médica Panamericana.

Puri, B. K. (2010). Progressive Structural Brain Changes in Schizophrenia. Expert Review of Neurotherapeutics, 10(1), 33-42.

Purves, D. (2004). Invitación a la Neurociencia. Editorial Médica Panamericana.

Qiu, A. Q., Adler, M., Crocetti, D., Miller, M. I., \& Mostofsky, S. H. (2010). Basal Ganglia Shapes Predict Social, Communication, and Motor Dysfunctions in Boys With Autism Spectrum Disorder. Journal of the American Academy of Child and Adolescent Psychiatry, 49(69), 539-551.

Qui, A. Q., Zhong, J. D., Graham, S., Chia, M. Y., \& Sim, K. (2009). Combined analyses of thalamic volumen, shape and White matter integrity in first-episode schizophrenia. Neuroimage, 47(4), 11631171.

Quintero, J., Navas, M., Fernández, A., \& Ortiz, T. (2009). Advances in attention deficit hyperactivity disoder. What does neuroimaging provide us with?. Actas Españolas de Psiquiatría, 37(6), 352-358.

Rabinovici, G. D., Furst, A. J., O’Neil, J. P., Racine, C. A., Mormino, E. C., Baker, S. L., .. Jagust, W. J. (2007). 11C-PIB PET imaging in Alzheimer disease and frontotemporal lobar degeneration. Neurology, $68(15), 1205-1212$.

Rabinovici, G. D., Seeley, W. W., Kim, E. J., Gorno-Tempini, M. L. Rascovsky, K., Pagliaro, T. A., .. . Rosen, H. J. (2008). Distinct MRI atrophy patterns in autopsy-proven Alzheimer's disease and frontotemporal lobar degeneration. American Journal of Alzheimers Disease and Other Dementias, $22(6), 474-488$.

Radua, J., \& Mataix-Cols, D. (2009). Voxel-wise meta-analysis of grey matter changes in obsessivecompulsive disorder. British Journal of Psychiatry, 195(5), 393-402.

Radua, J., van den Heuvel, O. A., Surguladze, S., \& Mataix-Cols, D. (2010). Meta-analytical comparison of voxel-based morphometry studies in obsessive-compulsive disorder vs other anxiety disorders. Archives of General Psychiatry, 67(7), 701-711. 
Ragland, J. D., Laird, A. R., Ranganath, C., Blumenfeld, R. S., Gonzales, S. M., \& Glahn, D. C. (2009). Prefrontal Activation Deficits During Episodic Memory in Schizophrenia. American Journal of Psychiatry, 166(8), 863-874.

Rajkowska, G., Halaris, A., \& Selemon, L.D. (2000). Reductions in neuronal and glial density characterize the dorsolateral prefrontal cortex in bipolar disorder. Biological Psychiatry, 49, 741-752.

Ramani, A., Jensen, J. H., \& Helpern, J.A. (2006). Quantitative MR imaging in Alzheimer disease. Radiology, 241(1), 26-44.

Rashid, W., \& Miller, D. H. (2008). Recent advances in neuroimaging of multiple sclerosis. Seminars in Neurology, 28(1), 46-55.

Rath, A. M. (1999). The complete Visible Human Project. Surgical and Radiologic Anatomy, 21(2), 142.

Ratiu, P., Hillen, B., Glaser, J., \& Jenkins, D. P. (2003). Visible Human 2.0-the next generation. Studies in Health Technology Informatics, 94, 275-281.

Ratiu, P., Talos, I. F., Haker, S., Lieberman, D., \& Everett, P. (2004). The tale of Phineas Gage, digitally remastered. Journal of Neurotrama, 21(5), 637-643.

Raz, A. (2004). Brain imaging data of ADHD. Psychiatric Times, 11(9), 1-2.

Redcay, E., \& Courchesne, E. (2005). When is the brain enlarged in autism? A meta-analysis of all brain size reports. Biological Psychiatry, 58, 1-9.

Redgrave, G. W., Bakker, A., Bello, N. T., Caffo, B. S., Coughlin, J. W., Guarda, A. S., . . Moran, T. H. (2008). Differential brain activation in anorexia nervosa to Fat and Thin words during a Stroop task. Neuroreport, $19(12), 1181-1185$.

Reich, D. S., Zackowski, K. M., Gordon-Lipkin, E. M., Smith, S. A., Chodkowski, B. A., Cutter, G. R., y Calabresi, P. A. (2008). Corticospinal tract abnormalities are associated with weakness in multiple sclerosis. American Journal of Neuroradiology, 29(2), 333-339.

Reidenberg, J.S., \& Laitman, J.T. (2002). The new face of gross anatomy. Anatomical Record, 269, 81-88.

Renshaw, P. (2008). MRI in psychiatric disease. Top Magnetic Resonance Imaging, 19(2), 69.

Robb, R. A., \& Hanson, D. P. (2006). Biomedical image visualization research using the Visible Human Datsets. Clinical Anatomy, 19(3), 240-253.

Richter, S., Asian, B., Gerwig, M., Wilhelm, H., Kramer, S., Todica, O., . . Timmann, D. (2007). Patients with chronic focal cerebellar lesions show no cognitive abnormalities in a bedside test. Neurocase, $13(1), 25-36$.

Riehemann, S., Volz, H. P., Stutzer, P., Smesny, S., Gaser, C., \& Sauer, H. (2001). Hypofrontality in neuroleptic-naive schizophrenic patients during the Wisconsin Card Sorting Test-an fMRI study. European Archives of Psychiatry and Clinical Neuroscience, 251, 66-71. 
Rimol, L. M., Hartberg, C. B., Nesvag, R., Fennema-Notestine, C., Hagler, D. J., Pung, C. J., . . Agartz, I. (2010). Cortical Thickness and Subcortical Volumes in Schizophrenia and Bipolar Disorder. Biological Psychiatry, 68(1), 41-50.

Rizzolo, L. J., \& Stewart, W. B. (2006). Should we continue teaching anatomy by dissection when ...? Anatomy Record Part B New Anatomist, 389(6), 215-218.

Rizzolo, L. J., Stewart, W. B., O'Brien, M., Haims, A., Rando, W., Abrahams, J., . . Aden, M. (2006). Design principales for developing an efficient clinical anatomy course. Medical Teacher, 28(2), 142151

Ro, T., Farné, A., Johson, R. M., Wedeen, V., Chu, Z., Wang, Z. J., . . Veauchamp, M. S. (2007). Feeling sounds after a thalamic lesion. Annals of Neurology, 62(5), 433-441.

Robb, R. A. (1998). From the Visible Human to real patients: development and evaluation of clinical procedures. Second Visible Human Project Conference Proceedings, 1-2 [CD-ROM].

Rocca, M. A., Mesaros, S., Pagani, E., Sormani, M. P., Comi, G., \& Fillippi, M. (2010). Thalamic Damage and Long-term Progression of Disability in Multiple Sclerosis. Radiology, 257(2), 463-469.

Rodier, P. M. (2003). Converging evidence for brain stem injury in autism. Development and psychopathology, 14(3), 537-557.

Rodríguez-Oroz, M. C., López-Azcarate, J., García-García, D., Alegre, M., Toledo, J., Valencia, M., .. . Obeso, J. A. (2011). Involvement of the subthalamic nucleus in impulse control disorders associated with Parkinson's disease. Brain, 134(1), 36-49.

Rosa, P. G. P., Schaufelberg, M. S., Uchida, R. R., Lappin, J. M., Menezes, P. R., Scazufca, M., .. . Busatto, G. F. (2010). Lateral Ventricles Differences Between First-episode Schizohrenia and FistEpisode Psychotic Bipolar Disorder: A popultion-based Morphometric MRI Study. World Journal of Biological Psychiatry, 11(7), 873-887.

Rosenbloom, M., Sullivan, E. V., \& Pfefferbaum, A. (2003). Using magnetic resonance imaging and diffusion tensor imaging to assess brain damage in alcoholics. Alcohol Research and Health, 27(2), 146-152.

Rosenkrantz, A. B., Neil, J., Kong, X. T., Melamed, J., Babb, J. S., Taneja, S. S., \& Taouli, B. (2010). Prostate Cancer: Comparison of 3D T2-Wighted With Conventional 2D T2-Wighted Imaging for Image Quality and Tumor Detection. American Journal of Roentgenology, 194(2), 446-452.

Ross, M. D. (1996). 3-D imaging in virtual environment: a scientific, clinical and teaching tool. Visible Human Project Conference Proceedings, 7-8. [CD-ROM].

Rosso, I. M., Cintron, C. M., Steingard, R. J., Renshaw, P. F., Young, A. D., \& Yurgelun-Todd, D. A. (2005). Amygdala and hippocampus volumes in pediatric major depression. Biological Psychiatry, $57(1), 21-26$. 
Rosso, I. M., Makris, N. Thermenos, H. W., Hodge, S. M., Brown, A., Kennedy, D., . . Seidman, L J. (2010). Prefrontal Cortex Gray Matter Volumes in Youth at Familial Risk for Schizophrenia from Harvard Adolescent High Risk Study. Schizophrenia Research, 123(1), 15-21.

Rostomian, A. H., Madison, C., Rabinovici, G. D., \& Jagust, W. J. (2011). Early 11C-PIB Frames and ${ }^{18}$ FFDG PET Measures Are Comparable: A Study Validated in a Cohort of AD and FTLD Patients. Journal of Nuclear Medicine, 52(2), 173-179.

Rotge, J. Y., Langbour, N., Guehi, D. Bioulac, B., Jaafari, N., Allard, M., . . Burbaud, P. (2010). Gray Matter Alterations in Obsessive-Compulsive Disorder: An Anatomic Likelihood Estimation MetaAnalysis. Neuropsychopharmacology, 35(5), 686-691.

Rowlands, J. A. (2002). The physics of computed radiography. Physical Medical Biology, 47, 123-166.

Rubin, M., \& Safdieh, J. E. (2008). Netter. Neuroanatomía Esencial. Elsevier Masson.

Rubinsztein, J. S., Fletcher, P. C., Rogers, R. D., Hol, L. W., Aigbirhio, F. I., Paykel, E. U., .. Sahakian, B. J. (2001). Decision-making in mania: a PET study. Brain,124(12), 2550-2563.

Ruiz, S. (2004). Evaluación de la perfusión sanguinea cerebral mediante tomografia por emisión de fotón único en el trastorno del estrés postraumático. Tesis Doctoral. Universidad de Barcelona.

Rund, B. R. (2009). Is schizophrenia a neurodegenerative disorder? Nordic journal of psychiatry, 63(3), 196-201.

Sah, P., Faber, E. S., López, D. A., \& Power, J. (2003). The amygdaloid complex: anatomy and physiology. Physiological Reviews, 83, 803-834.

Salvalini, L., Bichi, E., Costarelli, L., \& De Nicola, M. (2000). Clinical applications of 2D and 3D CT imaging of the airways. A review. European Journal of Radiologyy, 34(1), 9-25.

Sandi, C., \& Pinelo-Nava, M.T. (2007). Stress and memory: behavioral effects and neurobiological mechanisms. Neural Plasticity, 78-97.

Sapolsky, R. M. (2003). Stress and plasticity in the limbic system. Neurochemical Research, 28(11), 1735 1742.

Sava, S., \& Yurgelun-Todd, D. A. (2008). Functional magnetic resonance in psychiatry. Top Magnetic Resonance Imaging, 19(2), 71-79.

Savitz, J. B., \& Dreets, W. C. (2009). Imaging Phenotipes of Maor Depressive Disorder: Genetic Correlates. Neuroscience, 164(1), 300-330.

Scarabino, T., Salvolini, U., DiSalle, F., Duvernoy, H., \& Rabischong, P. (2006). Atlas of Morphology and Functional Anatomy of the Brain. Berlin: Springer.

Scheidhauer, K., Walter C., \& Seemann, M. (2004). FDG PET and other imaging modalities in the primary diagnosis of suspicious breast lesions. European Journal of Nuclear Medicine and Molecular Imaging, 31(1), 70-79. 
Scheline, Y. I., Mittler, B. L., \& Mintun, M. A. (2002). The hippocampus and depression. European Psychiatry, 17(3), 300-305.

Scherk, H. (2007). Hippocampus and amygdala in imaging for bipolar affective disorder. Nervenarzt, $78(2), 242-242$.

Scherk, H., Reith, W., \& Falkai, R. (2004). Changes in brain structure in bipolar affective disorders. Nervenarzt, 75(9), 861-8782.

Schiemann, T., Tiede, U., \& Höhne, K. H. (1996). The Visible Human within the VOXEL-MAN framework. The Visible Human Project Conference Proceedings, 7-8, [CD-ROM].

Schirner, M., Menrad, A., Stephens, A., Frenzel, T., Hauff, P., \& Licha, K. (2004). Molecular imaging of tumor angiogenesis. Annals of New York Academy of Science, 1014, 67-75.

Schneider, M., Retz, W., Coogan, A. Thome J, \& Rösler, M. (2006). Anatomical and functional brain imaging in adult attention-deficit/hiperactiity disorder (ADHD)- A neurological view. European Archives of Psyquiatry and Clinical neuroscience, 256 (s1), 32-41.

Schroeter, M. L., Stein, T., Maslowski, N., \& Neumann, J. (2009). Neural correlates of Alzheimer's disease and mild cognitive impairment: A systematic and quantitative metaanalysis involving 1351 patients. Neuroimage, 47(4), 1196-1206.

Schulder, M., Semas, T. J., \& Karimi, R. (2003). Thalamic stimulation in patients with multiple sclerosis: Long-term follow-up. Stereotactic and functional neurosurgery, 80(1-4), 48-55.

Schultz, R. T. (2005). Developmental deficits in social perception in autism: the role of the amygdala and fusiform face area. International Journal of Developmental Neuroscience, 23,125-141.

Schulz, K. P., Tang, C. Y., Fan, J., Marks, D. J., Cheung, A. M., Newcorn, J. H., \& Halperin, J. M. (2005). Differential prefrontal cortex activation during inhibitory control in adolescents with and without childhood attention-deficit/hyperactivity disoder. Neuropsychology, 19(3), 390-402.

Schumann, C. M., \& Amaral, D. G. (2006). Stereological Analysis of Amygdala Neuron Number in Autism. Journal of Neuroscience, 26(29), 7674-7679.

Schumann, C. M., Hamstra, J.,Goodlin-Jones, B. L., Lotspeich, L. J., Kwon, H., Buonocore, M. H., . . . Amaral, D. G. (2004). The amygdala is enlarged in children but not adolescents with autism; the hippocampus is enlarged at all ages. Journal of Neuroscience, 24, 6392-6401.

Sechrest, R. C. (1995). Looking at the Visible Man. World's first digital human body reference is now available on the Internet. Today's OR Nurse, 17(5), 13-14.

Seidman, L. J., Pantelis, C., Keshavan, M. S., Faraone, S. V., Goldstein, J. M., Horton, N. J., .. . Tsuang, M. T. (2003). A review and new report of medial temporal lobe dysfunction as a vulnerability indicator for schizophrenia: A magnetic resonance imaging morphometric family study of the parahippocampal gyrus. Schizophrenia Bulletin, 29(4), 803-830.

Seifert, M. D., \& Carmichael, S. W. (2006). Special issue on Visible Human Projects [editorial]. Clinical Anatomy, 19(3), 191-191 
Senger, S. (1996). Incorporating visible human project data into the undergraduate anatomy and physiology curriculum. Stud Health Technology Information, 29, 194-203.

Seoung, Y. H., Kim, H. M., Cho, S. B., Hong, S. W., Woo, D. C., \& Choe, B. Y. (2010). Evaluation of the Corpus Callosum of Patient with Alzheimer's Disease by Using Magnetic Resonance Diffusion Tensor Imaging. Journal of the Korean Physical Society, 57(5), 1257-1262.

Serene, J. A., Ashtari, M., Szeszko, P. R., \& Kumra, S. (2007). Neuroimaging studies of children with serious emotional disturbances: A selective review. Canadian Journal of Psychiatry, 52(3), 135-145.

Servera, F. A., Quaranta, A. C., Markarian, M. F., \& Nagel, J. R. (2005). Relación entre los valores de prolactina plasmática y las imágenes de hipófisis obtenidas en RM, LI Congreso Argentino de Radiología.

Serra, L. Cercignani, M., Lenzi, D., Perri, R., Fadda, L., Caltagirone, C., . . Bozzali, M. (2010). Grey and White Matter Changes at Different Stages of Alzheimer's Disease. Journal of Alzheimers Disease, 19(1), 147-159.

Sharma, N., \& Aggarwal, L. M. (2010). Automated medical image sementation techniques. Journal of Medical Physics, 35(1), 3-14.

Sharma, S., \& Ebadi, M. (2008). SPECT neuroimaging in translational research of CNS disorders. Neurochemistry International, 52(3), 352-362.

Shattuck, D. W., Mirza, M., Adisetiyo, V., Hojatkashani, C., Salamon, G., Narr, K. L., . . Toga, A. W. (2008). Construction of a 3D Probabilistic Atlas of Human Cortical Structures. Neuroimage, 39(3), 1064-1080.

Shaw, P. (2007). Intelligence and the developing human brain. Bioessays, 29(10), 962-973.

Sheline, Y. I., Mittler, B. L., \& Mintun, M. A. (2002). Hippocampus and depression. European Psychiatry, $17(3), 300-305$.

Shelton, D., Stetten, G., Aylward, S., Ibánez, L., Cois, A., \& Stewart, C. (2005). Teaching medical image analysis with the Insight Toolkit. Medical Image Analysis, 9(6), 605-611.

Sheridan, M. A., Hunshaw, S., \& D’Esposito, M. (2007). Efficiency of the prefrontal cortex during working memory in attention deficit/hyperactivity disorder. Journal of the American Academy of Child and Adolescent Psychiatry, 46(10), 1357-1366.

Sherman, S.M. (2007). The thalamus is more than just a relay. Current Opinion in Neurobiology, 17(4), 417-422.

Sherrington, C. S. (1906). The integrative action of the nervous system. New Haven: Yale University Press.

Shin, L. M., \& Liberzon, I. (2010). The neurocircuitry of fear, stress, and anxiety disorders. Neuropsychopharmacology, 35(1), 169-191.

Siever, L. J. (2008). Neurobiology of aggression and violence. American Journal of Psychiatry, 165(4), $429-442$. 
Silén, C., Wirell, S., kvist, J., Nylander, E., \& Smedby, O. (2008). Advanced 3D Visualization in StudentCentred Medical Education, Medical Teacher, 30, 115-124.

Silverstone, P. H., McGrath, B. M., \& Kim, H. (2005). Bipolar disorder and myo-inositol: a review of the magnetic resonance spectroscopy findings. Bipolar Disorders, 7, 1-10.

Sismanlar, S. G., Anik, Y., Coskun, A., Agaoglu, B., Karakaya, I., \& Yavuz, C. I. (2010). The volumetric differences of the fronto-temporal region in young offspring of schizophrenic patients. European child and adolescent psyquiatry, 19(2), 151-157.

Skuse, D. H. (2006). Genetic influences on the neural basis of social cognition. Philosophical Transactions of the Royal Society of London. Series B. Biological Sciences, 361(1476), 2129-2141.

Slavin, K. V. (1997). The Visible Human Project. Surgical Neurology, 48(6):638-639.

Smieskova, R., Fusar-Poli, P., Alien, P., Bendfeldt, K., Stieglitz, R. D., Drewe, J., . . Borgwardt, S. J. (2010). Neuroimaging predictors of transition to psychosis. A systematic review and meta-analysis. Neuroscience and Biobehavioral Reviews, 3488, 1297-1222.

Snell, R. S. (2008). Clinical Anatomy by Regions. Philadelphia: Lippincott Williams y Wilkings.

Snell, R. S. (2009). Clinical neuroanatomy. Philadelphia: Lippincott Williams y Wilkings.

Solis, J., Sitges, M., Levine, R. A., \& Hung, J. (2009). Ecocardiografía tridimensional. Nuevas perspectivas sobre la caracterización de la válvula mitral, Revista Española de Cardiología, 62, 188-98.

Somerville, L. H., Kim, H., Johnstone, T., Alexander, A., \& Whalen, P. J. (2004). Human Amygdala Responses During Presentation of Happy and Neutral Faces: Correlations with State Anxiety. Biological Psychiatry, 55, 897-890.

Soper, H. V. (2008). A Review of: "Woolsey, T., Hanaway, J., \& Gado, M. (2008). The Brain Atlas: A Visual Guide to the Human Central Nervous System, 3rd Ed.’', Applied Neuropsychology, 15(4), 298299.

Sparks, B. F., Friedman, S. D., Shaw, D. W., Aylward, E. H., Echelard, D., Artru, A. A., . . Dager, S. R. (2002). Brain structural abnormalities in young children with autism spectrum disorder. Neurology, 59, $184-192$.

Sperlling, J. M., Prvulovic, D., Linden, D. E., Singer, W., \& Stirn, A. (2006). Neuronal correlates of colourgraphemic synaesthesia: a fRMI study. Cortex, 42(2), 295-303.

Sperry, R. W. (1968). Hemisphere Deconnection and Unity in Conscious Awareness. American Psychologist, 23, 723-733.

Spitzer, V. M. (1997). The visible human: a new language for communication in health care education. Caduceus, 13(2), 42-48.

Spitzer, V. M., Ackerman, M. J., Scherzinger, A. L., \& Whitlock, D. (1996). The visible human male: a technical report. Journal of the American Medical Informatics Association, 3(2), 118-30. 
Spitzer, V. M., \& Scherzinger, A. L. (2006). Virtual anatomy: An anatomist's playground. Clinical Anatomy, 19(3), 192-203.

Spitzer, V. M., \& Whitlock, D. G. (1998). The Visible Human Dataset: the anatomical platform for human simulation. Anatomical Record, 253(2), 49-57.

Standring, S. (2005). Gray's Anatomy (39th ed.). London: Elsevier Churchill Livingstone.

Stanfield, A. C., McIntosh, A. M., Spencer, M. D., Philip, R., Gaur, S., \& Lawrie, S. M. (2008). Towards a neuroanatomy of autism: A systematic review and meta-analysis of structural magnetic resonance imaging studies. European Psychiatry, 23(4), 289-299.

Stathis, P., Panourias, I. G., Themistocleous, M. S., \& Sakas, D. E. (2007). Connections of the basal ganglia with the limbic system: implications for neuromodulation therapies of anxiety and affective disorders. Acta Neurochirurgica Supplement, 7(2), 575-586.

Stein, D. J., Phillips, K. A., Bolton, D., Fulford, K. W. M., Sadler, J. Z., \& Kendler, K. S. (2010). What is a mental/psychiatric disorder? From DSM-IV to DSM-V. Psychological Medicine, 1-7.

Stephan, K. E., Baldeweg, T., \& Friston, K. J. (2006). Synaptic plasticity and dysconnection in schizophrenia. Biological Psychiatry, 59, 929-939.

Stephens, B., Temkin, B., Krummel, T. M., \& Heinrichs, W. L. (2000). Virtual body structures: a 3D structure development tool from visible human data. Stud Health Technology Information, 70, 323-326.

Stoll, A., Renshaw, P., Yurgelun-Todd, D., \& Cohen, B. (2000). Neuroimaging in bipolar disorder: what have we learned?. Biological Psychiatry, 48(6), 505-517.

Strakowski, S. M., Delbello, M. P., \& Adler, C. M. (2005). The functional neuroanatomy of bipolar disorder: a review of neuroimaging findings. Molecular Psychiatry, 10, 105-116.

Strakowski, S.M., DelBello, M.P., Zimmerman, M.E., Getz, G.E., Mills, N.P., Ret, J., . . Adler, C. M. (2002). Ventricular and periventricular structural volumes in first- vs multiple-episode bipolar disorder. American Journal of Psychiatry, 159, 1841-1847.

Strakowski, S. M., DelBello, M. P., Adler, C., Cecil, K. M., \& Sax, K.W. (2000). Neuroimaging in bipolar disorder. Bipolar Disorders, 2, 148-164.

Strasser, H. C., Lilyestrom, J., Ashby, E. R., Honeycutt, N. A., Schretlen, D. J., Pulver, A. E., .. Pearlson, G. D. (2005). Hippocampal and ventricular volumes in pschotic and nonpsychotic bipolar patients compared with schizophrenia patients and comunity control subjects: a pilot study. Biological psychiatry, 15(6), 633-639.

Sudarsanan, B. S., Chaudhary, C. S., Pawar, A. A., \& Srivastava, K. (2007). Psychiatric Effects of Traumatic Brain Injury. Medical Journal Armed Forces India, 63(3), 2007.

Sugand, K., Abrahams, P., \& Khurana, A. (2010), The anatomy of anatomy: A review for its modernization. Anatomical Sciences Education, 3, 83-93. 
Summers, D. (2003). Harvard Whole Brain Atlas: www.med.harvard.edu/AANLIB/. Journal of Neurology, Neurosurgery and Psychiatry, 74(3), 288.

Surguladze, S. A., Brammer, M. J., Young, A. W., Andrew, C., Travis, M. J., Williams, S. C., \& Phillips M. L. (2003). A preferential increase in the extrastriate response to signals of danger. Neuroimage, 19, 1317-1328.

Sutherland, C, S., Kelly, J. J. P., Morrish, W., \& Sutherland, G. R. (2010). Identification of Disappearing Brain Lesions with intraoperative MRI Prevents Surgery. Neurosurgery, 67(4), 1061-1065.

Sutherland, G. R., Latour, I., \& Greer, A. D. (2008). Integrating an image guided robot with intraoperative MRI: A review of design and construction. IEEE Engineering in Medicine and Biology, 27, 59-65.

Sutherland, G. R., Newhook, P., Feil, G., Fielding, T., Greer, A. D., \& Latour, I. (2008). An image-guided MR compatible surgical robot. Neurosurgery, 62, 286-293.

Szeszko, P. R., Robinson, D. G., Ashtari ,M., Vogel, J., Betensky, J., Sevy, S., . . Bilder, R. M. (2008). Clinical and neuropsychological correlates of white matter abnormalities in recent onset schizophrenia. Neuropsychopharmacology, 33, 976-984.

Takahashi, T., Yücel, M, Lorenzetti, V., Nakamura, K., Whittle, S., Walterfang, M., . . Allen, N. B, (2009). Midline brain structures in patients with current and remitted major depression. Progress in Neruo-Psychofarmacology and Biological Psyquiatry, 33(6), 1058-1063.

Talairach, J., \& Tourneau, P. (1988). Co-Planar Stereotaxic Atlas of the Human Brain: 3-Dimensional Proportional System: An Approach to Cerebral Imaging. Thieme Medical Publishers: New York.

Talos, I., Jakab, M., Kikinis, R., \& Shenton, M. (2008). SPL-PNL Brain Atlas. Boston: Harvard Medical School.

Tamura, R., Kitamura, H., Hasegawa, N., \& Someya, T. (2010). Reduced thalamic volume observed across different subgroups of autism spectrum disorders. Psychiatry Research. Neuroimaging, 184(3), 186188.

Tanji, J., Shima, K., \& Mushiake, H. (2007). Concept-based behavioral planning and the lateral prefrontal cortex. Trends in Cognitive Sciences, 11(12), 528-534.

Tanskanen, P., Ridler, K., Murray, G. K., Haapea, M., Veijola, J. M., Jaaskelainen, E., . . Isohanni, M. K. (2010). Morphometric Brain Abnormalities in Schizophrenia in a Population-Based Sample: Relationship to Duration of Illness. Schizophrenia Bulletin 36(4), 766-777.

Temkin, B., Acosta, E., Hatfield, P., Onal, E., \& Tong, A. (2002). Web-based three-dimensional Virtual Body Structures: W3D-VBS. Journal of the American Medical Informatics Association, 9(5), 425-436.

Temkin, B., Acosta, E., Malvankar, A., \& Vaidyanath, S., (2006). An interactive three-dimensional virtual body structures system for anatomical training over the internet. Clinical Anatomy, 19(3). 267-274.

Thakkar, K. N., Polli, F. E., Joseph, R. M., Tuch, D.S., Hadjikhani, N., Barton, J.J.S., \& Manoach, D.S. (2008). Response monitoring, repetitie behaviour and anterior cingulate abnormalities in autism spectrum disorders (ASD). Brain, 131, 2464-2478. 
Théberge, J. (2008). Perfusion magnetic resonance imaging in psychiatry. Top Magnetic Resonance Imaging, 19(2), 111-30.

Todtenkopf, M. S., Vincent, S. L., \& Benes, F. M. (2005). A cross-study meta-analysis and threedimensional comparison of cell counting in the anterior cingulate cortex of schizophrenic and bipolar brain. Schizophrenia Research, 73(1), 79-89.

Toga, A. W. (2005). Computational biology for visualization of brain structure. Anatomical Enbryology, $210,433-438$.

Toga, A. W., \& Thomson, P. M. (2000). Image Registration and the Construction of Multidimensional Brain Atlases. Handbook of Medical Imaging.

Toh, M., Ackerman, M. J., \& Main, J. S., (1995). Interactive Brain Atlas with the "Visible Human Project" Data. Radiological Society of North America Annual Conference.

Toh, M., Banvard, R., Ackerman, M., Rodgers, R., \& Main, J. S., (1996). The Visible Human Project Web Page. Radiographics, 16, 1201-1206.

Toh, M., Falk, R. B., Horowitz, C. J., \& Main, J. S. (1995). Three-dimensional visualization of the "Visible Human-Project" data. Radiology, 197, 533.

Toh, M., Falk, R. B., Horowitz, C. J., \& Main, J. S., (1996). Digital Brain Atlas Using the "Visible Human Project" Data. Visible Human Project Conference.

Tokuda, J., Fischer, G. S., DiMaio, S. P., Gobbi, D. G., Csoma, C., Mewes, P. W., . . Hata, N. (2010). Integrated navigation and control software system for MRI-guided Robotic Prostate Interventions. Computerized Medical Imaging Graphics, 34(1), 3-8.

Tomimoto, H., Lin, J.X., Matsuo, A., Ihara, M., Ohtani, R., Shibata, M., . . Shibasaki, H. (2004). Different mechanisms of corpus callosum atrophy in Alzheimer's disease and vascular dementia. Journal of neurology, 251(4), 398-406.

Tordesillas-Gutierrez, D., Glahn, D. C., Franklin, C., Barret, J., Caetano, S. C., Soares, J. C., \& Fox, P. T. (2006). Structural study of the hippocampus in bipolar disoder: Comparison between euthymic patients and healthy subjects. Biological Psychiatry, 59(8), 81-81.

Tory, M., Moller, T., Atkins, M. S., \& Kirkpatric, A. E. (2004). Combining 2D and 3D views for orientation and relative position tasks. Proceedings of the SIGCHI conference on Human factors in computing systems, 176-182.

Treichler, P. A., Cartwright, L., . . Penley, C. (1998). The visible woman: imaging technologies, gender and science. New York: New York University Press.

Tripp, G., \& Wickens, J. R. (2009). Neurobiology of ADHD. Neuropharmacology, 57(7-8), 579-589.

Trotts, I., Mikula, S., \& Jones, E. G. (2007). Interactive Visualization of Multiresolution Image Stacks in 3D. Neuroimage, 35(3), 1038-1043. 
Trovar-Moll, F., Evangelou, I. E., Chiu, A. W., Richert, N. D., Ostuni, J. L., Ohayon, J. M., . . Bagnato, F. (2009). Thalamic Involvement and Its Impact on Clinical Disability in Patients with Multiple Sclerosis: A Diffusión Tensor Imaging Study at 3T. American Journal of Neuroradiology, 30(7), 1380-1386.

Tuch, D. S., Reese, T. G., Wiegell, M. R., \& Wedeen, V. J. (2003). Diffusion MRI of complex neural architecture. Neuron, 40(5), 885-895.

Tupler, L. A., \& De Bellis, M. D. (2006). Segmented hippocampal volume in children and adolescents with posttraumatic stress disoder. Biological Psychiatry, 59(6), 523-529.

Turk, D. J., Heatherton, T. F., Kelly, W. M., Funell, M. G., Gazzaniga, M. S., \& Macrae, C. N. (2002). Mike or me? Self-recognition in a split-brain patient. Nature neuroscience, 5(9), 841-842.

Turner, R., \& Jones, T. (2003). Techniques for imaging neuroscience. British Medical Bulletin, 65, 3-20.

Turney, W. (2007). Anatomy in a modern medical curriculum. Annals of the Royal College of Surgeons of England, 89(2), 104-107.

Uchino, A., Takase, Y., Nomiyama, K., Egashira, R., \& Kudo, S. (2006). Adquired lesions of the corpus callosum: MR Imaging. European Radiology, 16(4), 905-514.

Uddin, L. Q., \& Menon, V. (2009). The anterior insula in autism: Under-connected and under-examined. Neuroscience and Biobehavioral Reviews, 33(8), 1198-1203.

Ulay, H. T., \& Ertugrul, A. (2009). Neuroimaging Findings in Autism: A Brief Review. Turk Psikiyatri Dergisi, 20(2), 164-175.

Usher, J., Menzel, P., Schneider-Axmann, T., Kemmer, C., Reith, W., Falkai, P., . . Scherk, H. (2010). Increased right amígdala volumen in lithium-treated patients with bipolar I disorder. Acta Psychiatrica Scandinavica, 121(2), 119-124.

Vaidyanath, S., \& Temkin, B. (2006). Registration and Segmentation for the High Resolution Visible Human Male Images. Studies in Health Technology and Informatics, 119, 556-558.

Valencia-Calderón, C., Calderón-Valdiviezo, A., Muntané-Sánchez, A. Bechich, S., Oliveró-Rigau, R., \& Segura-Cros, C. (2009). Descripción y Fundamentos de la SPECT y la PET en el Diagnóstico de la Enfermedad Cerebrovascular. Revista ecuatoriana de neurología.

Valentini, V., Dinapoli, N., Nori, S., Mattiucci, G. C., Mantello, G., Marucci, L., . . Cellini, N. (2004). An application of visible human database in radiotherapy: tutorial for image guided external radiotherapy (TIGER). Radiotherapy and Oncology, 70(2), 165-169.

Van den Eynde, F., \& Treasure, J. (2009). Neuroimaging in Eating Disorders and Obesity: Implications for Research. Child and Adolescent Psyquiatric Clinics of North America, 18(1), 95-115.

Van den Heuvel, O. A., van der Werf, Y. D., Verhoef, K. M., de Wit, S., Berendse, H. W., Wolters, E. C., . .. Groenewegen, H. J. (2010). Frontal-striatal abnormalities underlying behaviours in the compulsiveimpulsive spectrum. Journal of the neurological sciences, 289(1-2),55-59. 
Van den Heuvel, O. A., Veltman D. J., Groenewegen, H. J., Cath, D. C., van Balkom A. J. L. M., van Hartskamp, J., . . van Dyck, R. (2005). Frontal-striatal dysfunction during planning in obsessivecompulsive disorder. Archives of general psychiatry, 62(3), 301-309.

Van der Kolk, B. A. (1997). The psychobiology of posttraumatic stress disorder. Journal of Clinical Psyquiatry, 58(9), 16-24.

Vang, F. J., Ryding, E., Traskman-Bendz, L., van Westen, D., \& Lindstrom, M. B. (2010). Size of basal ganglia in suicide attempters, and its association with temperament and serotonin transporter density. Psychiatry Research. Neuroimaging, 183(2), 177-179.

Van Kuyck, K., Gerard, N., Van Laere, K., Casteels, C., Pieters, G., Gabriels, L., \& Nuttin, B. (2009). Towards a neurocircuitry in anorexia nervosa: Evidence from functional neuroimaging studies. Journal of Psychiatric Research, 43(14), 1133-1145.

Van Tol, M. J., van der Wee, N. J. A., van den Heuvel, O.A A., Nielen, M. M. A., Demenescu, L. R., Aleman, A., .. V Veltman, D. J. (2010). Regional brain volume in depression and anxiety disorders. Archives of General Psychiatry, 67(10), 1002-1011.

Vedeniapin, A., Cheng, L., \& George, M. S. (2010). Feseability of simultaneous cognitive behavioral therapy and left prefrontal TMS for treatment resistant depression. Brain Stimulation, 3(4), 2017-210.

Venali, F., Deveze, A., Lallemant, B., Guevara, N., \& Mondain, M. (2010). Enhancement of temporal bone anatomy learning with computer 3D rendered imaging softwares. Medical Teacher, 32(7), 282-288.

Venkatasubramanian G, Jayakumar, P. N., Gangadhar, B. N., \& Keshavan, M. S. (2008). Automated MRI parcellation study of regional volume and thickness of prefrontal cortex (PFC) in antipsychoticnaive schizophrenia. Acta Psychiatrica Scandinavica, 117,420-431.

Verhoeven, J. S., De Cock, P., Lagae, L., \& Sunaert, S. (2010). Neuroimaging of autism. Neuroradiology, $52(1), 3-14$

Visser-Vandewalle, V., van der Linden, C., Temel, Y., Celik, H., Ackermans, L., Spincemaille, G., \& Caemaert, J. (2005). Long-term effects of bilateral subthalamic nucleus stimulation in advanced Parkinson disease: a four year follow-up study. Parkinsonism Related Disorders, 11(3), 157-165.

Vogt, B. A. (2005). Pain and emotion interactions in subregions of the cingulate gyrus. National Review of Neuroscience, 6(7), 533-544.

Walterfang, M., Yung, A., Wood, A. G., Reutens, D. C., Phillips, L., Wood, S. J., . . Pantelis, C. (2008). Corpus callosum shape alterations in individuals prior to the onset of psychosis. Schizophrenia Research, 103(1-3), 1-10.

Wang, J. N., Ekin, A., \& de Haan, G. (2008). Shape Analysis of Brain Ventricles for Improved Classification of Alzheimer's Patients. IEEE International Conference on Image Processing, 22522255 .

Warren, S., \& Warren, K. G. (2001). Multiple sclerosis. Geneva: World Health Organization. 
Weinberger, D. R. (1984). Brain disease and psychiatric illness: when should a psychiatrist order a CAT scan? American Journal of Psyquiatry, 141(12), 1521-1527.

Weniger, G., Lange, C., \& Irle, E. (2006). Abnormal size of the amygdala predicts impaired emotional memory in major depressive disorder. Journal of Affective Disorders, 94(1-3), 219-229.

Wernicke, C. (1874). The symptom complex of aphasia. Proceedings Boston Colloquium for Philosophy of Science, 4, 34-97.

Wetjen, N. M., Cohen-Gadol, A. A., Maher, C. O., Marsh, W. R., Meyer, F. B., \& Cascino, G. D. (2002). Frontal lobe epilepsy: diagnosis and surgical treatment. Neurosurgical Review, 25(3), 119-138.

Wexler, B. E., Zhu, H. T., Bell, M. D., Nicholis, S. S., Fulbright, R. K., Gore, J. C., . . Peterson, B. S. (2009). Neuropsychological Near Normality and Brain Structure Abnormality in Schizophrenia. American Journal of Psychiatry, 166(2), 189-195.

Whalen, P. J., Kaga, J., Cook, R. G., Davis, F. C., Kim, H., Polis, S., . . Johnstone, T. (2004). Human amygdala responsivity to masked fearful eye whites. Science, 306, 2061.

Whalen, P. J., Shin, L. M., McInerney, S. C., Fischer, H., Wright, C. I., \& Rauch, S. L. (2001). A functional MRI study of human amygdala responses to facial expressions of fear versus anger. Emotion, 1, 70-83.

White, T., Cullen, K., Rohrer, L. M., Karatekin, C., Luciana, M., Schmidt, M., . . Lim, K. O. (2008). Limbic structures and networks in children and adolescents with schizophrenia. Schizophrenia Bulletin, 34(1), 18-29.

White, T. P., Joseph, V., Francis, S. T., \& Liddle, P. F. (2010). Aberrant Saliece Network (biateral insula and anterior cingulate cortex) Connectivity During Information Processing in Schizophrenia. Schizophrenia Research, 123(2-3), 105-115.

Williams, L. M., Das, P., Harris, A. W. F., Liddell, B. B., Brammer, M. J., Olivieri, G., . . Gordon, E. (2004). Dysregulation of arousal and amygdala-prefrontal systems in paranoid schizophrenia. American Journal of Psychiatry, 161, 480-489.

Williams, M. A., Morris, A. P., McGlone, F., Abbott, D. F., \& Mattingley, J. B. (2004). Amygdala responses to fearful and happy facial expressions under conditions of binocular suppression. Journal of Neuroscience, 24, 2898-2904.

Williams, M. A., McGlone, F., Abbott, D. F, \& Mattingley, J. B. (2005). Differential amygdala responses to happy and fearful facial expressions depend on selective attention. Neuroimage, 24, 417-425.

Williams, L. M, Phillips, M. L., Brammer, M. J., Skerrett, D., Lagopoulos, J., Rennie, C., .. Gordon, E. (2001). Arousal dissociates amygdala and hippocampal fear responses: evidence from simultaneous fMRI and skin conductance recording. Neuroimage, 14, 1070-1079.

Wilson, C. R. E., Gaffan, D., Browning, P. G. F., \& Baxter, M. G. (2010). Functional localization within the prefrontal cortex: missing the forest for the trees?. Trends in Neurosciences, 33(12), 533-540.

Windsor, J. A., Diener, S., \& Zoha, F. (2008). Learning style and laparoscopic experience in psychomotor skill performance using a virtual reality surgical simulator. American Jorunal of Surgery, 195, 837-842. 
Witthaus, H. Mendes, U. Brüne, M., Özgürdal, S., Bohner, G., Gudlowski, Y., . . Juckel, G. (2010). Hippocampal subdivision and amygdalar volumes in patients in an at-risk mental state for schizophrenia. Journal of Psychiatry and Neuroscience, 35(1), 33-40.

Womer, F. Y., Kalmar, J. H., Wang, F., \& Blumberg, H. P. (2009). A ventral prefrontal-amygdala neural system in bipolar disorder: a view from neuroimaging research. Acta Neuropsychiatrica, 21(5), 228238.

Woolsey, T., Hanaway, J., \& Gado, M. (2008). The Brain Atlas: A Visual Guide to the Human Central Nervous System. New York: Wiley.

World Health Organization [WHO]. (2006). Global burden of neurological disorders: estimates and projections, WHO: Geneva. Acceso el 1 de febrero de 2010 de

http://www.who.int/mental_health/neurology/chapter_2_neuro_disorders_public_h_challenges.pdf

Wright, I. C., Rabe-Hesketh, S., Woodruff, P., David, A. S., Murray, M., \& Bullmore, E. T. (2000). Metaanalyses of regional brain volumes in schizophrenia. American Jorunal of Psychiatry,157,16-25.

Wylie, S. A., Ridderinkhof, K. R., Elias, W. J., Frysinger, R. C., Bashore, T. R., Downs, K. E., . . van den Wildenberg, W. P. M. (2010). Subthalamic Nucleus Stimulation Influences Expression and Supression of Impulsive Behaviour in Parkinson's Disease. Brain, 133(12), 3611-3624.

Xi, Z., \& Luning, W. (2009). REM sleep behavior disorder in a patient with pontine stroke. Sleep Medicine, $10(1), 143-146$.

Xia, J., Yang, M. J., Lei, Y., \& Zhou, Y. C. (2010). Neuronal degeneration in the hippocampus and dorsolateral prefrontal cortex in depressive disoders. Correlation between H-A-MRS and Minnesota Multiphasic Personality Inventory. Neural Regeneration Research, 5(20), 1587-1591.

Yang, T. T., Menon, V., Eliez, S., Blasey, C., White, C. D., Reid, A. J., . . Reiss, A. L. (2002). Amygdalar activation associatedwith positive and negative facial expressions. Neuroreport, 13, 1737-1741.

Yela, M. (1969). Manual del test. Desarrollo de superficies (2a edición). TEA Ediciones: Madrid.

Yokoyama, T., Hasegawa, K., \& Yagishita, S. (2010). An Autopsy Case of Multiple Sclerosis with Massive Involment of Basal Ganglia and Thalamus. Brain Pathology, 20(1), 84-84.

Yoo, T. S., \& Metaxas, D. N. (2005). Open science combining open data and open source software: medical image analysis with the Insight Toolkit. Medical Image Analyses, 9(6), 503-506.

Young, P. A. (2001). Neuroanatomía clínica funcional. Masson.

Yu, H., \& Neimat, J. S. (2008), The treatment of movement disorders by deep brain stimulation. Neurotherapeutics, 5(1), 26-36.

Yuan, L., Tang, L., Huang, W. H., Li, J. Y., Dai, J. X., Liu, C., . . Zhong, S. H. (2003). Construction of dataset for Virtual Chinese Male No.1. Academic Journal of the First Medical College of PLA, 23(6), 520-523. 
Yücel, M. Wood, S. J., Fornito, A., Riffkin, J., Velakoulis, D., \& Pantelis, C. (2003). Anterior cingulate dysfunction: implications for psychiatric disorders? Journal of Psychiatry Neuroscience, 28(5), 350354.

Zastrow, A., Kaiser, S., Stippich, C., Walther, S., Herzogn, W., Tchanturia, K., . . Friederich, H. C. (2009). Neural Correlates of Impaired Cognitive-Behavioral Flexibility in Anorexia Nervosa. American Journal of Psychiatry, 166(5), 608-616.

Zavitsanou, K., \& Dalton, V. S. (2010). Paranoid Schizophrenia is Characterised by Increased Cannabinoid CB1 Receptor Binding in the Dorsolateral Prefrontal Cortex. Schizophrenia Research, 117(2-3), 490490 .

Zhang, S. X., Heng, P. A., \& Liu, Z. J. (2006). Chinese visible human project. Clinical Anatomy, 19(3), 204-215.

Zhou, F. Q., Zee, C. S., Gong, H. H., Shiroishi, M., \& Li, J. P. (2010). Differential Changes in Deep and Cortical Gray Matters of Patients With Multiple Sclerosis: A Quantitative Magnetic Resonance Imaging Study. Journal of Computer Assisted Tomography, 34(3), 431-436.

Zhou, R. Henderson, E., \& Seamans, J. (1998). "Visualization of Visible Human Anatomical images (Visualization of anatomical images using the 3DSystems database). Second Visible Human Project Conference Proceedings, 1-2, [CD-ROM].

Zipursky, R. B., Meyer, J. H., \& Verhoeff, N. P. (2007). PET and SPECT imaging in psychiatric disorders. Canadian Journal of Psychiatry, 52(3),146-157

Zivadinov, R., \& Cox, J. L. (2007). Neuroimaging in multiple sclerosis, Neurobiology of Multiple Sclerosis, 79, 449-474. 


\section{Anexo I. Test de desarrollo de superficies}

Instrucciones (adaptado para presentación computarizada de Yela, 1969)

Fíjese en los dibujos que siguen. El dibujo de la izquierda es un trozo de papel que puede doblarse por las líneas de puntos de formar el cuerpo geométrico de la derecha. El papel debe doblarse de modo que la cara X esté en la indicada en la figura. Cuando se dobla el papel de este modo, ¿Dónde estará la línea de puntos 1 en la figura? Será el borde C.
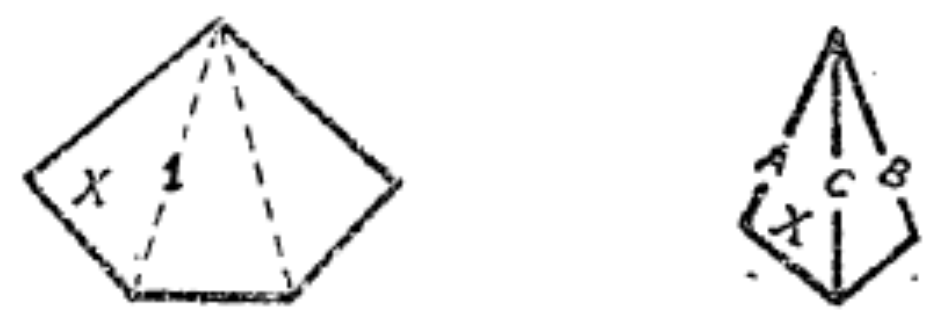

En el ejemplo siguiente, el dibujo puede doblarse para formar la figura de la derecha, de modo que la cara X caiga en la posición indicada. Si hacemos esto, ¿dónde estarán en la figura los bordes y la cara marcados con números? Para responder haga click en la letra que corresponda con cada número. La primera pregunta está ya contestada. Frente al 1 se haría click en $\mathrm{B}$, porque el borde 1 del dibujo es el borde $\mathrm{B}$ de la figura. Conteste Vs las demás preguntas.

Ejemplo
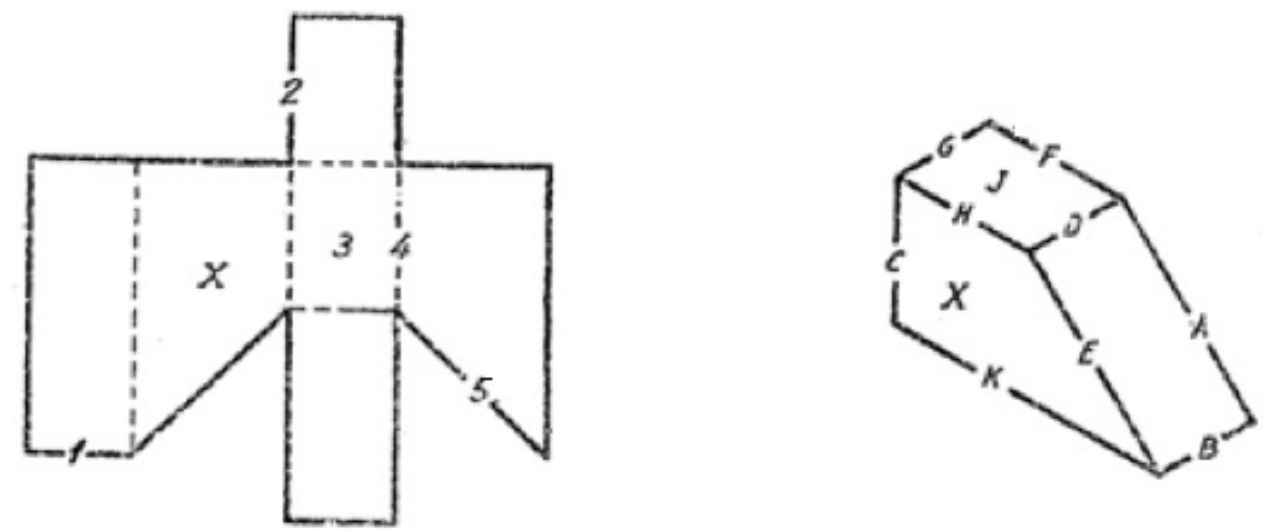

Hay 12 problemas como éste. Recuerde que la cara X está siempre señalada en los dos dibujos. Para continuar, haga click en continuar y resuelva el mayor número posible de problemas en los 14 minutos de tiempo límite. 
Figura 1
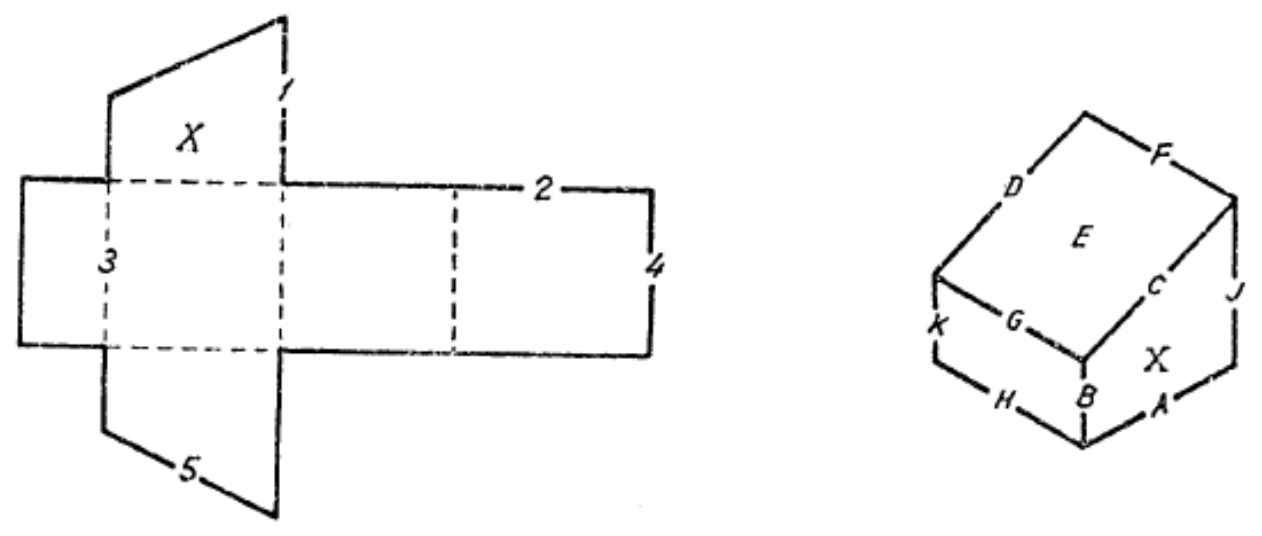

Figura 2
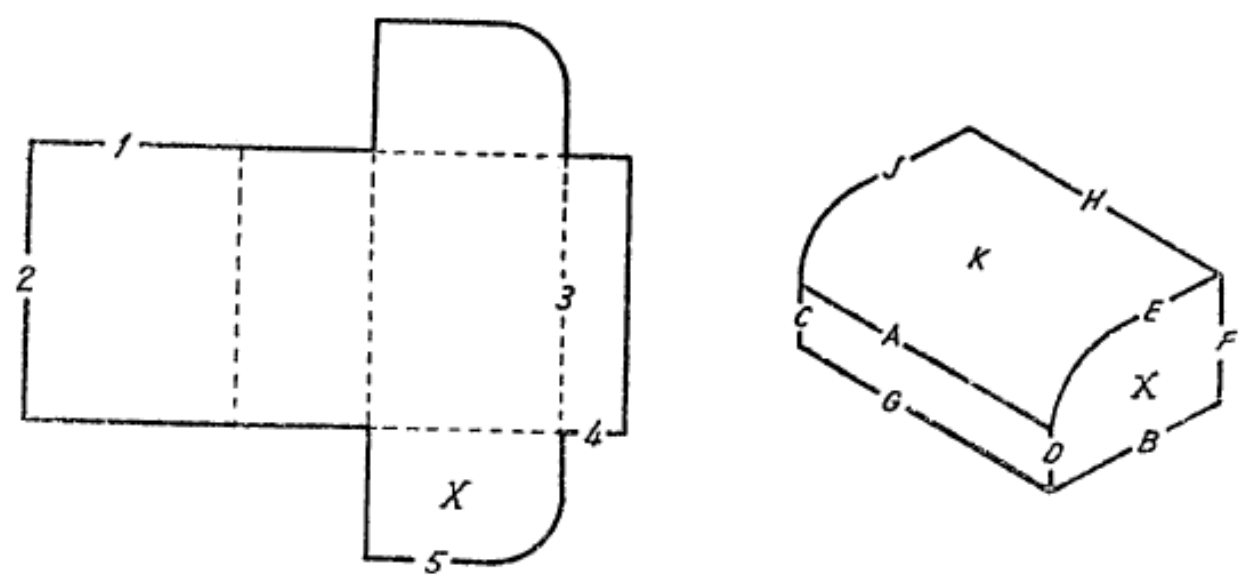

Figura 3
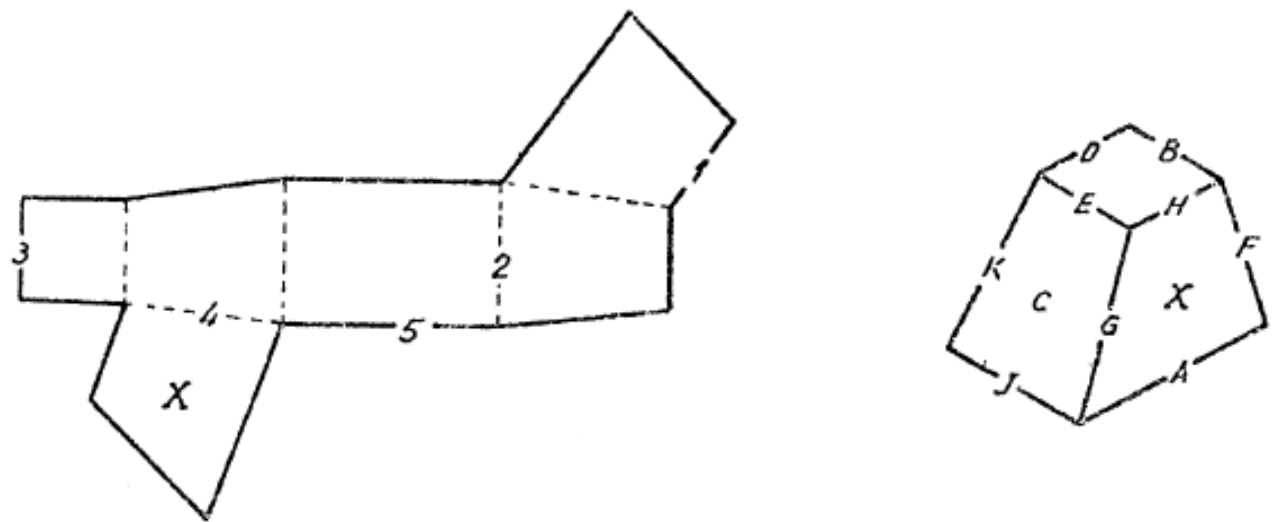

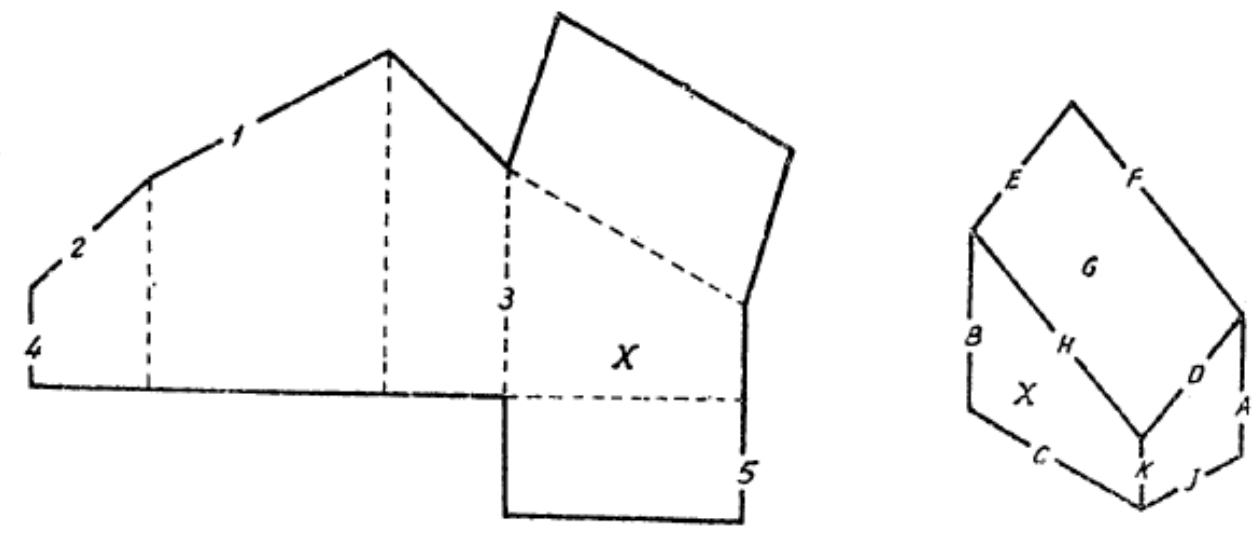

Figura 5
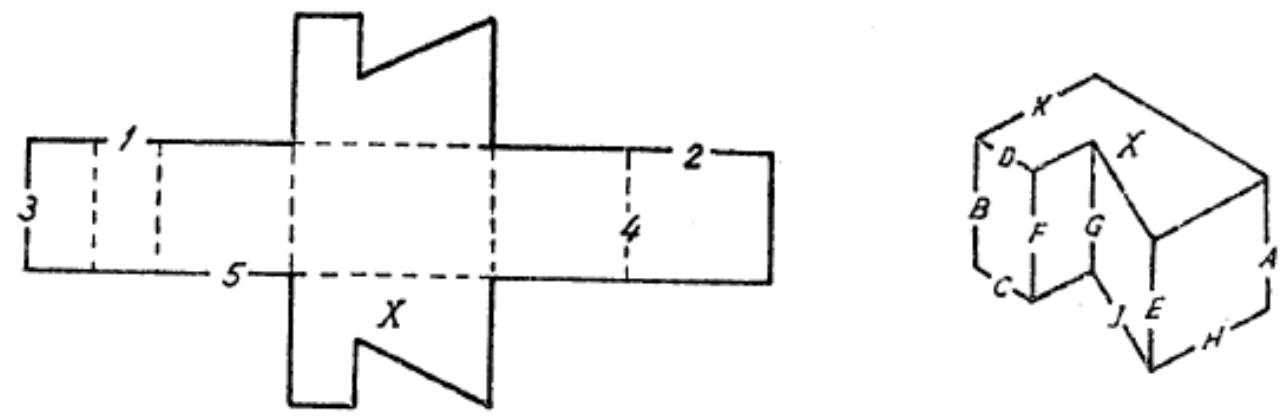

Figura 6
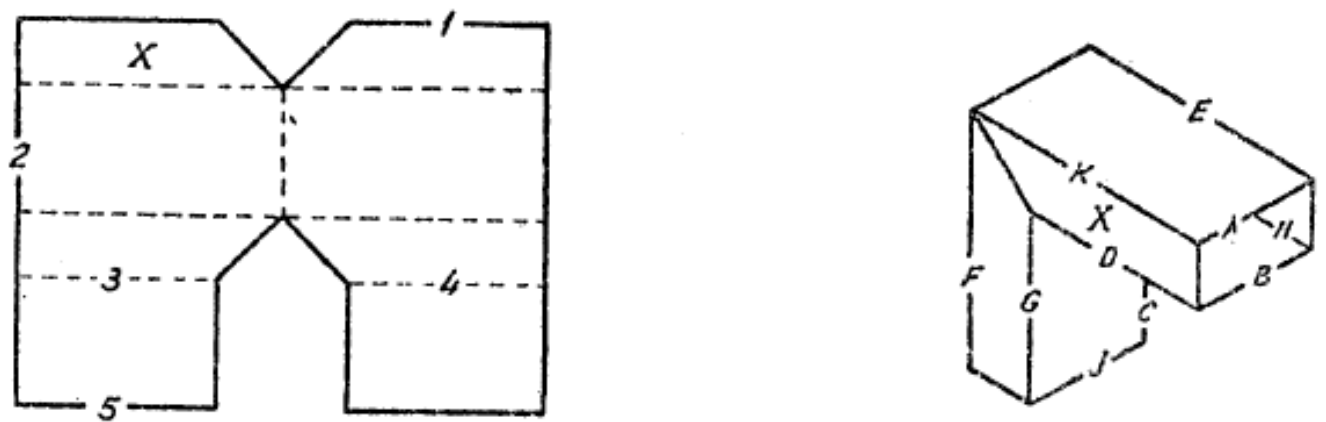

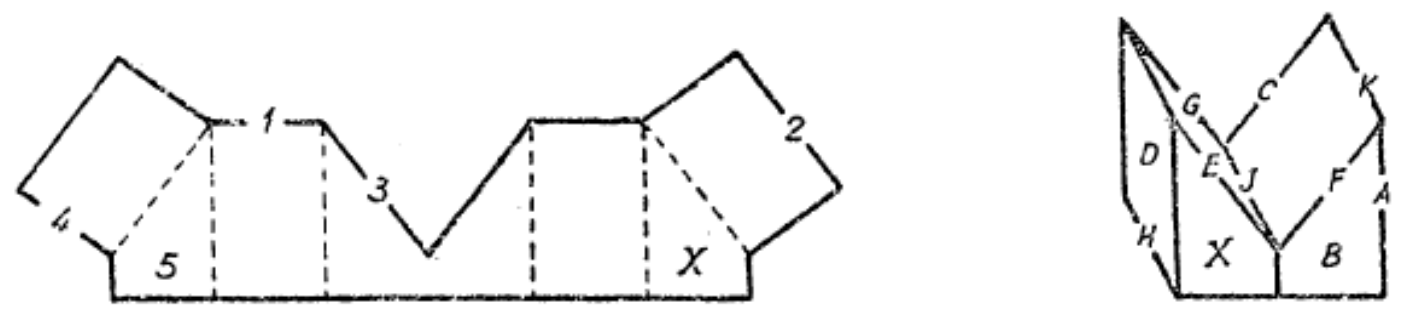

Figura 8
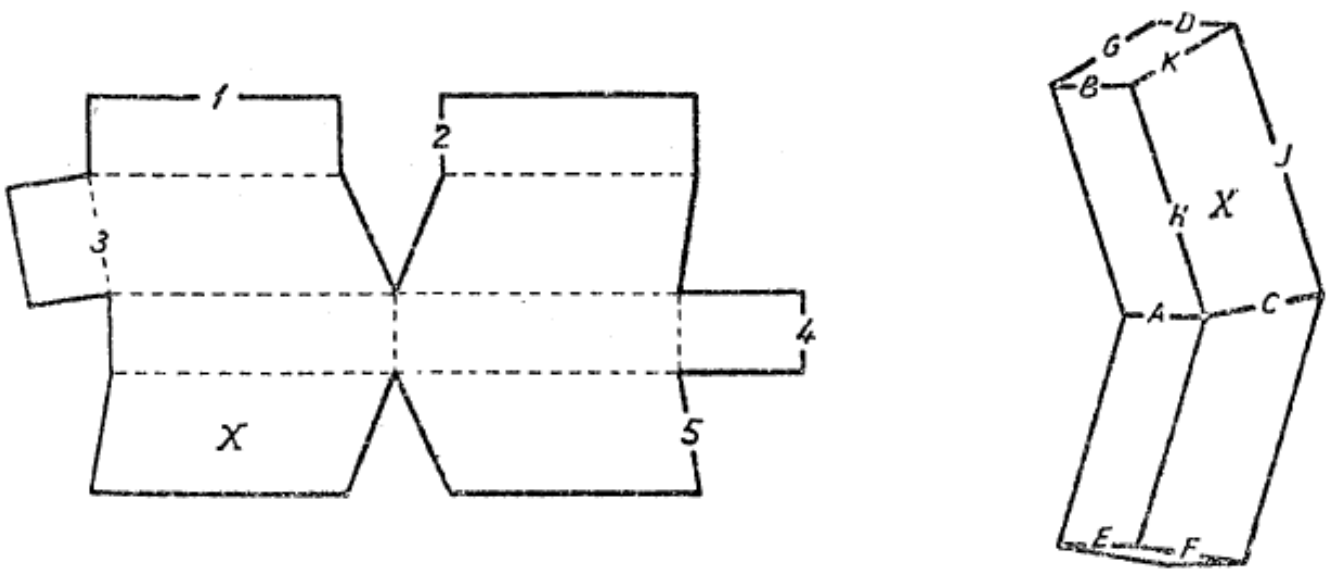

Figura 9
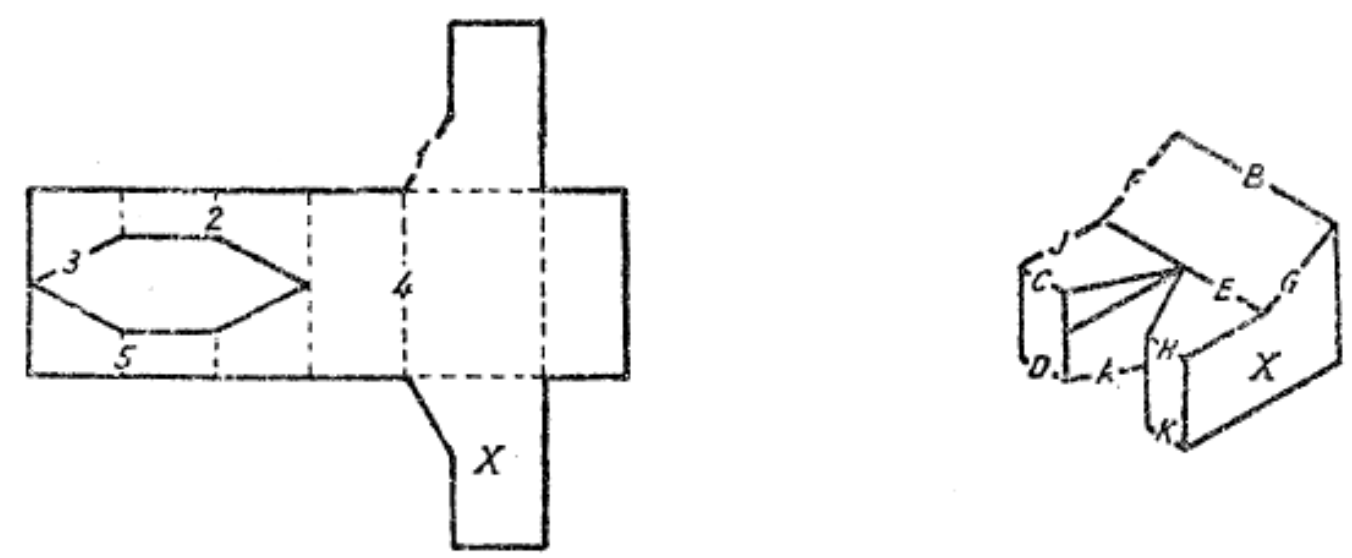
Figura 10
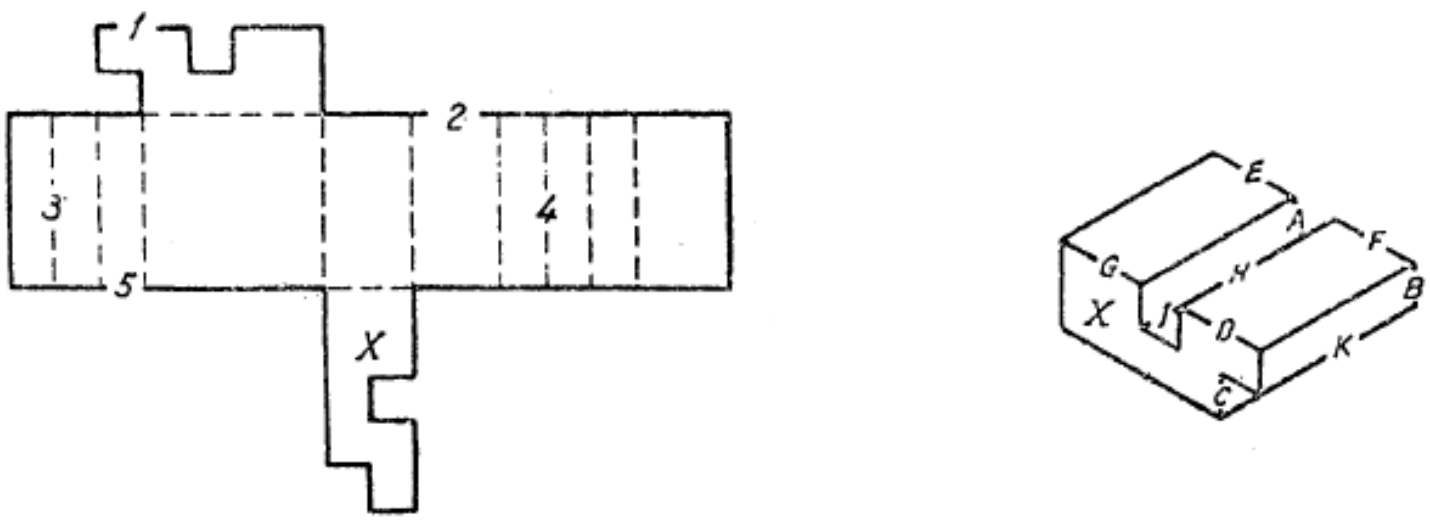

Figura 11
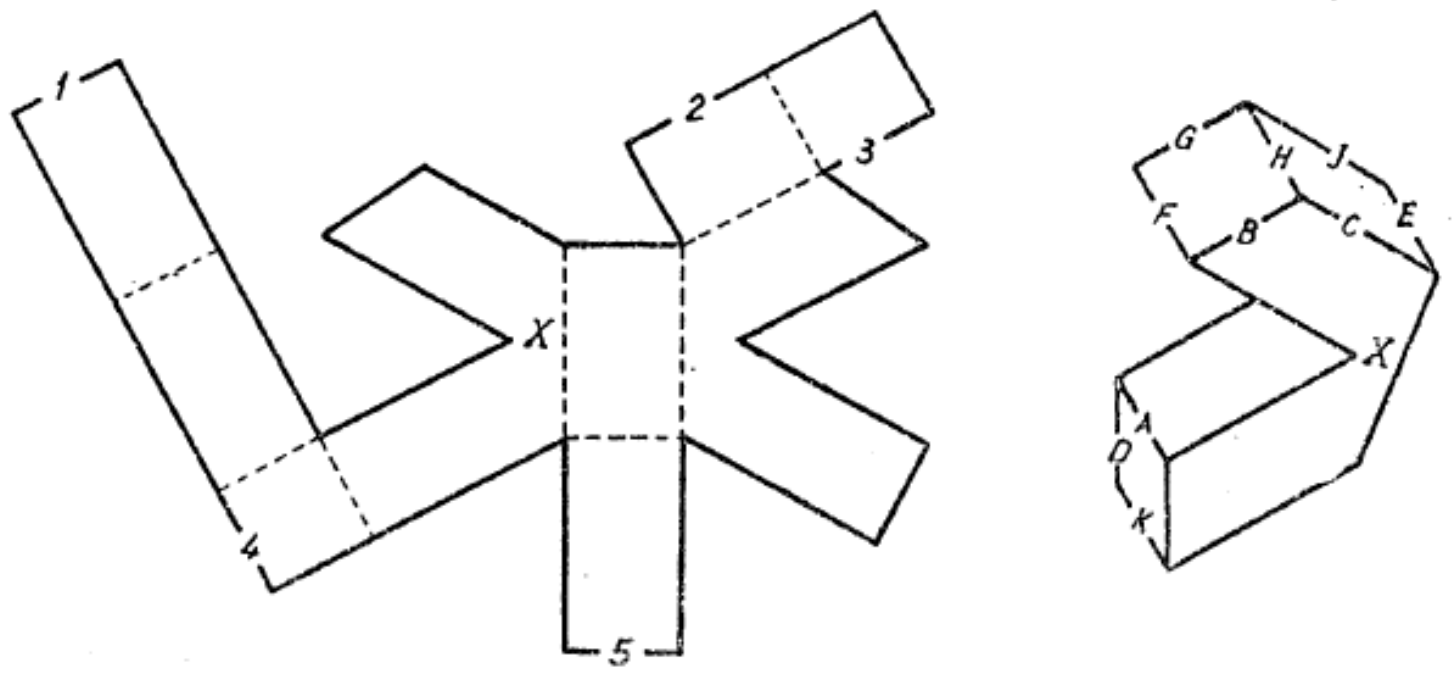

Figura 12
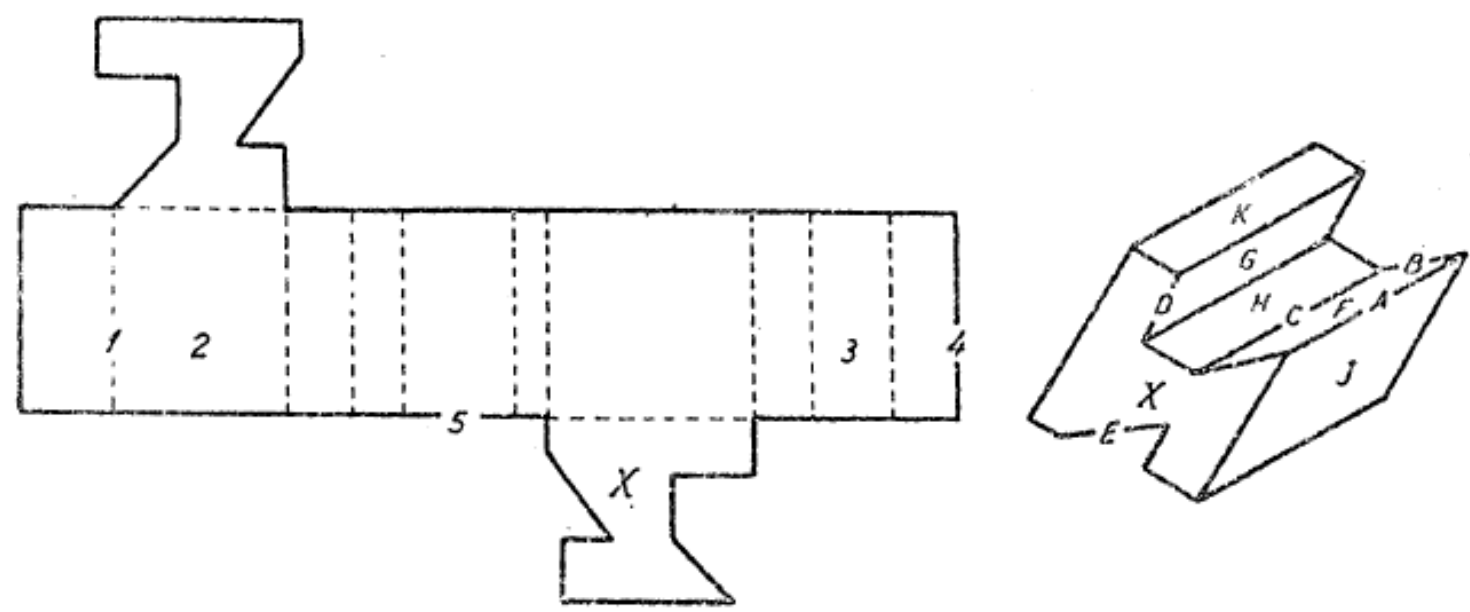


\section{Respuestas correctas}

\begin{tabular}{cccccc} 
& 1 & 2 & 3 & 4 & 5 \\
\hline Imagen 1. & J & C & H & E & D \\
Imagen 2. & J & A & G & D & E \\
Imagen 3. & D & J & E & F & A \\
Imagen 4. & F & D & B & K & J \\
Imagen 5. & C & J & G & E & K \\
Imagen 6. & G & A & H & C & D \\
Imagen 7. & K & G & C & J & B \\
Imagen 8. & H & A & G & E & F \\
Imagen 9. & F & C & A & B & K \\
Imagen 10. & F & E & K & J & C \\
Imagen 11. & F & C & G & D & K \\
Imagen 12. & A & J & G & C & E \\
\hline
\end{tabular}

